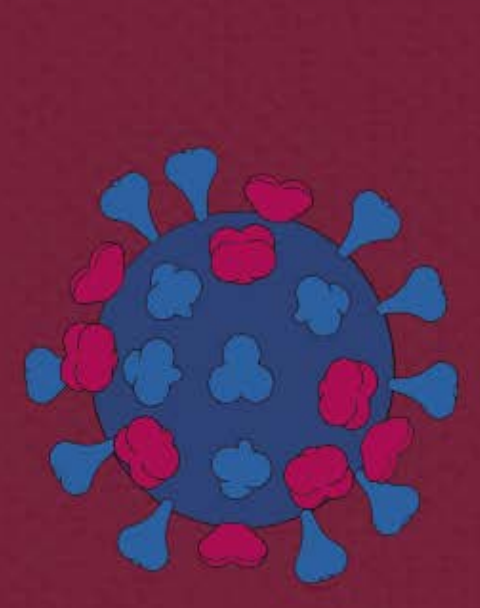
Quantification of Multivalent Biological Interactions

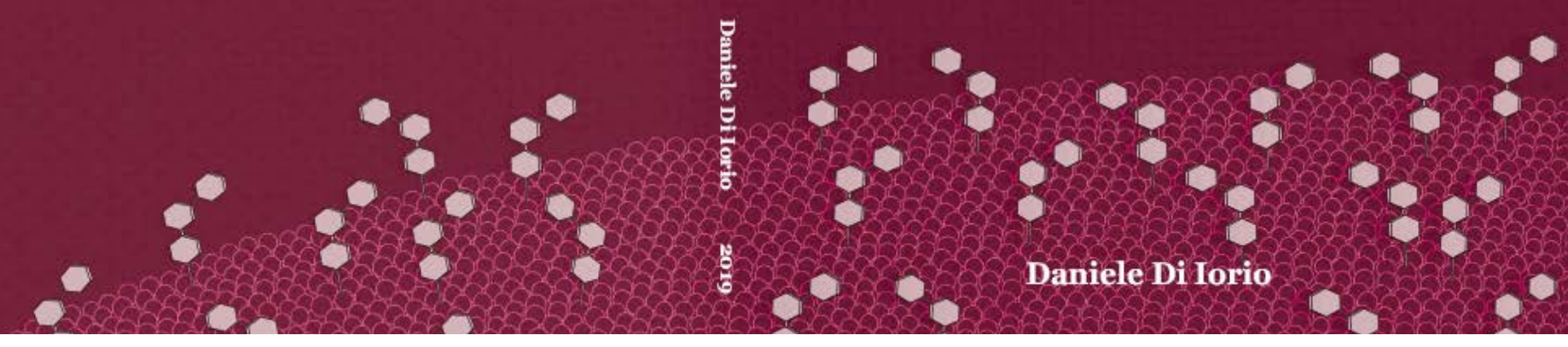




\section{DESIGNER SURFACES FOR THE QUANTIFICATION OF MULTIVALENT BIOLOGICAL INTERACTIONS}

Daniele Di Iorio 
Members of the committee:

$\begin{array}{lll}\text { Chairman: } & \text { Prof. dr. J. L. Herek } & \text { (University of Twente) } \\ \text { Promotor: } & \text { Prof. dr. ir. J. Huskens } & \text { (University of Twente) } \\ \text { Members: } & \text { Prof. dr. G. J. P. H. Boons } & \text { (University of Utrecht) } \\ & \text { Prof. dr. J. J. L. M. Cornelissen } & \text { (University of Twente) } \\ & \text { Prof. dr. R. Haag } & \text { (Freie Universität Berlin) } \\ & \text { Prof. dr. ir. P. Jonkheijm } & \text { (University of Twente) } \\ & \text { Dr. E. van der Vries } & \text { (University of Utrecht) }\end{array}$

The research described in this thesis was performed within the laboratories of the Molecular NanoFabrication (MnF) group, at the MESA+ institute for Nanotechnology, and the Faculty of Science and Technology (TNW) of the University of Twente. This research was supported by the European Union Horizon 2020 research and innovation programme under the Marie Sklodowska-Curie grant agreement $\mathrm{N}^{\circ} 642793$.
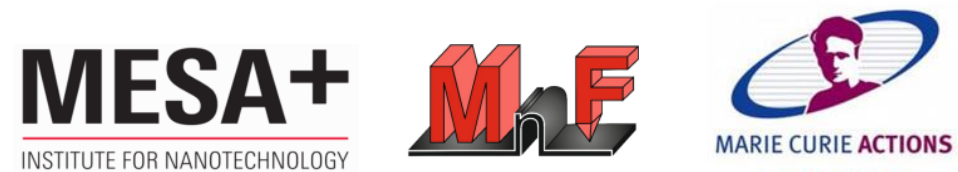

MULTI-APP

\section{Designer surfaces for the quantification of multivalent biological interactions}

Copyright (C) 2019, Daniele Di Iorio, Enschede, The Netherlands.

ISBN:

DOI:

Cover art:

Printed by:
978-90-365-4819-9

$10.3990 / 1.9789036548199$

Luca Ricciardi

Gildeprint, Enschede, The Netherlands 


\title{
DESIGNER SURFACES FOR THE QUANTIFICATION OF MULTIVALENT \\ BIOLOGICAL INTERACTIONS
}

\author{
DISSERTATION
}

to obtain

the degree of doctor at the University of Twente,

on the authority of the rector magnificus

prof. dr. T. T. M. Palstra,

on the account of the decision of the doctorate board,

to be publicly defended on

Thursday, September 12, 2019 at 16:45 h

by

Daniele Di Iorio

Born on July 10, 1990

In Formia, Italy 
This dissertation has been approved by the promotor:

Prof. dr. ir. J. Huskens

(University of Twente) 




\section{Table of Contents}

Chapter 1: General Introduction $\quad 1$

1.1 References 3

Chapter 2: Surface Modification with Control over Ligand 5 Density for the Study of Multivalent Biological Systems

2.1 Introduction 6

$\begin{array}{ll}2.2 \text { Multivalency at surfaces } & 7\end{array}$

2.2.1 Role of the ligand density on the surface 9

$\begin{array}{ll}2.3 \text { Methods for controlling the surface density } & 10\end{array}$

2.3.1 Mixing of molecules in solution $\quad 11$

2.3.2 Pre-modified polymers and proteins 16

2.3.3 Formation of 3D layers 20

2.4 Multivalent studies at functionalized platforms 21

2.4.1 Binding of molecules and polymers at interfaces 22

2.4.2 Binding of proteins and peptides at interfaces 23

2.4.3 Binding of viruses and virus-like particles at interfaces 26

2.4.4 Binding of cells and bacteria at interfaces 28

$\begin{array}{lll}2.5 & \text { Conclusions } & 29\end{array}$

2.6 References 30

Chapter 3: Clickable Poly-L-Lysine for the Formation of 39 Biorecognition Surfaces

$\begin{array}{lll}3.1 & \text { Introduction } & 40\end{array}$

3.2 Results and discussion $\quad 42$

3.3 Conclusions 51

3.4 Acknowledgments 52

3.5 Experimental section 52 
3.5.1 Materials $\quad 52$

3.5.2 Synthetic procedures $\quad 53$

3.5.3 Methods 55

3.6 References 57

Chapter 4: Patterning of Polymeric Biosensing Surfaces by 61 Modified Poly-L-Lysine Polymers

4.1 Introduction $\quad 62$

4.2 Results and discussion $\quad 63$

4.2.1 Soft lithography strategies based on modified PLL 63

4.2.2 Surface patterning by MIMIC 65

4.2.3 DNA recognition at MIMIC-patterned substrates $\quad 69$

$\begin{array}{lll}4.3 & \text { Conclusions } & 71\end{array}$

4.4 Acknowledgments 71

$\begin{array}{lll}4.5 & \text { Experimental section } & 72\end{array}$

$\begin{array}{lll}\text { 4.5.1 Materials } & 72\end{array}$

4.5.2 Methods $\quad 73$

$\begin{array}{lll}4.6 & \text { References } & 77\end{array}$

Chapter 5: Weak Multivalent Binding of Influenza 81

Hemagglutinin Nanoparticles at a Sialoglycan-Functionalized Supported Lipid Bilayer

$\begin{array}{lll}5.1 & \text { Introduction } & 82\end{array}$

$\begin{array}{lll}5.2 & \text { Results and discussion } & 84\end{array}$

5.2.1 Design and characterization of the SLB platform 84

5.2.2 Rosette binding on the SLB platform 88

$\begin{array}{lll}5.3 \text { Conclusions } & 100\end{array}$

$\begin{array}{lll}5.4 & \text { Acknowledgments } & 101\end{array}$

$\begin{array}{lll}5.5 & \text { Experimental section } & 102\end{array}$

$\begin{array}{lll}\text { 5.5.1 Materials } & 102\end{array}$

$\begin{array}{lll}\text { 5.5.2 Methods } & 102\end{array}$

$\begin{array}{lll}5.6 & \text { References } & 105\end{array}$ 
Chapter 6: Multivalent Interaction of the Influenza Virus at 109 Sialoglycan-functionalized Supported Lipid Bilayers

$\begin{array}{lll}6.1 & \text { Introduction } & 110\end{array}$

6.2 Results and discussion 111

6.2.1 Receptor density control at sialoglycan-modified SLBs 111

6.2.2 Virus binding at sialoglycan-modified SLBs 113

6.2.3 Quantification of the virus-receptor affinity at the SLB 117 platform

6.2.4 Influence of the receptor length on the interaction 122 affinity

6.3 Conclusions 123

6.4 Acknowledgments 124

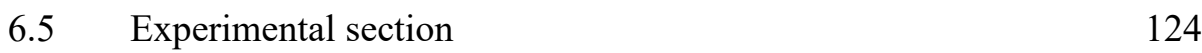

6.5.1 Materials 124

6.5.2 Methods 125

$\begin{array}{lll}6.6 & \text { References } & 126\end{array}$

Chapter 7: Recruitment of Receptors at Supported Lipid 129 Bilayers Promoted by Ligand-Modified Unilamellar Vesicles

$\begin{array}{lll}7.1 & \text { Introduction } & 130\end{array}$

$\begin{array}{lll}7.2 & \text { Results } & 131\end{array}$

7.2.1 Ensemble binding of 100-nm unilamellar vesicles to 131 supported lipid bilayers

7.2.2 Single-vesicle binding of giant unilamellar vesicles to 137 supported lipid bilayers

$\begin{array}{lll}7.3 & \text { Discussion } & 143\end{array}$

$\begin{array}{lll}7.4 & \text { Conclusions } & 148\end{array}$

$\begin{array}{lll}7.5 & \text { Acknowledgments } & 148\end{array}$

$\begin{array}{lll}7.6 & \text { Experimental section } & 148\end{array}$

$\begin{array}{lll}\text { 7.6.1 Materials } & 148\end{array}$

$\begin{array}{ll}\text { 7.6.2 Methods } & 149\end{array}$

$\begin{array}{lll}7.7 & \text { References } & 154\end{array}$ 
Summary

157

$\begin{array}{ll}\text { Samenvatting } & 161\end{array}$

$\begin{array}{ll}\text { Acknowledgments } & 163\end{array}$

$\begin{array}{ll}\text { About the author } & 167\end{array}$ 


\section{Chapter 1}

\section{General Introduction}

The influenza virus is a pathogen that causes severe infections in birds and mammals, including humans. ${ }^{1}$ Seasonal epidemics occur in humans, causing the infection of a large part of the population worldwide. ${ }^{2}$ Occasionally, more acute outbreaks or pandemics occur due to the adaptation of animal viruses to humans which efficiently transmit across the human population. ${ }^{3}$ Specifically, in the last 130 years, six pandemics have occurred causing the death of millions of people. ${ }^{4}$ For this reason, influenza remains a threat to global health and an important economic burden as well.

Different variants of viruses are characterized by the specific glycoproteins hemagglutinin (HA) and neuraminidase (NA) displayed on the virus membrane. ${ }^{5}$ In particular, HA plays an important role in the first stage of the virus infection, when multiple HAs bind in a multivalent fashion to sialic acid receptors expressed on the cell surface. ${ }^{6}$ Subsequent to the virus uptake, the infection starts and the virus replicates. The specificity of the virus for a particular species therefore resides in the affinity of these glycoproteins for specific receptors. Alteration or mutation at the receptor binding site can be thus at the origin of phenomena such as interspecies transfection.

To better understand the molecular mechanisms that are behind these biological phenomena, it is important to develop platforms that are able to mimic and quantify the interactions at the interface. The fabrication of such platforms can contribute to the development of (bio)sensors that can predict the infectivity or the hazard of new emerging virus strains.

Adequate surface modification methods are required, which ensure the control of specific properties. Among all, the control of the surface ligand density as well as the prevention of non-specific interactions are two of the major requirements that need to be met in the modification of surfaces for biosensing applications. Development of such methods can therefore be extended to a wide range of, both monovalent and multivalent, biological interactions.

The research described in this thesis aims at developing surface functionalization methods for the investigation of multivalent biological systems at interfaces. Specifically, two different approaches were chosen here to modify substrates. One part of the work is focused on the formation of poly-L-lysine (PLL)-based monolayers on several types of substrates (Chapters 3 and 4). In the second part (Chapters 5-7), supported lipid bilayers (SLBs) are 
investigated as a platform technology. The control over the ligand density at the interface and the quantification of the interactions are two major objectives presented in this work.

Chapter 2 provides a literature overview of literature methods employed in the modification of surfaces which provide control over the ligand density. Particular emphasis is put on methods employed for the study of biological systems.

Chapter 3 reports the development of a fast and effective substrate functionalization method for the selective immobilization of biomolecules, employing the combination of PLL adsorption and click chemistry. This system has been employed to investigate the immobilization of DNA probes on both silicon dioxide and gold surface. The capability of such probes to recognize complementary sequences in solution has been investigated. Finally, control over the DNA probe density on the surfaces has been assessed by surface adsorption and electrochemical methods.

In Chapter 4, modified PLLs have been developed for the effective modification of polymeric substrates such as cyclic olefin polymer (COP) and Ormostamp, both employable in the fabrication of (bio)medical devices, with biomolecules. As a proof of concept, DNA probes were used for the modification of these substrates. Soft lithography techniques were used for the patterning of PLL on the surface for the further modification with DNA probes. Antifouling properties, stability of the surface modification and biorecognition capability have been assessed.

Chapter 5 describes the development of a SLB platform for the quantification of multivalent interactions of influenza viruses at the interface. Biotinylated SLBs were used in order to functionalize surfaces with streptavidin (SAv) and subsequently with biotinylated polymeric receptors. The control over the surface ligand density by variation of the lipid composition was investigated. Recombinant hemagglutinin (HA) nanoparticles were employed instead of full viruses for a better quantification of the interactions and the interaction area.

Based on the findings of Chapter 5, the same platform was used in Chapter 6 for the study of the interaction of full viruses with receptor-modified surfaces. Selectivity and specificity of the virus-receptor interaction were successfully tested. Quantification of the interactions was targeted using full titrations with viruses. Parameters such as glycan receptor density and glycan length were varied in order to investigate their effect on the overall virus binding.

Finally, in Chapter 7, SLBs have been employed for the investigation of the phenomenon of receptor clustering in cell membranes. In particular, the recruitment of SAv upon binding of multivalent biotinylated small and giant unilamellar vesicles was studied. Densities of SAv receptors on the surface and of biotin in the vesicles were varied in order to study their effect on the binding in a quantitative fashion. An analysis of the molecular parameters involved in the interaction, such as the number of receptors recruited and the interacting area, is provided here. 


\subsection{References}

1. Landolt, G. A.; Olsen, C. W., Up to New Tricks - A Review of Cross-Species Transmission of Influenza A Viruses. Anim. Health Res. Rev. 2007, 8, 1-21.

2. Medina, R. A.; García-Sastre, A., Influenza A Viruses: New Research Developments. Nat. Rev. Microbiol. 2011, 9, 590-603.

3. Garten, R. J.; Davis, C. T.; Russell, C. A.; Shu, B.; Lindstrom, S.; Balish, A.; Sessions, W. M.; Xu, X.; Skepner, E.; Deyde, V.; Okomo-Adhiambo, M.; Gubareva, L.; Barnes, J.; Smith, C. B.; Emery, S. L.; Hillman, M. J.; Rivailler, P.; Smagala, J.; de Graaf, M.; Burke, D. F.; Fouchier, R. A. M.; Pappas, C.; Alpuche-Aranda, C. M.; López-Gatell, H.; Olivera, H.; López, I.; Myers, C. A.; Faix, D.; Blair, P. J.; Yu, C.; Keene, K. M.; Dotson, P. D.; Boxrud, D.; Sambol, A. R.; Abid, S. H.; St. George, K.; Bannerman, T.; Moore, A. L.; Stringer, D. J.; Blevins, P.; DemmlerHarrison, G. J.; Ginsberg, M.; Kriner, P.; Waterman, S.; Smole, S.; Guevara, H. F.; Belongia, E. A.; Clark, P. A.; Beatrice, S. T.; Donis, R.; Katz, J.; Finelli, L.; Bridges, C. B.; Shaw, M.; Jernigan, D. B.; Uyeki, T. M.; Smith, D. J.; Klimov, A. I.; Cox, N. J., Antigenic and Genetic Characteristics of Swine-Origin 2009 A(H1N1) Influenza Viruses Circulating in Humans. Science 2009, 325, 197-201

4. Taubenberger, J. K.; Kash, J. C., Influenza Virus Evolution, Host Adaptation, and Pandemic Formation. Cell Host Microbe 2010, 7, 440-451.

5. Fouchier, R. A. M.; Munster, V.; Wallensten, A.; Bestebroer, T. M.; Herfst, S.; Smith, D.; Rimmelzwaan, G. F.; Olsen, B.; Osterhaus, A. D. M. E., Characterization of a Novel Influenza A Virus Hemagglutinin Subtype (H16) Obtained from Black-Headed Gulls. J. Virol. 2005, 79, 2814-2822.

6. Mammen, M.; Choi, S.-K.; Whitesides, G. M., Polyvalent Interactions in Biological Systems: Implications for Design and Use of Multivalent Ligands and Inhibitors. Angew. Chem. Int. Ed. 1998, 37, 2754-2794. 


\section{Chapter 2}

\section{Surface Modification with Control over Ligand Density for the Study of Multivalent Biological Systems}

In the study of multivalent interactions at interfaces, the density of the ligands or receptors displayed at the interface plays a pivotal role, affecting overall binding affinities and valencies involved in the interactions. In order to control the ligand or receptor density at the interface, several approaches have been used, concerning the functionalization of a wide range of surfaces. In this chapter, different methods employed in the modification of surfaces with controlled densities of ligands are being reviewed. Examples of such methods encompass the formation of self-assembled monolayers (SAMs), supported lipid bilayers (SLB) or polymeric layers on surfaces. Particular emphasis is given to the methods employed in the study of different types of multivalent biological interactions and their working principles. 


\subsection{Introduction}

Multivalency is a fundamental principle involved in a wide variety of biological systems, such as protein-protein interactions, cellular recognition and modulation of cell signaling. ${ }^{1-3}$ Several weak, non-covalent and reversible interactions, for example between proteins and carbohydrates, can provide an overall strong and highly specific binding when occurring in a multivalent fashion. In this way, enhancement of binding affinities of several orders of magnitude is generally achieved. ${ }^{4}$

The enhancement of the affinity due to multivalent interactions plays an important role in the improvement of selectivity in the target recognition in biological processes. ${ }^{5}$ Pathogens, for example, take advantage of multiple protein-carbohydrate interactions for cell adhesion which is the onset for the invasion or infection of the host cell. ${ }^{6}$ One of the most studied multivalent systems is the influenza virus, which binds multivalently with its hemagglutinin (HA) protein to sialic acid residues expressed on the cell surface in the first stage of the infection (Figure 2.1A). The cholera toxin (CT) secreted by Vibrio cholerae, composed of one toxic A subunit and five identical B subunits responsible of the uptake of the toxin, binds multivalently to GM1 residues of epithelial cells in the small intestine facilitating endocytosis (Figure 2.1B). ${ }^{7,8}$ More examples have been extensively reported in literature. ${ }^{1,9}$

The study and the quantification of multivalent interactions is important in order to obtain molecular insight into the biological systems in which they are involved. For this reason numerous synthetic systems have been developed to investigate multivalency and its principles. Some contributions in this field have promoted the understanding of multivalent interactions both in solution and at surfaces in a quantitative manner. ${ }^{10,11}$

Applications of multivalency principles have been investigated in several fields. Multivalent molecules have been synthesized, for example, to induce cellular responses. ${ }^{12}$ Application of strong multivalent receptor-protein interactions have been employed for the preparation of inhibitors of pathogens such as Escherichia coli ${ }^{13}$ or influenza. ${ }^{14}$ Other multivalent molecules, such as dendrimers, have been extensively used in nanomedicine. ${ }^{15}$ A large number of multivalent structures, employing scaffolds to which multiple ligands are anchored, have been synthesized, with varying size, shape, valency and physical characteristics for a wide range of applications. ${ }^{16,17}$ 
(A)

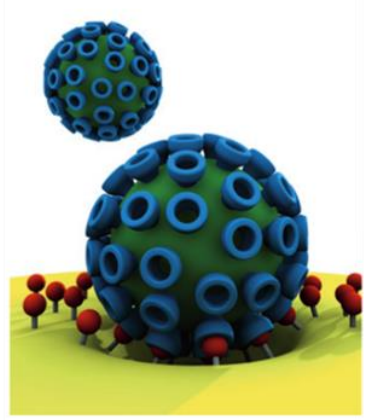

(B)

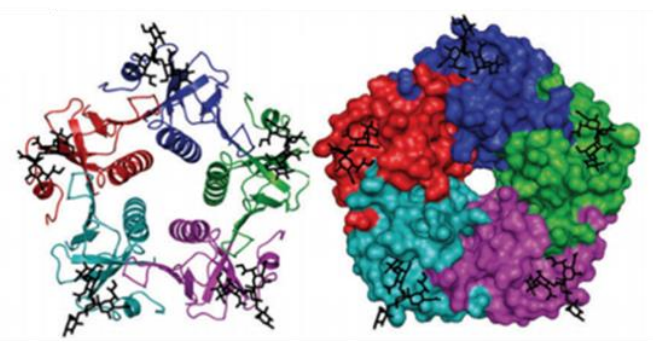

Figure 2.1. Examples of biological multivalent systems. (A) Schematic representation of the multivalent interaction of a virus with a cell membrane. Adapted from ref. 2 with permission from John Wiley and Sons. (B) Structure of the pentavalent B subunits of cholera toxin binding to five mannose residues. Reproduced from ref. 8 by permission of The Royal Society of Chemistry.

In this Chapter, a general overview of the surface functionalization methods employed for the study of multivalent interactions at interfaces is provided, with a focus on the methods that allow control over the ligand density. In particular, this chapter aims at providing an overview of functionalization methods for two-dimensional surfaces. Modification of nanoparticle surfaces with controlled ligand density, although largely reported in literature, ${ }^{18-}$ ${ }^{20}$ is beyond the scope of this review. In the first part, surface modification methods employed for the control of the of ligand density is discussed. The second part aims at providing an overview of multivalent systems investigated at interfaces.

\subsection{Multivalency at surfaces}

Although less investigated than multivalent systems in solution, multivalent interactions at interfaces are particularly important. ${ }^{21}$ Surfaces modified with several monovalent ligands or receptors can be considered as multivalent platforms at which multivalent interactions can be studied. ${ }^{21}$ Therefore, interactions at surfaces (e.g. of cell membranes, self-assembled monolayers and lipid membranes) can be investigated in order to better understand multivalency principles and their effect on biological systems.

Several studies of multivalent principles at interfaces have been reported. A large contribution was given by Reinhoudt and Huskens in this field by their studies of multivalent systems binding at $\beta$-cyclodextrin self-assembled monolayers (CD SAMs). ${ }^{22-25}$ In their studies, these so-called molecular printboards have been developed for the selective binding of molecules with defined valencies and binding affinities. Moreover, models have been described for the interpretation of the binding of multivalent molecules to interfaceimmobilized receptors. 
Concomitant to the study of the fundamental principles of multivalency, the application of multivalent interactions at interfaces has been largely investigated. Multivalent binding of molecules and proteins at functionalized surfaces has been used in nanotechnology for the fabrication of dynamic nanochips or biosensors. Reversible DNA binding on surfaces was achieved by using photolabile multivalent dendrons, which release DNA upon UV irradiation due to degradation and charge-switching multivalency. ${ }^{26}$ In another example, Fragoso et al. immobilized Cytochrome $\mathrm{c}$ at an electrode surface via multivalent supramolecular interactions. ${ }^{27}$ Tkac and coworkers developed lectin biosensors for the detection of glycoproteins with a detection limit in the femtomolar range (Figure 2.2A). ${ }^{28}$ More recently, Chen and coworkers reported a dynamic supramolecular multivalent platform capable of specifically capturing and releasing bacteria (Figure 2.2B). ${ }^{29}$ Numerous glycan microarrays have been developed for the selective modification of surfaces with monovalent or multivalent ligands in order to bind carbohydrate binding proteins (CBP) in a multivalent fashion. ${ }^{30,31}$ In this way, the binding affinities and selectivities of CBPs for specific receptors have been investigated.

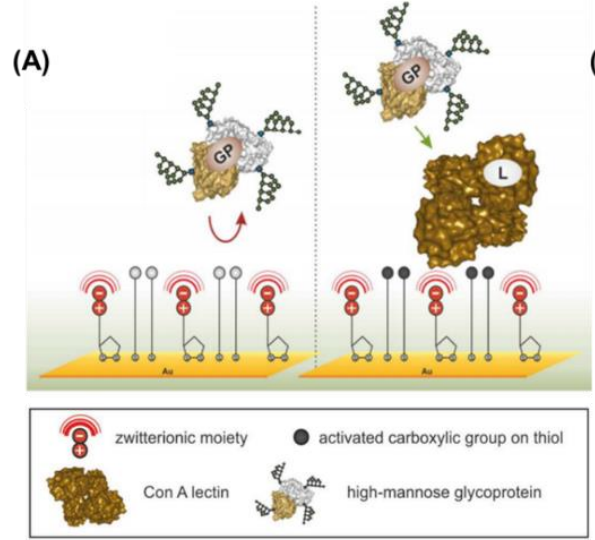

(B)

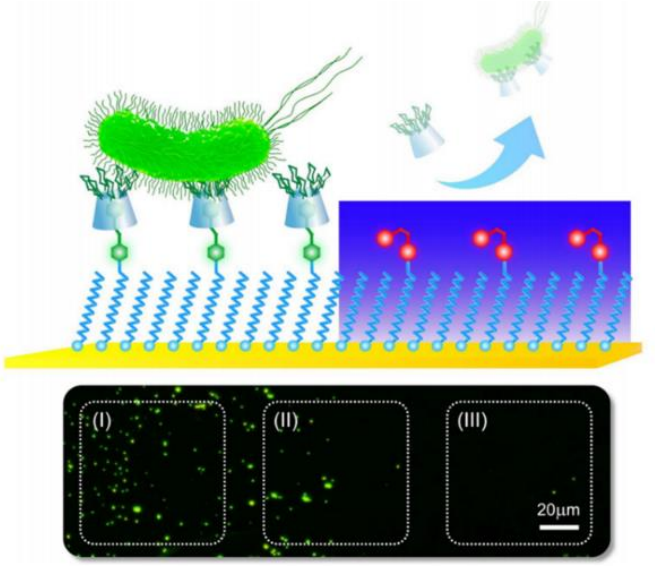

Figure 2.2. (A) Schematic representation of a self-assembled monolayer of 11-mercaptoundecanoic formed on a gold surface, and subsequent activation of the $-\mathrm{COOH}$ group for the immobilization of lectins for the detection of glycoproteins. Adapted with permission from ref. 28. Copyright (2013) American Chemical Society. (B) Localized release of bacteria on the Au surface: area (I) refers to the region without UV irradiation, area (II) to the boundary region, and area (III) to the region irradiated with UV. Adapted with permission from ref. 29. Copyright (2017) American Chemical Society. 


\subsubsection{Role of the ligand density on the surface}

In the study of multivalent biological systems, bioactive surfaces need to meet specific requirements to provide an optimal performance of interaction. First of all, surfaces must provide a high and well-controlled binding capacity of the biomolecules, which must prevent, at the same time, their denaturation upon binding. Secondly, non-specific interactions of biomolecules need to be prevented. Therefore, adequate surface modifications that provide antifouling properties are required..$^{32}$ Additionally, ligand-receptor interactions are known to be strongly dependent on a threshold ligand density. ${ }^{33}$ In multivalent interactions, the average density of ligands on the surface needs to match the density of binding sites of the receptors in order to provide an efficient recognition. ${ }^{34}$ In the case of low ligand densities, average inter-ligand distances are too large and only weak monovalent interactions occur. When ligand densities reach a minimum value (threshold), multivalent interactions can occur, providing a stronger and more stable binding. For this reason, the surface ligand density appears to be a fundamental parameter that needs to be taken into account for the achievement of optimal interactions at the interface.

The importance of the control of the ligand density at surfaces was discussed by Kiessling and coworkers with an illustrative example in their study of the interaction of concanavalin (ConA) with mannose-functionalized surfaces. ${ }^{35}$ ConA, a tetrameric lectin with a binding affinity for mannose residues and presenting binding sites with a distance of approximately $6.5 \mathrm{~nm}$, can bind divalently to ligand-functionalized surfaces. In this study, the authors observed that the adsorption of ConA on gold surfaces, detected by SPR, was strongly dependent on the saccharide density at the interface (Figure 2.3A). Specifically, a small adsorption of proteins onto the surface was observed at low ligand surface densities, for which the average carbohydrate spacing was larger than $6.5 \mathrm{~nm}$. The reduced adsorption was attributed to a weak monovalent ligand-receptor interaction. By increasing the carbohydrate density on the surface (i.e. with an average distance of less than $6.5 \mathrm{~nm}$ ), a much higher protein adsorption was obtained owing to the occurring multivalent interaction. A further increase of the ligand density, however, did not result in an increased amount of protein bound to the surface. Due to the rigidity, the low valency and large spacing of ConA, several carbohydrates remained unbound at the surface.

Additional effects such as steric hindrance or electrostatic repulsion between ligands on the surface may affect the overall ligand-receptor interaction, leading to alteration or even a decrease of binding affinities at increasing ligand densities. Cremer and coworkers, for example, have reported an effect of ligand clustering in the binding of the cholera toxin $\mathrm{B}$ subunit (CTB) with ganglioside GM1 at a supported lipid bilayer (SLB). By varying the 
concentration of GM1 from 0.02 to $10.0 \mathrm{~mol} \%$ in the phospholipid membrane, the binding of cholera toxin proteins was weakened upon increase of the ligand density (Figure 2.3B). ${ }^{36}$

(A)

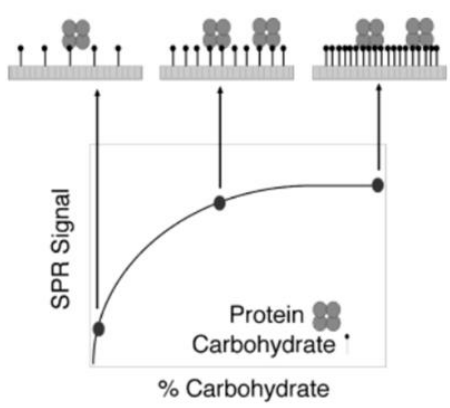

(B)

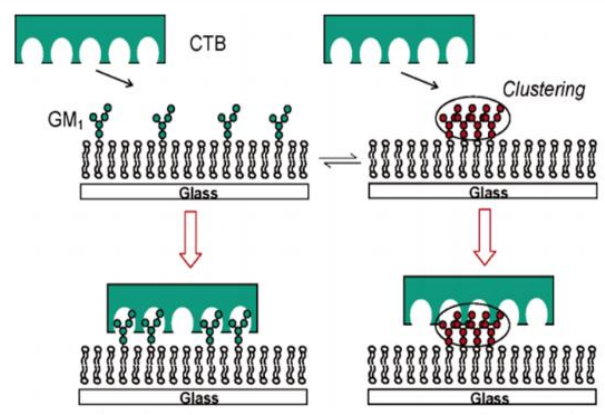

Figure 2.3. (A) Schematic model of the binding of ConA on mannose-modified surfaces. In case of low mannose densities, the average distance between residues is too large to enable ConA to bind with two residues. At an intermediate carbohydrate coverage, the distance between mannose residues allows the protein to interact with multiple carbohydrates on the surface. A high ligand density does not lead to a further increase of the amount of protein bound to the surface. Reprinted with permission from ref. 35. Copyright (2003) American Chemical Society. (B) Schematic representation of the inhibition of CTB binding caused by clustering of GM1. Reprinted with permission from ref. 36. Copyright (2007) American Chemical Society.

\subsection{Methods for controlling the surface density}

Several approaches for the functionalization of surfaces with a wide range of ligands have been reported. Self-assembled monolayers (SAMs), supported lipid bilayers (SLBs) and different types of polymers have been extensively employed for the functionalization of substrates with ligands such as carbohydrates, peptides or DNA strands. Among all the surface modification strategies, three main conceptual approaches can be used for the modification of surfaces with a precise control over the ligand density displayed at the interface: i) mixing of active and inactive ligands; ii) using pre-functionalized polymers or proteins; iii) controlling surface modification in three-dimensional structures. In this section, some examples for each of the mentioned method are reported. A brief overview of the different types of chemistry employed for the modification of surfaces is also provided. 


\subsubsection{Mixing of molecules in solution}

Among the different approaches generally employed for the control over the ligand density on the surface, the mixing of functionalized and non-functionalized molecules in solution prior to the functionalization of surfaces is by far the most used. In particular, two main approaches can be used for a controlled modification of substrates: Surfaces can be modified in a first step with active functional groups such as N-hydroxysuccinimide (NHS) or click chemistry groups, which subsequently react with ligands bearing proper chemical modification. Alternatively, ligand-modified molecules can be directly reacted onto the surface. In both cases, the molar ratio of functionalized molecules in the mixture determines the density of ligands displayed at the surface. This method is mainly used with SAMs, SLBs and protein-modified surfaces.

\section{Self-assembled monolayers (SAMs)}

One of the most commonly employed surface modification methods for the study of interactions at interfaces is the formation of SAMs ${ }^{37}$ SAMs are well-known two-dimensional nanostructures formed by the ordered assembly of molecules onto a large variety of solid surfaces. ${ }^{38}$ The two most commonly used classes of SAMs are the sulfur-containing molecules (sulfides, disulfides and thiols) on gold (and other noble metal) substrates and the alkylsilanes on oxide surfaces. Due to the ease of preparation, the high stability, and the possibility of modifying substrates with desired properties, SAMs have been largely employed for the modification of surfaces for a wide range of applications. Detailed descriptions of the properties and applications of SAMs have been exhaustively illustrated in several reviews. ${ }^{38-40}$

The formation of SAMs of sulfur-containing molecules on gold is an exquisite method for the modification of surfaces with controlled ligand density. ${ }^{41}$ The most commonly used method to form SAMs consists of the mixing of alkanethiols in different ratios with thiols containing a functional group, such as NHS or maleimide. Subsequently, ligands bearing complementary functional groups (i.e. amino groups or thiols) are reacted onto the thiolmodified substrates. Alternatively, in order to improve the antifouling properties of the SAMs, thiols containing poly(ethylene glycol) (PEG) chains are used in the mixtures. Gold surfaces are therefore incubated with these solutions in order to form monolayers with a stochastic display of functional groups. By varying the molar fraction of thiols bearing functional groups in the thiol mixture, it is possible to accurately tune the ligand density on the surface in the second step. This method has been used for a large variety of applications such as the formation of micro-arrays and (bio)sensors for multivalent interactions. ${ }^{42-44}$ 
Impedimetric glycan biosensors have been developed using mixtures of thiols on gold substrates by Hushegyi et al..$^{45}$ Mixed SAMs of sialic acid residues were made with controlled ligand densities. Specifically, mixtures of 11-mercaptoundecanoic acid (MUA) with 6mercaptoexanol were used for the functionalization of gold substrates, with MUA molar fractions ranging from 5\% to 50\%. After activation of the carboxylic acid groups of MUA with EDC/NHS, the formed esters were reacted with amine-terminated glycans. By using the same approach, Magnusson and coworkers functionalized surfaces with controllable densities of modified chemoattractant peptides. ${ }^{46}$ Solutions of maleimide-terminated and OEG-containing alkyldisulfides were used for the formation of SAMs on gold (Figure 2.4). Cys-terminated ligands were subsequently bound on the surface by coupling with maleimide. In another example, Mrksich and coworkers formed SAMs on gold using thiols presenting maleimide groups for the anchoring of carbohydrates and peptides. ${ }^{47}$

(A)

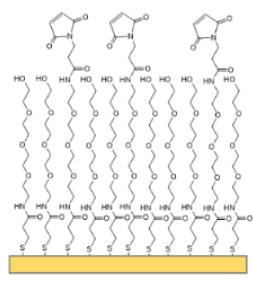

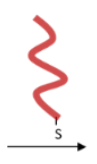

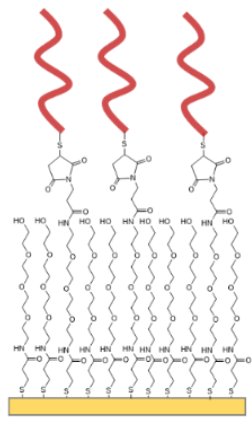

(B)

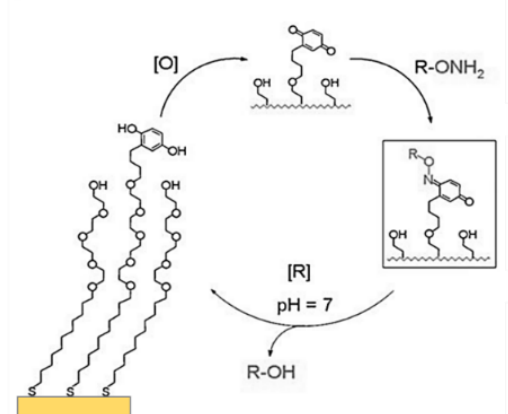

Figure 2.4. (A) Immobilization of Cys-modified peptides on gold surfaces modified with SAMs formed from maleimide and OEG-containing thiols. The maleimide allows the specific functionalization with peptides whereas the OEG improves the antifouling properties of the surface. Adapted with permission from ref. 46. Copyright (2008) American Chemical Society. (B) Schematic representation of electrochemical oxidation [O] of hydroquinone to quinone and subsequent reaction with a soluble oxyamine-tagged ligand $\left(\mathrm{RONH}_{2}\right)$ to give the redox-active oxime conjugate on the surface. Adapted from ref. 48 with permission from John Wiley and Sons.

Yousaf and Mrksich pioneered the formation of electroactive SAMs for the controlled functionalization of surfaces with ligands. ${ }^{48}$ Hydroquinone-functionalized thiols, which can be chemically or electrochemically oxidized to benzoquinone, were employed for the modification of surfaces. After oxidation, the obtained quinone monolayer can subsequently react, for example, with cyclo-pentadiene-modified peptides by a Diels-Alder reaction, ${ }^{49,50}$ or with oxyamine ligands to give a redox-active oxime conjugate ${ }^{51}$ on the surface (Figure 
2.4B). In this way, a large variety of biologically active ligands can be reversibly anchored to the surface. Surfaces were, for example, functionalized using high-throughput microarray technology with controlled densities of FLAG or RGD peptide ligands. After the immobilization of the thiolated hydroquinone, the hydroquinone headgroups were converted to quinone by electrochemical oxidation at $750 \mathrm{mV}$. In this way the quinone monolayer was reacted with an aminooxy-functionalized peptide. The molar fraction of hydroquinonefunctionalized thiols in the formation of the SAM regulates the peptide ligand density at the interface.

By exploiting click chemistry reactions, Dubacheva et al. reported the formation of SAMs composed of mixed pegylated thiols with and without azide functional groups for the modification of surfaces with controlled ferrocene (Fc) or adamantane (Ad) densities. ${ }^{52}$ Alkyne derivatives of the guests were added to the surface by exploiting the azide-alkyne click reaction. Control of the guest density was achieved by tuning the fraction of azidemodified thiols mixed with the regular PEG thiol in the first step. The variation of the functional group densities from 0.5 to $330 \mathrm{pmol} / \mathrm{cm}^{2}$ led to average distances between neighboring ferrocenes ranging from 18 to $0.7 \mathrm{~nm}$, respectively.

With a different approach, SAMs can be directly formed with ligand-functionalized thiols. In this approach, a chemical modification of the ligand is performed prior to adsorption onto the surface. In this way, Houseman et al. functionalized surfaces with controlled densities of Gly-Arg-Gly-Asp-Ser (GRGDS) peptide ligands by exploiting the formation of alkanethiolbased SAMs on gold..$^{53}$

The formation of silane monolayers on glass substrates is a valid alternative for the functionalization of surfaces with ligands. Compared to thiol-based SAMs, silane-terminated monolayers have a higher chemical stability, thus allowing a broader range of chemical reactions on surfaces. ${ }^{54}$ However, silanes present the disadvantage of being highly reactive. Moreover, the control over ligand density appears to be less predictable for silane-based monolayers than for thiols on gold. A binary mixed SAM consisting of 3aminopropyltriethoxysilane (APTES) and octadecyltrimethoxysilane (ODS) showed that APTES is significantly enriched in the mixed SAM compared to the starting solution. ${ }^{55}$ Similarly, when amino-terminated silanes and methyl-terminated silanes were mixed in different ratios to form SAMs on aluminum oxide surfaces by co-adsorption of the silanes, the composition of the monolayer, as studied with AFM, contact angle, XPS and mechanical tests, indicated that the amine-terminated silanes adsorbed two times faster than the methylterminated silanes. ${ }^{56}$ An efficient modification of substrates with controlled ligand densities was achieved by Wayment et al. by mixing a low concentration of (3aminopropyl)triethoxysilane (APTES) and a much larger concentration of (2cyanoethyl)triethoxysilane (CETES). The low amino group density on the surface due to the 
presence of APTES, allowed the modification of surfaces with a very low fraction of biotin moieties $\left(<10^{-7}\right) \cdot{ }^{57}$

\section{Supported lipid bilayers (SLBs)}

Although extensively used for the study of biological interactions at interfaces, SAMs resemble only remotely real biological membranes and lack some typical membrane properties, such as membrane fluidity, which is essential to mimic mobility and ligand reorganization occurring at cell membranes upon interactions. ${ }^{58}$ In this regard, the formation of SLBs has emerged as a valid alternative method for the modification of surfaces for biological studies. ${ }^{59,60}$ SLBs are two-dimensional fluid platforms consisting of phospholipids retaining some of the relevant properties of cell membranes. ${ }^{61}$ Phospholipid vesicles, under specific conditions, rupture on activated hydrophilic surfaces such as mica, glass and silicon, forming a notably stable lipid bilayer. ${ }^{59}$ The presence of a thin water layer (approx. $10 \AA$ thick $)^{62}$ between the formed lipid bilayer and the underlying surface allows the mobility of the lipids on the surface providing fluidity to SLBs. In particular, the fluidity of the system can be regulated by varying the chemical composition of the SLB. ${ }^{63}$

SLBs have been reported to present excellent antifouling properties, preventing the nonspecific adsorption of proteins and cells onto their surface.${ }^{64}$ Methods for the introduction of ligands/receptors of choice in the SLB have been reported in literature. ${ }^{61}$ Briefly, lipids modified with a particular functional moiety can be added to the lipid mixture during the vesicle preparation and thus get displayed on the surface after the formation of the SLB. Subsequently, as in the case of SAMs, modified ligands that react or interact with these functional groups can be anchored onto the surface. In a different approach, ligand-modified lipids can be directly added to the lipid mixture before the formation of the SLB. In both approaches, controlling the molar fraction of functionalized lipids in the lipid mixture provides an exquisite method to control the surface density.

Several ligands and receptors have been anchored to SLBs with tunable densities by exploiting both non-covalent and covalent interactions. Biotinylated lipids can be introduced in SLBs by mixing 1,2-dioleoyl-sn-glycero-3-phosphocholine (DOPC) or 1-palmitoyl-2oleoyl-glycero-3-phosphocholine (POPC) lipids with biotinylated phosphatidylethanolamine (biotin-DOPE) during the preparation of vesicles. ${ }^{65}$ Streptavidin (SAv) can, therefore, be used as a linker for the further functionalization of surfaces with biotinylated linkers by exploiting the strong non-covalent biotin-SAv interaction. ${ }^{66}$ Koçer and Jonkheijm, for example, varied the amounts of DOPE-biotin (between 0.01 and $1 \mathrm{~mol} \%$ ) in fluid DOPC and non-fluid DPPC-based SLBs in order to functionalize surfaces with varying RGD ligand densities. ${ }^{67}$ Alternatively, lipid molecules containing a nitrilotriacetic acid (NTA) head group 
can be doped into the SLB, and proteins modified with histidine tags can be chelated with the NTA lipids in the presence of $\mathrm{Ni}^{2+}$ ions. ${ }^{68}$ Multiple histidine are typically added to ensure, at the same time, the stability of the attachment of the proteins and their proper orientation at the interface. Lipids modified with two NTA moieties (bis-NTA) were synthesized by Piehler and coworkers for the modification of SLBs with histidine-tagged proteins. ${ }^{69}$

In the case of covalent modification of SLBs, lipids containing reactive functional groups, as for example maleimide, can be incorporated into the bilayer for the binding of complementary, e.g. thiol, functionalized molecules or proteins containing cysteine residues. Thid et al. used vesicles doped with 0-5\% maleimide-terminated lipids for the formation of SLBs on $\mathrm{SiO}_{2}$ substrates, which were subsequently functionalized with IKVAV-containing peptides. ${ }^{70}$ A different approach consists of the direct modification of biomolecules with a lipid that can be inserted into the SLB. Control of the surface ligand density can be quantitatively achieved by adjusting the molar fraction of modified lipids in the lipid mixture during the preparation of the vesicle. Synthetic glycolipids have been used, for example, for the introduction of controlled densities of glycans in SLBs. ${ }^{36,71,72}$

As a valid alternative to SLBs, supported lipid monolayers (SLMs) can be also employed for the modification of surfaces with ligands. Methods as Langmuir-Blodgett or LangmuirSchaefer can be used for the formation of monolayers. ${ }^{73}$ Alternatively, SLMs can be formed from the rupture of lipid vesicles on hydrophobic self-assembled monolayers. ${ }^{74}$ Octadecanethiol on gold or octadecyltrichlorosilane on glass surfaces are two typical examples of hydrophobic monolayers used for hybrid bilayer formation, owing to the possibility of forming highly ordered and well-packed monolayers. ${ }^{75,76}$

Kiessling and coworkers developed an SLM in order to control the mannose ligand density on surfaces (Figure 2.5) ${ }^{77}$ In their studies, POPC liposomes containing different ratios of synthetic glycolipids bearing mannose groups where added on gold surfaces prefunctionalized with alkanethiols. As in the case of SLBs, by tuning the molar ratio of synthetic glycolipids in the mixture with POPC during the formation of liposomes, it was possible to control the density of mannose exposed on the surface. 


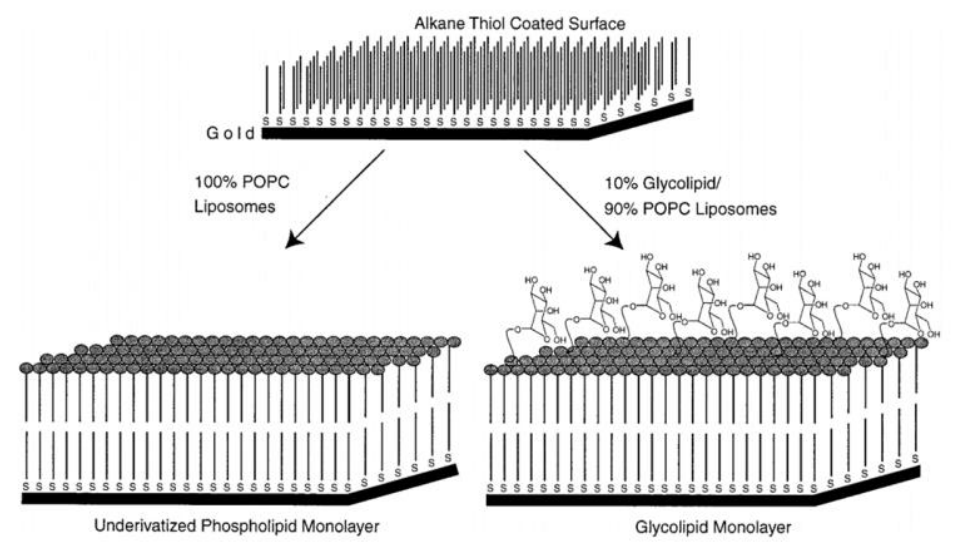

Figure 2.5. Scheme illustrating control over ligand density using supported lipid monolayers. Adapted with permission from ref. 77. Copyright 1998 American Chemical Society.

\section{Formation of protein layers}

The formation of protein layers on surfaces has been also employed for the control of the surface density on the surface. In particular, the functionalization of substrates with SAv has been largely used for the modification of surfaces with biotinylated receptors. Techniques such as biolayer interferometry (BLI), for example, employ SAv-covered surfaces for the modification of surfaces with controlled densities of saccharides. By controlling the molar ratio of biotinylated ligands with biotinylated dummy molecules, it is possible to tune the ligand density displayed on the surface. Xiong et al. functionalized surfaces with varying densities of sialic acid residues this way. ${ }^{78,79}$

\subsubsection{Pre-modified polymers and proteins}

The use of modified polymers or proteins represent an alternative way to functionalize surfaces with control over the exposed ligand density. In particular, polymers and proteins can be modified with specific ligands prior to their adsorption. The modification and the inter-ligand spacing on the polymer backbone or the protein provides thereby control of the ligand density displayed at the interface.

Several examples of polymers and polyelectrolytes which allow an easy and controlled modification have been reported. Among several types of polymers, poly-L-lysine (PLL) has been extensively employed for the modification of surfaces with ligands. Owing to its positive charge at physiological $\mathrm{pH}$, PLL can adsorb spontaneously from aqueous solutions 
on negatively charged substrates (such as glass, titanium, niobium oxide) by electrostatic interactions, thus forming molecular monolayers. ${ }^{80}$ At the same time, the presence of terminal amino groups present at the lateral chains allows easy modification of the polymer. ${ }^{80,81}$ PLL can be, for example, grafted with (PEG) chains by an NHS coupling reaction to generate PLL-graft-PEG (PLL-g-PEG), and the grafting ratio can be easily controlled during the synthesis step. PLL-g-PEG has been generated carrying additional biologically relevant ligands such as peptides, ${ }^{82}$ biotin $^{83}$ or NTA $^{84}$ at the termini of the PEG side chains allowing the display of these ligands on the functionalized surface. The control of the grafting ratio of the copolymer leads to the possibility of tailoring the ligand density on the surface. Among several reported examples, Barth et al. showed the possibility of tuning the saccharide density on the surface by using mannoside-functionalized PLL- $g$-PEG. ${ }^{85}$ In this study, a series of PLL-g-PEGs was synthesized containing either mono or oligo-mannosides, and these polymers were assembled on $\mathrm{Nb}_{2} \mathrm{O}_{5}$-coated glass surfaces. The mannose surface density was hereby varied between 0 and $26 \mathrm{pmol} / \mathrm{cm}^{2}$.

More recently, Duan and coworkers employed oligo(ethylene glycol) (OEG)-grafted PLL (PLL-OEG) for the fabrication of a bio-functionalized film on nano-bioFETs. ${ }^{86}$ OEG and OEG-biotin moieties were grafted in different ratios to produce PLL-g-OEG-biotin containing different ligand densities. The total degree of functionalization of the PLL was varied to study the optimal functionalization to obtain both stability of the PLL on the surface and maximal adsorption of SAv. In our group, maleimide (Mal) groups were used instead of biotin in order to generate substrates modified with tunable densities of functional groups. ${ }^{87}$ By exploiting the coupling between maleimide and thiolated peptide nucleic acid (PNA), PNA probes were displayed on the surface to form a biorecognition surface that allows the detection of complementary DNA (cDNA). The responses for cDNA hybridization were found to depend on the PNA probe density displayed at the interface which was set during the preceding PLL synthesis step, by controlling the amount of Mal in the polymer.

Another intriguing example of control over ligand spacing using polypeptides is given in the work of Lin et al. ${ }^{88}$ Here, a polyproline helix type II (PPII), which is a non-charged polypeptide, was used as a scaffold for the binding of proteins onto surfaces. PPII was selectively modified at one side with glycans, whereas the other side was modified with fluorous groups which allowed the anchoring of the peptide on fluorous slides (Figure 2.6A). By tuning the number and the position of lateral fluorous chains, the display of the polymers on the surface was controlled. The surface density control was achieved by diluting the functionalized scaffold with unfunctionalized ones. ${ }^{88}$

Alternatively, neoglycoproteins have been used to control the density of ligands on surfaces. Gildersleeve and coworkers have presented the use of glycoproteins bearing mannose residues for the modification of surfaces (Figure 2.6B). ${ }^{34} \mathrm{With}$ this method, mannose residues 
with different lengths were displayed on the surfaces to bind multivalently ConA proteins. Ligand density control was achieved by mixing BSA with glycoproteins in solution prior to adsorption onto the surface.

(A)

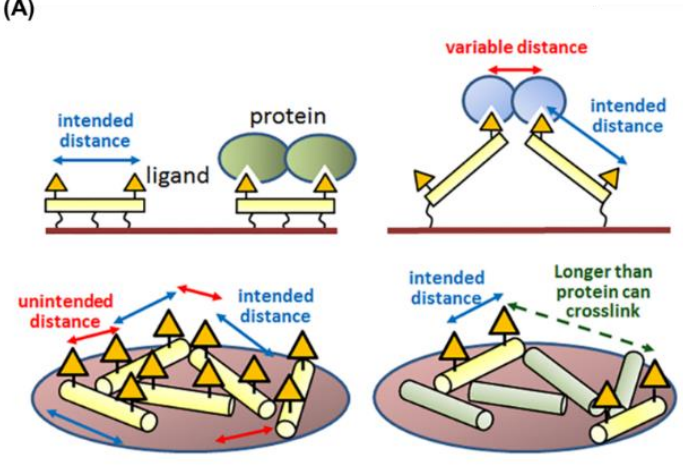

(B)

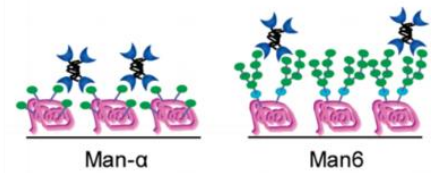

High Neoglycoprotein Density

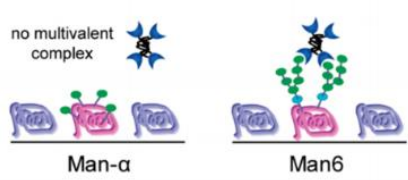

Low Neoglycoprotein Density

Figure 2.6. (A) Schematic representation of different arrangements of polyproline scaffolds on fluorous surfaces for the control of carbohydrate densities. Reprinted with permission from ref. 88. Copyright (2017) American Chemical Society. (B) Different binding modes of ConA proteins to substrates with high and low neoglycoprotein density. Reprinted with permission from ref. 34. Copyright (2010) American Chemical Society.

\section{Polymer brushes}

An attractive alternative approach to engineer surfaces with controlled ligand density is represented by the use of polymer brushes. These polymers consists of either block copolymers or end-grafted polymers which are tethered to a surface at one end, allowing the formation of coatings with desirable thickness in a nanometric range. ${ }^{89}$ The other end of the polymer chain, instead, presents a functionality which can influence the property of the surface and can allow secondary functionalization of substrates. Several reviews have been reported, thoroughly describing properties and applications of this class of polymers. ${ }^{90-92}$ By reacting or anchoring ligands such as carbohydrates or peptides to the functional groups displayed at polymer brushes, it is possible to modify surfaces with ligands with controlled density. ${ }^{93,}, 94$

Haag and coworkers reported a polyglycerol (PG)-based block copolymer, synthesized from PG and a poly(allyl glycidyl ether) (PAGE), which was used for the functionalization of a large variety of surfaces with controlled RGD peptide densities. ${ }^{95}$ Interestingly, the addition of azide groups in the PG copolymer can allow secondary modification of the polymer with RGD by exploiting the strain-promoted cyclo-addition. By mixing azide-terminated with 
bromide-terminated polymers it was possible to tune the grafting density of RGD on the surface.

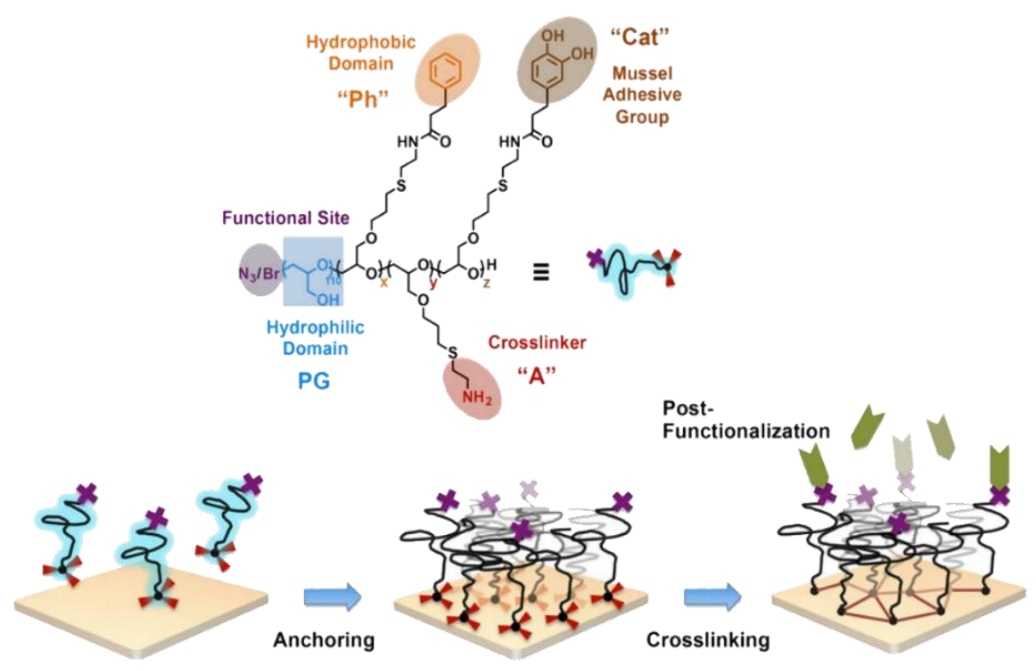

Figure 2.7. Representation of surface modification with PG-based amphiphilic block copolymers. The PG catechol groups contribute to binding to polar surfaces, while the phenyl groups are used for anchoring to non-polar surfaces. The $\mathrm{N}_{3}$ or $\mathrm{Br}$ terminal groups allow secondary modification of the surfaces. Adapted with permission from ref. 95. Copyright (2017) American Chemical Society.

In a different example, polymer brushes were grafted from a surface by using surfaceinitiated atom transfer radical polymerization (SI-ATRP). Non-fouling poly(2-hydroxyethyl methacrylate) (PHEMA) and poly(poly(ethylene glycol)methacrylate) (PPEGMA) brushes were prepared on glass and silicon substrates with thicknesses between 20 and $150 \mathrm{~nm}$ with controlled RGD densities. ${ }^{90}$ Post-modification of the surface, performed with different concentrations of RGD-based peptide ligands in solution, led to ligand surface densities ranging between $0.5-12 \mathrm{pmol} / \mathrm{cm}^{2}$.

Shi et al. presented the use of polymer brushes in combination with non-covalent host-guest interactions for the control of lysine ligand densities. ${ }^{96}$ Lysine-functionalized surfaces were prepared by integrating lysine-modified CD derivatives by host-guest interactions onto adamantyl-pre-modified copolymer brushes. Control of the localized and average lysine density at the surface was achieved by changing the lysine valency on the CD scaffolds and by diluting lysine-modified $\mathrm{CD}$ with pure $\mathrm{CD}$, respectively (Figure 2.8). The influence of surface presentation of lysine residues and their local density in the binding affinity of plasminogen (Plg) was investigated by using lysine-modified polymer brushes. As a main conclusion, the displacement and the density of the lysines was found to affect not only the 
binding affinities but also the valency of the overall interactions. Copolymer surfaces modified with heptavalent lysines $\left[\mathrm{CD}(\mathrm{Lys})_{7}\right]$ showed higher Plg adsorption and higher Plg binding affinities compared to the monovalent ones $\left[\mathrm{CD}(\operatorname{Lys})_{1}\right]$.

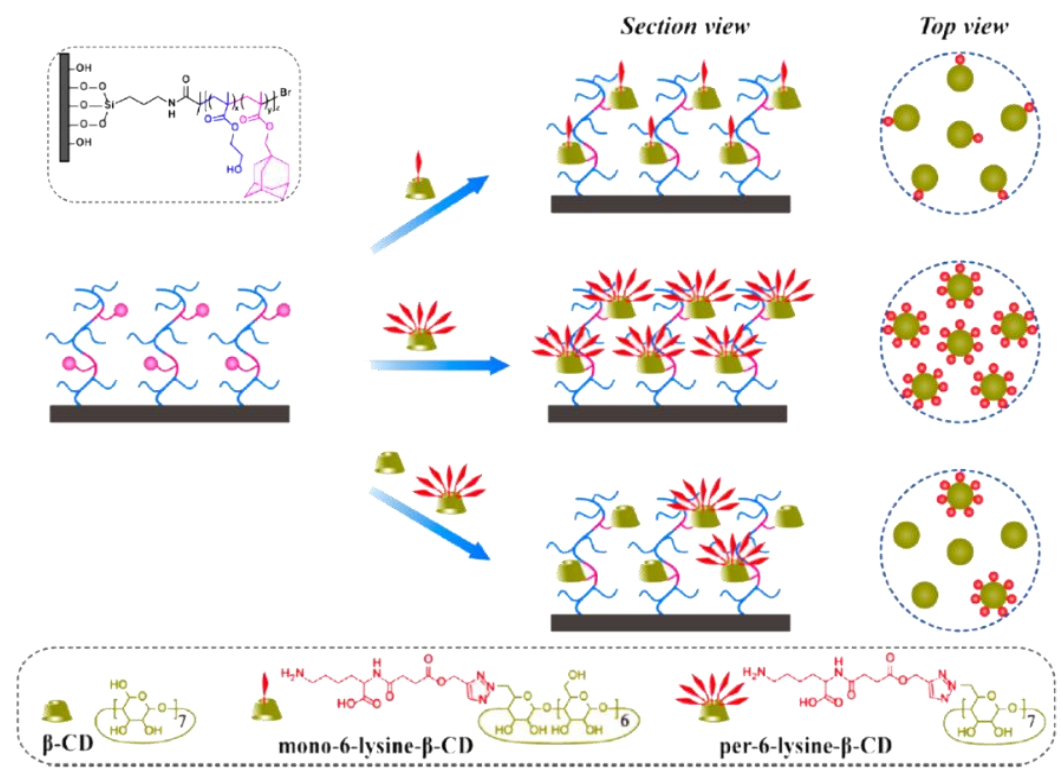

Figure 2.8. Schematic representation of the modulation of localized and average lysine densities of surfaces by host-guest interactions using polymer brushes. Adamantyl-modified polymer brushes are modified with lysine-functionalized cyclodextrins bearing different numbers of lysines in order to produce different surface ligand densities. Adapted with permission from ref. 96. Copyright (2015) American Chemical Society.

\subsubsection{Formation of 3D layers}

While the formation of monolayers and bilayers are the most used methods for the functionalization of surfaces with ligands, these platforms allow only a 2D arrangement of the ligands on surfaces. However, the formation of a 3D environment, which resembles the in vivo conditions of biological interactions, can be particularly important in the study of biological systems. Cells, for examples, have shown different responses when placed in a 3D environment compared to $2 \mathrm{D} .{ }^{41,97}$

In order to achieve a surface modification with 3D structures, glycodendrimers have been anchored onto surfaces. Pieters and coworkers anchored glycodendrimer-based glycan microarrays on porous aluminum oxide. ${ }^{98-99}$ Specifically, alkyne-functionalized dendrimers 
were anchored on a maleimide-functionalized surface via an amine functional group linked to the core of the dendrimers. Subsequently, azide-functionalized carbohydrates were linked onto the surface by copper-catalyzed click chemistry. By controlling the valency of the carbohydrate-modified dendrimers, the ligand density at the surfaces was varied.

Alternatively, microarrays based on end-point immobilization of oriented glycopolymers have been employed to mimic natural cell surface glycans in 3D. Sun and coworkers presented an O-cyanate chain-end functionalized glycopolymer for the modification of surfaces with glycans. ${ }^{100}$ Glycopolymers were pre-complexed with boronic acid ligands composed of varying lengths and then immobilized by isourea-bond formation at high $\mathrm{pH}$ onto an amine-functionalized glass slide. After the immobilization, the boronic acid ligands were released from the immobilized glycopolymers at a reduced $\mathrm{pH}$ to generate the oriented and density-controlled glycopolymer microarray.

In a different approach, Musah et al. immobilized polyacrylamide-based hydrogels on a glass surface with varying densities of RGD peptides. ${ }^{101}$ Specifically, hydrogels bearing succinimidyl ester groups were used for the modification of surfaces. After the formation of the hydrogel, the activated esters were reacted with a mixture of an amine bearing a maleimide group and glucamine. While the former was used for peptide attachment by the coupling with a cysteine residue, the latter was employed as inert component. The ratio of glucamine and the maleimide-containing amine was varied in order to tune the peptide density. In another study by Murphy et al., PEG-based hydrogels where modified with varying densities of RGD peptides. ${ }^{102}$ The ligand density on the surfaces was varied by mixing RGD and RDG (inactive peptide) hydrogels, while keeping the total peptide concentration constant.

\subsection{Multivalent studies at functionalized platforms}

A large number of multivalent systems such as molecules, proteins, viruses or cells has been investigated at ligand-functionalized platforms. CD-modified surfaces have been used, for example, for the binding of multivalent polymers, and SAMs have been used for the formation of glycan arrays for the study of the interactions of proteins and cells. In this section, an overview of some relevant examples reported in the literature is provided. Examples of platforms with control over the ligand density are here reported, in which the density-dependent, multivalent affinity and binding behavior has been investigated. Examples of multivalent reversible binding are also discussed in this section. 


\subsubsection{Binding of molecules and polymers at interfaces}

The multivalent binding of several types of molecules at interfaces has been reported. Both small oligovalent ligands and large polyvalent polymers and dendrimers have been investigated, showing strong binding affinities for ligand-modified surfaces. The improved binding affinities and stability of the molecules on the surface, in comparison to the monovalent parent interaction, have been found to correlate with the multivalent nature of the interactions. Several examples of synthetic multivalent host-guest interactions at interfaces have been reported by Huskens and coworkers, providing a detailed understanding of the thermodynamic contributions of multivalent binding at interfaces. ${ }^{103-104}$ Stronger binding affinities were observed for multivalent interactions at the interface compared to the equivalent systems in solution due to a local high concentration (also called effective molarity) of receptors created by surface immobilization.

In a recent report, the binding of fluorescent dye-labelled multivalent azopyridine molecules to gold and plastic substrates was investigated by Valderrey et al. ${ }^{105}$ In this work, heteroternary host-guest complexes of multivalent azopyridines with methyl viologen/cucurbit[8]uril inclusion complexes were formed at viologen-functionalized surfaces. Surface binding constants of multivalent ligands, determined by SPR, showed binding affinities that were two orders of magnitude higher than that of the monovalent one. Interestingly, supramolecular exchange experiments performed by patterning of mono and divalent molecules on surfaces, showed a substitution of the monovalent guest by the multivalent ones.

The dynamic binding of multivalent redox-active ferrocenyl dendrimers at $\beta$-CD monolayers was investigated by Nijhuis et al. ${ }^{106,} 107$ The dendrimers of higher generations formed kinetically stable supramolecular assemblies at the $C D$ surface presenting up to eight multivalent interacting pairs. Desorption of the dendrimers was achieved by electrochemical oxidation of the Fc end groups of the dendrimers which led to an efficient unbinding of the molecules from the host surface. Desorption and re-adsorption of the dendrimers were repeated several times without significant decomposition of the system.

Several examples of the binding of polyvalent polymers at modified platforms have been reported. Polymer systems have been used as models for the investigation of biological interactions. The multivalent interaction of $p$-tert-butylphenyl or adamantyl-functionalized poly(iso-butene-alt-maleic acid)s at CD SAMs, leading to thermodynamically and kinetically stable multivalent assemblies, was reported by Crespo-Biel et al. ${ }^{108}$ The polymer concentration and the nature or number of the functionalization did not affect the adsorption notably, nor did addition of monovalent competitors in solution lead to measurable polymer desorption, showing the strength of the overall interaction. The polymers were found to 
adsorb in a conformationally fully unwound fashion, leading to very thin $(<1 \mathrm{~nm})$ layers with practically complete usage of the polymer-attached guest sites.

Dubacheva et al. reported the interaction of CD-modified hyaluronan (HA) polymers with ferrocene ( $\mathrm{Fc}$ ) or adamantane (Ad)-modified surfaces (see above).$^{52}$ The variation of Ad and Fc densities allowed the study of the superselective binding behavior of the multivalent polymers. In this work, an analytical model was developed that provides quantitative predictions of the tuning of the superselective binding properties of the polymer, based on molecular characteristics such as affinity and valency. The effect of the ligand mobility at surfaces to the superselective binding was recently investigated. ${ }^{109}$ The binding of multivalent CD-modified HA polymers was found to be enhanced and shifted to lower receptor densities at fluid interfaces (based on SLBs) compared to immobile ones (based on SAMs).

\subsubsection{Binding of proteins and peptides at interfaces}

Multivalent interactions at interfaces of a wide range of proteins have been investigated, which generally showed a strong dependence of the overall binding affinity on the surface ligand density. One of the most studied polyvalent proteins is ConA. The weak binding affinity of ConA to mono-saccharide ligands $\left(K_{\mathrm{a}} \sim 10^{4} \mathrm{M}^{-1}\right)$, enforced by multivalent interactions, together with its tetrameric structure, makes ConA an ideal model for the study of protein-carbohydrate interactions at the interface. ${ }^{110}$ Hereby some of the most relevant examples of studies of the binding of ConA at surfaces are reported.

Sato et al. designed a lectin-recognizing molecular interface for ConA by using SAMs consisting of 12-mercaptododecyl $\beta$-maltoside $\left(\mathrm{MalC}_{12} \mathrm{SH}\right)$ and $\mathrm{OH}$-terminated thiols $\left(\mathrm{HOC}_{n} \mathrm{SH}\right.$, of varying length) as filling molecules (Figure 2.9A). ${ }^{111}$ Variations of both ligand density and dummy thiol length led to the optimization of the protein-carbohydrate interaction. Specifically, the enhancement of the valency of the interaction was controlled by creating a significant height difference between the saccharide and the terminus of the filling molecule. An optimal ligand density was found at $10 \%$ of $\mathrm{MalC}_{12} \mathrm{SH}$ in the mixed monolayer. Kiessling and coworkers investigated the multivalent binding of ConA at SLMs, where the best sensitivity of the interaction was achieved with $10 \%$ of functionalization with mannose in the total lipid mixture. ${ }^{77}$ Alternatively, a mannose-containing cross-linked polyacrylamide (c-PAAm) was employed as a surface-immobilized polyvalent ligand for the multivalent recognition of ConA on surfaces. ${ }^{112} \mathrm{With}$ this approach, high-affinity binding $\left(\sim 10^{6} \mathrm{M}^{-1}\right)$ and highly sensitive detection were achieved. 
(A)

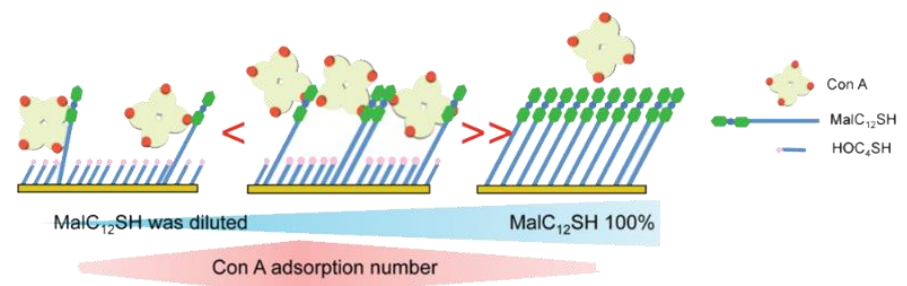

(B)

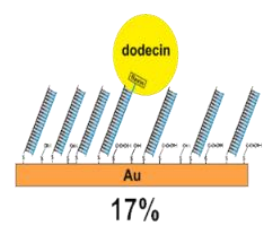

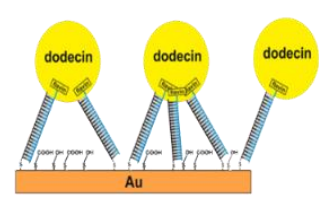

$100 \%$
(C)

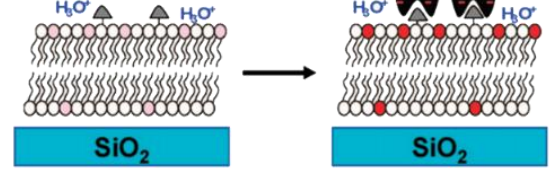

Figure 2.9. Multivalent binding of proteins on ligand-presenting platforms. A) Schematic representation of binding of ConA for different densities of $\beta$-maltoside. Different densities of saccharide-modified thiols in the total thiol mixture causes a difference in the binding valency and affinity of ConA. Reprinted with permission from ref. 111. Copyright (2012) American Chemical Society. (B) Schematic representation of the formation of a flavin-modified dsDNA layer. The use of DNA mixtures with and without flavin allows the variation of flavin density on the surface, leading to different valency in the overall interaction with dodecin proteins. Adapted with permission from ref. 115. Copyright (2015) American Chemical Society. (C) Binding of an ant-biotin antibody on a biotinmodified SLB resulting in an increased fluorescence of Texas Red DHPE-lipids. Adapted with permission from ref. 116. Copyright (2009) American Chemical Society.

A wide range of multivalent protein-carbohydrate interactions at interfaces has been investigated. SAMs containing mannose, lactose, or $\alpha$-Gal trisaccharide were used in the study of specific carbohydrate-protein interactions with ConA, ECL-lactose and anti-Gal, respectively. Overall binding constants for these interactions were determined by QCM, SPR and electrochemistry studies. ${ }^{113}$

The multivalent binding of the Lens culinaris (LENS) lectin was investigated on mannosefunctionalized crystalline $\operatorname{Si}(111)$ surfaces. ${ }^{114}$ After the modification of the surfaces with glycan residues by "click" coupling, the multivalent interactions were investigated by quantitative attenuated total reflectance Fourier transform infrared spectroscopy (ATRFTIR) and atomic force microscopy (AFM). The variation of the ligand density at the surface (varied from $7.2 \times 10^{12}$ to $1.2 \times 10^{14}$ molecules per $\mathrm{cm}^{2}$ ) showed an effect on the protein binding, and optimal binding was achieved at a fraction of $10 \mathrm{~mol} \%$ of mannose residues on the surface. At a lower mannose density $(1 \mathrm{~mol} \%)$, only monovalent interactions occurred, 
which resulted in a decrease of protein adsorption. At high ligand density (100\%) instead, limitations in protein adsorption were observed as a consequence of steric hindrance between mannose residues, as the average inter-ligand density $(0.91 \mathrm{~nm})$ resulted to be lower than the size of the carbohydrate recognition domain $(1.4 \mathrm{~nm}) .{ }^{114}$

Nöll and coworkers reported the multivalent interaction of the flavoprotein dodecin with a flavin-terminated DNA monolayer. ${ }^{115}$ Surfaces were modified with controlled densities of flavin by using single-stranded DNA (ssDNA) which was stably anchored on a gold surface using three dithiane groups. In a following step, a complementary flavin-modified ssDNA was added for hybridization. By mixing flavin-free and flavin-modified complementary DNA in different ratios, it was possible to tune the ligand density displayed at the interface. The density was found to influence the valency of the dodicin interaction at the interface. Low flavin surface coverages $(<17 \%)$ led to weak monovalent binding with the protein, while at high densities ( $>31 \%$ ) multiple binding events allowed a more stable multivalent binding (Figure 2.9B). At high flavin coverage up to three binding pockets were estimated to be accessible for each dodecin due to the octahedral arrangement of the six dodecin binding pockets. By using multivalent interactions, dodecin proteins were also tested for the generation of stable sandwich-type flavin-apododecin-flavin architectures on surfaces. ${ }^{115}$

The multivalent interaction of anti-biotin antibodies and cholera toxin B subunits with biotin and GM1-modified surfaces, respectively, was presented by the group of Cremer. ${ }^{116}$ SLBs were doped with $\mathrm{pH}$-sensitive ortho-Texas Red-DHPE lipids, which fluoresce at acidic $\mathrm{pH}$ and become non-fluorescent at higher $\mathrm{pH}$. The binding of a negatively charged protein, causing a local decrease of $\mathrm{pH}$ at the interface, affected the fluorescence at the SLB (Figure 2.9C). By following the increase in fluorescence intensity upon binding of the protein, equilibrium dissociation constants were obtained with affinities in the $\mathrm{nM}$ range.

Cremer and coworkers inserted 2,4-dinitrophenyl (DPN) in the SLBs, and studied the effect of the density of DPN to the binding with their associated IgG antibodies by using a highthroughput microfluidic device. ${ }^{117}$ By mixing DPN-conjugated lipids with egg phosphatidylcholine (egg-PC) in different ratios in the vesicle preparation step, the DPN density in the lipid membranes was varied from 0.1 to $5.0 \mathrm{~mol} \%$. Interestingly, the results showed that the density affects the affinity of the interaction. The apparent dissociation constant, $K_{\text {Dapp }}$, between DNP and the antibodies, obtained with epifluorescence microscopy, increased by about a factor of 10 by increasing the DNP density from 0.1 to $3.75 \mathrm{~mol} \%$, while higher densities did not lead to a further increased affinity.

Joubert et al. formed microarrays based on poly(bis-SorbPC) lipids doped with GM1 lipids for the study of the interaction with the cholera toxin protein. ${ }^{118}$ After UV-initiated polymerization, air stable poly(lipid) bilayer microarrays were obtained. GM1 molar ratios in the lipid mixture were varied from 0 to $10 \%$ leading to varying adsorption of labeled CTB 
proteins. The extent of binding of CTB in each spot, detected by fluorescence microscopy, was correlated to the mole percentage of GM1. CTB proteins were successfully removed from surfaces by exposure of GM1-modified arrays to denaturants. In this way the regeneration of the arrays was achieved, and the CTB binding capability was confirmed after multiple regeneration cycles.

Brock and coworkers investigated the binding selectivity of oligo-histidines to immobilized multiple NTA moieties. ${ }^{119}$ By means of microarrays, mono-, bis-, tris- and tetrakis-NTA chelators were spotted at different surface densities. The ability of histidine-based multivalent binders to discriminate fluorescently labelled hexa and decahistidine peptides was tested. This work showed that, when both peptides were incubated together, an increased affinity of decahistidine was observed compared to hexahistidine, while also showing a strong dependence on the chelator density. Binding assays by dual-color total internal reflection fluorescence spectroscopy revealed active exchange of $\mathrm{His}_{6}$ by $\mathrm{His}_{10}$, thus confirming the high selectivity towards His 10 .

\subsubsection{Binding of viruses and virus-like particles at interfaces}

Interactions of viruses with receptor-modified surfaces have been widely investigated. Functionalization of surfaces with precise control of the ligand densities was achieved for the development of biosensing surfaces able to detect low concentrations of virus in solution. Quantification of the interaction of several types of viruses was also achieved. Mixed SAMs with control over the density of sialic acid residues were developed by Hushegyi et al. (see above) to form impedimetric glycan biosensors for the detection of the influenza A virus (IAV) hemagglutinins in the attomolar range. ${ }^{45}$ Aptamer-based sensors (aptasensors) were developed by Bai and coworkers for the detections of IAV. ${ }^{120}$ The aptamer surface density appeared to affect the binding affinity between surface-anchored aptamers and viruses, showing a more than 100 times higher sensitivity when the surface density was increased from $4.8 \times 10^{11}$ to $14 \times 10^{11}$ molecules $/ \mathrm{cm}^{2}$ (Figure 2.10A). Alternatively, a mucin-mimetic glycopolymer-based microarray was employed for the study on the binding of IAV with sialic acid receptors (Figure 2.10B). ${ }^{121}$ Printing of azide-modified glycopolymers on cyclooctynecoated surfaces produced microarrays with increasing glycopolymer densities. H1N1 and H3N2 viruses were incubated on the platform, showing selectivity for specific glycans. Reversible binding of viral proteins and viruses was obtained by using $\mathrm{pH}$-switchable monolayers. Recently, Sellergren and coworkers reported the interaction of the H5N1 (A/Anhui/2005) influenza virus on a sialic acid-modified reversible SAM (rSAM). ${ }^{122}$ 
(A)

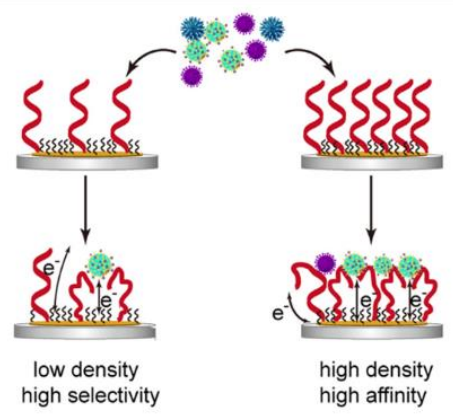

(B)
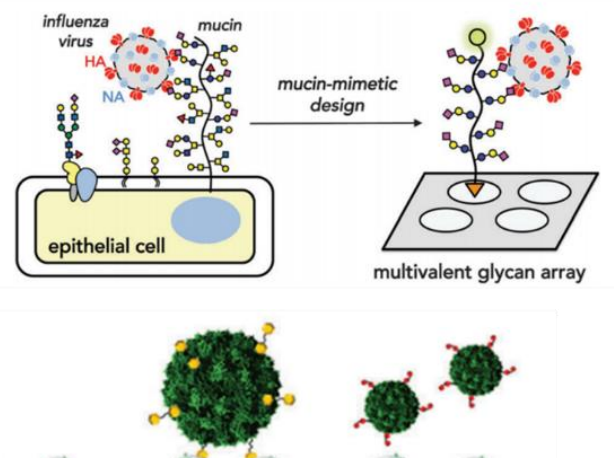

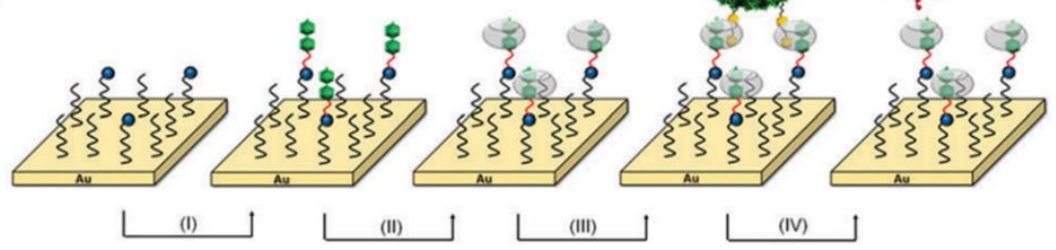

(C)

Figure 2.10. (A) Representation of the interaction of IAV with aptamer-modified sensors in which the density of aptamers on the surface affects the binding affinity of viruses. Adapted from ref. 120 with permission from Elsevier. (B) Schematic representation of the interaction of IAV with a mucin-mimetic microarray. Reproduced from ref. 121 by permission of The Royal Society of Chemistry. (C) Schematic representation of stepwise assembly of the $\mathrm{CB}[8]$ monolayers and subsequent multivalent interaction of modified CCMV viruses. Reproduced from ref. 123 by permission of The Royal Society of Chemistry.

Weineisen et al. reported the controlled and switchable immobilization of modified viruses on surfaces. ${ }^{123}$ Azobenzene-modified Cowpea chlorotic mottle virus (CCMV) was multivalently bound to surfaces by the formation of a photoresponsive, hetero-ternary complex between azobenzene, cucurbit[8]uril (CB[8]) and methylviologen (MV). The association constant $\left(K_{\mathrm{a}}=1.4 \times 10^{6} \mathrm{M}^{-1}\right)$ obtained for this system was found to be several orders of magnitude higher than that of a single interaction $\left(K_{\mathrm{a}}=3 \times 10^{3} \mathrm{M}^{-1}\right)^{124}$, showing the multivalent nature of the binding. Subsequent irradiation of the surface with UV light for 5 min caused a trans-cis isomerization of the azobenzene moieties resulting in the release of the viruses.

Höök and coworkers presented a study of a multivalent model system for the investigation of virus binding at interfaces. In order to mimic virion association to a cell membrane, small lipid vesicles (100 nm diameter) were used. The binding of the vesicles to an SLB was achieved through multiple cholesterol-based DNA linker molecules. Total internal reflection microscopy was used to track single attached vesicles, which showed that the variation of the 
numbers of linking DNA tethers led to variation of the vesicle diffusion coefficient on the surface. $^{125}$

\subsubsection{Binding of cells and bacteria at interfaces}

A large variety of platforms has been modified with receptors for the investigation of the interactions of cells and bacteria at surfaces. SAMs of alkanethiols were formed on gold surfaces presenting RGD peptides for the study of the attachment of cells. The microenvironment in which the ligands are displayed affects the attachment and the morphology of the adhering cells. ${ }^{53}$ In other studies, SLBs functionalized with 19-mer peptides containing the IKVAV sequence were used to investigate the attachment of PC12 $2^{126}$ and $\mathrm{AHP}^{127}$ cells on the surface. A nonlinear correlation was observed between the density of IKVAV presented on the SLB and the number of attached AHP cells, showing a threshold of ligand density necessary for cell attachment. The effect of the ligand density on the cell behavior has also been reported in other reviews. ${ }^{41,128}$

An example of multivalent interactions of bacteria at the interface was presented by Guo and coworkers, in which SLB-based microarrays were developed for the adhesion of E. coli. ${ }^{72}$ The density of mannose on the surface was varied over 2 orders of magnitude (between 0.002-0.3 molecules per $\mathrm{nm}^{2}$ ), showing that the FimH adhesion protein of E. coli changes avidity from monovalent to multivalent as the density of mannose increases (Figure 2.11). The same interaction was studied by Van Weerd et al., utilizing an SLB-based platform on which a continuous, locked-in mannose gradient was formed. ${ }^{129}$ This study demonstrated the specific binding of FimH proteins and the selective binding above a threshold density of mannose. Binding affinities corresponding to a $K_{\mathrm{d}}$ of $0.9 \times 10^{-21} \mathrm{M}$ were obtained, confirming the multivalent nature of the interaction, as monovalent interactions have been reported to be in the $\mu \mathrm{M}$ range. ${ }^{130}$ 


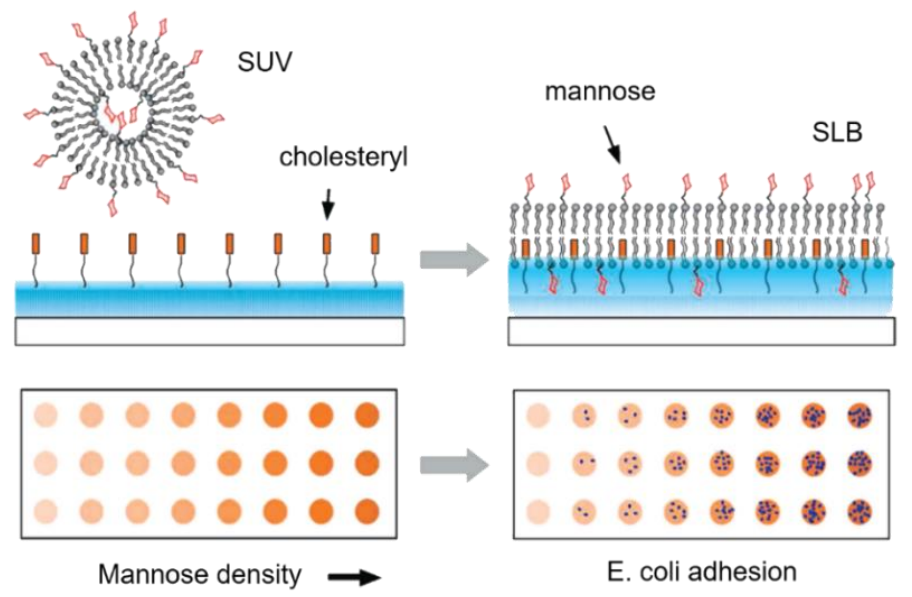

Figure 2.11. Formation of a mannose-presenting SLB surface, made from unilamellar vesicles, and a schematic illustration of a glycan density gradient microarray for studying pathogen adhesion. Glycan density on the surface can be tuned by varying the molar ratio of the glycan-functionalized lipid in the mixture during the preparation of the vesicles. Adapted with permission from ref. 72. Copyright (2009) American Chemical Society.

\subsection{Conclusions}

The ligand density displayed at the interface is a fundamental parameter in the study of the multivalent systems. The variation of the density of ligands appears to influence the valency involved in the multivalent interactions and, therefore, the overall binding affinity and selectivity. In this chapter, a review of the surface modification methods employed in the functionalization of surfaces has been provided.

The first part has focused on the different chemical approaches employed for the modification of surfaces for the control of the ligand density. SAMs, SLBs, modified polymers and proteins have been extensively used for a controlled functionalization of surfaces with ligands. Inter-ligand distances on surfaces that match spacing of the receptor binding sites of proteins generally improve the binding of proteins. Moreover, the importance of a ligand threshold density has been shown, as a minimum density of ligands is required to provide strong multivalent interactions.

In the second part of this chapter, examples of multivalent systems have been discussed. The binding of multivalent molecules, proteins, viruses and cells have been extensively investigated. The development of methodologies for studying multivalent interactions at interfaces through density variation is important for a detailed understanding of the relevant molecular aspects of the interaction. 
The use of platforms for the study of biological interactions at interfaces, despite the increase in the last years, is still very limited. However, the development of such platforms that allow selective biological recognition events and their quantification is essential for a wide range of applications. For example, biosensors for the identification of pathogens such as bacteria and viruses could provide timely treatments of patients after an infection. Sensors for the quantification of virus interactions with cell receptors can be useful for the development of virus warning systems in the prevention of epidemics or pandemics. Alternatively, platforms can be employed for the development and testing of new drugs. A future synergy of chemists, biologists, biochemists and biophysicists in this field can contribute to a fast outgrowth of platforms able to investigate a wide range of biological interactions.

\subsection{References}

1. Mammen, M.; Choi, S.-K.; Whitesides, G. M., Polyvalent Interactions in Biological Systems: Implications for Design and Use of Multivalent Ligands and Inhibitors. Angew. Chem. Int. Ed. 1998, 37, 2754-2794.

2. Fasting, C.; Schalley, C. A.; Weber, M.; Seitz, O.; Hecht, S.; Koksch, B.; Dernedde, J.; Graf, C.; Knapp, E.-W.; Haag, R., Multivalency as a Chemical Organization and Action Principle. Angew. Chem. Int. Ed. 2012, 51, 10472-10498.

3. Mulder, A.; Huskens, J.; Reinhoudt, D. N., Multivalency in supramolecular chemistry and nanofabrication. Org. Biomol. Chem. 2004, 2, 3409-3424.

4. Mahon, E.; Barboiu, M., Synthetic multivalency for biological applications. Org. Biomol. Chem. 2015, 13, 10590-10599.

5. Kim, Y.; Cao, Z.; Tan, W., Molecular assembly for high-performance bivalent nucleic acid inhibitor. P. Natl. Acad. Sci. 2008, 105, 5664-5669.

6. Lu, W.; Pieters, R. J., Carbohydrate-protein interactions and multivalency: implications for the inhibition of influenza A virus infections. Expert Opin. Drug Dis. 2019, 14, 387-395.

7. Merritt, E. A.; Sarfaty, S.; Akker, F. V. D.; L'Hoir, C.; Martial, J. A.; Hol, W. G. J., Crystal structure of cholera toxin B-pentamer bound to receptor GM1 pentasaccharide. Protein Sci. 1994, 3, 166-175.

8. Branson, T. R.; Turnbull, W. B., Bacterial toxin inhibitors based on multivalent scaffolds. Chem. Soc. Rev. 2013, 42, 4613-4622.

9. Bernardi, A.; Jiménez-Barbero, J.; Casnati, A.; De Castro, C.; Darbre, T.; Fieschi, F.; Finne, J.; Funken, H.; Jaeger, K.-E.; Lahmann, M.; Lindhorst, T. K.; Marradi, M.; Messner, P.; Molinaro, A.; Murphy, P. V.; Nativi, C.; Oscarson, S.; Penadés, S.; Peri, F.; Pieters, R. J.; Renaudet, O.; Reymond, J.-L.; Richichi, B.; Rojo, J.; Sansone, F.; Schäffer, C.; Turnbull, W. B.; Velasco-Torrijos, T.; Vidal, S.; Vincent, S.; Wennekes, T.; Zuilhof, H.; Imberty, A., Multivalent glycoconjugates as anti-pathogenic agents. Chem. Soc. Rev. 2013, 42, 4709-4727.

10. Mulder, A.; Auletta, T.; Sartori, A.; Del Ciotto, S.; Casnati, A.; Ungaro, R.; Huskens, J.; Reinhoudt, D. N., Divalent Binding of a Bis(adamantyl)-Functionalized Calix[4]arene to $\beta$ cyclodextrin-based Hosts: An Experimental and Theoretical Study on Multivalent Binding in Solution and at Self-Assembled Monolayers. J. Am. Chem. Soc. 2004, 126, 6627-6636.

11. Huskens, J.; Prins, L. J.; Haag, R.; Ravoo, B. J., Multivalency: Concepts, Research \& Applications. Wiley: 2018. 
12. Kiessling, L. L.; Gestwicki, J. E.; Strong, L. E., Synthetic Multivalent Ligands as Probes of Signal Transduction. Angew. Chem. Int. Ed. 2006, 45, 2348-2368.

13. Gouin, S. G.; Wellens, A.; Bouckaert, J.; Kovensky, J., Synthetic Multimeric Heptyl Mannosides as Potent Antiadhesives of Uropathogenic Escherichia coli. ChemMedChem 2009, 4, 749-755.

14. Papp, I.; Sieben, C.; Sisson, A. L.; Kostka, J.; Böttcher, C.; Ludwig, K.; Herrmann, A.; Haag, R., Inhibition of Influenza Virus Activity by Multivalent Glycoarchitectures with Matched Sizes. ChemBioChem 2011, 12, 887-895.

15. Rolland, O.; Turrin, C.-O.; Caminade, A.-M.; Majoral, J.-P., Dendrimers and nanomedicine: multivalency in action. New Journal of Chemistry 2009, 33 (9), 1809-1824.

16. Lundquist, J. J.; Toone, E. J., The Cluster Glycoside Effect. Chem. Rev. 2002, 102, 555-578.

17. Baldini, L.; Casnati, A.; Sansone, F.; Ungaro, R., Calixarene-based multivalent ligands. Chem. Soc. Rev. 2007, 36 (2), 254-266.

18. Wang, X.; Ramström, O.; Yan, M., Quantitative Analysis of Multivalent Ligand Presentation on Gold Glyconanoparticles and the Impact on Lectin Binding. Anal. Chem. 2010, 82, 90829089 .

19. Takae, S.; Akiyama, Y.; Otsuka, H.; Nakamura, T.; Nagasaki, Y.; Kataoka, K., Ligand Density Effect on Biorecognition by PEGylated Gold Nanoparticles: Regulated Interaction of RCA120 Lectin with Lactose Installed to the Distal End of Tethered PEG Strands on Gold Surface. Biomacromolecules 2005, 6 (2), 818-824.

20. Elias, D. R.; Poloukhtine, A.; Popik, V.; Tsourkas, A., Effect of ligand density, receptor density, and nanoparticle size on cell targeting. Nanomed-Nanotechnol 2013, 9, 194-201.

21. Huskens, J., Multivalent interactions at interfaces. Curr. Opin. in Chem. Biol. 2006, 10, 537543.

22. Huskens, J.; Deij, M. A.; Reinhoudt, D. N., Attachment of Molecules at a Molecular Printboard by Multiple Host-Guest Interactions. Angew. Chem. Int. Ed. 2002, 41, 4467-4471.

23. Huskens, J.; Mulder, A.; Auletta, T.; Nijhuis, C. A.; Ludden, M. J. W.; Reinhoudt, D. N., A Model for Describing the Thermodynamics of Multivalent Host-Guest Interactions at Interfaces. J. Am. Chem. Soc. 2004, 126, 6784-6797.

24. Onclin, S.; Mulder, A.; Huskens, J.; Ravoo, B. J.; Reinhoudt, D. N., Molecular Printboards: Monolayers of $\beta$-Cyclodextrins on Silicon Oxide Surfaces. Langmuir 2004, 20, 5460-5466.

25. Auletta, T.; Dordi, B.; Mulder, A.; Sartori, A.; Onclin, S.; Bruinink, C. M.; Péter, M.; Nijhuis, C. A.; Beijleveld, H.; Schönherr, H.; Vancso, G. J.; Casnati, A.; Ungaro, R.; Ravoo, B. J.; Huskens, J.; Reinhoudt, D. N., Writing Patterns of Molecules on Molecular Printboards. Angew. Chem. Int. Ed. 2004, 43, 369-373.

26. Kostiainen, M. A.; Smith, D. K.; Ikkala, O., Optically Triggered Release of DNA from Multivalent Dendrons by Degrading and Charge-Switching Multivalency. Angew. Chem. Int. Ed. 2007, 46, 7600-7604.

27. Fragoso, A.; Caballero, J.; Almirall, E.; Villalonga, R.; Cao, R., Immobilization of Adamantane-Modified Cytochrome $\mathrm{c}$ at Electrode Surfaces through Supramolecular Interactions. Langmuir 2002, 18, 5051-5054.

28. Bertok, T.; Klukova, L.; Sediva, A.; Kasák, P.; Semak, V.; Micusik, M.; Omastova, M.; Chovanová, L.; Vlček, M.; Imrich, R.; Vikartovska, A.; Tkac, J., Ultrasensitive Impedimetric Lectin Biosensors with Efficient Antifouling Properties Applied in Glycoprofiling of Human Serum Samples. Anal. Chem. 2013, 85, 7324-7332.

29. Zhan, W.; Wei, T.; Cao, L.; Hu, C.; Qu, Y.; Yu, Q.; Chen, H., Supramolecular Platform with Switchable Multivalent Affinity: Photo-Reversible Capture and Release of Bacteria. ACS Appl. Mater. Inter. 2017, 9, 3505-3513. 
30. Narla, S. N.; Nie, H.; Li, Y.; Sun, X.-L., Multi-dimensional glycan microarrays with glycomacroligands. Glycoconjugate J. 2015, 32, 483-495.

31. Park, S.; Gildersleeve, J. C.; Blixt, O.; Shin, I., Carbohydrate microarrays. Chem. Soc. Rev. 2013, 42, 4310-4326.

32. Yu, Q.; Zhang, Y.; Wang, H.; Brash, J.; Chen, H., Anti-fouling bioactive surfaces. Acta Biomater. 2011, 7, 1550-1557.

33. Martinez-Veracoechea, F. J.; Frenkel, D., Designing super selectivity in multivalent nanoparticle binding. P. Natl. Acad. Sci. U.S.A. 2011, 108, 10963-10968.

34. Zhang, Y.; Li, Q.; Rodriguez, L. G.; Gildersleeve, J. C., An Array-Based Method To Identify Multivalent Inhibitors. J. Am. Chem. Soc. 2010, 132, 9653-9662.

35. Smith, E. A.; Thomas, W. D.; Kiessling, L. L.; Corn, R. M., Surface Plasmon Resonance Imaging Studies of Protein-Carbohydrate Interactions. J. Am. Chem. Soc. 2003, 125, 61406148.

36. Shi, J.; Yang, T.; Kataoka, S.; Zhang, Y.; Diaz, A. J.; Cremer, P. S., GM1 Clustering Inhibits Cholera Toxin Binding in Supported Phospholipid Membranes. J. Am. Chem. Soc. 2007, 129, 5954-5961.

37. Wink, T.; J. van Zuilen, S.; Bult, A.; P. van Bennekom, W., Self-assembled Monolayers for Biosensors. Analyst 1997, 122, 43R-50R.

38. Love, J. C.; Estroff, L. A.; Kriebel, J. K.; Nuzzo, R. G.; Whitesides, G. M., Self-Assembled Monolayers of Thiolates on Metals as a Form of Nanotechnology. Chem. Rev. 2005, 105, 1103-1170.

39. Onclin, S.; Ravoo, B. J.; Reinhoudt, D. N., Engineering Silicon Oxide Surfaces Using SelfAssembled Monolayers. Angew. Chem. Int. Ed. 2005, 44, 6282-6304.

40. Ulman, A., Formation and Structure of Self-Assembled Monolayers. Chem. Rev. 1996, 96, 1533-1554.

41. Satav, T.; Huskens, J.; Jonkheijm, P., Effects of Variations in Ligand Density on Cell Signaling. Small 2015, 11, 5184-99.

42. Love, K. R.; Seeberger, P. H., Carbohydrate Arrays as Tools for Glycomics. Angew. Chem. Int. Ed. 2002, 41, 3583-3586.

43. Zhi, Z.-L.; Laurent, N.; Powell, A. K.; Karamanska, R.; Fais, M.; Voglmeir, J.; Wright, A.; Blackburn, J. M.; Crocker, P. R.; Russell, D. A.; Flitsch, S.; Field, R. A.; Turnbull, J. E., A Versatile Gold Surface Approach for Fabrication and Interrogation of Glycoarrays. ChemBioChem 2008, 9, 1568-1575.

44. Frasconi, M.; Mazzei, F.; Ferri, T., Protein immobilization at gold-thiol surfaces and potential for biosensing. Anal. and Bioanal. Chem. 2010, 398, 1545-1564.

45. Hushegyi, A.; Bertok, T.; Damborsky, P.; Katrlik, J.; Tkac, J., An ultrasensitive impedimetric glycan biosensor with controlled glycan density for detection of lectins and influenza hemagglutinins. Chem. Commun. 2015, 51, 7474-7477.

46. Wetterö, J.; Hellerstedt, T.; Nygren, P.; Broo, K.; Aili, D.; Liedberg, B.; Magnusson, K.-E., Immobilized Chemoattractant Peptides Mediate Adhesion and Distinct Calcium-Dependent Cell Signaling in Human Neutrophils. Langmuir 2008, 24, 6803-6811.

47. Houseman, B. T.; Gawalt, E. S.; Mrksich, M., Maleimide-Functionalized Self-Assembled Monolayers for the Preparation of Peptide and Carbohydrate Biochips. Langmuir 2003, 19, 1522-1531.

48. Chan, E. W. L.; Park, S.; Yousaf, M. N., An Electroactive Catalytic Dynamic Substrate that Immobilizes and Releases Patterned Ligands, Proteins, and Cells. Angew. Chem. Int. Ed. 2008, 47, 6267-6271. 
49. Yousaf, M. N.; Houseman, B. T.; Mrksich, M., Turning On Cell Migration with Electroactive Substrates. Angew. Chem. Int. Ed. 2001, 40, 1093-1096.

50. Yousaf, M. N.; Houseman, B. T.; Mrksich, M., Using electroactive substrates to pattern the attachment of two different cell populations. P. Natl. Acad. Sci. 2001, 98, 5992-5996.

51. Hoover, D. K.; Lee, E.-j.; Chan, E. W. L.; Yousaf, M. N., Electroactive Nanoarrays for Biospecific Ligand Mediated Studies of Cell Adhesion. ChemBioChem 2007, 8, 1920-1923.

52. Dubacheva, G. V.; Curk, T.; Auzély-Velty, R.; Frenkel, D.; Richter, R. P., Designing multivalent probes for tunable superselective targeting. P. Natl. Acad. Sci. U.S.A. 2015, 112, 5579-5584.

53. Houseman, B. T.; Mrksich, M., The microenvironment of immobilized Arg-Gly-Asp peptides is an important determinant of cell adhesion. Biomaterials 2001, 22, 943-955.

54. Haensch, C.; Hoeppener, S.; Schubert, U. S., Chemical modification of self-assembled silane based monolayers by surface reactions. Chem. Soc. Rev. 2010, 39, 2323-2334.

55. Tong, Y.; Tyrode, E.; Osawa, M.; Yoshida, N.; Watanabe, T.; Nakajima, A.; Ye, S., Preferential Adsorption of Amino-Terminated Silane in a Binary Mixed Self-Assembled Monolayer. Langmuir 2011, 27, 5420-5426.

56. Lee, I.; Wool, R. P., Controlling Amine Receptor Group Density on Aluminum Oxide Surfaces by Mixed Silane Self Assembly. Thin Solid Films 2000, 379, 94-100.

57. Wayment, J. R.; Harris, J. M., Controlling Binding Site Densities on Glass Surfaces. Anal. Chem. 2006, 78, 7841-7849.

58. Jung, H.; Robison, A. D.; Cremer, P. S., Multivalent ligand-receptor binding on supported lipid bilayers. J. Struct. Biol. 2009, 168, 90-94.

59. Richter, R. P.; Bérat, R.; Brisson, A. R., Formation of Solid-Supported Lipid Bilayers: An Integrated View. Langmuir 2006, 22, 3497-3505.

60. Loose, M.; Schwille, P., Biomimetic membrane systems to study cellular organization. $J$. Struct. Biol. 2009, 168, 143-151.

61. van Weerd, J.; Karperien, M.; Jonkheijm, P., Supported Lipid Bilayers for the Generation of Dynamic Cell-Material Interfaces. Adv. Healthc. Mater. 2015, 4, 2743-2779.

62. Cremer, P. S.; Boxer, S. G., Formation and Spreading of Lipid Bilayers on Planar Glass Supports. The J. Phys. Chem. B 1999, 103, 2554-2559.

63. Seu, K. J.; Cambrea, L. R.; Everly, R. M.; Hovis, J. S., Influence of Lipid Chemistry on Membrane Fluidity: Tail and Headgroup Interactions. Biophys. J. 2006, 91, 3727-3735.

64. Glasmästar, K.; Larsson, C.; Höök, F.; Kasemo, B., Protein Adsorption on Supported Phospholipid Bilayers. J. Colloid. Interf. Sci. 2002, 246, 40-47.

65. Kaizuka, Y.; Douglass, A. D.; Varma, R.; Dustin, M. L.; Vale, R. D., Mechanisms for segregating $\mathrm{T}$ cell receptor and adhesion molecules during immunological synapse formation in Jurkat T cells. P. Natl. Acad. Sci. 2007, 104, 20296-20301.

66. González, M.; Bagatolli, L. A.; Echabe, I.; Arrondo, J. L.; Argaraña, C. E.; Cantor, C. R.; Fidelio, G. D., Interaction of biotin with streptavidin. Thermostability and conformational changes upon binding. J. Biol. Chem. 1997, 272, 11288-11294.

67. Koçer, G.; Jonkheijm, P., Guiding hMSC Adhesion and Differentiation on Supported Lipid Bilayers. Adv. Healthc. Mater. 2017, 6, 1600862.

68. Nye, J. A.; Groves, J. T., Kinetic Control of Histidine-Tagged Protein Surface Density on Supported Lipid Bilayers. Langmuir 2008, 24, 4145-4149.

69. Lata, S.; Gavutis, M.; Piehler, J., Monitoring the Dynamics of Ligand-Receptor Complexes on Model Membranes. J. Am. Chem. Soc. 2006, 128, 6-7.

70. Thid, D.; Bally, M.; Holm, K.; Chessari, S.; Tosatti, S.; Textor, M.; Gold, J., Issues of Ligand Accessibility and Mobility in Initial Cell Attachment. Langmuir 2007, 23, 11693-11704. 
71. Shen, L.; Wang, Y.; Lin, C.-I.; Liu, H.-w.; Guo, A.; Zhu, X. Y., Membrane Environment Can Enhance the Interaction of Glycan Binding Protein to Cell Surface Glycan Receptors. ACS Chem. Biol. 2014, 9, 1877-1884.

72. Zhu, X. Y.; Holtz, B.; Wang, Y.; Wang, L.-X.; Orndorff, P. E.; Guo, A., Quantitative Glycomics from Fluidic Glycan Microarrays. J. Am. Chem. Soc. 2009, 131, 13646-13650.

73. Stottrup, B. L.; Veatch, S. L.; Keller, S. L., Nonequilibrium Behavior in Supported Lipid Membranes Containing Cholesterol. Biophys. J. 2004, 86, 2942-2950.

74. Gray, J. C.; Webster, C. I.; Williams, D. H.; Packman, L. C.; Cooper, M. A., Kinetic analysis of high-mobility-group proteins HMG-1 and HMG-I/Y binding to cholesterol-tagged DNA on a supported lipid monolayer. Nucleic Acids Res. 2000, 28, 1618-1624.

75. Castellana, E. T.; Cremer, P. S., Solid supported lipid bilayers: From biophysical studies to sensor design. Surf. Sci. Rep. 2006, 61, 429-444.

76. Babayco, C. B.; Turgut, S.; Smith, A. M.; Sanii, B.; Land, D.; Parikh, A. N., A comparison of lateral diffusion in supported lipid monolayers and bilayers. Soft Matter 2010, 6, 58775881.

77. Mann, D. A.; Kanai, M.; Maly, D. J.; Kiessling, L. L., Probing Low Affinity and Multivalent Interactions with Surface Plasmon Resonance: Ligands for Concanavalin A. J. Am. Chem. Soc. 1998, 120, 10575-10582.

78. Xiong, X.; Coombs, P. J.; Martin, S. R.; Liu, J.; Xiao, H.; McCauley, J. W.; Locher, K.; Walker, P. A.; Collins, P. J.; Kawaoka, Y.; Skehel, J. J.; Gamblin, S. J., Receptor binding by a ferret-transmissible H5 avian influenza virus. Nature 2013, 497, 392-396.

79. Xiong, X.; Martin, S. R.; Haire, L. F.; Wharton, S. A.; Daniels, R. S.; Bennett, M. S.; McCauley, J. W.; Collins, P. J.; Walker, P. A.; Skehel, J. J.; Gamblin, S. J., Receptor binding by an H7N9 influenza virus from humans. Nature 2013, 499, 496-499.

80. Kenausis, G. L.; Vörös, J.; Elbert, D. L.; Huang, N.; Hofer, R.; Ruiz-Taylor, L.; Textor, M.; Hubbell, J. A.; Spencer, N. D., Poly(1-lysine)-g-Poly(ethylene glycol) Layers on Metal Oxide Surfaces: Attachment Mechanism and Effects of Polymer Architecture on Resistance to Protein Adsorption. J. Phys. Chem. B 2000, 104, 3298-3309.

81. Huang, N.-P.; Michel, R.; Voros, J.; Textor, M.; Hofer, R.; Rossi, A.; Elbert, D. L.; Hubbell, J. A.; Spencer, N. D., Poly(1-lysine)-g-poly(ethylene glycol) Layers on Metal Oxide Surfaces: Surface-Analytical Characterization and Resistance to Serum and Fibrinogen Adsorption. Langmuir 2001, 17, 489-498.

82. VandeVondele, S.; Vörös, J.; Hubbell, J. A., RGD-grafted poly-1-lysine-graft-(polyethylene glycol) copolymers block non-specific protein adsorption while promoting cell adhesion. Biotechnol. Bioeng. 2003, 82, 784-790.

83. Huang, N.-P.; Vörös, J.; De Paul, S. M.; Textor, M.; Spencer, N. D., Biotin-Derivatized Poly(l-lysine)-g-poly(ethylene glycol): A Novel Polymeric Interface for Bioaffinity Sensing. Langmuir 2002, 18, 220-230.

84. Zhen, G.; Falconnet, D.; Kuennemann, E.; Vörös, J.; Spencer, N. D.; Textor, M.; Zürcher, S., Nitrilotriacetic Acid Functionalized Graft Copolymers: A Polymeric Interface for Selective and Reversible Binding of Histidine-Tagged Proteins. Adv. Funct. Mater. 2006, 16, 243-251.

85. Barth, K. A.; Coullerez, G.; Nilsson, L. M.; Castelli, R.; Seeberger, P. H.; Vogel, V.; Textor, M., An Engineered Mannoside Presenting Platform: Escherichia coli Adhesion under Static and Dynamic Conditions. Adv. Funct. Mater. 2008, 18, 1459-1469.

86. Duan, X.; Mu, L.; Sawtelle, S. D.; Rajan, N. K.; Han, Z.; Wang, Y.; Qu, H.; Reed, M. A., Functionalized Polyelectrolytes Assembling on Nano-BioFETs for Biosensing Applications. Adv. Funct. Mater. 2015, 25, 2279-2286. 
87. Movilli, J.; Rozzi, A.; Ricciardi, R.; Corradini, R.; Huskens, J., Control of Probe Density at DNA Biosensor Surfaces Using Poly(l-lysine) with Appended Reactive Groups. Bioconjugate Chem. 2018, 29, 4110-4118.

88. Lin, T.-H.; Lin, C.-H.; Liu, Y.-J.; Huang, C. Y.; Lin, Y.-C.; Wang, S.-K., Controlling Ligand Spacing on Surface: Polyproline-Based Fluorous Microarray as a Tool in Spatial Specificity Analysis and Inhibitor Development for Carbohydrate-Protein Interactions. ACS Appl. Mater. Inter. 2017, 9, 41691-41699.

89. Senaratne, W.; Andruzzi, L.; Ober, C. K., Self-Assembled Monolayers and Polymer Brushes in Biotechnology: Current Applications and Future Perspectives. Biomacromolecules 2005, 6, 2427-2448.

90. Tugulu, S.; Silacci, P.; Stergiopulos, N.; Klok, H.-A., RGD—Functionalized polymer brushes as substrates for the integrin specific adhesion of human umbilical vein endothelial cells. Biomaterials 2007, 28, 2536-2546.

91. Zhao, B.; Brittain, W. J., Polymer brushes: surface-immobilized macromolecules. Prog. Polym. Sci. 2000, 25, 677-710.

92. Minko, S., Responsive Polymer Brushes. J. Macromol. Sci. C 2006, 46, 397-420.

93. Jiang, H.; Xu, F.-J., Biomolecule-functionalized polymer brushes. Chem. Soc. Rev. 2013, 42, 3394-3426.

94. Edmondson, S.; Osborne, V. L.; Huck, W. T. S., Polymer brushes via surface-initiated polymerizations. Chem. Soc. Rev. 2004, 33, 14-22.

95. Yu, L.; Cheng, C.; Ran, Q.; Schlaich, C.; Noeske, P.-L. M.; Li, W.; Wei, Q.; Haag, R., Bioinspired Universal Monolayer Coatings by Combining Concepts from Blood Protein Adsorption and Mussel Adhesion. ACS Appl. Mater. Inter. 2017, 9, 6624-6633.

96. Shi, X.; Zhan, W.; Chen, G.; Yu, Q.; Liu, Q.; Du, H.; Cao, L.; Liu, X.; Yuan, L.; Chen, H., Regulation of Protein Binding Capability of Surfaces via Host-Guest Interactions: Effects of Localized and Average Ligand Density. Langmuir 2015, 31, 6172-6178.

97. Tibbitt, M. W.; Anseth, K. S., Hydrogels as extracellular matrix mimics for 3D cell culture. Biotechnol. Bioeng. 2009, 103, 655-663.

98. Branderhorst, H. M.; Ruijtenbeek, R.; Liskamp, R. M. J.; Pieters, R. J., Multivalent Carbohydrate Recognition on a Glycodendrimer-Functionalized Flow-Through Chip. ChemBioChem 2008, 9, 1836-1844.

99. Parera Pera, N.; Branderhorst, H. M.; Kooij, R.; Maierhofer, C.; van der Kaaden, M.; Liskamp, R. M. J.; Wittmann, V.; Ruijtenbeek, R.; Pieters, R. J., Rapid Screening of Lectins for Multivalency Effects with a Glycodendrimer Microarray. ChemBioChem 2010, 11, 18961904.

100. Narla, S. N.; Sun, X.-L., Glyco-macroligand microarray with controlled orientation and glycan density. Lab on a Chip 2012, 12, 1656-1663.

101. Musah, S.; Morin, S. A.; Wrighton, P. J.; Zwick, D. B.; Jin, S.; Kiessling, L. L., Glycosaminoglycan-Binding Hydrogels Enable Mechanical Control of Human Pluripotent Stem Cell Self-Renewal. ACS Nano 2012, 6, 10168-10177.

102. Nguyen, E. H.; Zanotelli, M. R.; Schwartz, M. P.; Murphy, W. L., Differential effects of cell adhesion, modulus and VEGFR-2 inhibition on capillary network formation in synthetic hydrogel arrays. Biomaterials 2014, 35, 2149-2161.

103. Perl, A.; Gomez-Casado, A.; Thompson, D.; Dam, H. H.; Jonkheijm, P.; Reinhoudt, D. N.; Huskens, J., Gradient-driven motion of multivalent ligand molecules along a surface functionalized with multiple receptors. Nat. Chem. 2011, 3, 317-322. 
104. Gomez-Casado, A.; Dam, H. H.; Yilmaz, M. D.; Florea, D.; Jonkheijm, P.; Huskens, J., Probing Multivalent Interactions in a Synthetic Host-Guest Complex by Dynamic Force Spectroscopy. J. Am. Chem. Soc. 2011, 133, 10849-10857.

105. Valderrey, V.; Wiemann, M.; Jonkheijm, P.; Hecht, S.; Huskens, J., Multivalency in Heteroternary Complexes on Cucurbit[8]uril-functionalized Surfaces: Self-assembly, Patterning, and Exchange Processes. ChemPlusChem, 2019, 84, 1-8.

106. Nijhuis, C. A.; Huskens, J.; Reinhoudt, D. N., Binding Control and Stoichiometry of Ferrocenyl Dendrimers at a Molecular Printboard. J. Am. Chem. Soc. 2004, 126, 1226612267.

107. Nijhuis, C. A.; Yu, F.; Knoll, W.; Huskens, J.; Reinhoudt, D. N., Multivalent Dendrimers at Molecular Printboards: Influence of Dendrimer Structure on Binding Strength and Stoichiometry and Their Electrochemically Induced Desorption. Langmuir 2005, 21, 78667876.

108. Crespo-Biel, O.; Péter, M.; Bruinink, C. M.; Ravoo, B. J.; Reinhoudt, D. N.; Huskens, J., Multivalent Host-Guest Interactions between $\beta$-Cyclodextrin Self-Assembled Monolayers and Poly(isobutene-alt-maleic acid)s Modified with Hydrophobic Guest Moieties. Chem.Eur. J. 2005, 11, 2426-2432.

109. Dubacheva, G. V.; Curk, T.; Frenkel, D.; Richter, R. P., Multivalent Recognition at Fluid Surfaces: The Interplay of Receptor Clustering and Superselectivity. J. Am. Chem. Soc. 2019, $141,2577-2588$.

110. Weatherman, R. V.; Kiessling, L. L., Fluorescence Anisotropy Assays Reveal Affinities of C- and O-Glycosides for Concanavalin A1. J. Org. Chem. 1996, 61, 534-538.

111. Sato, Y.; Yoshioka, K.; Murakami, T.; Yoshimoto, S.; Niwa, O., Design of Biomolecular Interface for Detecting Carbohydrate and Lectin Weak Interactions. Langmuir 2012, 28, 1846-1851.

112. Yu, L.; Huang, M.; Wang, P. G.; Zeng, X., Cross-Linked Surface-Grafted Glycopolymer for Multivalent Recognition of Lectin. Anal. Chem. 2007, 79, 8979-8986.

113. Zhang, Y.; Luo, S.; Tang, Y.; Yu, L.; Hou, K.-Y.; Cheng, J.-P.; Zeng, X.; Wang, P. G., Carbohydrate-protein interactions by "clicked" carbohydrate self-assembled monolayers. Anal. Chem. 2006, 78, 2001-2008.

114. Yang, J.; Chazalviel, J.-N.; Siriwardena, A.; Boukherroub, R.; Ozanam, F.; Szunerits, S.; Gouget-Laemmel, A. C., Quantitative Assessment of the Multivalent Protein-Carbohydrate Interactions on Silicon. Anal. Chem. 2014, 86, 10340-10349.

115. Gutiérrez Sánchez, C.; Su, Q.; Schönherr, H.; Grininger, M.; Nöll, G., Multi-Ligand-Binding Flavoprotein Dodecin as a Key Element for Reversible Surface Modification in Nanobiotechnology. ACS Nano 2015, 9, 3491-3500.

116. Jung, H.; Robison, A. D.; Cremer, P. S., Detecting Protein-Ligand Binding on Supported Bilayers by Local pH Modulation. J. Am. Chem. Soc. 2009, 131, 1006-1014.

117. Yang, T.; Baryshnikova, O. K.; Mao, H.; Holden, M. A.; Cremer, P. S., Investigations of Bivalent Antibody Binding on Fluid-Supported Phospholipid Membranes: The Effect of Hapten Density. J. Am. Chem. Soc. 2003, 125, 4779-4784.

118. Joubert, J. R.; Smith, K. A.; Johnson, E.; Keogh, J. P.; Wysocki, V. H.; Gale, B. K.; Conboy, J. C.; Saavedra, S. S., Stable, Ligand-Doped, Poly(bis-SorbPC) Lipid Bilayer Arrays for Protein Binding and Detection. ACS Appl. Mater. Inter. 2009, 1, 1310-1315.

119. André, T.; Reichel, A.; Wiesmüller, K.-H.; Tampé, R.; Piehler, J.; Brock, R., Selectivity of Competitive Multivalent Interactions at Interfaces. ChemBioChem 2009, 10, 1878-1887.

120. Bai, C.; Lu, Z.; Jiang, H.; Yang, Z.; Liu, X.; Ding, H.; Li, H.; Dong, J.; Huang, A.; Fang, T.; Jiang, Y.; Zhu, L.; Lou, X.; Li, S.; Shao, N., Aptamer selection and application in multivalent 
binding-based electrical impedance detection of inactivated $\mathrm{H} 1 \mathrm{~N} 1$ virus. Biosens. Bioelectron. 2018, 110, 162-167.

121. Huang, M. L.; Cohen, M.; Fisher, C. J.; Schooley, R. T.; Gagneux, P.; Godula, K., Determination of receptor specificities for whole influenza viruses using multivalent glycan arrays. Chem. Commun. 2015, 51, 5326-5329.

122. Yeung, S. Y.; Mucha, A.; Deshmukh, R.; Boutrus, M.; Arnebrant, T.; Sellergren, B., Reversible Self-Assembled Monolayers (rSAMs): Adaptable Surfaces for Enhanced Multivalent Interactions and Ultrasensitive Virus Detection. ACS Central Science 2017, 3, 1198-1207.

123. Weineisen, N. L.; Hommersom, C. A.; Voskuhl, J.; Sankaran, S.; Depauw, A. M. A.; Katsonis, N.; Jonkheijm, P.; Cornelissen, J. J. L. M., Photoresponsive, reversible immobilization of virus particles on supramolecular platforms. Chem. Commun. 2017, 53, 1896-1899.

124. Sankaran, S.; van Weerd, J.; Voskuhl, J.; Karperien, M.; Jonkheijm, P., Photoresponsive Cucurbit[8]uril-Mediated Adhesion of Bacteria on Supported Lipid Bilayers. Small 2015, 11, 6187-6196.

125. Block, S.; Zhdanov, V. P.; Höök, F., Quantification of Multivalent Interactions by Tracking Single Biological Nanoparticle Mobility on a Lipid Membrane. Nano Lett. 2016, 16, 43824390.

126. Svedhem, S.; Dahlborg, D.; Ekeroth, J.; Kelly, J.; Höök, F.; Gold, J., In Situ Peptide-Modified Supported Lipid Bilayers for Controlled Cell Attachment. Langmuir 2003, 19, 6730-6736.

127. Thid, D.; Holm, K.; Eriksson, P. S.; Ekeroth, J.; Kasemo, B.; Gold, J., Supported phospholipid bilayers as a platform for neural progenitor cell culture. J. Biomed. Mater. Res. A 2008, 84A, 940-953.

128. Koçer, G.; Jonkheijm, P., About Chemical Strategies to Fabricate Cell-Instructive Biointerfaces with Static and Dynamic Complexity. Adv. Healthc. Mater. 2018, 7, 1701192.

129. van Weerd, J.; Sankaran, S.; Roling, O.; Sukas, S.; Krabbenborg, S.; Huskens, J.; le Gac, S.; Ravoo, B. J.; Karperien, M.; Jonkheijm, P., A Microfluidic Device with Continuous Ligand Gradients in Supported Lipid Bilayers to Probe Effects of Ligand Surface Density and Solution Shear Stress on Pathogen Adhesion. Adv. Mater. Interfaces 2016, 3, 1600055.

130. Bouckaert, J.; Mackenzie, J.; De Paz, J. L.; Chipwaza, B.; Choudhury, D.; Zavialov, A.; Mannerstedt, K.; Anderson, J.; Piérard, D.; Wyns, L.; Seeberger, P. H.; Oscarson, S.; De Greve, H.; Knight, S. D., The affinity of the FimH fimbrial adhesin is receptor-driven and quasi-independent of Escherichia coli pathotypes. Mol. Microbiol. 2006, 61, 1556-1568. 


\section{Chapter 3}

\section{Clickable Poly-L-Lysine for the Formation of Biorecognition Surfaces}

The use of click chemistry reactions for the conjugation of molecules onto surfaces has rapidly increased over the past years owing to their mild reaction conditions and their bioorthogonality. In this chapter, a novel substrate functionalization method for the immobilization of biomolecules onto surfaces, employing copper-free click chemistry reactions, is reported. Poly-L-lysine (PLL) polymers modified with click chemistry moieties were employed for the modification of gold and silicon dioxide surfaces. The fast adsorption of PLL on activated surfaces together with the versatile reaction conditions offered by catalyst-free click chemistry provides an excellent way to functionalize surfaces in a fast and selective way. As a proof of concept, surfaces were modified with DNA probes which showed the capability of recognizing complementary DNA sequences from aqueous solutions. Quartz crystal microbalance with dissipation monitoring (QCM-D) showed the successful formation of PLL monolayers and the subsequent attachment of DNA probes and DNA recognition. Quantification of the probe density displayed at the interface was achieved both by measuring the mass adsorption of DNA with QCM-D and by electrochemical methods. 


\subsection{Introduction}

The immobilization of biomolecules onto surfaces is of fundamental importance in several fields such as analytical chemistry, medical diagnostics, tissue engineering and biomolecular chemistry. ${ }^{1-3}$ Therefore, surface modification routes for the controlled immobilization of biomolecules on substrates have attracted enormous interest over the last decade. ${ }^{4}$ In particular, monolayers have been prepared on surfaces by several methods in order to guarantee the bio-activity of the biomolecules such as enzymes, antibodies or nucleic acids, and to exert control over their functionalization at the molecular scale. ${ }^{5-7}$

Important routes for the ligation of molecules are the click chemistry reactions. Other surface modification methods may have undesired effects, such as incomplete conversion, low specificity, and side reactions, and these have been overcome successfully by employing click reactions. Click reactions have been studied first in solution, and have subsequently been extended to a wide range of surfaces. ${ }^{8}$ The conventional copper-catalyzed azide-alkyne cycloaddition (CuAAC) has been extensively used for the controlled modification of surfaces and for the formation of patterns on surfaces in a rapid and controlled way for biological applications. ${ }^{9-11}$ However, the use of $\mathrm{Cu}$ ions, or other metals, as a catalyst poses a serious disadvantage for several applications. In biological applications, for example, $\mathrm{Cu}$ ions are known to be cytotoxic ${ }^{12}$ and can disturb the conformation of the biomolecule, such as DNA. ${ }^{13}$ In electronic applications, instead, metal ions on the surface can affect the conductivity of the substrate. ${ }^{14,15}$ For this reason, catalyst-free bio-orthogonal click reactions have been developed, which provide a remarkable contribution to the field of bioconjugation. ${ }^{16,17}$ The strain-promoted alkyne-azide cycloaddition (SPAAC) reaction between ring-strained cyclooalkynes and azides, pioneered by Bertozzi and co-workers, shows fast and selective bioconjugation in solution. ${ }^{18,19}$ Even though the SPAAC reaction presents lower reaction rates than the $\mathrm{CuAAC}$ reaction, the coupling between cyclooctynes and azides in solution is achieved at ambient temperature without the use of a metallic catalyst. As the rates and conversion of SPAAC reactions strongly depend on the exact chemical structure of the cyclooctyne, a large number of cyclooctyne derivatives have been developed in order to improve the reactivity for azides. ${ }^{19-23}$ Due to the advantages delivered by this type of chemistry, SPAAC reactions have been used for the modification of surfaces. ${ }^{2,4,16,17,23,24}$

More recently, the inverse electron-demand Diels-Alder (iEDDA) reaction of tetrazine with strained alkenes reported by Fox et al. introduced a broader range of compounds with even faster kinetics into the area of click chemistry. ${ }^{25}$ Tetrazine can react with trans-cyclooctyne (TCO) or norbornene groups at room temperature, atmospheric pressure and micromolar concentrations with faster kinetics and allowing up to $100 \%$ conversion, while avoiding byproducts. Since their introduction, this type of reaction has therefore gained increased 
attention and has emerged as a promising strategy for the conjugation of biomolecules. ${ }^{26}$ Reactions of tetrazine with trans-cyclooctene (TCO) were used for the modification of electrodes, ${ }^{27}$ for the formation of small molecules micro-arrays, ${ }^{28}$ and for the immobilization of proteins ${ }^{29}$ or carbohydrates ${ }^{30}$ in micropatterns within a few min.

Most of the surface modification methods reported before employ covalent immobilization of one of the two click chemistry moieties onto the surface prior to the conjugation. As an alternative method to the covalent modification of substrates, the physisorption of modified polyelectrolytes on surfaces for the immobilization of biomolecules has shown several advantages. ${ }^{31}$ In particular, poly-L-lysine (PLL) has been reported to present excellent biochemical properties such as biocompatibility and hydrophilicity. At physiological $\mathrm{pH}$, the amino groups of the lateral chains of the lysine are positively charged, allowing a fast adsorption of the PLL on a broad variety of negatively charged substrates through multiple electrostatic interactions. ${ }^{32,33}$ The modification of the polymer with additional functional groups and non-ionic, anti-fouling side-chains, such as oligo(ethylene glycol) (OEG), enables the engineering of surfaces with selective receptors as well as antifouling properties. A variety of different functional groups have been explored. For example, PLL has been functionalized with biotin to be conjugated with streptavidin. ${ }^{34}$ Alternatively, the RGD peptide motif has been used to promote cell binding, ${ }^{35}$ and modification with maleimide has been used to bind PNA with control over the density at the surface. ${ }^{36}$ However, the modification of PLL with 'clickable' units to achieve bioconjugation at surfaces, has so far not been reported.

Here we report a surface functionalization method for a fast and selective immobilization of molecules onto substrates by using PLL polymers modified with click chemistry moieties. The employment of these polymers provides the combined advantages of using polyelectrolytes and click chemistry reactions for the modification of surfaces. In order to functionalize surfaces in a fast and controlled way, PLL was first modified with either methyl-tetrazine $(\mathrm{Tz})$ or dibenzocyclooctyl (DBCO) functional groups and adsorbed onto surfaces for the subsequent immobilization of, respectively, TCO- or azido-modified biomolecules via fast and catalyst-free bioorthogonal click reactions. In order to test the proper reactivity and selectivity of the functionalized surfaces, DNA probes were anchored onto the surface. A subsequent hybridization with complementary DNA (cDNA) to the immobilized probe on the surface was investigated in order to prove the accessibility of DNA probes onto the surface. Variation of the degree of functionalization of PLL was investigated for the quantification of the DNA probe density at the interface. The deposition of the polymer on the surface, as well as the functionalization with DNA probes and the recognition of cDNA sequences was analyzed with quartz crystal microbalance with dissipation monitoring (QCM-D) and electrochemical methods. 


\subsection{Results and discussion}

Figure 3.1 shows a schematic representation of the stepwise approach used in this work to selectively functionalize surfaces with DNA. Hereto, PLL was grafted with OEG units and either Tz or DBCO moieties. The grafting of OEG to the polymer improves the antifouling properties of PLL, thus preventing non-specific adsorption of molecules onto the PLLfunctionalized surface. Short OEG chains are here preferred over longer ones for a better control over the PLL grafting. ${ }^{37}$ Specifically, three different types of polymers have been synthesized: one displaying only OEG as functionalization (PLL-OEG), one presenting both OEG and DBCO (PLL-OEG-DBCO) and one with OEG and Tz (PLL-OEG-Tz). The different PLLs were afterwards absorbed in one step onto activated substrates, thus displaying the respective functional groups at the interface. Consequently, TCO or DBCOmodified DNA (15 nts) was added on the surface for the catalyst-free coupling with $\mathrm{Tz}$ and DBCO, respectively. Afterwards, the correct formation of a DNA probe layer onto the surface and the possibility of forming DNA duplexes was tested by the addition of fully complementary DNA (cDNA) sequences (36 nts, see Experimental Section). Noncomplementary (ncDNA) sequences were used as well to perform control measurements. The modification of substrates with modified PLL, as well as the further immobilization of DNA probes and their interaction with the corresponding cDNA sequences, were monitored in situ and in real time by QCM-D. 

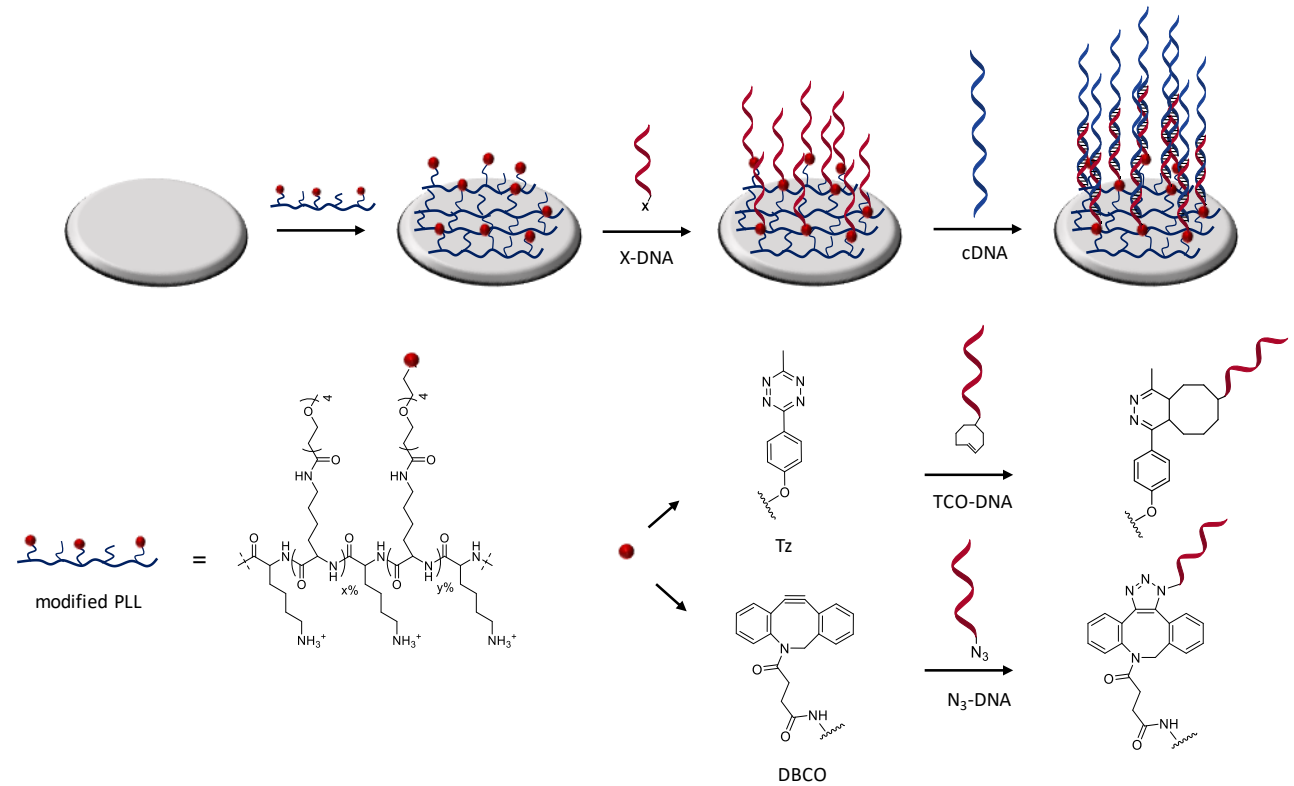

Figure 3.1. Schematic representation of the functionalization of activated surfaces with clickable PLL to bind complementarily functionalized DNA probes. After activation, silicon dioxide and gold surfaces are functionalized with either Tz or DBCO-functionalized PLL. Hereafter, TCO or azide-DNA sequences are selectively anchored on the PLL-modified surface by click chemistry reactions. The proper presentation of DNA probes on the surface is monitored by the hybridization with cDNA sequences.

Modified PLLs were synthesized by adapting a previously reported procedure. ${ }^{38}$ PLL (MW $15-30 \mathrm{kDa}$ ) was functionalized in a one-step reaction, by mixing different molar ratios of NHS-(OEG) $)_{4}$-methyl (without a functional group) and either NHS-(OEG) ${ }_{4}$-Tz or NHS(OEG) $)_{4}$-DBCO (see Scheme 3.1, Experimental Section). By varying the molar ratios of the components in the mixture it is possible to tune the degrees of functionalization of the PLL. Therefore the abbreviation PLL-OEG $(x)-\mathrm{X}(y)$ is used for a PLLs modified with $x \%$ of OEG and $y \%$ of functional group X grafted to the PLL.

High degrees of functionalization of the PLL can prevent the adsorption of the polymer on the surface, while a low degree of functionalization adversely affects its antifouling properties. ${ }^{38}$ Consequently, a total functionalization of approximately $30-40 \%$ of the lysine groups was used throughout this work. After the synthesis and purification by dialysis, ${ }^{1} \mathrm{H}-$ NMR was used to quantify the total degree of functionalization $(x+y)$ of the polymer, employing the relative integrals of the peaks at $3.0 \mathrm{ppm}$ (free lysine) and at $3.1 \mathrm{ppm}$ (functionalized lysine). Characteristic peaks of the functional groups were employed to 
derive the degree $(y)$ of functional group attachment. Table 3.1 shows the PLLs synthesized and the degrees of functionalization calculated by NMR.

Table 3.1. Degrees of functionalization of modified PLLs calculated by NMR.

\begin{tabular}{|c|c|c|c|}
\hline Modified PLL & $\begin{array}{c}\text { Free lysine } \\
\% \%\end{array}$ & $\begin{array}{l}\text { Coupled } \\
\text { lysine \% }\end{array}$ & $\begin{array}{c}\text { Tz/DBCO } \\
\%\end{array}$ \\
\hline PLL-OEG & 72.0 & 28.0 & 0 \\
\hline PLL-OEG $31.7-\mathrm{Tz}_{0.5}$ & 67.8 & 32.2 & 0.5 \\
\hline $\mathrm{PLL} \mathrm{OEG}_{26.0-} \mathrm{Tz}_{4.9}$ & 69.1 & 30.9 & 4.9 \\
\hline PLL-OEG $_{27.3}-\mathrm{Tz}_{14.6}$ & 58.1 & 41.9 & 14.6 \\
\hline $\mathrm{PLL}^{-O E G_{24.5}-\mathrm{DBCO}_{6.7}}$ & 68.8 & 31.2 & 6.7 \\
\hline
\end{tabular}

After the synthesis, the adsorption of PLL polymers was tested on both silicon dioxide and gold substrates. Figure 3.2 shows a typical QCM measurement where both $\mathrm{SiO}_{2}$ and gold surfaces were modified with PLL-OEG-Tz to test the immobilization of TCO-DNA and the subsequent recognition of cDNA. After the activation of the substrates by UV/ozone, the surfaces were flushed with a solution of PLL-OEG-Tz $(0.1 \mathrm{mg} / \mathrm{mL}$, in PBS at $\mathrm{pH} 7.4)$. Right after injection of the PLL solution, a clear and rapid frequency change $(\Delta f)$ was observed, confirming a fast self-assembly of the modified polymer onto the surface. An only moderate desorption of the PLL after rinsing with buffer indicated the stability of the remaining polymer, and the small dissipation signals confirmed the formation of a thin and rather rigid PLL film. No relevant differences between the two substrate materials were observed. 
(A)

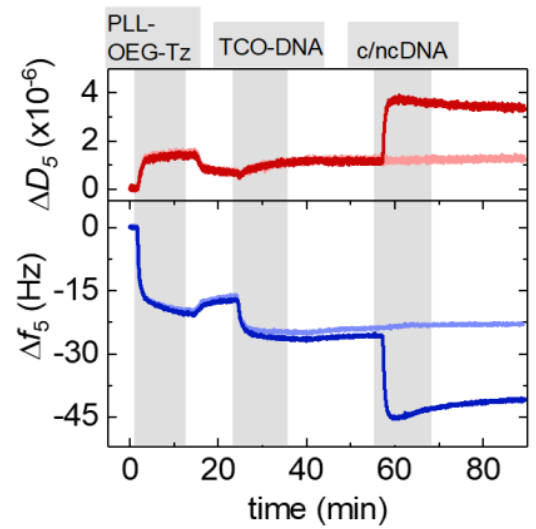

(B)

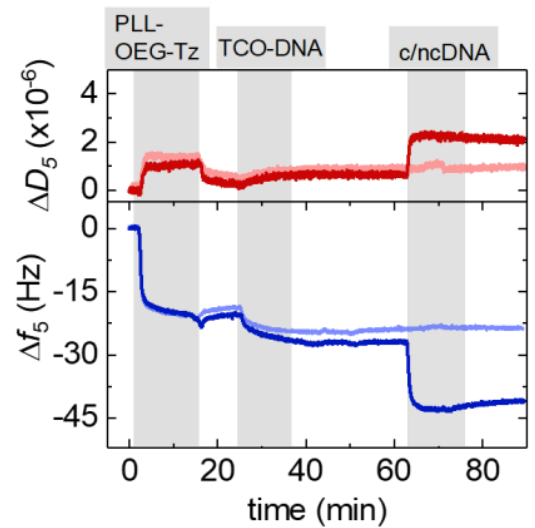

Figure 3.2. QCM-D sensograms of the assembly of PLL-OEG(26.0)-Tz(4.9) (0.1 mg/mL in PBS) on silicon dioxide (A) and gold (B) surfaces, followed by TCO-DNA ( $1 \mu \mathrm{M}$ in PBS) and cDNA ( $1 \mu \mathrm{M}$ in PBS). The frequency shift $\left(\Delta f_{5}\right)$ is represented by the blue lines and the dissipation signal $\left(D_{5}\right)$ by the red lines. The dark-colored lines represent traces using cDNA, while the light-colored ones indicate the use of ncDNA as a control. All adsorption steps are shown in grey vertical bars, while the washing steps with PBS are in white.

After surface functionalization with PLL-OEG-Tz, TCO-DNA $(1 \mu \mathrm{M})$ was flushed over the PLL-modified substrates. A clear frequency shift, observed upon TCO-DNA addition, demonstrated a fast attachment of DNA probes on the surface, thus confirming the successful Tz-TCO coupling within 10-15 min. The observed reaction time is in agreement with previously reported systems in which Tz-functionalized surfaces reacted with norbornenemodified molecules within 15 min. $^{8}$

Subsequently, the availability of DNA probes for the recognition of a specific complementary DNA (cDNA) was tested by flushing solutions of cDNA or ncDNA (36 nts, $1 \mu \mathrm{M}$ ). The clear frequency change, and concomitant dissipation change, upon binding of cDNA and the stability of the signal upon rinsing with buffer demonstrate the effective hybridization of the cDNA strands. The formation of DNA duplexes at the interface, stretching out from the surface, causes a change of the viscoelastic properties of the layers which is represented by an increase of the dissipation signal. ${ }^{39}$ In contrast, the absence of both frequency and dissipation changes upon addition of ncDNA confirmed that DNA binds exclusively in the presence of the complementary sequence. 
(A)

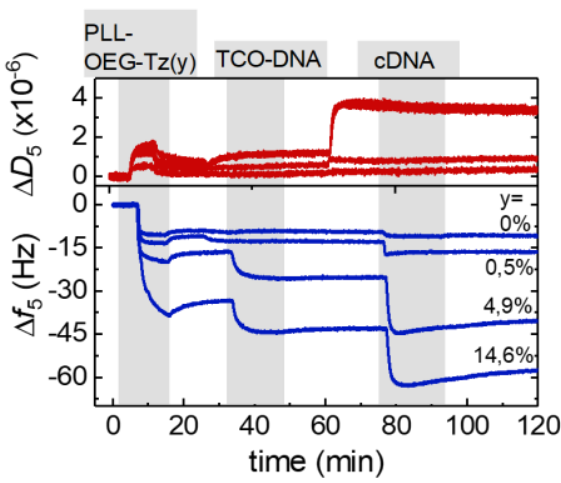

(C)

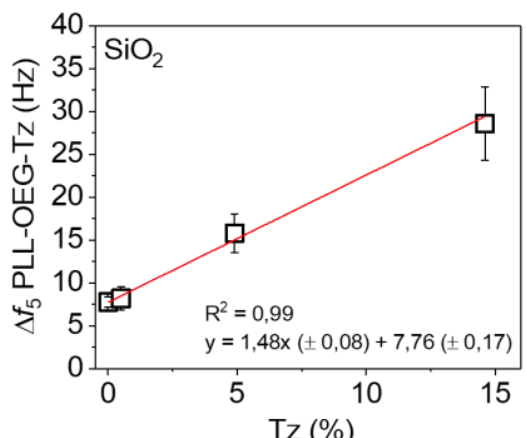

(E)

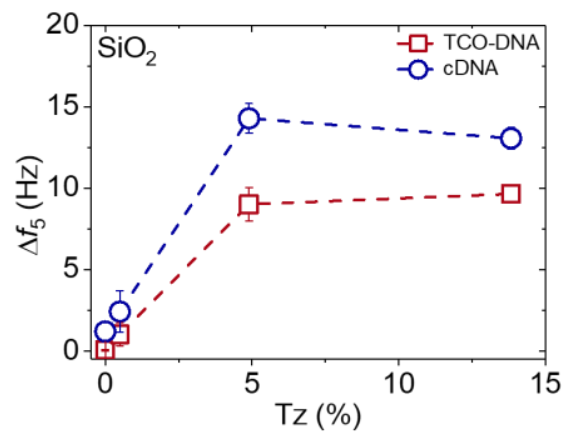

(B)

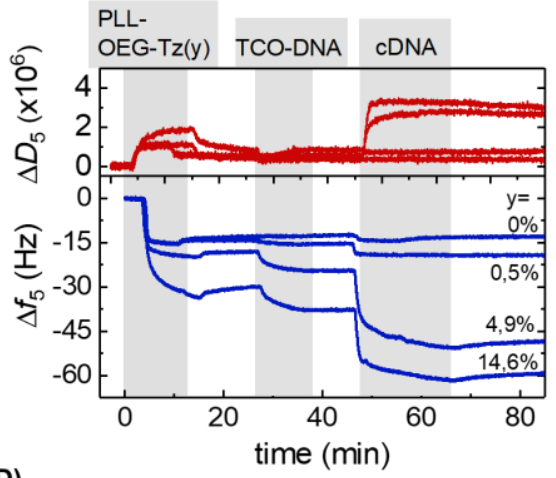

(D)

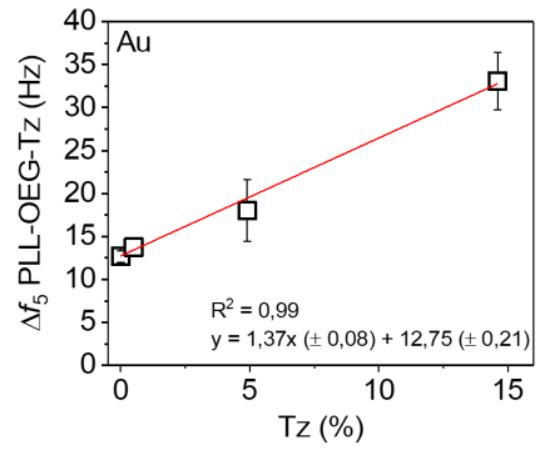

(F)

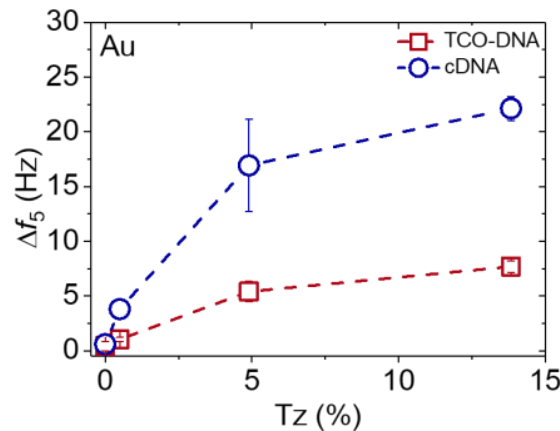

Figure 3.3. (A, B) QCM-D sensograms of the assembly of PLL-OEG-Tz functionalized with varying percentages of $\mathrm{Tz}(0,0.5,4.9$ and 14.6), followed by coupling with TCO-DNA and adsorption of cDNA, for both $\mathrm{SiO}_{2}$ (A) gold (B) substrates. The frequency shift $\left(\Delta f_{5}\right)$ is represented by the blue lines and the dissipation signal $\left(\Delta D_{5}\right)$ by the red lines. $(\mathrm{C}, \mathrm{D})$ Correlation between adsorption of PLL-OEG-Tz, expressed in $\Delta f 5$, as a function of varying percentages of $\mathrm{Tz}$ for $\mathrm{SiO}_{2}$ (C) and gold (D) substrates. The red lines represent linear fits to the data points. (E, F) Correlation between the $\Delta f_{5}$ obtained upon addition of TCO-DNA (red) and cDNA (blue) for increasing degrees of functionalization of PLL with $\mathrm{Tz}$, measured for both $\mathrm{SiO}_{2}(\mathrm{E})$ and gold (F) substrates. Dashed lines are guides to the eye. 
The effect of the Tz content in the PLL backbone on the adsorption of DNA was assessed by QCM. Different amounts of Tz anchored to the PLL are expected to lead to varying amounts of DNA probes and therefore different responses for the cDNA absorption. Hereto, PLLs containing different degrees of functionalization with Tz groups $(0 \%, 0.5 \%, 4.9 \%$ and $14.6 \%)$ were tested, and all adsorption steps were plotted as a function of the percentage of $\mathrm{Tz}$ in the PLL backbone, for both gold and $\mathrm{SiO}_{2}$ surfaces. Figure 3.3A/B shows the full QCM time traces obtained upon adsorption of PLL, TCO-DNA and cDNA for different PLLs on both types of surfaces.

For the PLL adsorption step, the observed frequency shifts appeared to be quite strongly, but linearly, dependent on the degree of Tz functionalization (Figure 3.3C/D). Plotting the same data as a function of the total degree of PLL functionalization (data not shown) did not reveal a clear trend. The observed trends for the degree of $\mathrm{Tz}$ (Figure 3.3C/D) cannot be explained solely by the increase in molecular weight upon functionalization with Tz. Possibly, differences in the adsorbed PLL surface density occur and/or in the degree of hydration of the adsorbed PLL. However, these aspects were not investigated further here.

In the case of PLL-OEG $(\mathrm{Tz}=0 \%)$, the absence of $\mathrm{Tz}$ groups on the surface prevented the binding of TCO-DNA, thus confirming the specificity of the Tz-TCO conjugation on the surface (Figure 3.3A/B). The low adsorption of cDNA $(\leq 2 \mathrm{~Hz})$ confirmed the antifouling properties of the designed PLL. For low Tz contents (i.e., 0.5 and 4.9), the data shows a clear correlation between the Tz density at the interface and TCO-DNA absorption (Figure 3.3E/F). At higher Tz contents, instead, no further increase of the amount of TCO-DNA on the surface was observed. These results indicate that a saturation of the surface with TCODNA probes is obtained at approx. 5\% of Tz in the PLL backbone (Figure 3.3E/F). This is attributed to electrostatic repulsion and steric hindrance between the DNA probes. Very similar trends were observed for the adsorption steps of cDNA, indicating that the hybridization efficiency was not affected by variations of the degree of Tz functionalization. Some differences in the adsorption steps were, however, observed for the two types of substrates. First of all, the TCO-DNA steps appeared to be larger on $\mathrm{SiO}_{2}$ surfaces compared to gold. Moreover, adsorption of cDNA appeared to be larger on the gold surface indicating a higher hybridization efficiency and/or a difference in the degree of hydration. At the same time, some dissipation changes were observed for the TCO-DNA adsorption steps, whereas smaller increments were observed on gold substrates compared to $\mathrm{SiO}_{2}$. These observations may suggest that differences in the substrate charge occur after activation which might influence the adsorption of TCO-DNA and cDNA in subsequent steps and/or the hydration of the layer. As a consequence, the apparent hybridization efficiency, defined as the ratio of the frequency shifts induced by cDNA and TCO-DNA, was higher for gold surfaces compared to silicon dioxide. By taking into account the different lengths of the TCO-DNA 
(15 nts) and cDNA (36 nts), hybridization efficiencies (uncorrected for possible differences and changes in hydration) of $130 \%$ and $65 \%$ were obtained for gold and silicon dioxide surfaces, respectively. Different DNA lengths as well as the formation of a DNA duplex can cause a change in the degree of hydration, which is detected by QCM. ${ }^{39,40}$

Control over the probe density is important for an optimal interaction of the immobilized probes with the target molecule. ${ }^{41}$ For example, when considering the design of sensors for DNA detection, steric hindrance between the probes and electrostatic repulsion between DNA strands can cause a loss of hybridization efficiency. When deriving probe densities from QCM measurements, the hydration of the molecules needs to be taken into account. Here, we assume that the $80 \%$ of the mass absorbed in the TCO-DNA step is due to water. ${ }^{39}$ This leads to a calculated DNA probe at the $\mathrm{SiO}_{2}$ substrates ranging from 0.43 to $4.8 \times 10^{12}$ molecules $/ \mathrm{cm}^{2}$, whereas for gold substrates a density between 0.44 to $3.3 \times 10^{12}$ molecules $/ \mathrm{cm}^{2}$ was obtained. The hybridization step leads to values ranging respectively between 0.47 and $2.8 \times 10^{12}$ molecules $/ \mathrm{cm}^{2}$, and between 0.73 and $4.3 \times 10^{12}$ molecules $/ \mathrm{cm}^{2}$ for silicon dioxide and gold surfaces, respectively. Notably, the density obtained from the measurements appear to be below the reported limit for electrostatic repulsion, where values of above $5 \times 10^{12}$ molecules $/ \mathrm{cm}^{2}$ are known to affect the hybridization efficiency. ${ }^{41}$

Recently, our group demonstrated that using PLL functionalized with maleimide, the density of PNA probes on the surface can be controlled in the preceding synthetic step of the customized PLL. ${ }^{36}$ Based on the empirical prediction of PNA probes on the surface by using PLL-OEG-maleimide, in which each percentage of grafted maleimide in the PLL corresponds to $1.24 \pm 0.02 \times 10^{12}$ probes per $\mathrm{cm}^{2}$, it was possible to predict the density of DNA also with the current system. By adopting the same relationship for PLL-OEG-Tz, we calculated probe densities ranging between 0.66 and $6.1 \times 10^{12}$ DNA probes $/ \mathrm{cm}^{2}$. These values are in good agreement with the quantification of DNA probes obtained from the QCM measurements described above. The difference observed between the predicted and the calculated values can be attributed to a different water content that cannot be precisely estimated by QCM. Another reason may be found in differences between the maleimide and tetrazine moieties which may induce a different adsorption behavior due to differences in size and hydrophobicity.

To underline the versatility of the PLL chemistry to provide a selective biorecognition layer, a different click chemistry was tested. For this purpose, PLL was functionalized with DBCO, which is known to react with azido groups with a slower kinetics compared to the Tz-TCO coupling. ${ }^{4}$ Based on the results obtained with PLL-OEG-Tz, the functionalization of the PLL with DBCO was tuned to around 6\%. After the synthesis and characterization of the polymer, the surface modification and the coupling with azide-modified DNA were monitored with QCM-D (Figure 3.4). Silicon dioxide surfaces were modified with PLL-OEG-DBCO, which 
gave clear frequency and dissipation changes. Thereafter, $\mathrm{N}_{3}$-DNA was flushed over the surface, and again a clear frequency shift was observed, confirming that the reaction between the two click chemistry moieties was successful.

(A)

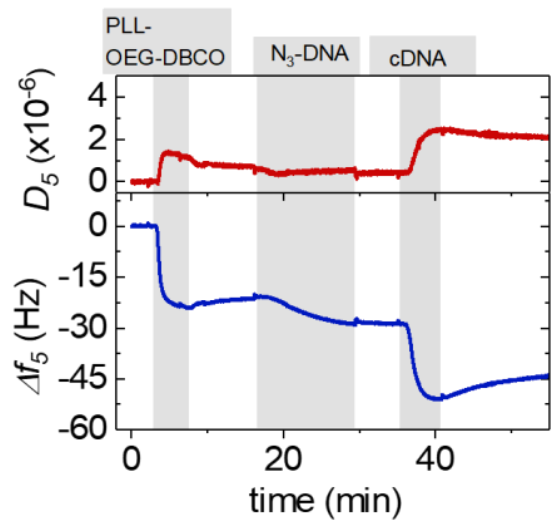

(B)

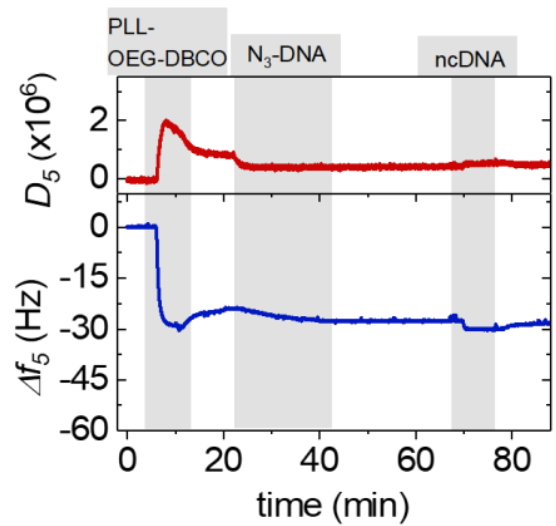

Figure 3.4. QCM-D sensograms of the assembly of PLL-OEG-DBCO(6.7) $(0.1 \mathrm{mg} / \mathrm{mL}$ in PBS) on silicon dioxide surfaces, followed by $\mathrm{N}_{3}$-DNA $(1 \mu \mathrm{M}$ in PBS) and either (A) cDNA ( $1 \mu \mathrm{M}$ in PBS) or (B) ncDNA ( $1 \mu \mathrm{M}$ in PBS). The frequency shift $\left(\Delta f_{5}\right)$ is represented by the blue line and the dissipation signal $\left(\Delta D_{5}\right)$ by the red line. All adsorption steps are shown in grey vertical bars, while the washing steps with PBS are shown in white.

As expected, the reaction rate of the coupling of DBCO with azido-DNA appeared to be somewhat slower than the rate observed for the reaction between Tz and TCO-DNA. The half-time of the reaction of DBCO with azido-DNA measured by QCM resulted to be approx. 5 min, while, under the same conditions the Tz-TCO coupling showed a half-time of approx. $1 \mathrm{~min}$. After the probe coupling, a solution of cDNA was added, and hybridization of the DNA occurred as visualized by a clear change of both frequency and dissipation. In case of a control using ncDNA, no frequency change was observed. For this system, based on the recorded frequency shift, we obtained a density of $3.5 \times 10^{12}$ molecules $/ \mathrm{cm}^{2}$ for the $\mathrm{N}_{3}$-DNA, and $3.0 \times 10^{12}$ molecules $/ \mathrm{cm}^{2}$ for the cDNA. These values are in good agreement with the density obtained previously with PLL-OEG-Tz, indicating that PLL functionalization above $5 \%$ does not increase the DNA probe density on the surface. Additionally, the predicted DNA probe density for such PLL functionalization, calculated as described before, indicated a density of approx. $8.3 \times 10^{12}$ molecules $/ \mathrm{cm}^{2}$. The discrepancy between the calculated and predicted values can be attributed, as in the case of PLL-OEG-Tz, to the estimation of water content of the DNA and difference in size and hydrophobicity between maleimide and DBCO 
moieties. At the same time, the predicted value does not take into account the steric hindrance and the electrostatic repulsion that might occur at such DNA probe densities.

As an additional method to study the probe density and to show the applicability of the click chemistry/PLL method for electrochemical biosensing schemes, we employed chronocoulometry (CC) as a convenient electrochemical method for the detection of the adsorbed analytes on an electrode surface. ${ }^{42,43} \mathrm{CC}$ is a fast and non-destructive technique, particularly useful for analytes like DNA, RNA, which are quite susceptible to degradation, ${ }^{44}$ and the method has recently been used to detect single or duplex strands of DNA immobilized on an electrode surface. In this method, the surface-bound DNA probe moieties are exposed to a cationic redox probe in solution, such as ruthenium(II/III)hexamine (RuHex), which electrostatically interacts with the phosphate groups of the DNA probe. The CC signal is proportional to the density of phosphate groups of the nucleic acids present at the surface, and a follow-up hybridization step can therefore be observed by an increase of the adsorbed RuHex probe molecules. ${ }^{43}$ Accordingly, we used here the interaction of RuHex to DNA to obtain information about the coupling of DNA probes at the surface, and to detect the surface coverage before and after the hybridization step. PLL-OEG-Tz bearing 0.5 and $4.9 \%$ of Tz were used in these measurements. The gold electrodes were modified with PLL-OEG-Tz $(0.25 \mathrm{mg} / \mathrm{mL})$ in PBS solution. After rinsing the surface, a solution of TCO-DNA $(1 \mu \mathrm{M}$ in PBS) was added onto the electrode for $1 \mathrm{~h}$, and subsequently cDNA ( $1 \mu \mathrm{M}$ in PBS) was adsorbed during an additional $1 \mathrm{~h}$. Typical CC curves for the gold electrodes were obtained in the presence of $50 \mu \mathrm{M}$ RuHex in $20 \mathrm{mM}$ Tris buffer (Figure 3.5), while the type and density of PLL were varied.

The surface densities for TCO-DNA, resulting from the CC measurements, were $1.1 \times 10^{12}$ molecules $/ \mathrm{cm}^{2}$ and $2.3 \times 10^{12}$ molecules $/ \mathrm{cm}^{2}$ for PLL-OEG-Tz 0.5 and $4.9 \%$ respectively. The densities of cDNA were found to be 2.0 and $3.4 \times 10^{12}$ molecules $/ \mathrm{cm}^{2}$, respectively. These values are in reasonable agreement with the previously reported results in which densities between 1 and $10 \times 10^{12}$ molecules $/ \mathrm{cm}^{2}$ were measured. ${ }^{45}$ However, both in the case of the DNA probe and the cDNA, these values are very comparable to the ones calculated from the QCM measurements. The relatively small observed differences can be, once more, attributed to the difficulty in estimating the exact water content in the QCM measurements. At the same time, the hybridization efficiency calculated for this system appears to be higher than $100 \%$, indicating a possible overestimation of the DNA density calculated with this method. Interestingly, a different behavior was observed, instead, in case of $\mathrm{N}_{3}$-DNA. As shown in Figure 3.5, the measured DNA probe density appeared to be lower than the measured cDNA, thus resulting in a lower hybridization efficiency. At the same time, no clear difference was observed between values of cDNA densities obtained with PLL-OEG$\mathrm{Tz}_{4.9}$ and PLL-OEG-DBCO 6.7 . This observation can find an explanation in the different 
degrees of functionalization of the PLL. In particular, a higher amount of DBCO can lead to the (observed) surface functionalization with DNA probes. However, due to steric hindrance and electrostatic repulsion, not all the probes can hybridize with cDNA, resulting in a lower hybridization efficiency. Therefore, these results support the previous observations, where at a PLL functionalization above $5 \%$, no further increase of cDNA was observed.

(A)

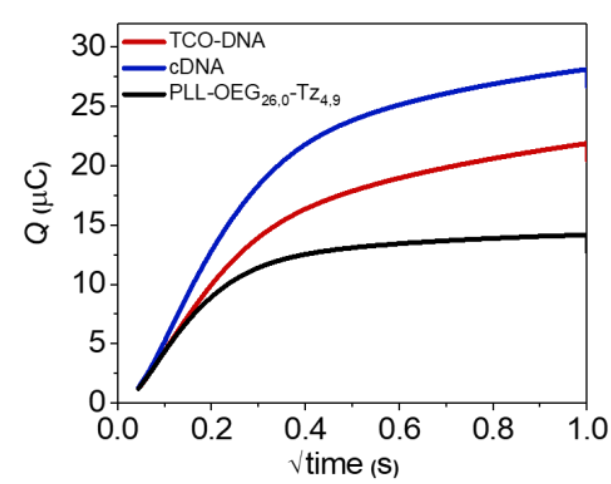

(B)

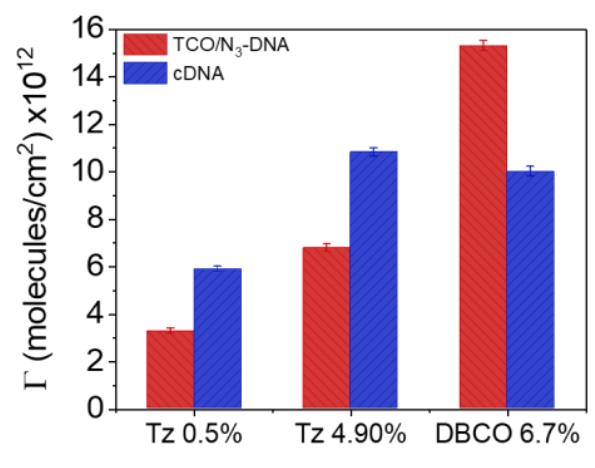

Figure 3.5. (A) Example of CC curves measured for the gold electrodes modified with $0.25 \mathrm{mg} / \mathrm{mL}$ of PLL-OEG-Tz4.9, $1 \mu \mathrm{M}$ TCO-DNA and cDNA in the presence of $50 \mu \mathrm{M}$ RuHex in $20 \mathrm{mM}$ Tris buffer. (B) Surface coverage of Au electrode surfaces modified with PLL-OEG-Tz0.5, PLL-OEG-Tz4.9 and PLL-OEG-DBCO 6.7 and subsequently with TCO-DNA and $\mathrm{N}_{3}$-DNA, before and after hybridization with cDNA.

\subsection{Conclusions}

In conclusion, a surface modification method has been developed, based on PLL polymers functionalized with catalyst-free click chemistry moieties, for a fast and selective immobilization of biomolecules. Gold and silicon dioxide surfaces have been functionalized selectively with DNA probe molecules in less than 20 min using two different coupling chemistries, and the modified surfaces showed hybridization with fully complementary DNA sequences while not responding to non-complementary DNA. The correlation between PLL functionalization and DNA density was assessed, resulting in a surface saturation with DNA for PLL functionalization above 5\%. This surface modification method appears to be suitable for the modification of substrates for biomedical applications, in which biosensors can be developed with a precise control of probe density. Furthermore, we believe that this method 
can be applied for fast surface immobilization of a several types of biomolecules, such as proteins and antibodies, thus allowing the recognition of a broad range of analytes in solution.

\subsection{Acknowledgments}

Sander Koeman is acknowledged for the help with the QCM measurements and Dr. Almudena Marti Morant for the electrochemical measurements.

\subsection{Experimental section}

\subsubsection{Materials}

Phosphate-buffered saline tablets (PBS, pH 7.4), and poly-L-lysine-HBr (PLL-HBr) (15-30 $\mathrm{kDa}$ ), DMSO $\geq 99.9 \%$ anhydrous, sodium dodecyl sulfate (SDS) $\geq 98.5 \%$, and $\mathrm{DBCO}^{-O_{E}} \mathrm{E}_{4}-$ NHS were purchased from Sigma Aldrich and used without further purification. Methyl$\mathrm{OEG}_{4}-\mathrm{NHS}$ was purchased from ThermoFischer Scientific, while methyltetrazine-OEG 4 NHS was purchased from Click chemistry tools. TCO-DNA (15 nt, 5'-TCO-PEG $4-\mathrm{C}_{5}-$ TCGTACCATCTATCC-3') and ${ }^{\prime} \mathrm{N}_{3}$-DNA (15 nt, 5'-Azido-PEG ${ }_{4}-\mathrm{C}_{5}{ }^{-}$ TCGTACCATCTATCC-3') were obtained from Biomers, cDNA (36 nt, 5'CGCGGTCTCAGGATACCCCCCGGATAGATGGTACGA-3') and ncDNA (36 nt, 5'AATGCTTCTCGCGCTTTTTTTTAGACTTCGCGCGTT-3') sequences were purchased from Eurofins Genomic. Au and $\mathrm{SiO}_{2}$ QCM chips (AT cut, $5 \mathrm{MHz}, 14 \mathrm{~mm}$ diameter) were purchased from Biolin Scientific. Milli-Q water with a resistivity $>18 \mathrm{M} \Omega \mathrm{cm}$ was used in all experiments. 
(A)<smiles>[B][C@@H]1O[C@@H](COP(=O)(O)OCCCCCNC(=O)CCOCCOCCOCCOCCNC(=O)OC2CC/C=C\CCC2)[C@H](OP(=O)(O)O[Na])[C@@H]1O</smiles>

(B)

$$
\text { (c) }
$$

Figure 3.6: Chemical structures of the TCO linker (A) and of the azido linker (B) used in this work for the modified DNA sequences. The exact sequences are described in the Materials.

\subsubsection{Synthetic procedures}

\section{Synthesis of PLL-OEG-Tz}

PLL-OEG(x)-Tz(y) with varying percentages of functionalization where synthesized based on a procedure reported by Duan et al (see Scheme 3.1). ${ }^{38}$ PLL was dissolved in PBS $(\mathrm{pH}=7.2)$ at a concentration of $10 \mathrm{mg} / \mathrm{mL}$. NHS-OEG ${ }_{4}-\mathrm{methyl}$ and $\mathrm{NHS}^{-O_{E}} \mathrm{H}_{4}$ methyltetrazine, both dissolved in DMSO at a concentration of $250 \mathrm{mM}$, were added to the PLL solution simultaneously under nitrogen atmosphere in desired ratios. The total volume of the mixture was adjusted with PBS in order to obey the maximum solubility of $1.8 \mathrm{mM}$ of $\mathrm{NHS}_{-} \mathrm{OEG}_{4}$-methyltetrazine. The reaction was conducted for $4 \mathrm{~h}$ at room temperature under vigorous stirring. Afterwards, the reaction mixture was dialyzed with a dialysis membrane (cut-off 6-8 $\mathrm{kDa}$ ) for 3 days against PBS and water. The solution was then freeze-dried overnight. The final product was stored at $-20^{\circ} \mathrm{C}$ as a stock solution of $10 \mathrm{mg} / \mathrm{mL}$ in MilliQ water. 


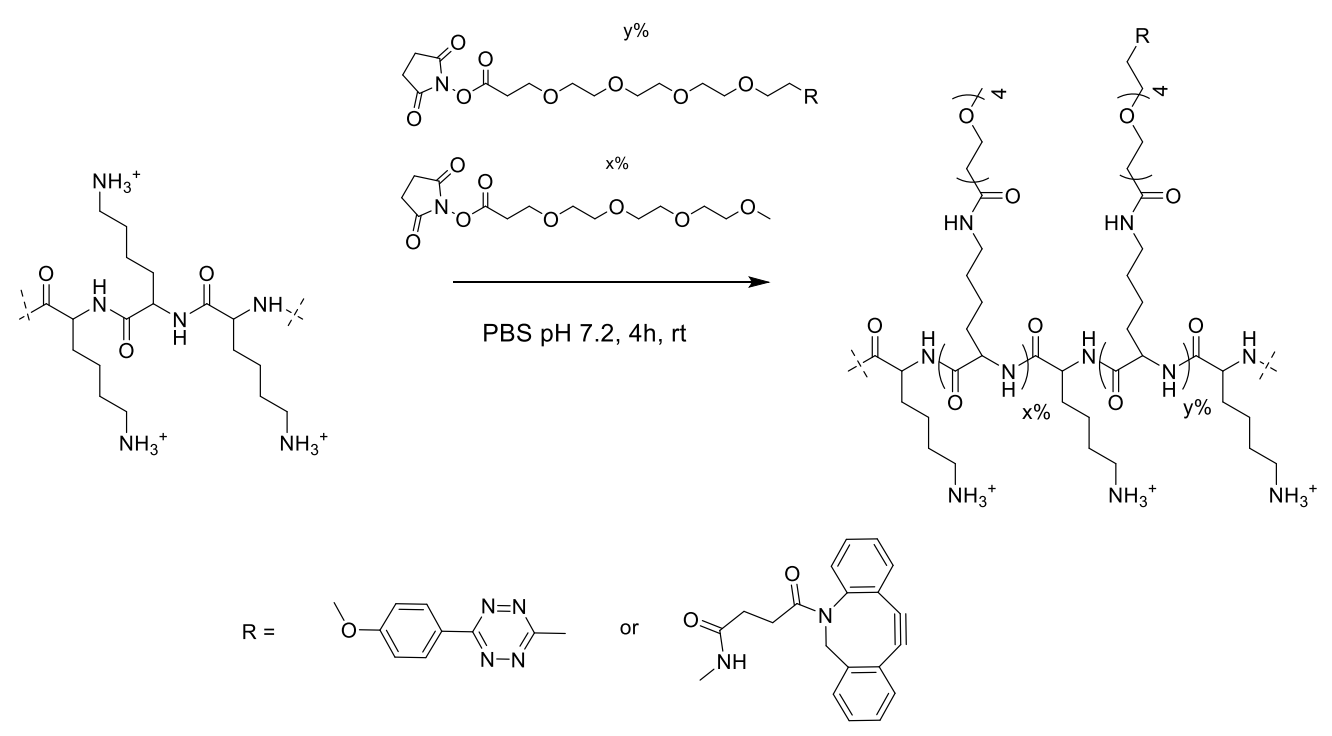

Scheme 3.1. Synthesis of PLL-OEG-Tz and PLL-OEG-DBCO. PLL is reacted with desired relative ratios of either Tz-OEG4-NHS or DBCO- OEG4-NHS, and methyl-OEG4-NHS ester to give the final modified PLL with the desired degrees of functionalization.

${ }^{1} \mathrm{H}$ NMR of PLL-OEG-Tz $\left(400 \mathrm{MHz} \mathrm{D}_{2} \mathrm{O}\right) \delta[\mathrm{ppm}]=1.26-1.56\left(\right.$ lysine $\left.\gamma-\mathrm{CH}_{2}\right), 1.61-1.82$ (lysine $\beta, \delta-\mathrm{CH}_{2}$ ), 2.49 (ethylene glycol $\mathrm{CH}_{2}$ from both $\mathrm{OEG}$ and $\mathrm{Tz}$ coupled, $-\mathrm{CH}_{2}-\mathrm{C}(=\mathrm{O})$ $\mathrm{NH}$ ), 2.99 (free lysine, $\mathrm{H}_{2} \mathrm{~N}-\mathrm{CH} 2$ ), 3.16 (ethylene glycol $\mathrm{CH}_{2}$ of coupled lysine from both OEG and Tz, $\mathrm{C}(=\mathrm{O})-\mathrm{NH}-\mathrm{CH}_{2}-$ ), 3.35 (OEG methoxy, -O- $\mathrm{CH}_{3}$ ), 3.58-3.79 (ethylene glycol from both OEG and $\mathrm{Tz}, \mathrm{CH}_{2}-\mathrm{O}-$ ), 4.29 (lysine backbone, $\mathrm{NH}-\mathrm{CH}-\mathrm{C}(\mathrm{O})-$ ), 8.4 and 7.2 (tetrazine from coupled $\mathrm{Tz}, \mathrm{HCAr}=\mathrm{CArH}$ ).

The overall grafting ratio (the percentage of the OEG and OEG-Tz chains) was determined by adapting a previously reported procedure. ${ }^{36}$ The grafting densities of tetrazine moieties ( $\mathrm{y} \%)$ were calculated by eqn 1 :

$\%$ functionalization $=\frac{\text { integral of one Tz peak }}{\text { integral of free lysine }+ \text { integral of coupled lysine }} \times 100$

\section{Synthesis of PLL-OEG-DBCO}

PLL-OEG-DBCO was synthesized in a similar way as PLL-OEG-Tz (see Scheme 3.1). NHS$\mathrm{OEG}_{4}$-DBCO was dissolved in DMSO at a concentration of $50 \mathrm{mM}$, and this solution was

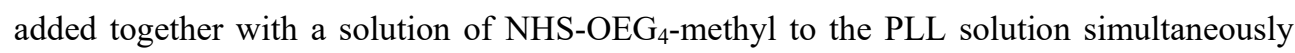
under nitrogen atmosphere in the desired ratio. The reaction was conducted for $4 \mathrm{~h}$ at room 
temperature under vigorous stirring. Afterwards, the reaction mixture was dialyzed with a dialysis membrane (cut-off 6-8 kDa) for 3 days against PBS and water. The solution was freeze-dried overnight. The final product was stored at $-20^{\circ} \mathrm{C}$ as a stock solution of 10 $\mathrm{mg} / \mathrm{mL}$ in Milli-Q water.

${ }^{1} \mathrm{H}$ NMR of PLL-OEG-Tz (400 MHz D $\left.2 \mathrm{O}\right) \delta[\mathrm{ppm}]=1.26-1.56\left(\right.$ lysine $\left.\gamma-\mathrm{CH}_{2}\right), 1.61-1.82$ (lysine $\beta, \delta-\mathrm{CH}_{2}$ ), 2.49 (ethylene glycol $\mathrm{CH}_{2}$ from both $\mathrm{OEG}$ and DBCO coupled, $-\mathrm{CH}_{2}-$ $\mathrm{C}\left(=\mathrm{O}\right.$ )-NH), 2.99 (free lysine, $\mathrm{H}_{2} \mathrm{~N}-\mathrm{CH}_{2}$ ), 3.16 (ethylene glycol $\mathrm{CH}_{2}$ of coupled lysine from both OEG and DBCO, $\left.\mathrm{C}(=\mathrm{O})-\mathrm{NH}-\mathrm{CH}_{2}-\right), 3.35$ (OEG methoxy, $\left.-\mathrm{O}-\mathrm{CH}_{3}\right), 3.58-3.79$ (ethylene glycol from both OEG and $\mathrm{DBCO}, \mathrm{CH}_{2}-\mathrm{O}-$ ), 4.29 (lysine backbone, $\left.\mathrm{NH}-\mathrm{CH}-\mathrm{C}(\mathrm{O})-\right), 7.42$ (DBCO from coupled DBCO, CArH).

The grafted densities of DBCO moieties (y\%) were calculated by eqn 2 :

$\%$ of functionalization $=\frac{(\text { integral of DBCO peak }) / 4}{\text { integral of free lysine+integral of coupled lysine }} \times 100$

\subsubsection{Methods}

\section{Quartz crystal microbalance with dissipation monitoring (QCM-D)}

QCM-D measurements were performed with a Q-Sense E4 4-channel quartz crystal microbalance with a peristaltic pump (Biolin Scientific). All experiments were performed in PBS buffer (0.01 M phosphate and $0.138 \mathrm{M} \mathrm{NaCl}$ and $0.0027 \mathrm{M} \mathrm{KCl}, \mathrm{pH} 7.4$ ) using a flow rate of $100 \mu \mathrm{L} / \mathrm{min}$ at $22^{\circ} \mathrm{C}$ and operated with four parallel flow chambers.

Gold surfaces were cleaned using basic Piranha solution (Milli-Q water : $\mathrm{H}_{2} \mathrm{O}_{2}(30 \%)$ : $\mathrm{NH}_{4} \mathrm{OH}(25 \%)$, in ratio 5:1:1) for $5 \mathrm{~min}$, then rinsed with Milli-Q water, dried in a $\mathrm{N}_{2}$ stream and treated with UV-ozone for $10 \mathrm{~min}$. Silicon dioxide surfaces were submerged in 2\% SDS in water and sonicated for $10 \mathrm{~min}$. Afterwards, the surfaces were rinsed with Milli-Q water and activated for $20 \mathrm{~min}$ in UV-ozone.

The relationship between the measured frequency shift $(\Delta f)$ and the adsorbed mass per unit area $(\Delta m)$ was established using the Sauerbrey equation (eqn 3):

$$
\Delta f=-C \Delta m
$$


where $C$ is the Sauerbrey constant $\left(17.7 \mathrm{ng} \mathrm{Hz}^{-1}\right.$ at $\left.f=5 \mathrm{MHz}\right)$. Throughout this work, the fifth overtone was used for the normalized frequency $\left(\Delta f_{5}\right)$ and dissipation $\left(\Delta D_{5}\right)$.

\section{Electrochemical measurements}

All electrochemical measurements were performed with a $\mathrm{CHI} 760 \mathrm{D}$ potentiostat $(\mathrm{CH}$ Instruments, Austin, Texas), connected to an electrochemical cell containing the modified gold chip as a working electrode, an $\mathrm{Ag} / \mathrm{AgCl}$ reference electrode, and a platinum wire as a counter electrode. Chronocoulometry (CC) for the quantification of the DNA (TCO-DNA or $\mathrm{N}_{3}$-DNA) surface density and monitoring of the hybridization with the cDNA was carried out in $50 \mu \mathrm{M}$ of RuHex in $20 \mathrm{mM}$ Tris buffer $(\mathrm{pH}=7.4)$. The buffer was purged with nitrogen for $15 \mathrm{~min}$ before the experiments. To obtain a stable signal, the solution was left to equilibrate for $5 \mathrm{~min}$ before each measurement. All measurements were taken under the same conditions where a two-step potential was employed with the following parameters: initial potential $=-0.5 \mathrm{~V}$; final potential $=0.2 \mathrm{~V}$; pulse width $=1 \mathrm{~s}$; pulse period $=1000 \mathrm{~ms}$; sample interval $=0.002 \mathrm{~s}$; quiet time $=2 \mathrm{~s}$.

\section{Quantification of DNA}

The surface coverage of DNA was calculated by using the following equation:

$$
Q_{\text {total }}=\frac{2 n F A D_{0}{ }^{1 / 2} C_{0}^{+}}{\pi^{1 / 2}} t^{1 / 2}+Q_{d l}+\mathrm{n} F A \Gamma_{0}
$$

Where $n$ is the number of electrons in the electrode reaction $(n=1), F$ is the Faraday constant (96485 C/equivalent), $A$ is the electrode area $\left(0.044 \mathrm{~cm}^{2}\right), Q_{\mathrm{dl}}$ is the capacitive charge (C), $n F A \Gamma_{0}$ is the charge produced by the adsorbed RuHex and $\Gamma_{0}$ is the amount of RuHex confined on the electrode surface $\left(\mathrm{mol} / \mathrm{cm}^{2}\right)$. The intercept at $t=0$ is the sum of the capacitive charge $\left(Q_{d l}\right)$ and the surface excess terms $\left(n F A \Gamma_{0}\right)$.

$$
Q_{\text {total }}=Q_{\mathrm{dl}}+\mathrm{n} F A \Gamma_{0}
$$

To achieve a much more indicative view of DNA surface density, a meaningful conversion is necessary. $\Gamma_{\mathrm{DNA}}$, the probe coverage in molecules $/ \mathrm{cm}^{2}$, can be written as in Eq. 5 , where $m$ is the number of base pairs in the DNA, $z$ is the charge of the redox molecules $(z=3)$ and $N_{\mathrm{A}}$ is Avogadro's number.

$$
\Gamma_{D N A}=\Gamma_{0}\left(\frac{z}{m}\right) N_{A}
$$


Substituting Eq. 5 into Eq. 6:

$$
\Gamma_{D N A}=\frac{Q_{t o t a l}-Q_{d l}}{n F A}\left(\frac{z}{m}\right) N_{A}
$$

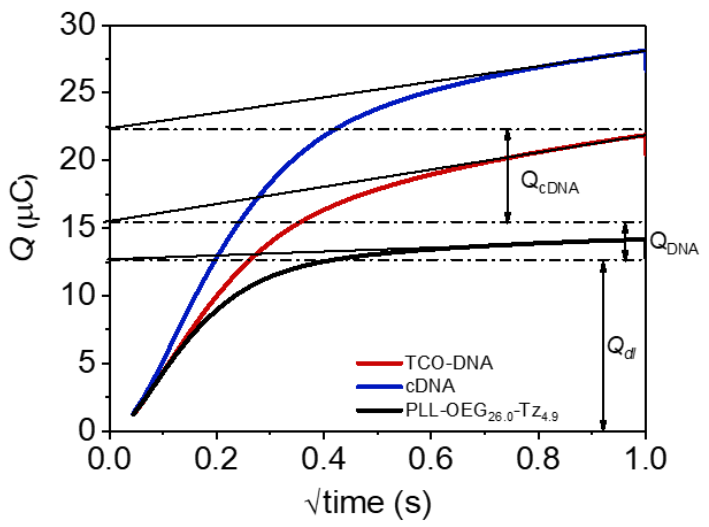

Figure 3.7. CC measurements showing a typical DNA density calculation. The represented Figure is the same as Figure 3.5, with additional indications for the calculation of DNA densities, where $Q_{\mathrm{dl}}$ represents the capacitive charge, $Q_{\mathrm{DNA}}$ is the measured charge for TCO-DNA and $Q_{\mathrm{cDNA}}$ is the charge measured upon addition of cDNA.

\subsection{References}

1. Lee, H.; Rho, J.; Messersmith, P. B., Facile Conjugation of Biomolecules onto Surfaces via Mussel Adhesive Protein Inspired Coatings. Adv.Mater. 2009, 21, 431-434.

2. Kuzmin, A.; Poloukhtine, A.; Wolfert, M. A.; Popik, V. V., Surface Functionalization Using Catalyst-Free Azide-Alkyne Cycloaddition. Bioconjugate Chem. 2010, 21, 2076-2085.

3. Nebhani, L.; Barner-Kowollik, C., Orthogonal Transformations on Solid Substrates: Efficient Avenues to Surface Modification. Adv. Mater. 2009, 21, 3442-3468.

4. Escorihuela, J.; Marcelis, A. T. M.; Zuilhof, H., Metal-Free Click Chemistry Reactions on Surfaces. Adv. Mater. Interfaces 2015, 2, 1500135.

5. Samanta, D.; Sarkar, A., Immobilization of bio-macromolecules on self-assembled monolayers: methods and sensor applications. Chem. Soc. Rev. 2011, 40, 2567-2592.

6. Ruiz-Taylor, L. A.; Martin, T. L.; Zaugg, F. G.; Witte, K.; Indermuhle, P.; Nock, S.; Wagner, P., Monolayers of derivatized poly-L-lysine)-grafted poly(ethylene glycol) on metal oxides as a class of biomolecular interfaces. Proc. Natl. Acad. Sci. U.S.A. 2001, 98, 852-857.

7. Liu, Y.; Yu, J., Oriented immobilization of proteins on solid supports for use in biosensors and biochips: a review. Microchimica Acta 2016, 183, 1-19. 
8. Sen, R.; Gahtory, D.; Escorihuela, J.; Firet, J.; Pujari, S. P.; Zuilhof, H., Approach Matters: The Kinetics of Interfacial Inverse-Electron Demand Diels-Alder Reactions. Chem.-Eur. J. 2017, 23, 13015-13022.

9. Im, S. G.; Bong, K. W.; Kim, B.-S.; Baxamusa, S. H.; Hammond, P. T.; Doyle, P. S.; Gleason, K. K., Patterning Nanodomains with Orthogonal Functionalities: Solventless Synthesis of Self-Sorting Surfaces. J. Am. Chem. Soc. 2008, 130, 14424-14425.

10. Michel, O.; Ravoo, B. J., Carbohydrate Microarrays by Microcontact "Click" Chemistry. Langmuir 2008, 24, 12116-12118.

11. Sun, X.-L.; Stabler, C. L.; Cazalis, C. S.; Chaikof, E. L., Carbohydrate and Protein Immobilization onto Solid Surfaces by Sequential Diels-Alder and Azide-Alkyne Cycloadditions. Bioconjugate Chem. 2006, 17, 52-57.

12. Gaetke, L. M.; Chow, C. K., Copper toxicity, oxidative stress, and antioxidant nutrients. Toxicology 2003, 189, 147-163.

13. Tajmir-Riahi, H. A.; Langlais, M.; Savoie, R., A laser Raman spectroscopic study of the interaction of calf-thymus DNA with $\mathrm{Cu}(\mathrm{II})$ and $\mathrm{Pb}$ (II) ions: metal ion binding and DNA conformational changes. Nucleic Acids Res. 1988, 16, 751-762.

14. Davydova, M.; de los Santos Pereira, A.; Bruns, M.; Kromka, A.; Ukraintsev, E.; Hirtz, M.; Rodriguez-Emmenegger, C., Catalyst-free site-specific surface modifications of nanocrystalline diamond films via microchannel cantilever spotting. RSC Adv. 2016, 6, $57820-57827$.

15. Wu, F.; Zhang, D.-W.; Wang, J.; Watkinson, M.; Krause, S., Copper Contamination of SelfAssembled Organic Monolayer Modified Silicon Surfaces Following a "Click" Reaction Characterized with LAPS and SPIM. Langmuir 2017, 33, 3170-3177.

16. Manova, R.; van Beek, T. A.; Zuilhof, H., Surface Functionalization by Strain-Promoted Alkyne-Azide Click Reactions. Angew. Chem. Int. Ed. 2011, 50, 5428-5430.

17. Wijdeven, M. A.; Nicosia, C.; Borrmann, A.; Huskens, J.; van Delft, F. L., Biomolecular patterning of glass surfaces via strain-promoted cycloaddition of azides and cyclooctynes. RSC Adv. 2014, 4, 10549-10552.

18. Agard, N. J.; Prescher, J. A.; Bertozzi, C. R., A Strain-Promoted [3 + 2] Azide-Alkyne Cycloaddition for Covalent Modification of Biomolecules in Living Systems. J. Am. Chem. Soc. 2004, 126, 15046-15047.

19. Codelli, J. A.; Baskin, J. M.; Agard, N. J.; Bertozzi, C. R., Second-Generation Difluorinated Cyclooctynes for Copper-Free Click Chemistry. J. Am. Chem. Soc. 2008, 130, 11486-11493.

20. Sletten, E. M.; Bertozzi, C. R., A Hydrophilic Azacyclooctyne for Cu-Free Click Chemistry. Org. Lett. 2008, 10, 3097-3099.

21. Debets, M. F.; van Berkel, S. S.; Dommerholt, J.; Dirks, A. J.; Rutjes, F. P. J. T.; van Delft, F. L., Bioconjugation with Strained Alkenes and Alkynes. Accounts Chem. Res. 2011, 44, 805-815.

22. Orski, S. V.; Sheppard, G. R.; Arumugam, S.; Arnold, R. M.; Popik, V. V.; Locklin, J., Rate Determination of Azide Click Reactions onto Alkyne Polymer Brush Scaffolds: A Comparison of Conventional and Catalyst-Free Cycloadditions for Tunable Surface Modification. Langmuir 2012, 28, 14693-14702.

23. Prim, D.; Rebeaud, F.; Cosandey, V.; Marti, R.; Passeraub, P.; Pfeifer, M. E., ADIBO-based "click" chemistry for diagnostic peptide micro-array fabrication: physicochemical and assay characteristics. Molecules 2013, 18, 9833-9849.

24. Orski, S. V.; Poloukhtine, A. A.; Arumugam, S.; Mao, L.; Popik, V. V.; Locklin, J., High Density Orthogonal Surface Immobilization via Photoactivated Copper-Free Click Chemistry. J. Am. Chem. Soc. 2010, 132, 11024-11026. 
25. Blackman, M. L.; Royzen, M.; Fox, J. M., Tetrazine Ligation: Fast Bioconjugation Based on Inverse-Electron-Demand Diels-Alder Reactivity. J. Am. Chem. Soc. 2008, 130, 1351813519.

26. Knall, A.-C.; Slugovc, C., Inverse electron demand Diels-Alder (iEDDA)-initiated conjugation: a (high) potential click chemistry scheme. Chem. Soc. Rev. 2013, 42, 5131-5142.

27. Ehret, F.; Wu, H.; Alexander, S. C.; Devaraj, N. K., Electrochemical Control of Rapid Bioorthogonal Tetrazine Ligations for Selective Functionalization of Microelectrodes. J. Am. Chem. Soc. 2015, 137, 8876-8879.

28. Zhang, C.-J.; Tan, C. Y. J.; Ge, J.; Na, Z.; Chen, G. Y. J.; Uttamchandani, M.; Sun, H.; Yao, S. Q., Preparation of Small-Molecule Microarrays by trans-Cyclooctene Tetrazine Ligation and Their Application in the High-Throughput Screening of Protein-Protein Interaction Inhibitors of Bromodomains. Angew. Chem. Int. Ed. 2013, 52, 14060-14064.

29. Wang, P.; Na, Z.; Fu, J.; Tan, C. Y. J.; Zhang, H.; Yao, S. Q.; Sun, H., Microarray immobilization of biomolecules using a fast trans-cyclooctene (TCO)-tetrazine reaction. Chem. Commun. 2014, 50, 11818-11821.

30. Roling, O.; Mardyukov, A.; Lamping, S.; Vonhören, B.; Rinnen, S.; Arlinghaus, H. F.; Studer, A.; Ravoo, B. J., Surface patterning with natural and synthetic polymers via an inverse electron demand Diels-Alder reaction employing microcontact chemistry. Org. Biomol. Chem. 2014, 12, 7828-7835.

31. Schena, M.; Shalon, D.; Davis, R. W.; Brown, P. O., Quantitative Monitoring of Gene Expression Patterns with a Complementary DNA Microarray. Science 1995, 270, 467-470.

32. Kenausis, G. L.; Vörös, J.; Elbert, D. L.; Huang, N.; Hofer, R.; Ruiz-Taylor, L.; Textor, M.; Hubbell, J. A.; Spencer, N. D., Poly(l-lysine)-g-Poly(ethylene glycol) Layers on Metal Oxide Surfaces: Attachment Mechanism and Effects of Polymer Architecture on Resistance to Protein Adsorption. The J. Phys. Chem. B 2000, 104, 3298-3309.

33. Huang, N.-P.; Michel, R.; Voros, J.; Textor, M.; Hofer, R.; Rossi, A.; Elbert, D. L.; Hubbell, J. A.; Spencer, N. D., Poly(1-lysine)-g-poly(ethylene glycol) Layers on Metal Oxide Surfaces: Surface-Analytical Characterization and Resistance to Serum and Fibrinogen Adsorption. Langmuir 2001, 17, 489-498.

34. Zhen, G.; Eggli, V.; Vörös, J.; Zammaretti, P.; Textor, M.; Glockshuber, R.; Kuennemann, E., Immobilization of the Enzyme $\beta$-Lactamase on Biotin-Derivatized Poly(l-lysine)-gpoly(ethylene glycol)-Coated Sensor Chips: A Study on Oriented Attachment and Surface Activity by Enzyme Kinetics and in Situ Optical Sensing. Langmuir 2004, 20, 10464-10473.

35. VandeVondele, S.; Vörös, J.; Hubbell, J. A., RGD-grafted poly-1-lysine-graft-(polyethylene glycol) copolymers block non-specific protein adsorption while promoting cell adhesion. Biotechnol. Bioeng. 2003, 82, 784-790.

36. Movilli, J.; Rozzi, A.; Ricciardi, R.; Corradini, R.; Huskens, J., Control of Probe Density at DNA Biosensor Surfaces Using Poly(l-lysine) with Appended Reactive Groups. Bioconjugate Chem. 2018, 29, 4110-4118.

37. Han, Z.; Wang, Y.; Duan, X., Biofunctional polyelectrolytes assembling on biosensors - A versatile surface coating method for protein detections. Analytica Chimica Acta 2017, 964, 170-177.

38. Duan, X.; Mu, L.; Sawtelle, S. D.; Rajan, N. K.; Han, Z.; Wang, Y.; Qu, H.; Reed, M. A., Functionalized Polyelectrolytes Assembling on Nano-BioFETs for Biosensing Applications. Adv. Funct. Mater. 2015, 25, 2279-2286.

39. Larsson, C.; Rodahl, M.; Höök, F., Characterization of DNA Immobilization and Subsequent Hybridization on a 2D Arrangement of Streptavidin on a Biotin-Modified Lipid Bilayer Supported on SiO2. Anal.Chem. 2003, 75, 5080-5087. 
40. Su, X.; Wu, Y.-J.; Knoll, W., Comparison of surface plasmon resonance spectroscopy and quartz crystal microbalance techniques for studying DNA assembly and hybridization. Biosens. Bioelectron. 2005, 21, 719-726.

41. Peterson, A. W.; Heaton, R. J.; Georgiadis, R. M., The effect of surface probe density on DNA hybridization. Nucleic Acids Res. 2001, 29, 5163-5168.

42. Ji, J.; Liu, Y.; Wei, W.; Zhang, Y.; Liu, S., Quantitation of DNA methyltransferase activity via chronocoulometry in combination with rolling chain amplification. Biosens.Bioelectron. 2016, 85, 25-31.

43. Lao, R.; Song, S.; Wu, H.; Wang, L.; Zhang, Z.; He, L.; Fan, C., Electrochemical Interrogation of DNA Monolayers on Gold Surfaces. Anal. Chem. 2005, 77, 6475-6480.

44. Ganguly, A.; Benson, J.; Papakonstantinou, P., Sensitive Chronocoulometric Detection of miRNA at Screen-Printed Electrodes Modified by Gold-Decorated MoS2 Nanosheets. ACS Appl. Bio Mater. 2018, 1, 1184-1194.

45. Yao, B.; Liu, Y.; Tabata, M.; Zhu, H.; Miyahara, Y., Sensitive detection of microRNA by chronocoulometry and rolling circle amplification on a gold electrode. Chem. Commun. 2014, 50, 9704-9706. 


\section{Chapter 4}

\section{Patterning of Polymeric Biosensing Surfaces by Modified Poly-L-Lysine Polymers*}

The immobilization of biomolecules onto plastic surfaces employable in the fabrication of biomedical devices is generally a challenging issue, as the absence of functional groups in such materials does not allow the use of common surface chemistries. This chapter reports the use of modified poly-L-lysine (PLL) as an effective method for the selective modification of polymeric materials with biomolecules. Cyclic olefin polymer (COP) and Ormostamp surfaces were patterned with modified PLLs displaying either biotin or maleimide functional groups by means of micromolding in capillaries (MIMIC). The surface modification and its stability were tested with fluorescence microscopy, contact angle and X-ray photoelectron spectroscopy (XPS), showing an effective functionalization of substrates stable for over 20 days. By exploiting the strong biotin-streptavidin interaction or the thiol-maleimide coupling, DNA and PNA probes were successfully displayed on the surface of the materials showing the capability to specifically recognize complementary DNA sequences from solution.

\footnotetext{
* Part of this chapter has been published as: J. Movilli, D. Di Iorio, A. Rozzi, J. Hiltunen, R. Corradini, J. Huskens, ACS Appl. Polym. Mater., submitted.
} 


\subsection{Introduction}

The interest in novel polymer materials for microfabrication and biomedical applications has rapidly increased owing to their moldability, optical clarity and high solvent resistance. ${ }^{1,2}$ Especially in biotechnology and biosensing applications, the use of plastic substrates has been intensively fueled by the need for reliable, cost-effective ways of producing simple-touse devices, such as microfluidic and optical chips, lab-on-a-chip devices and disposable biosensing systems. ${ }^{3,4,5}$

Multiple examples of polymeric materials have been described for biomedical and biosensing purposes. Polycarbonate (PC) substrates have been used for the detection of $\mathrm{DNA}^{3}$ and in microarrays, poly(dimethylsiloxane) (PDMS) in microfluidic chips for digital $\mathrm{PCR}^{6}$ and DNA detection in nanochannels, ${ }^{7}$ and cyclic olefin (co)polymer (COP/COC) platforms for sandwich immuno-assays for antibodies ${ }^{5}$ and micro-electromechanical systems (MEMS). ${ }^{8}$ In particular COP substrates are gaining interest as materials in biotechnology and biosensing owing to their ideal properties such as optical transparency, good chemical resistance and low water absorption. ${ }^{9}$ Similarly, Ormostamp has been successfully investigated as material for biosensing applications owing to its excellent imprinting capabilities. ${ }^{10,11}$ However, in general all plastic materials present a major drawback of lacking chemically reactive groups to allow for stable, covalent surface functionalization. The absence of functional groups therefore prohibits the direct use of commonly applied surface functionalization protocols, such as thiol adsorption on gold ${ }^{12,13}$ or silanization on $\mathrm{SiO}_{2}$ substrates. ${ }^{14,15}$

Alternative functionalization methods, comprising photografting, ${ }^{16,17}$ photochemical patterning $^{1}$ and APTES silanization after oxidative treatment, ${ }^{5,18}$ have been exploited to anchor biomolecules to the initially unreactive polymeric substrates. Likewise, the use of positively charged polymers on negatively charged surfaces has been demonstrated to be an effective method to modify both metallic and metal oxide substrates, introducing at the same time specific functional moieties and antifouling properties. ${ }^{19-23}$ Particularly poly-L-lysine (PLL) and modified versions thereof, which are biocompatible and positively charged at physiological $\mathrm{pH}$, have been proven to adsorb strongly onto negatively charged substrates such as inorganic $\left(\mathrm{SiO}_{2},{ }^{24} \mathrm{TiO}_{2},{ }^{25} \mathrm{Nb}_{2} \mathrm{O}_{5},{ }^{26}\right)$ and polymeric ones for example polydimethylsiloxane (PDMS), ${ }^{27,28}$ poly(methyl methacrylate) (PMMA) ${ }^{28}$ and polystyrene (PS). ${ }^{29}$ Stable electrostatic interactions are achieved upon activation of these surfaces, retaining high stability and reliability over time.

Owing to the easy functionalization and fast self-assembly of PLL, grafted antifouling poly(ethylene glycol) (PEG) groups ${ }^{30,31}$ and binding moieties, such as biotin,,$^{32,28}$ nitrilotriacetic acid (NTA), ${ }^{33,34}$ catechol, ${ }^{35}$ and functional RGD peptides ${ }^{36}$ or fluorescein ${ }^{37}$ were anchored onto fully covered oxide or polymer substrates. At the same time, 
micropatterns and microarrays for selective immobilization were formed with modified PLLPEG polymers on multiple metal oxide surfaces in combination with stamping, ${ }^{37,38}$ molecular-assembly ${ }^{39,40}$ and electrochemical ${ }^{41}$ patterning techniques. Duan et al. reported silicon nano-BioFET biosensors covered by a uniform layer of PLL co-grafted with short oligo(ethylene glycol) $\left(\mathrm{OEG}_{4}\right)$ and $\mathrm{OEG}_{4}$-biotin moieties, retaining the anti-fouling properties and strong surface adhesion. ${ }^{42}$ Recently, we have demonstrated that PLL polymers with customizable fractions of OEG and maleimide moieties can be easily adsorbed onto both gold and silicon dioxide surfaces, while controlling the type and the density of probe molecules at the interface in the preceding synthetic step. ${ }^{43}$

In this Chapter, we report an approach to functionalize different types of plastic surfaces commonly used in biosensing applications, such as COP and Ormostamp, by exploiting the adsorption of PLL grafted with $\mathrm{OEG}_{4}$-biotin or $\mathrm{OEG}_{4}$-maleimide for fast and efficient immobilization of biomolecules. Aim of this work is to demonstrate the versatility and stability of modified PLL polymers in combination with patterning techniques to form microstructures at various polymeric surfaces. By exploiting the electrostatic interactions between the negatively charged polymer surface and the positively charged modified PLL, a self-assembled monolayer is formed on the surface, bestowing the possibility of bioorthogonally anchoring a wide range of molecules of biological interest. In particular, COP and Ormostamp surfaces were patterned by micromolding in capillaries (MIMIC) with modified PLL. Modified PLLs bearing biotin or maleimide as reactive moieties were employed as adhesion layers, to which biomolecules can be anchored by different reactions. Engineered DNA and peptide nucleic acid (PNA) probes were immobilized on the substrates as proof of concept for the detection of complementary DNA (cDNA) sequences in solution.

\subsection{Results and discussion}

\subsubsection{Soft lithography strategies based on modified PLL}

Figure 4.1 shows a schematic overview of the soft lithography strategy used to pattern the surface of polymer substrates (of COP and Ormostamp (as a thin layer on poly(ethylene terephthalate), PET) with modified PLL, and their proof-of-principle application to DNA detection. The formation of bioresponsive patterns was achieved by MIMIC (Figure 4.1A/B). Upon oxygen plasma activation, COP and Ormostamp substrates were functionalized with biotin or maleimide-modified PLL.

PLL polymers (15-30 kDa) were grafted with oligo(ethylene glycol) (OEG) spacers, and either biotin or maleimide (Mal) moieties, following reported procedures. ${ }^{42,43}$ All the 
modified PLLs synthesized, namely PLL-OEG, PLL-OEG-biotin and PLL-OEG-Mal, present the OEG functionality to enhance the antifouling properties of the substrate, providing concomitantly a secondary functional group for further bio-orthogonal modification, such as biotin or maleimide (Figure 4.1C). The total degree of functionalization of the PLL polymers has been determined by ${ }^{1} \mathrm{H}-\mathrm{NMR}$ (see Table 4.4, Experimental section), and has been intentionally kept between $20 \%$ and $40 \%$, to maintain a balance between a stable surface adhesion and antifouling properties. ${ }^{42-44}$

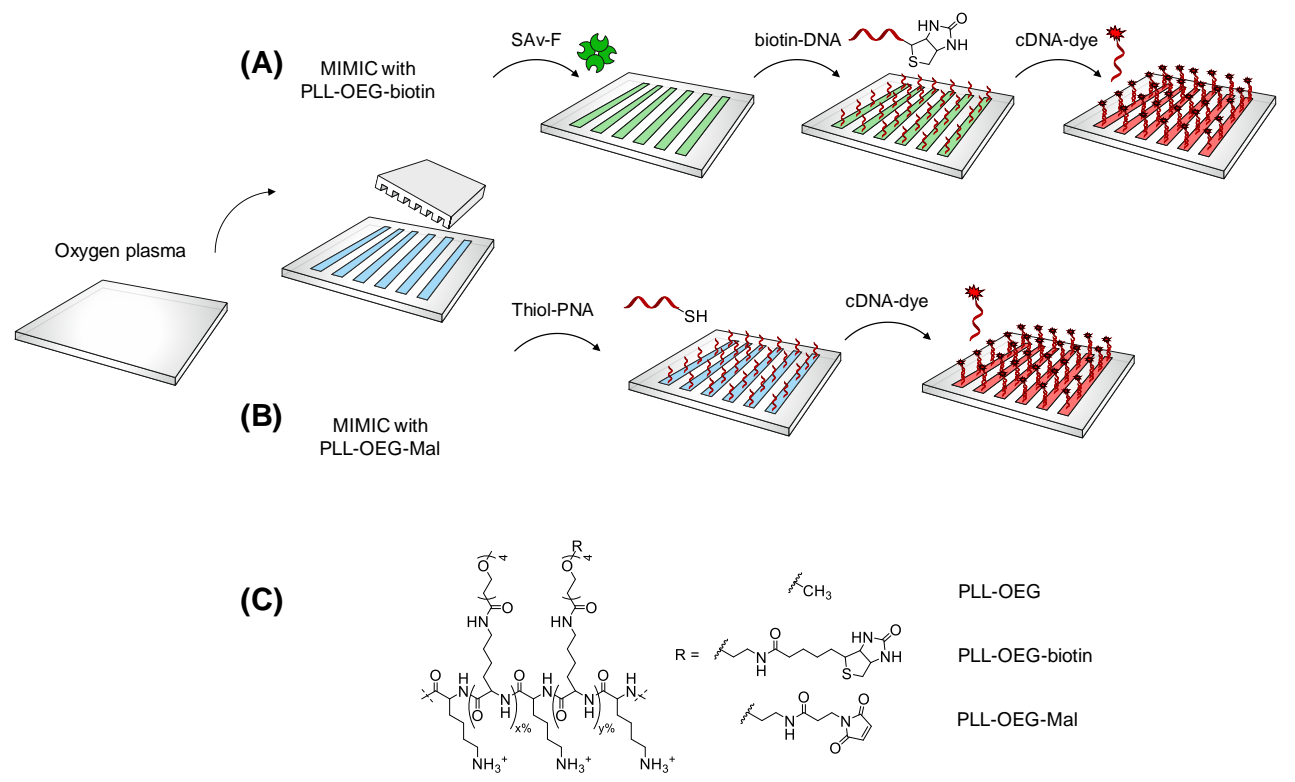

Figure 4.1. Soft lithography methods used to pattern polymeric substrates with PLL. After oxygen plasma treatment, MIMIC with either (A) PLL-OEG-biotin or (B) PLL-OEG-Mal defines modified PLL lines on COP or Ormostamp substrates, which are used to orthogonally anchor specific probes as (A) biotinylated DNA or (B) thiol-PNA for cDNA detection. (C) Structures of the PLL polymers, modified with OEG, OEG-biotin, OEG-Mal, employed for the surface functionalization. $\mathrm{x}$ and $\mathrm{y}$ indicate the relative fractions of the modified lysine subunits. Structures of the dyes with linkers and oligonucleotide sequences are shown in the Experimental section.

Subsequently, DNA probes were anchored on the surface in order to selectively recognize complementary DNA sequences in solution. PLL-OEG-biotin or PLL-OEG-Mal were used to either anchor streptavidin conjugated with fluorescein isothiocyanate (SAv-F) and biotinylated DNA (biotin-DNA ${ }_{1}$ ) by exploiting the non-covalent SAv-biotin interaction, or to covalently bind PNA-thiol probes on the substrate by using the specific thiol-ene reaction, 
respectively (structure of dyes and probe sequences are given in the Experimental section). Fluorescently labelled cDNA was used to visualize the resulting patterns using fluorescence microscopy.

\subsubsection{Surface patterning by MIMIC}

In order to investigate the applicability of modified PLLs on different polymeric materials, we used the thermoplastic COP and the thermosetting Ormostamp as substrates. After activation by oxygen plasma, a PDMS mold (containing channels $100 \mu \mathrm{m}$ wide and spaced $100 \mu \mathrm{m})$ was used to pattern PLL-OEG-biotin $(0.1 \mathrm{mg} / \mathrm{ml}$ in PBS, $\mathrm{pH} 7.4)$ by MIMIC. After removal of the stamp and rinsing the substrate, fluorescently labelled SAv-F (PBS, pH 7.4) was adsorbed.
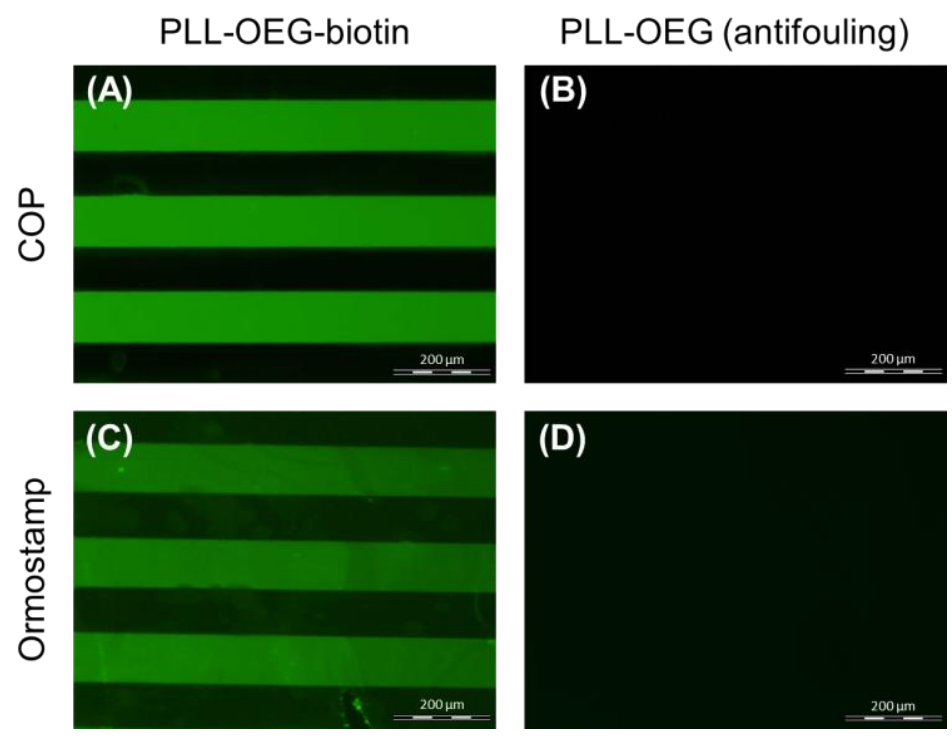

Figure 4.2. Fluorescence microscopy images of SAv-F on (A,B) COP (1500 ms, ISO 200) and (C,D) Ormostamp (2000 ms, ISO 400) surfaces, upon patterning (A,C) PLL-OEG-biotin or (B,D) PLL-OEG (antifouling) by MIMIC (scheme of Figure 4.1A). All experiments were performed using $0.1 \mathrm{mg} / \mathrm{ml}$ of modified PLL polymers during MIMIC, and $0.1 \mathrm{mg} / \mathrm{ml}$ of SAv-F in PBS at $\mathrm{pH} 7.4$ during subsequent incubation.

Figure 4.2A and 4.2C show clear fluorescent lines obtained after the functionalization of the substrates, owing to the successful adsorption of SAv-F onto both patterned surfaces. The empty areas in between the lines indicates that the SAv bound only to the areas where PLLbiotin was deposited. The absence of clear fluorescent lines in the control experiments 
(Figure 4.2B and 4.2D), where patterns were made with only PLL-OEG, i.e., without biotin moieties prior to the SAv-F binding, confirms the absence of non-specific adsorption of SAv. Therefore, also the antifouling behavior of the locally self-assembled PLL on the plastic surface was proven. The line edge irregularities along the fluorescent lines on the Ormostamp surface (Figure 4.2C) are likely due to imperfections and roughness of the material itself. Overall, PLL can be successfully adsorbed on both materials owing to the electrostatic interactions between the positively charged amino groups at the lysine side chains at physiological $\mathrm{pH}^{49,25}$ and the negatively charged surfaces after oxygen plasma treatment, and the subsequent molecular recognition is specific.

To further confirm the attachment of the PLL polymers to the substrates, contact angle goniometry was performed on COP and Ormostamp substrates fully covered with PLL-OEG. The measurements (Table 4.1) indicate for both substrates a similar value of approximately $31.5^{\circ}$, proving the adsorption of the modified PLL. This value was measured homogeneously all over the surface.

Table 4.1 Contact angle values of COP and Ormostamp substrates before and after activation, and after immersion in PLL-OEG solution in PBS 7.4 (control substrates dipped just PBS solution). Thereafter, substrates where immersed in Milli-Q water and the contact angle values monitored up to 10 days. Standard deviations (in brackets) were calculated measuring three different spots of the same substrate.

\begin{tabular}{|c|c|c|c|c|c|c|}
\hline Substrate & $\begin{array}{c}\text { Before } \\
\text { activation }\end{array}$ & $\begin{array}{c}\text { After } \\
\text { activation }\end{array}$ & $\begin{array}{c}\text { After } \\
\text { PLL-OEG }\end{array}$ & Day 1 & Day 4 & Day 10 \\
\hline Bare COP & $\begin{array}{c}96.7^{\circ} \\
\left( \pm 1.2^{\circ}\right)\end{array}$ & $<15^{\circ}$ & $\begin{array}{c}<15^{\circ} \\
\text { (only PBS) }\end{array}$ & $\begin{array}{c}23.0^{\circ} \\
\left( \pm 1.5^{\circ}\right)\end{array}$ & $\begin{array}{c}25.7^{\circ} \\
\left( \pm 2.7^{\circ}\right)\end{array}$ & $\begin{array}{c}38.9^{\circ} \\
\left( \pm 2.6^{\circ}\right)\end{array}$ \\
\hline $\begin{array}{l}\text { PLL-OEG } \\
\text { on COP }\end{array}$ & l & I & $\begin{array}{c}31.7^{\circ} \\
\left( \pm 2.7^{\circ}\right)\end{array}$ & $\begin{array}{c}32.4^{\circ} \\
\left( \pm 2.1^{\circ}\right)\end{array}$ & $\begin{array}{c}35.9^{\circ} \\
\left( \pm 2.6^{\circ}\right)\end{array}$ & $\begin{array}{c}35.6^{\circ} \\
\left( \pm 1.3^{\circ}\right)\end{array}$ \\
\hline $\begin{array}{c}\text { Bare } \\
\text { Ormostamp }\end{array}$ & $\begin{array}{c}58.5^{\circ} \\
\left( \pm 1.1^{\circ}\right)\end{array}$ & $<15^{\circ}$ & $\begin{array}{c}<15^{\circ} \\
\text { (only PBS) }\end{array}$ & $\begin{array}{c}20.3^{\circ} \\
\left( \pm 1.2^{\circ}\right)\end{array}$ & $\begin{array}{c}23.4^{\circ} \\
\left( \pm 1.6^{\circ}\right)\end{array}$ & $\begin{array}{c}27.6^{\circ} \\
\left( \pm 2.2^{\circ}\right)\end{array}$ \\
\hline $\begin{array}{c}\text { PLL-OEG } \\
\text { on } \\
\text { Ormostamp }\end{array}$ & l & I & $\begin{array}{c}31.4^{\circ} \\
\left( \pm 1.9^{\circ}\right)\end{array}$ & $\begin{array}{c}33.4^{\circ} \\
\left( \pm 2.7^{\circ}\right)\end{array}$ & $\begin{array}{c}34.9^{\circ} \\
\left( \pm 2.5^{\circ}\right)\end{array}$ & $\begin{array}{c}35.3^{\circ} \\
\left( \pm 2.8^{\circ}\right)\end{array}$ \\
\hline
\end{tabular}


In addition, X-ray photoelectron spectroscopy (XPS) was performed on fully functionalized COP surfaces. Figure 4.3A and 4.3B report the N1s and S2p spectra, respectively, for bare, PLL-OEG, and PLL-OEG-biotin-functionalized surfaces. Nitrogen peaks were visible only on substrates functionalized with PLL (both PLL-OEG and PLL-OEG-biotin), while the presence of the $S 2 p$ peak of the sulfur was observed only for the PLL-OEG-biotin modification, confirming the desired functionalization of the substrates. All atom percentages are given in Table 4.2. The carbon data show a decrease upon adsorption of PLL, caused by the larger amount of heteroatoms in PLL compared to the polymer substrate. The highly comparable carbon decrease and concomitant $\mathrm{N}$ and $\mathrm{O}$ increase observed for PLL-OEG and PLL-OEG-biotin compared to the unmodified substrate, indicate adsorption of the PLL variants with comparable coverage.

(A)

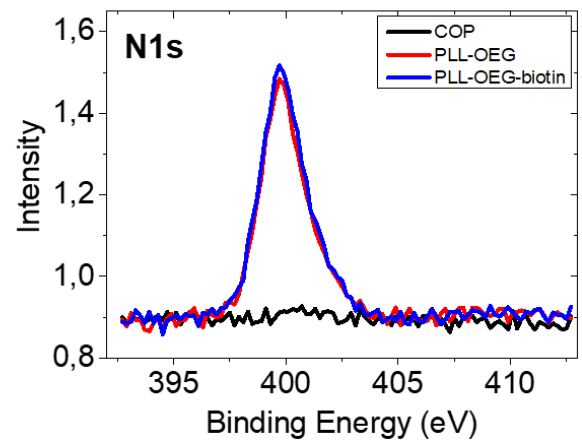

(B)

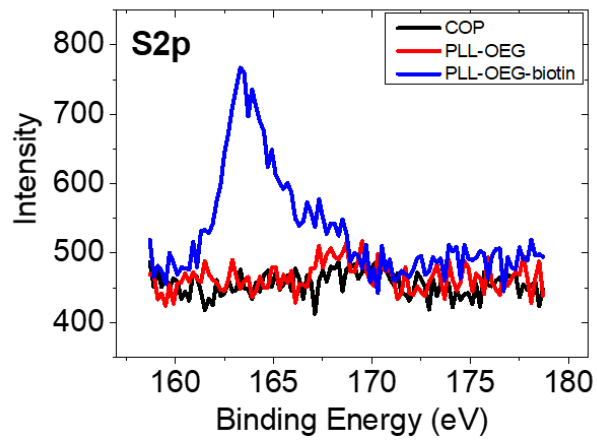

Figure 4.3. XPS element spectra of (A) nitrogen and (B) sulfur for COP surfaces: non-functionalized (black), functionalized with PLL-OEG (red) or with PLL-OEG-biotin (blue).

Table 4.2. XPS values from bare and functionalized COP samples.

\begin{tabular}{|c|c|c|c|c|}
\hline Sample & \multicolumn{4}{|c|}{ Element } \\
\hline & $\mathrm{C}$ & $\mathrm{N}$ & $\mathrm{O}$ & $\mathrm{S}$ \\
\hline Bare COP & 86.19 & 0.21 & 13.53 & 0.07 \\
\hline COP with PLL-OEG & 78.41 & 5.19 & 16.37 & 0.03 \\
\hline COP with PLL-OEG-biotin & 77.63 & 5.65 & 16.52 & 0.20 \\
\hline
\end{tabular}



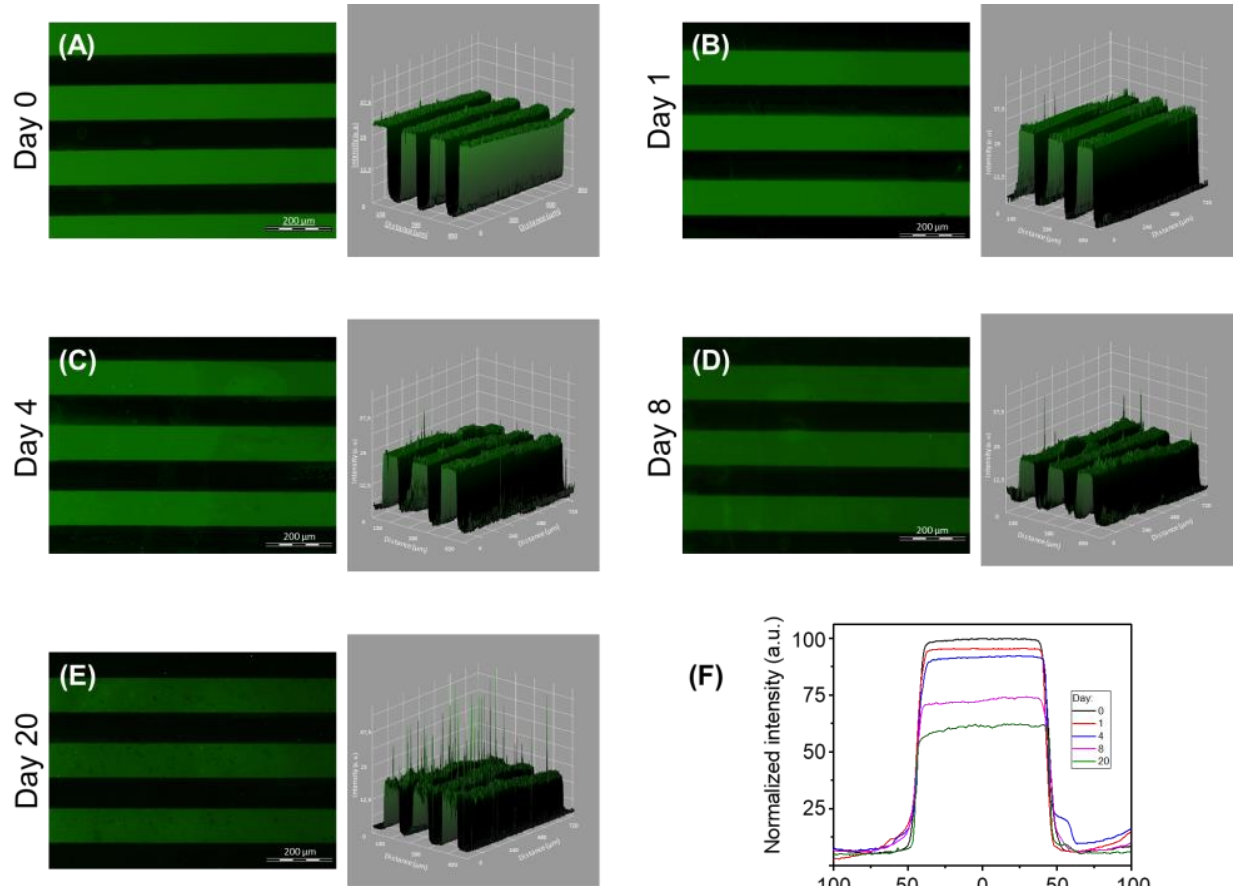

(F)

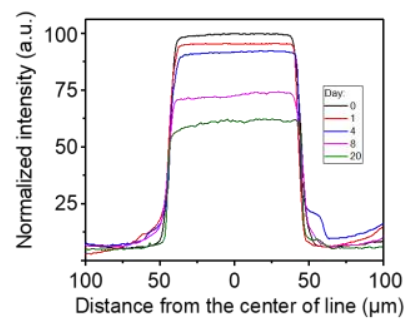

Figure 4.4. Fluorescence microscopy images and corresponding 3D fluorescence intensity profiles of a COP substrate patterned by MIMIC with PLL-OEG-biotin followed by the adsorption of SAv-F (1500 $\mathrm{ms}$, ISO 200) and stored in a solution of PBS (pH 7.4) and BSA (1.0 mg/ml) for (A) 0, (B) 1, (C) 4, (D) 8, E) 20 days. (F) Normalized fluorescence intensity profiles (average) of the COP sample patterned with PLL-OEG-biotin and SAv-F monitored after incubation in PBS solution with $1.0 \mathrm{mg} / \mathrm{ml} \mathrm{BSA}$, at day 0 (black), 1 (red), 4 (blue), 8 (purple) and 20 (green). The experiment was performed using 0.1 $\mathrm{mg} / \mathrm{ml}$ solutions of PLL-OEG-biotin and $0.1 \mathrm{mg} / \mathrm{ml}$ of SAv-F in PBS at $\mathrm{pH} 7.4$.

The surface functionalization with modified PLL requires stability for a considerable period of time in order to be used in biomedical devices. Contact angle measurements showed only slightly increased contact angles for PLL-modified surfaces over 10 days when leaving such functionalized substrates in Milli-Q (Table 4.1), which confirmed long-term coverage of the substrates with PLL. Additionally, the stability of a MIMIC-patterned substrate in solution was tested both over time (Figure 4.4) and upon ultrasonication. Figure 4.4F shows the normalized intensity of fluorescent SAv-F-patterned lines on PLL-biotin-covered COP, monitored during 0, 1, 4, 8 and 20 days in PBS ( $\mathrm{pH} 7.4$ ) with $1.0 \mathrm{mg} / \mathrm{ml}$ bovine serum albumin (BSA) to mimic biological samples. The fluorescence intensity slowly decreased over time with a total loss of $40 \%$ after 20 days (Figure $4.4 \mathrm{~F}$ ). The same effect was observed by 10 min sonication with an intensity loss of around 7\% (not shown). Some pattern inhomogeneities were observed as well, in particular after 20 days (Figure 4.4E). These 
results contrast to some extent the contact angle data described above. Possibly, the loss of fluorescence over time is caused by photobleaching of the dye as well as detachment of SAv (by denaturation), but some partial desorption of PLL cannot be excluded.

\subsubsection{DNA recognition at MIMIC-patterned substrates}

The ability of easily customizing patterned surfaces upon self-assembly of modified PLL is highly appealing for the detection of biomolecules such as proteins and DNA. Therefore, we tested the biosensing properties of two differently modified PLL polymers, PLL-OEG-biotin and PLL-OEG-Mal, to detect cDNA sequences from solution both on COP and Ormostamp biochip surfaces (Figure 4.5). As described above, we used MIMIC with either PLL-OEGbiotin or PLL-OEG-Mal followed by the anchoring of the probes (Figure 4.1A/B). In the case of PLL-OEG-biotin, the consecutive immobilization of SAv-F $(0.1 \mathrm{mg} / \mathrm{ml})$ and biotin-DNA $(1 \mu \mathrm{M})$ formed the biorecognition pattern on the surface of COP. In the case of PLL-OEG$\mathrm{Mal}$, the thiolated probe $\mathrm{PNA}_{2}$ (activated by TCEP treatment just before coupling) ${ }^{43}$ was reacted onto the Ormostamp surface.

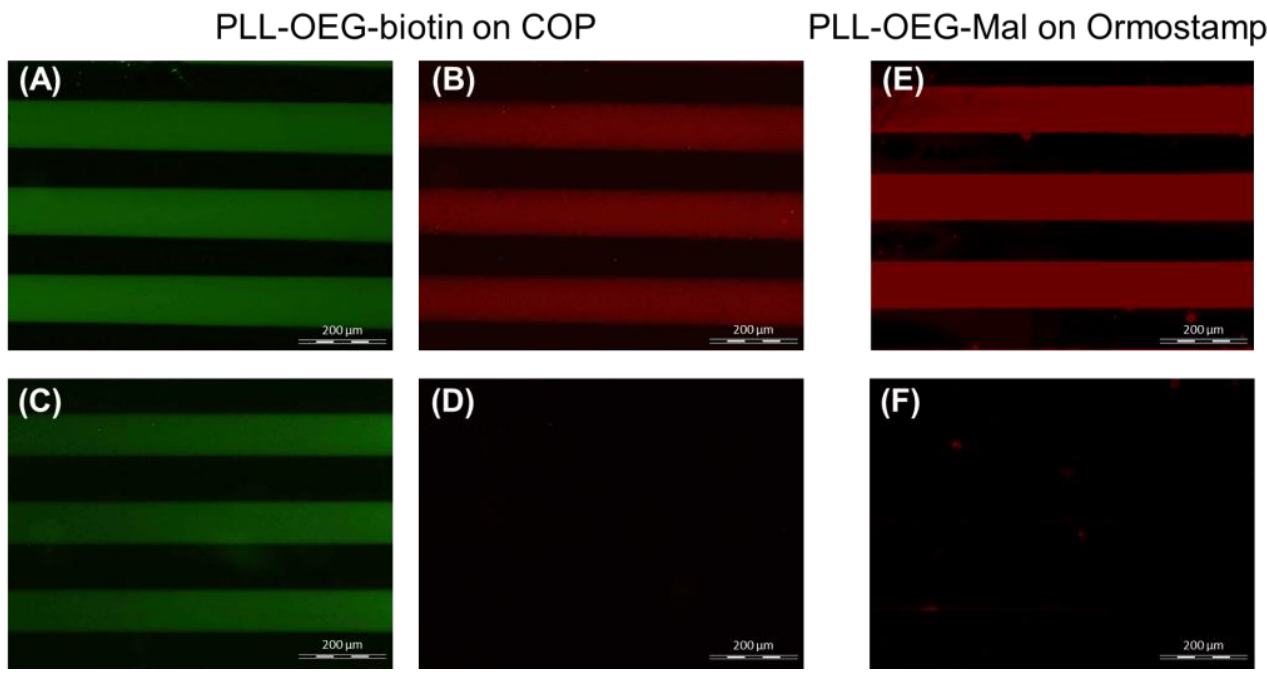

Figure 4.5. Fluorescence microscopy images of COP (A-D) and Ormostamp (E-F) substrates. COP substrates were patterned (using MIMIC) with PLL-OEG-biotin, followed by the consecutive deposition of SAv-F and biotin-DNA 1 . Ormostamp substrates, instead, were functionalized with PLLOEG-Mal and reacted with thiol-PNA 2 . Subsequently, COP substrates were incubated with cDNA1RRED (A,B) or ncDNA 1 -RRED (C,D), while Ormostamp substrates were incubated with cDNA2RRED (E) or ncDNA2-RRED (F). Samples were imaged in the green (A,C, SAv-F) and red (B,D-F, RRED) channels, where the image pairs $A / B$ and $C / D$ were measured at the same area of the same samples. All experiments were performed using $0.1 \mathrm{mg} / \mathrm{ml}$ solutions of modified PLL polymers, 0.1 $\mathrm{mg} / \mathrm{ml}$ of SAv-F, and $1 \mu \mathrm{M}$ of DNA/PNA probes, cDNA and ncDNA in PBS at $\mathrm{pH}$ 7.4. Fluorescence parameters used: (A,C) 1500 ms, ISO 200, (B,D) 2000 ms, ISO 200, (E,F) 2500 ms, ISO 200. 
Upon immobilization of the probes (biotin- $\mathrm{DNA}_{1}$ or $\mathrm{PNA}_{2}$ ) onto the surfaces, solutions of corresponding fluorescent dye-functionalized cDNA-Rhodamine Red (RRED) sequences were put onto the substrates. Figure $4.5 \mathrm{~B}$ and $4.5 \mathrm{E}$ show the fluorescence images of the $\mathrm{COP}$ and Ormostamp substrates after the cDNA-RRED additions. In case of the COP substrates, functionalized with PLL-OEG-biotin and fluorescent SAv, the presence of clear and bright red patterns shows that the hybridization of the cDNA with the DNA probe had occurred successfully. Moreover, the co-localization of the green lines (Figure 4.5A), indicating the presence of SAv, with the red ones (Figure 4.5B), due to the presence of $\mathrm{cDNA}_{1}$-RRED, confirms the selective hybridization of the cDNA to the areas covered with the biotin-DNA probe, indicating the absence of non-specific interactions. When, in a similar experiment, the same type of biorecognition surface was treated with a non-complementary DNA grafted with the RRED dye (ncDNA 1 -RRED), the concomitant presence of green (Figure 4.5C) and the absence of red fluorescence (Figure 4.5D) confirmed the binding selectivity of cDNA. Analogously, the $\mathrm{PNA}_{2}$ molecule grafted to PLL-OEG-Mal polymer on Ormostamp exhibited a similarly selective and specific response as evidenced by the comparison between Figure $4.5 \mathrm{E}$ and $4.5 \mathrm{~F}$, employing the complementary and non-complementary DNA sequences, respectively. These results show not only the similar behavior and applicability for both types of materials surfaces, but also the possibility of using different engineered probes (DNA and PNA) on the polymer surface. Moreover, the use of PLL-OEG-Mal presents the additional advantage of functionalizing substrates with a probe in a single step, avoiding the extra SAv addition used for the functionalization with PLL-OEG-biotin.

To test the stability of the $\mathrm{PNA}_{2} / \mathrm{CDNA}_{2}$-RRED-patterned Ormostamp, the substrate was sonicated for $10 \mathrm{~min}$. Despite a loss of fluorescence intensity of about $10 \%$ after the treatment (not shown), the line width and homogeneity were maintained, indicating the strong, spatioselective adhesion of PLL on Ormostamp and the subsequent formation of the cDNA/PNA complex.

The DNA biorecognition of a probe-modified PLL-OEG-Mal layer on a polymer substrate was also tested in continuous flow by quartz crystal microbalance with dissipation (QCMD). $\mathrm{A} \mathrm{SiO}_{2}$ chip, spin-coated and cured with a thin film of Ormostamp, was activated by oxygen plasma, and then subjected to a solution of either PLL-OEG-Mal or PLL-OEG (as a control), followed by anchoring of the deprotected thiol-PNA 2 . Figure 4.6 shows the QCM$\mathrm{D}$ time traces (frequency shifts, $\Delta f$, in blue) of the binding process for $\mathrm{CDNA}_{2}-\mathrm{RRED}$ and ncDNA 2 -RRED sequences on the PLL-OEG-Mal and antifouling PLL-OEG layers. A detectable frequency shift was only observed for $\mathrm{cDNA}_{2}$ adsorbed on a $\mathrm{PNA}_{2}$-bound PLLOEG-Mal layer, confirming the successful adhesion of PLL, the subsequent probe binding and specific hybridization. 
(A)

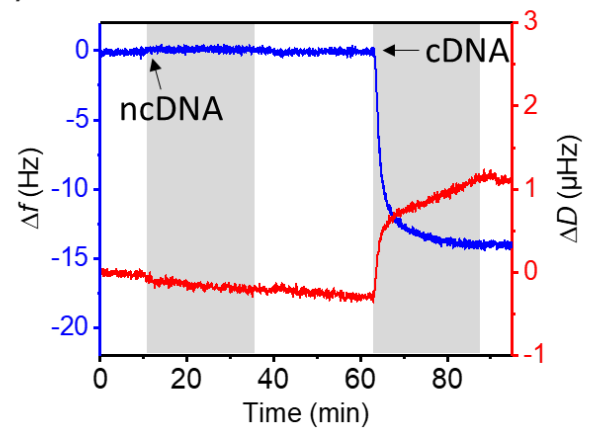

(B)

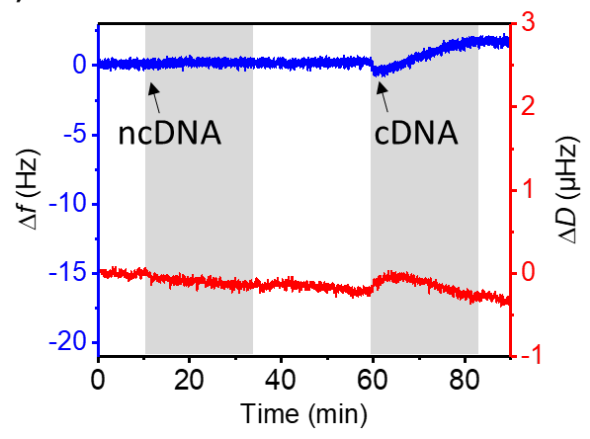

Figure 4.6. QCM time trace for the evaluation of the selectivity of the $\mathrm{PNA}_{2}$-functionalized PLL-OEGMal layer. Thin film Ormostamp spin-coated QCM chips $\left(\mathrm{SiO}_{2}\right)$, activated by oxygen plasma, were functionalized with $0.1 \mathrm{mg} / \mathrm{ml}$ solution of (A) PLL-OEG-Mal and (B) PLL-OEG (control), followed by incubation with $1 \mu \mathrm{M}$ of activated PNA 2 solution (PBS, 7.4). After rinsing with Milli-Q water and blown dry under nitrogen flow, both chips were mounted in the QCM chamber and flushed with $1 \mu \mathrm{M}$ solutions ncDNA 2 -RRED and $\mathrm{cDNA}_{2}$-RRED, consecutively. A PBS washing step at $\mathrm{pH} 7.4$ (white bars) was flushed, between each step. The 5 th overtone was used for both $\Delta \mathrm{f}$ and $\Delta \mathrm{D}$

\subsection{Conclusions}

In summary, we have demonstrated the versatile formation of micro-patterns on two different polymeric materials (COP and Ormostamp) by exploiting modified poly-L-lysine polymers for orthogonal adhesion and selective recognition of biomolecules. As a proof of concept, DNA and PNA probes were anchored onto the polymeric substrates, and the formed biorecognition surfaces showed excellent selectivity for complementary DNA sequences. All in all, these results underline the versatility of modified PLL in combination with patterning techniques for biorecognition and future biosensing applications, on a large variety of substrate materials. The strategy outlined here to attach modified PLL with customized appending groups is promising for the specific and stable anchoring of biomolecules onto virtually any polymeric substrate that presents negative charges. This work may contribute to the development of customized responsive (bio)interfaces in medical devices, environment-friendly biosensors and versatile coatings.

\subsection{Acknowledgments}

Jacopo Movilli in acknowledged for the experiments with the Ormostamp substrates. Andrea Rozzi and Prof. Roberto Corradini are acknowledged for providing the PNA probes and Jussi Hiltunen for providing the Ormostamp substrates. 


\subsection{Experimental section}

\subsubsection{Materials}

Poly-L-lysine hydrobromide ( $\mathrm{MW}=15-30 \mathrm{kDa}$ by viscosity), EDC, NHS and tablets for 10 mM PBS solution ( $\mathrm{pH} 7.4$ ), 3-trichlorosilylpropylmethacrylate, 2-hydroxyethylmethacrylate (HEMA), ethyleneglycoldimethacrylate (EGDMA), bovine serum albumin, ammonium persulfate (APS) and $\mathrm{NaCl}$ salt were purchased from Sigma-Aldrich. Methyl-OEG 4 -NHS ester, biotin- $\mathrm{OEG}_{4}-\mathrm{NHS}$ ester and $\mathrm{Mal}_{-}-\mathrm{OEG}_{4}-\mathrm{NHS}$ ester, the $\mathrm{Zeba}^{\mathrm{TM}}$ spin desalting columns (7 kDa MWCO, $5 \mathrm{~mL}$ ), the immobilized TCEP disulfide reducing gel (tris[2-carboxyethyl] phosphine hydrochloride immobilized onto 4\%-crosslinked beaded agarose) and the streptavidin-Fluorescein conjugate were obtained from ThermoFisher Scientific. Oligonucleotides were purchased from Eurofins Genomics and used as received. $\mathrm{SiO}_{2} \mathrm{QCM}$ chips (with fundamental frequency of $5 \mathrm{MHz}$ ) were purchased from Biolin Scientific. Poly(dimethylsiloxane) Sylgard 184 and curing agent were used as received from Dow Corning. Ormostamp material and MA-T1050 were purchased from Microresist.

(A)

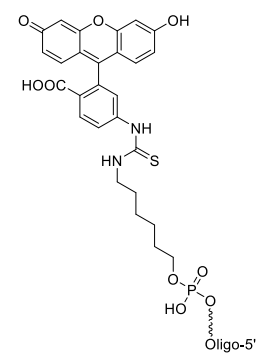

(B)

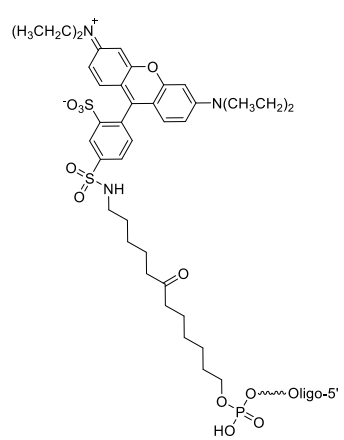

(C)

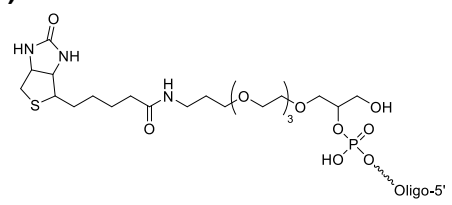

(D)<smiles>CC(C)(CCOCC(C)(C)C(=O)Nc1ccccc1)NC(=O)CCSSc1ccccn1</smiles>

Figure 4.7. Structure of the (A) Fluorescein, (B) Rhodamine Red (RRED) dyes linked to the ncDNA and cDNA molecules, and (C) biotin tetra(ethylene glycol) linker and (D) protected thiol 3-(2pyridyldithio)propionyl (SPDP)-tetra(ethylene glycol) linker at the PNA molecules (see Table 4.3 below). 
Table 4.3. Sequences of functionalized DNA and PNA molecules used.

\begin{tabular}{|c|c|c|}
\hline Oligo & Sequence $5^{\prime} \rightarrow 3^{\prime}$ (number of nucleotides) & Role \\
\hline biotin-DNA 1 & $\begin{array}{l}\text { BITEG-ATG CGC AGC GCG TTG GCA } \\
\text { CGC (21) }\end{array}$ & DNA Probe \\
\hline PNA2 & $\begin{array}{l}\text { SPDP-dPEG } 4 \text {-CTA CGC CAC CAG CT- } \\
\text { Gly-NH } 2(14) ; \varepsilon(260 \mathrm{~nm}): 127900 \mathrm{M}^{-1} \mathrm{~cm}^{-1}\end{array}$ & $\begin{array}{l}\text { PNA probe } \\
\text { WT KRAS }\end{array}$ \\
\hline $\begin{array}{l}\text { cDNA1- } \\
\text { RRED }\end{array}$ & $\begin{array}{c}\text { RRED-GCG TGC CAA CGC GCT GCG } \\
\text { CAT }(21)\end{array}$ & $\begin{array}{l}\text { Complementary to } \\
\text { biotin-DNA } 1 \text { (MIMIC) }\end{array}$ \\
\hline $\begin{array}{l}\text { ncDNA1- } \\
\text { RRED }\end{array}$ & $\begin{array}{l}\text { RRED-ATG CGC AGC GCG TTG GCA } \\
\text { CGC (21) }\end{array}$ & $\begin{array}{l}\text { Non-complementary to } \\
\text { biotin-DNA } 1 \text { (MIMIC) }\end{array}$ \\
\hline $\begin{array}{l}\text { cDNA2- } \\
\text { RRED }\end{array}$ & RRED-AGC TGG TGG CGT AG (14) & $\begin{array}{l}\text { Complementary to } \\
\text { PNA }_{2}(\text { MIMIC + QCM) }\end{array}$ \\
\hline $\begin{array}{l}\text { ncDNA2- } \\
\text { RRED }\end{array}$ & RRED-CTA CGC CAC CAG CT (14) & $\begin{array}{l}\text { Non-complementary to } \\
\text { PNA }_{2} \text { (MIMIC + QCM) }\end{array}$ \\
\hline
\end{tabular}

\subsubsection{Methods}

\section{Synthesis of modified PLLs}

All modified PLLs were synthesized according to previously reported procedures. ${ }^{42,43}$ ${ }^{1} \mathrm{H}$ NMR (400 MHz D $2 \mathrm{O}$ ) PLL-OEG(26.1)-biotin(5.7) $\delta[\mathrm{ppm}]=1.26-1.58$ ((lysine $\left.\gamma-\mathrm{CH}_{2}\right)$, 1.63-1.85 (lysine $\beta, \delta-\mathrm{CH}_{2}$ ), 2.25 (biotin linker, $-\mathrm{CH}_{2}-\mathrm{C}(=\mathrm{O})-\mathrm{NH}-$ ), 2.49 (ethylene glycol $\mathrm{CH}_{2}$ from both $\mathrm{OEG}$ and biotin coupled, $-\mathrm{CH}_{2}-\mathrm{C}(=\mathrm{O})-\mathrm{NH}$ ), 2.75 (biotin, $-\mathrm{S}_{-}-\mathrm{CH}_{2}-$ ), 2.98 (free lysine $\mathbf{c}, \mathrm{H}_{2} \mathrm{~N}_{-} \mathrm{CH}_{2}$ ) ), 3.15 (ethylene glycol $\mathrm{CH}_{2}$ of coupled lysine from both $\mathrm{OEG}$ and biotin b, $\mathrm{C}\left(=\mathrm{O}\right.$ )-NH- $\mathrm{CH}_{2}-$ ), 3.35 (OEG methoxy, -O- $\mathrm{CH}_{3}$ ), 3.53-3.78 (oligo ethylene glycol from both OEG and biotin, $\mathrm{CH}_{2}-\mathrm{O}-$ ), 4.26 (lysine backbone a, NH-CH-C(O)-), 4.40 (biotin $\mathbf{d}_{1}$, $\mathrm{CH}-\mathrm{NH}-\mathrm{C}(=\mathrm{O})-\mathrm{NH}-$ ), 4.59 (biotin $\mathbf{d}_{2},-\mathrm{CH}-\mathrm{NH}-\mathrm{C}(=\mathrm{O})-\mathrm{NH}-$ ).

Adapting a previously reported procedure, ${ }^{5,6}$ the quantification of grafted percentages of compounds OEG and biotin were achieved by using the integral ratios of characteristic peaks at the ${ }^{1} \mathrm{H}-\mathrm{NMR}$. All the integrals were normalized using the peak at $4.29 \mathrm{ppm}$ (lysine backbone a, NH-CH-C(O)-). The specific integrals are at $3.00 \mathrm{ppm}$ (free lysine c, $\mathrm{H} 2 \mathrm{~N}-\mathrm{CH} 2$ ), 
$3.15 \mathrm{ppm}\left(\mathrm{CH}_{2}\right.$ of coupled lysine of both biotin and $\mathrm{OEG}$ side groups $\mathbf{b}$, for both $\mathrm{OEG}$ and biotin), and the sum of both integrals at 4.40 and $4.59 \mathrm{ppm}$ (biotin $\mathbf{d}_{1}$ and $\mathbf{d}_{2},-\mathrm{CH}-\mathrm{NH}-\mathrm{C}(=\mathrm{O})$ $\mathrm{NH}-$ ).

All integrals of interest $\left(\mathbf{b}, \mathbf{c}\right.$, and $\left.\mathbf{d}_{\mathbf{1}}+\mathbf{d}_{2}\right)$ correspond to two protons and they can be used with no further modification. Moreover, the sum of $\mathbf{b}$ and $\mathbf{c}$ equals the $100 \%$ of Lys (both functionalized and free) at the PLL backbone. Therefore eq. 1 and 2 were used to calculate the molfraction of OEG $(\mathrm{x} \%)$ and biotin ( $\mathrm{y} \%)$ for the PLL-OEG-biotin employed:

$$
\begin{array}{ll}
\text { biotin } \%=\left[\left(\boldsymbol{d}_{\mathbf{1}}+\boldsymbol{d}_{\mathbf{2}}\right) /(\boldsymbol{b}+\boldsymbol{c})\right] * 100 & \text { Eq.1 } \\
\text { OEG\% }=[\boldsymbol{b} /(\boldsymbol{b}+\boldsymbol{c})] * 100-\text { biotin } \% & \text { Eq. } 2
\end{array}
$$

${ }^{1} \mathrm{H}$ NMR (400 MHz D $2 \mathrm{O}$ ) PLL-OEG(20.3)-Mal(4.5) $\delta$ [ppm] = 1.26-1.56 (lysine $\gamma-\mathrm{CH}_{2}$ ), 1.61-1.82 (lysine $\beta, \delta-\mathrm{CH}_{2}$ ), 2.49 (ethylene glycol $\mathrm{CH}_{2}$ from both OEG and Mal coupled, $\mathrm{CH}_{2}-\mathrm{C}\left(=\mathrm{O}\right.$ )-NH), 2.99 (free lysine, $\mathrm{H}_{2} \mathrm{~N}-\mathrm{CH}_{2}$ ), 3.16 (ethylene glycol $\mathrm{CH}_{2}$ of coupled lysine from both $\mathrm{OEG}$ and $\left.\mathrm{Mal}, \mathrm{C}(=\mathrm{O})-\mathrm{NH}-\mathrm{CH}_{2}-\right), 3.35\left(\mathrm{OEG}\right.$ methoxy, $\left.-\mathrm{O}-\mathrm{CH}_{3}\right), 3.58-3.79$ (oligo ethylene glycol from both OEG and Mal, $\mathrm{CH}_{2}-\mathrm{O}-$ ), 4.29 (lysine backbone, NH-CH-C(O)-), 6.85 (maleimide from coupled Mal, $-\mathrm{C}(=\mathrm{O})-\mathrm{CH}-\mathrm{CH}-\mathrm{C}(=\mathrm{O})-)$.

The amount of grafted OEG and Mal to both PLL-OEG and PLL-OEG-Mal polymer was quantified by ${ }^{1} \mathrm{H}-\mathrm{NMR}$ according to our previously reported procedure. ${ }^{5}$

Table 4.4. Functionalization of PLL used in this work.

\begin{tabular}{|c|c|c|}
\hline Type of modified PLL & OEG\% & biotin/Mal\% \\
\hline PLL-OEG & 24.9 & $/$ \\
\hline PLL-OEG-biotin & 26.1 & 5.7 \\
\hline PLL-OEG-Mal & 20.3 & 4.5 \\
\hline
\end{tabular}

\section{Preparation of PDMS substrates}

PDMS substrates (for use of the stamping device) and molds for MIMIC were prepared as reported previously. ${ }^{50,51,45}$ In short, a 10:1 (v/v) mixture of poly(dimethylsiloxane) and curing agent Sylgard 184 was casted against either a flat petri dish or a silicon master with etched structures $(100 \times 100 \mu \mathrm{m})$ prepared by lithography. After overnight curing at $60^{\circ} \mathrm{C}$, the 
PDMS in the petridish was stored as is, while the PDMS on the silicon master was cut in small MIMIC molds, and their edges were opened with a scalpel before storing.

\section{MIMIC on COP/Ormostamp}

MIMIC was performed following previously reported procedures. ${ }^{50,45}$ Both PDMS mold and either COP or Ormostamp substrates (approx. $1.5 \times 1 \mathrm{~cm}$ ) were cleaned by sonication in a mixture of Milli-Q water and EtOH (1:1), dried by a stream of nitrogen and activated by oxygen plasma for $1 \mathrm{~min}$ (Plasma Prep II, SPI Supplies; 200-230 mTorr, $40 \mathrm{~mA}$ ). Thereafter, the mold was placed on top of the activated polymeric material to form the network of channels, owing to the conformal contact. A drop (10-20 $\mu \mathrm{l})$ of desired modified PLL solution $(0.1 \mathrm{mg} / \mathrm{ml}$ in PBS, $\mathrm{pH}$ 7.4) was placed at the open edge of the PDMS mold and the liquid filled the channels as a result of capillary forces. The mold was peeled off, and the patterned PLL lines were rinsed copiously with Milli-Q water.

\section{Functionalization of substrates patterned by MIMIC}

PLL-OEG-biotin patterned substrates were functionalized by consecutively depositing $80 \mu \mathrm{l}$ of $0.1 \mathrm{mg} / \mathrm{ml} \mathrm{SAv}-\mathrm{F}$ solution in PBS (pH 7.4) for $5 \mathrm{~min}$, and $1 \mu \mathrm{M}$ of biotin-DNA in the same buffer for $10 \mathrm{~min}$. The substrates patterned with PLL-OEG-Mal were covered for $10 \mathrm{~min}$ with $80 \mu \mathrm{l}$ solution of PNA-thiol probe $(1 \mu \mathrm{M}$ in PBS, $\mathrm{pH} 7.4)$, freshly deprotected from the disulfide group (SPDP = 3- (2-pyridyldithio)propionyl) using the TCEP reducing gel following the procedure described in our previous work. ${ }^{43}$ Hybridization experiments were performed by placing on top of both patterned recognition surfaces (COP and Ormostmap) 80-100 $\mu$ l of corresponding ncDNA-RRED or cDNA-RRED solutions ( $1 \mu \mathrm{M}$ in PBS, pH 7.4) for $10 \mathrm{~min}$. After every deposition step, substrates were rinsed with Milli-Q water and blown dry in a stream of nitrogen.

\section{Fully covered COP/Ormostamp substrates for contact angle and XPS measurements}

COP and Ormostamp substrates $(1.5 \times 1.0 \mathrm{~cm})$ were activated as previously described, immersed in a solution of PLL-OEG $(0.1 \mathrm{mg} / \mathrm{ml}$ in PBS, $\mathrm{pH} 7.4)$ for $30 \mathrm{~min}$ and then rinsed with Milli-Q water. Control samples were immersed in PBS (pH 7.4) solution, without PLL. Contact angle measurements were recorded before and after the activation, and after the functionalization. Control experiments where done dipping the activated substrates in just PBS solution. Thereafter, the substrates were stored in Milli-Q water, and the contact angle was monitored for 10 days. COP substrates for XPS were prepared following the same procedure, and fully dipped in the solutions of pure PBS, without or with PLL-OEG or PLLOEG-biotin (0.1 mg/ml, $\mathrm{pH} 7.4)$. 


\section{Spin-coating of Ormostamp on $\mathrm{SiO}_{2}$ QCM and PET substrates}

For all regular Ormostamp substrates described above, using an adapted procedure previously reported, ${ }^{52}$ a drop of Ormostamp solution was manually dispensed on a PET substrate. By using a laboratory customized imprinting set-up, a flat glass wafer previously coated with anti-adhesion coating tridecafluoro-(1,1,2,2)-tetrahydrooctyl-trichlorosilane was pressed against uncured Ormostamp. UV-light from OmniCure LX400 with $365 \mathrm{~nm}$ LED source was exposed through the glass wafer acting as an imprint tool. After being released from the mold, a flat layer of approximately $30 \mu \mathrm{m}$ of cured Ormostamp was formed on the PET substrate.

Prior to coating, the QCM chips were treated by oxygen plasma (Pico, Diener Electronic $\mathrm{GmbH})$ for $30 \mathrm{~s}$. The Ormostamp material was diluted in Ma-T1050 (1:10,v/v) and spincoated at $3000 \mathrm{rpm}$ for $60 \mathrm{~s}$. After the spinning, the Ma-T1050 thinner was evaporated out at $130^{\circ} \mathrm{C}$ for $10 \mathrm{~min}$ on a hot plate. To UV-cure the Ormostamp layer, QCM chips were placed in a vacuum chamber (Pico, Diener Electronic $\mathrm{GmbH}$ ) and UV-light from OmniCure ${ }^{\circledR}$ LX400 with $365 \mathrm{~nm}$ LED source was exposed through a window, forming a $200 \mathrm{~nm}$ Ormostamp thin layer.

\section{Quartz crystal microbalance with dissipation monitoring (QCM-D)}

Silica-coated (50 nm, QSX303) QCM-D sensors from LOT-Quantum were spin-coated with Ormostamp, and then washed with Milli-Q water and EtOH, sonicated in EtOH for 5 min, dried in a stream of nitrogen and finally oxidized in oxygen plasma (Plasma Prep II, SPI Supplies; 200-230 mTorr, $40 \mathrm{~mA}$ ) for $1 \mathrm{~min}$. Activated chips were fully immersed in a solution of either PLL-OEG or PLL-OEG-Mal $(0.1 \mathrm{mg} / \mathrm{ml}$ in PBS, $\mathrm{pH} 7.4)$ for $30 \mathrm{~min}$, followed by incubation in $1 \mu \mathrm{M}$ of activated $\mathrm{PNA}_{2}$ thiol solution (PBS, $\mathrm{pH} 7.4$ ) for $30 \mathrm{~min}$. After each modification step, the Ormostamp-coated chips were gently rinsed with Milli-Q water and dried in a stream of nitrogen. QCM-D measurements were performed using a QSense E4 4-channel quartz crystal microbalance with a peristaltic pump (Biolin Scientific), monitoring the $5^{\text {th }}$ fundamental overtone. All experiments were performed in PBS buffer $(\mathrm{pH}$ 7.4) with a flow rate of $80 \mu \mathrm{l} / \mathrm{min}$ at $22^{\circ} \mathrm{C}$.

\section{X-ray photoelectron spectroscopy (XPS).}

XPS measurements were performed using a Quantera SXM machine (scanning XPS microprobe) from Physical Electronics equipped with a monochromatic $\mathrm{Al} \mathrm{K} \alpha \mathrm{X}$-ray source $(1486.6 \mathrm{eV})$. During the analyses, the filament current was kept at $2.6 \mathrm{~mA}$ and the power at 50 Watt. The working chamber pressure was maintained at $310^{-8}$ torr. The size of the X-ray beam used in the analysis was $200 \mu \mathrm{m}$. 


\section{Fluorescence microscopy}

Fluorescence microscopy images were taken in air using an Olympus inverted research microscope IX71 equipped with a mercury burner U-RFL-T as light source and a digital Olympus DP70 camera. A combination of Dapi and Olympus cubes were used to have blue $\left(\lambda_{\mathrm{ex}}=430 \mathrm{~nm} ; \lambda_{\mathrm{em}}=470 \mathrm{~nm}\right)$, green $\left(460 \mathrm{~nm} \leq \lambda_{\mathrm{ex}} \leq 490 \mathrm{~nm} ; \lambda_{\mathrm{em}}=525 \mathrm{~nm}\right)$ and red $(510$ $\mathrm{nm} \leq \lambda_{\mathrm{ex}} \leq 550 \mathrm{~nm} ; \lambda_{\mathrm{em}} \geq 590 \mathrm{~nm}$ ) filter. The linear (average) and 3D intensity profiles were obtained by a rectangular selection over the whole picture, elaborated with Image $\mathrm{J}$ software.

\subsection{References}

1. Kim, J.; Hong, D.; Jeong, S.; Kong, B.; Kang, S. M.; Kim, Y. G.; Choi, I. S. Aryl Azide Based, Photochemical Patterning of Cyclic Olefin Copolymer Surfaces with Non-Biofouling Poly[(3(Methacryloylamino)Propyl)Dimethyl(3- Sulfopropyl)Ammonium Hydroxide]. Chem. - An Asian J. 2011, 6, 363-366.

2. Hochrein, M. B.; Reicht, C.; Krause, B.; Rädler, J. O.; Nickel, B. Structure and Mobility of Lipid Membranes on a Thermoplastic Substrate. Langmuir 2006, 22, 538-545.

3. Li, Y.; Wang, Z.; Ou, L. M. L.; Yu, H. Z. DNA Detection on Plastic: Surface Activation Protocol to Convert Polycarbonate Substrates to Biochip Platforms. Anal. Chem. 2007, 79, 426-433.

4. Becker, H.; Gärtner, C. Polymer Microfabrication Technologies for Microfluidic Systems. Anal. Bioanal. Chem. 2008, 390, 89-111.

5. Raj, J.; Herzog, G.; Manning, M.; Volcke, C.; MacCraith, B. D.; Ballantyne, S.; Thompson, M.; Arrigan, D. W. M. Surface Immobilisation of Antibody on Cyclic Olefin Copolymer for Sandwich Immunoassay. Biosens. Bioelectron. 2009, 24, 2654-2658.

6. Fu, Y.; Zhou, H.; Jia, C.; Jing, F.; Jin, Q.; Zhao, J.; Li, G. A Microfluidic Chip Based on Surfactant-Doped Polydimethylsiloxane (PDMS) in a Sandwich Configuration for Low-Cost and Robust Digital PCR. Sensors Actuators, B Chem. 2017, 245, 414-422.

7. Peng, R.; Li, D. Detection and Sizing of Nanoparticles and DNA on PDMS Nanofluidic Chips Based on Differential Resistive Pulse Sensing. Nanoscale 2017, 9, 5964-5974.

8. Ma, K.-S.; Reza, F.; Saaem, I.; Tian, J. Versatile Surface Functionalization of Cyclic Olefin Copolymer (COC) with Sputtered SiO2 Thin Film for Potential BioMEMS Applications. $J$. Mater. Chem. 2009, 19, 7914-7920.

9. Laib, S.; MacCraith, B. D. Immobilization of Biomolecules on Cycloolefin Polymer Supports. Anal. Chem. 2007, 79, 6264-6270.

10. Klukowska, A.; Kolander, A.; Bergmair, I.; Muhlberger, M.; Leichtfried, H.; Reuther, F.; Grutzner, G.; Schuftner, R. Novel Transparent Hybrid Polymer Working Stamp for UVImprinting. Microelectron. Eng. 2009, 86, 697-699.

11. Hiltunen, M.; Hiltunen, J.; Stenberg, P.; Aikio, S.; Kurki, L.; Vahimaa, P.; Karioja, P. Polymeric Slot Waveguide Interferometer for Sensor Applications. Opt. Express 2014, 22, 7229-7237.

12. Bain, C. D.; Troughton, E. B.; Tao, Y. T.; Evall, J.; Whitesides, G. M.; Nuzzo, R. G. Formation of Monolayer Films by the Spontaneous Assembly of Organic Thiols from Solution onto Gold. J. Am. Chem. Soc. 1989, 111, 321-335.

13. Bain, C. D.; Evall, J.; Whitesides, G. M. Formation of Monolayers by the Coadsorption of Thiols on Gold: Variation in the Head Group, Tail Group, and Solvent. J. Am. Chem. Soc. 
1989, $111,7155-7164$.

14. Luderer, F.; Walschus, U. Immobilization of Oligonucleotides for Biochemical Sensing by Self-Assembled Monolayers: Thiol-Organic Bonding on Gold and Silanization on Silica Surfaces. Top. Curr. Chem. 2005, 260 (September), 37-56.

15. Briand, E.; Humblot, V.; Landoulsi, J.; Petronis, S.; Pradier, C. M.; Kasemo, B.; Svedhem, S. Chemical Modifications of Au/SiO 2 Template Substrates for Patterned Biofunctional Surfaces. Langmuir 2011, 27, 678-685.

16. Yang, W. T.; Ranby, B. Bulk Surface Photografting Process and Its Applications .1. Reactions and Kinetics. J. Appl. Polym. Sci. 1996, 62, 533-543.

17. Rohr, T.; Ogletree, D. F.; Svec, F.; Fréchet, J. M. J. Surface Functionalization of Thermoplastic Polymers for the Fabrication of Microfluidic Devices by Photoinitiated Grafting. Adv. Funct. Mater. 2003, 13, 264-270.

18. Gandhiraman, R. P.; Gubala, V.; O’Mahony, C. C.; Cummins, T.; Raj, J.; Eltayeb, A.; Doyle, C.; James, B.; Daniels, S.; Williams, D. E. PECVD Coatings for Functionalization of Pointof-Care Biosensor Surfaces. Vacuum 2012, 86, 547-555.

19. Brink, C.; Österberg, E.; Holmberg, K.; Tiberg, F. Using Poly(Ethylene Imine) to Graft Poly(Ethylene Glycol) or Polysaccharide to Polystyrene. Colloids and Surfaces 1992, 66, 149156.

20. Konradi, R.; Pidhatika, B.; Mühlebach, A.; Textor, M. Poly-2-Methyl-2-Oxazoline: A Peptidelike Polymer for Protein-Repellent Surfaces. Langmuir 2008, 24, 613-616.

21. Lee, J. H.; Kopecek, J.; Andradet, J. D. Protein-Resistant Surfaces Prepared by PEOContaining Block Copolymer Surfactant. 1989, 23, 351-368.

22. Feller, L. M.; Cerritelli, S.; Textor, M.; Hubbell, J. A.; Tosatti, S. G. P. Influence of Poly(Propylene Sulfide-Block-Ethylene Glycol) Di- And Triblock Copolymer Architecture on the Formation of Molecular Adlayers on Gold Surfaces and Their Effect on Protein Resistance: A Candidate for Surface Modification in Biosensor Research. Macromolecules 2005, 38, 10503-10510.

23. Pidhatika, B.; Möller, J.; Vogel, V.; Konradi, R. Nonfouling Surface Coatings Based on Poly(2-Methyl-2-Oxazoline). Chim. Int. J. Chem. 2008, 62, 264-269.

24. Ruiz-Taylor, L. a.; Martin, T. L.; Zaugg, F. G.; Witte, K.; Indermuhle, P.; Nock, S.; Wagner, P. Monolayers of Derivatized Poly(L-Lysine)-Grafted Poly(Ethylene Glycol) on Metal Oxides as a Class of Biomolecular Interfaces. Proc. Natl. Acad. Sci. 2001, 98, 852-857.

25. Kenausis, G. L.; Vörös, J.; Elbert, D. L.; Huang, N.; Hofer, R.; Ruiz-Taylor, L.; Textor, M.; Hubbell, J. A.; Spencer, N. D. Poly(L-Lysine)-g-Poly(Ethylene Glycol) Layers on Metal Oxide Surfaces: Attachment Mechanism and Effects of Polymer Architecture on Resistance to Protein Adsorption †. J. Phys. Chem. B 2000, 104, 3298-3309.

26. Pasche, S.; De Paul, S. M.; Vörös, J.; Spencer, N. D.; Textor, M. Poly(l-Lysine)-GraftPoly(Ethylene Glycol) Assembled Monolayers on Niobium Oxide Surfaces: A Quantitative Study of the Influence of Polymer Interfacial Architecture on Resistance to Protein Adsorption by ToF-SIMS and in Situ OWLS. Langmuir 2003, 19, 9216-9225.

27. Lee, S.; Vörös, J. An Aqueous-Based Surface Modification of Poly(Dimethylsiloxane) with Poly(Ethylene Glycol) to Prevent Biofouling. Langmuir 2005, 21, 11957-11962.

28. Marie, R.; Beech, J. P.; Vörös, J.; Tegenfeldt, J. O.; Höök, F. Use of PLL-g-PEG in MicroFluidic Devices for Localizing Selective and Specific Protein Binding. Langmuir 2006, 22, 10103-10108.

29. Sun, K.; Xie, Y.; Ye, D.; Zhao, Y.; Cui, Y.; Long, F.; Zhang, W.; Jiang, X. Mussel-Inspired Anchoring for Patterning Cells Using Polydopamine. Langmuir 2012, 28, 2131-2136.

30. Elbert, D. L.; Hubbell, J. A. Reduction of Fibrous Adhesion Formation by a Copolymer 
Possessing an Affinity for Anionic Surfaces. J. Biomed. Mater. Res. 1998, 42, 55-65.

31. Jost W. Lussia, b, Didier Falconnetc, Jeffrey A. Hubbella, Marcus Textorc, G. C. Pattern Stability under Cell Culture Conditions-A Comparative Study of Patterning Methods Based on PLL-g-PEG Background Passivation. Biomaterials 2005, 27, 2534-2541.

32. Huang, N.; Vörös, J.; De Paul, S. M.; Textor, M.; Spencer, N. D. Biotin-Derivatized Poly( 1 Lysine)-g-Poly(Ethylene Glycol): A Novel Polymeric Interface for Bioaffinity Sensing. Langmuir 2002, 18, 220-230.

33. Zhen, G.; Falconnet, D.; Kuennemann, E.; Vörös, J.; Spencer, N. D.; Textor, M.; Zürcher, S. Nitrilotriacetic Acid Functionalized Graft Copolymers: A Polymeric Interface for Selective and Reversible Binding of Histidine-Tagged Proteins. Adv. Funct. Mater. 2006, 16, 243-251.

34. Guoliang Zhen; Zurcher, S.; Falconnet, D.; Fei Xu; Kuennemann, E.; Textor, M. NTAFunctionalized Poly(L-Lysine)-g-Poly(Ethylene Glycol): A Polymeric Interface for Binding and Studying 6 His-Tagged Proteins. 2005 IEEE Eng. Med. Biol. 27th Annu. Conf. 2005, 10361038.

35. Saxer, S.; Portmann, C.; Tosatti, S.; Gademann, K.; Zürcher, S.; Textor, M. Surface Assembly of Catechol-Functionalized Poly(L-Lysine)- Graftpoly(Ethylene Glycol) Copolymer on Titanium Exploiting Combined Electrostatically Driven Self-Organization and Biomimetic Strong Adhesion. Macromolecules 2010, 43, 1050-1060.

36. VandeVondele, S.; Vörös, J.; Hubbell, J. A. RGD-Grafted Poly-l-Lysine-Graft-(Polyethylene Glycol) Copolymers Block Non-Specific Protein Adsorption While Promoting Cell Adhesion. Biotechnol. Bioeng. 2003, 82, 784-790.

37. Csucs, G.; Michel, R.; Lussi, J. W.; Textor, M.; Danuser, G. Microcontact Printing of Novel Co-Polymers in Combination with Proteins for Cell-Biological Applications. Biomaterials 2003, 24, 1713-1720.

38. Saravia, V.; Küpcü, S.; Nolte, M.; Huber, C.; Pum, D.; Fery, A.; Sleytr, U. B.; Toca-Herrera, J. L. Bacterial Protein Patterning by Micro-Contact Printing of PLL-g-PEG. J. Biotechnol. 2007, 130, 247-252.

39. Falconnet, D.; Koenig, A.; Assi, F.; Textor, M. A Combined Photolithographic and MolecularAssembly Approach to Produce Functional Micropatterns for Applications in the Biosciences. Adv. Funct. Mater. 2004, 14, 749-756.

40. Michel, R.; Lussi, J. W.; Csucs, G.; Reviakine, I.; Ketterer, B.; Danuser, G.; Hubbell, J. A.; Textor, M.; Spencer, N. D. Selective Molecular Assembly Patterning: A New Approach to Micro- and Nanochemical Patterning of Surfaces for Biological Applications. Langmuir 2002, 18, 3281-3287.

41. Tang, C. S.; Petronis, S.; Schmutz, P.; Vörös, J.; Textor, M.; Keller, B. Locally Addressable Electrochemical Patterning Technique (LAEPT) Applied to Poly(L-Lysine)-GraftPoly(Ethylene Glycol) Adlayers on Titanium and Silicon Oxide Surfaces. Biotechnol. Bioeng. 2005, 91, 285-295.

42. Duan, X.; Mu, L.; Sawtelle, S. D.; Rajan, N. K.; Han, Z.; Wang, Y.; Qu, H.; Reed, M. a. Functionalized Polyelectrolytes Assembling on Nano-BioFETs for Biosensing Applications. Adv. Funct. Mater. 2015, 25, 2279-2286.

43. Movilli, J.; Rozzi, A.; Ricciardi, R.; Corradini, R.; Huskens, J. Control of Probe Density at DNA Biosensor Surfaces Using Poly-L-Lysine with Appended Reactive Groups. Bioconjug. Chem. 2018, 29, 4110-4118.

44. Han, Z.; Wang, Y.; Duan, X. Biofunctional Polyelectrolytes Assembling on Biosensors - A Versatile Surface Coating Method for Protein Detections. Anal. Chim. Acta 2017, 964, 170177.

45. Moonen, P. F.; Bat, E.; Voorthuijzen, W. P.; Huskens, J. Soft-Lithographic Patterning of Room 
Temperature-Sintering Ag Nanoparticles on Foil. RSC Adv. 2013, 3, 18498-18505.

46. Egholm, M.; Buchardt, O.; Christensen, L.; Behrens, C.; Freier, S. M.; Driver, D. A.; Berg, R. H.; Kim, S. K.; Norden, B.; Nielsen, P. E. Pna Hybridizes To Complementary Oligonucleotides Obeying the Watson-Crick Hydrogen-Bonding Rules. Nature 1993, 365, 566-568.

47. Chakrabarti, M.; Frederick P. Schwarz. Thermal Stability of PNA/DNA and DNA/DNA Duplexes by Differential Scanning Calorimetry. Nucleic Acids Res. 1999, 27, 4801-4806.

48. Demidov, V. V.; Potaman, V. N.; Frank-Kamenetskil, M. D.; Egholm, M.; Buchard, O.; Sönnichsen, S. H.; Nlelsen, P. E. Stability of Peptide Nucleic Acids in Human Serum and Cellular Extracts. Biochem. Pharmacol. 1994, 48, 1310-1313.

49. Choksakulnimitr, S.; Masuda, S.; Tokuda, H.; Takakura, Y.; Hashida, M. In Vitro Cytotoxicity of Macromolecules in Different Cell Culture Systems. J. Control. Release 1995, 34, 233-241.

50. Calabretta, A.; Wasserberg, D.; Posthuma-Trumpie, G. a; Subramaniam, V.; van Amerongen, A.; Corradini, R.; Tedeschi, T.; Sforza, S.; Reinhoudt, D. N.; Marchelli, R.; et al. Patterning of Peptide Nucleic Acids Using Reactive Microcontact Printing. Langmuir 2011, 27, 15361542.

51. Kim, E.; Xia, Y.; Whitesides, G. M. Micromolding in Capillaries: Applications in Materials Science. J. Am. Chem. Soc. 1996, 118, 5722-5731.

52. Wang, M.; Hiltunen, J.; Uusitalo, S.; Puustinen, J.; Lappalainen, J.; Karioja, P.; Myllylä, R. Fabrication of Optical Inverted-Rib Waveguides Using UV-Imprinting. Microelectron. Eng. 2011, 88, 175-178. 


\section{Chapter 5}

\section{Weak Multivalent Binding of Influenza Hemagglutinin Nanoparticles at a Sialoglycan- Functionalized Supported Lipid Bilayer*}

Quantification of the multivalent interactions of influenza viruses binding at interfaces may provide ways to tackle key biological questions regarding influenza virulence and zoonoses. Yet, the deconvolution of the contributions of molecular and interfacial parameters, such as valency, interaction area and receptor density, to the binding of whole viruses is hindered by difficulties in the direct determination of these parameters. We report here a chemical platform technology to study the binding of multivalent recombinant hemagglutinin ( $\mathrm{rHA}$ ) nanoparticles at artificial sialoglycan cell receptor-presenting interfaces in which all these parameters can be derived, thus allowing the desired full and quantitative binding analysis. $\mathrm{SiO} 2$ substrates were functionalized with supported lipid bilayers containing a targeted and tunable fraction of a biotinylated lipid, followed by the adsorption of streptavidin and biotinylated polyvalent 2,3- or 2,6-sialyl lactosamine (SLN). rHA nanoparticles were used as a virus mimic to provide a good prediction of the number of interactions involved in binding. Low nanomolar affinities and selectivities for binding at the 2,6-SLN platforms were observed for rHA particles from three different virus variants. When fitting the data to a multivalency model, the nanomolar overall affinity appears to be achieved by 6-9 HA-sugar molecular interaction pairs, which individually present a rapid association/dissociation behavior. This dynamic behavior may be an essential biological attribute in the functioning of the influenza virus.

\footnotetext{
* Part of this Chapter has been published as: D. Di Iorio, M. L. Verheijden, E. van der Vries, P. Jonkheijm, J. Huskens, ACS Nano 2019, 13, 3413-3423.
} 


\subsection{Introduction}

Influenza remains a threat to global health causing millions of human infections and substantial mortality every year. ${ }^{1,2}$ Influenza A viruses are subtyped based on the antigenic properties of the two glycoproteins hemagglutinin (HA) and neuraminidase (NA). ${ }^{3}$ HA is responsible for binding of the virus to sialic acid (SA)-terminated carbohydrates present at cell membranes, and the resulting adsorption of the virus to a cell membrane embodies the onset of the infection. The initial virus attachment to the cell is regulated by multivalent interactions, where homotrimeric HA binds to SAs and multiple HA trimers are involved in the interaction with the carbohydrate-covered cell surface. ${ }^{4}$ The NA, instead, facilitates the release of the virus from the cell after reproduction, by cleaving the SA residues present on the cell membrane. ${ }^{5}$

The overall affinity of the virus binding depends on the virus strain, expressed in the occurrence of different HA and NA subtypes, in combination with the specific form and density of SA presented at the membrane. Together, these factors determine the specificity of a virus for a particular host species. For example, avian influenza viruses bind preferentially to 2,3-sialyl-( $N$-acetyl-lactosamine) residues (2,3-SLN) while human influenza viruses show a preference for 2,6-sialyl-( $N$-acetyl-lactosamine) residues (2,6-SLN). ${ }^{6,7}$ Switching of a virus' specificity to another host species occasionally occurs, and may cause a pandemic when such a 'zoonotic' virus further adapts to humans by improving its replication/transmission efficiencies. ${ }^{8,9}$ The latest example - the outbreak of the 2009 influenza pandemic ${ }^{10}$ - stresses the importance of a thorough understanding of the factors driving such events. Alteration of the binding specificity is essential at this first stage, and this involves, for instance, mutation at the HA binding site and/or re-assortment of different HA and NA glycoproteins. However, subsequent adaptations appear to be required, ${ }^{8,9}$ including those that improve the functional balance between the HA and NA glycoproteins. To better understand these virus changes, it will be key to thoroughly understand the relationship between multivalent HA binding and virus infectivity at the molecular level.

A first step towards an improved molecular understanding is to provide a platform to study the binding selectivity of various virus strains for different SA residues and to quantify their interaction at these artificial cell surface mimics. Some examples of 2D sensor platforms bearing surface modifications for the study of the interaction of viruses with model cell receptors have been reported..$^{8,11,12}$ These platforms, based on streptavidin-modified surfaces at which a fast and easy modification with biotinylated receptors or aptamers is achieved, allow an efficient detection of viruses. However, this type of surface modification does not resemble the structure and properties of the cell surface, such as, for example, the membrane fluidity. Moreover, the sugar density at cell membranes is known to affect the binding 
characteristics of the influenza virus strongly, by influencing the valency and the multivalent effect of the overall interaction. ${ }^{13,14}$ Therefore, it is important to design platforms that allow a good control over the SA density at the surface.

Various methods have been developed to achieve control over surface densities of ligands or receptors, using self-assembled monolayers (SAMs) or (fluid) supported lipid bilayers (SLBs), to obtain static or laterally mobile layers, respectively. ${ }^{15-17}$ For example, the surface density of surface-exposed NTA(Ni) moieties was controlled using mixed SAMs of suitably modified thiols for $\mathrm{His}_{6}$-tag protein immobilization, ${ }^{18}$ the surface density of arginine-glycineaspartic acid (RGD) peptide was varied using SAMs to investigate the effect on cell binding, ${ }^{19}$ and the surface density of biotin was controlled both using SAMs and SLBs to investigate the multivalent binding of streptavidin. ${ }^{20}$ However, so far, SLBs have not been used to quantify the interaction of influenza viruses.

A surface analytical technique such as biolayer interferometry (BLI), has proven to be suitable for the study of virus-platform interactions, and it allows the determination of the selectivity of different virus variants or mutants for specific SA residues at surfaces at which the SA density is varied. ${ }^{8}$ However, a molecular understanding of the avidity observed for the interactions between influenza viruses and SAs is required to better understand the mechanism of virus infection and the role of multivalent binding therein. Another important open question is whether the bound virus remains dynamic upon adsorption, which is in large part determined by the nature of the multivalent binding. Technical issues of the BLI technique, such as limited knowledge of the surface presentation of the sugars at the detection platforms, as well as biological ones, such as the inhomogeneity of whole virus samples regarding size distribution, contact area when adsorbing to a surface and distribution of HA and NA proteins, prohibit a better understanding of the valency of the binding and the resulting multivalent effects.

Here, we report a SA receptor-presenting SLB platform that functions as a mimic for a cell membrane, and aims to provide control over the receptor density. Together with the use of recombinant protein clusters ("rosettes") of HA (rHA) as virus models, this system enables control of the interaction area between the surface and the virus-like particle, and thereby of the binding valency. The surface modification with SLBs provides a well-known cell membrane mimic that offers ease of preparation, controlled functionalization by incorporation of tunable fractions of functionalized lipids, and excellent non-fouling properties. ${ }^{21}$ By introducing tunable amounts of biotinylated lipids in the SLB, followed by the attachment of streptavidin (SAv), the surfaces have been functionalized with biotinylated human or avian receptors with control over their surface density. rHA rosettes bind selectively to the receptors, and their interactions have been quantified using quartz crystal microbalance with dissipation monitoring (QCM-D). The tunable sugar density at the SLB 
platform, together with the controlled valency of the rHA protein cluster in its interaction with this platform, enables the use of a multivalent binding model to quantify the multivalent interaction in terms of the individual affinity constant of a single HA-receptor site, the valency, and the, receptor density-dependent, effective molarity.

\subsection{Results and discussion}

\subsubsection{Design and characterization of the SLB platform}

In order to achieve control over the interaction area between the cell surface mimic and a virus particle, we have employed small rHA nanoparticles, also called rosettes, as a model for the influenza virus, while at the same time reducing complicating factors due to the heterogeneity of whole influenza viruses regarding their size, shape, and HA and NA fractions. Transmission electron microscopy (TEM) measurements (Figure 5.1) showed that these rosettes are approximately $22 \mathrm{~nm}$ in size and consist of, on average, 10-12 recombinant $\mathrm{HA}_{0}(\mathrm{rHA})$ trimers embedded in a surfactant layer. ${ }^{22,23} \mathrm{rHAs}$ of different influenza A/H1N1 viruses, with affinities for different receptors, have been used here: Influenza viruses A/California/07/2009 (Cal/09), A/New Caledonia/20/99 (NC/99) and A/Brisbane/59/07 (Bris/07) virus. All three viruses have been reported to bind preferentially to human sialic acid (2,6-SLN) residues. ${ }^{24-26}$

(A)

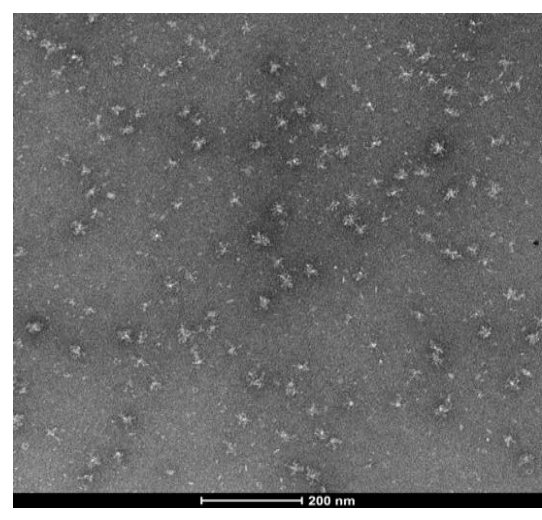

(B)

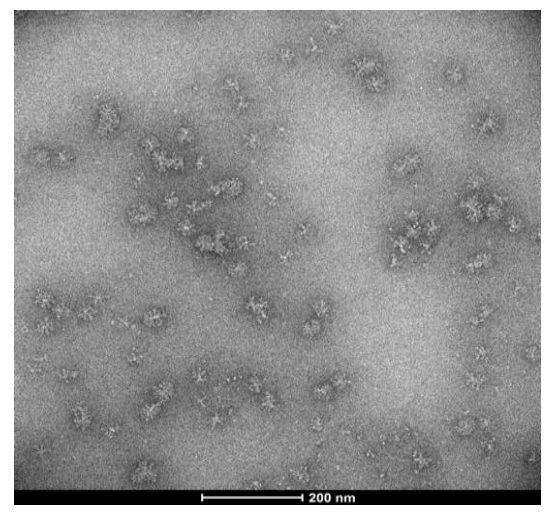

Figure 5.1. Electron micrograph of HA trimer rosettes from influenza virus embedded in phosphotungstic acid (PTA, 1\% (w/v), pH 7.4). (A) rHA rosettes from A/New Caledonia/20/99. (B) rHA rosettes from A/Brisbane/59/07. 
The SLB-based interaction platform was built up in a number of steps as schematically presented in Figure 5.2A. Unilamellar vesicles consisting of both 1,2-dioleoyl-sn-glycero-3phosphocholine (DOPC) lipids and a targeted fraction of the lipid 1,2-dioleoyl-sn-glycero-3phosphoethanolamine-N-(biotinyl) (DOPE-biotin) were prepared by extrusion, using a polycarbonate membrane with $100 \mathrm{~nm}$ pore size, and their size was measured to be $78 \pm 29$ $\mathrm{nm}$ by dynamic light scattering (DLS). Such vesicles are known to adhere to and rupture on oxidized glass substrates, resulting in SLBs that display biotin moieties at the SLB-water interface. $^{20,27}$ SLBs consisting of zwitterionic DOPC lipids have been demonstrated to suppress non-specific interactions effectively. ${ }^{21}$ This is of particular importance here, considering that the binding of viruses to the SLBs is based on multiple weak specific interactions, necessitating the suppression of non-specific interactions.

(A)

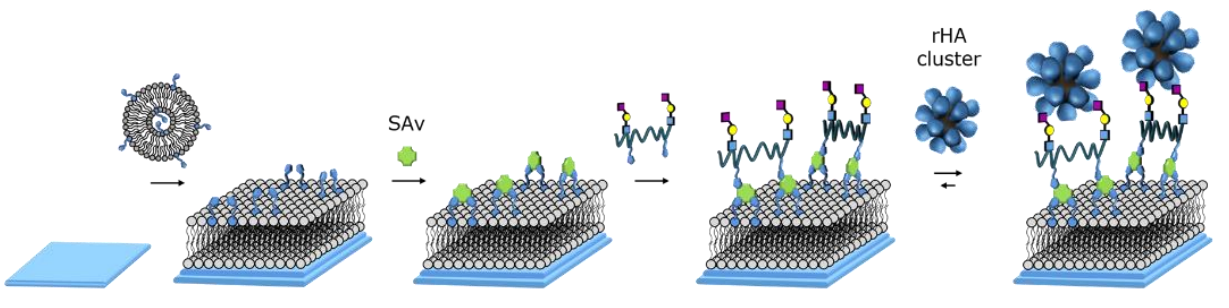

(B)

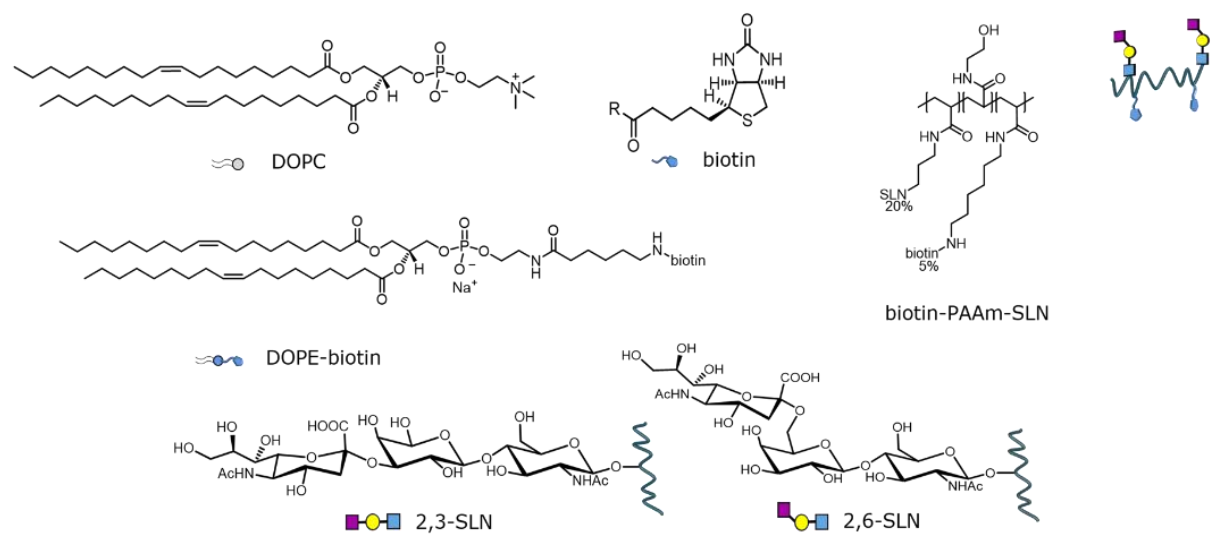

Figure 5.2. Schematic representation of the SLN-modified SLB platform and its interaction with rHA nanoparticles. (A) Step-by-step formation of the platform: the first step consists of the formation of the biotinylated SLB on a silicon oxide substrate presenting water at the interface, followed by adsorption of SAv and subsequently by the adsorption of biotinylated polyvalent SLN (biotin-PAAm-SLN) that can interact with the rosettes. (B) Molecular structure of the molecules used for the formation of the platform. 
The density of biotin moieties displayed at the SLB can be conveniently controlled by mixing in the desired fraction, here varied from 0.1 to $5 \%$, of the DOPE-biotin lipid during vesicle preparation. Subsequently, streptavidin (SAv) was bound to the surface by exploiting the strong biotin-SAv interaction. The surface-bound SAv presents additional free binding pockets, and these were used to bind a poly[ $N$-(2-hydroxyethyl)acrylamide]-based (PAAm) polymer (biotin-PAAm-SLN, see Figure 5.2B), presenting both biotin and SLN moieties in a random fashion at the PAAm backbone. Polymers with an average of 22 SLN moieties and 5.5 biotins per polymer chain (thus with a ratio of 4 SLNs per biotin unit) were used. By controlling the biotin density in the SLB, the SAv density and ultimately the SLN density can be tuned. Such polymers are routinely used for the variation of SLN density in virus binding studies using BLI. ${ }^{28,29}$

QCM-D was used to monitor in-situ the step-by-step formation of the SLB platform as well as the interaction of the rosettes with surface-bound SLNs (Figure 5.2A), thus allowing quantitative comparison of the experiments for different (2,6 and 2,3) SLN receptors and different rHA particles. An important consideration when using QCM-D for the (quantitative) analysis of biological entities at surfaces is the contribution of hydrated mass to the QCM-D output parameters, i.e. frequency $(f)$ and dissipation $(D)$. Because the associated water fraction is generally unknown, the relative surface coverages of bound molecules or particles can be determined from the QCM-D output (as the relative coverage will depend linearly on the frequency shift), but the absolute coverages cannot be determined exactly. Therefore, we primarily used the frequency shifts $(\Delta f)$ to obtain relative coverages of rHA rosettes. Yet, the relative contribution of the mass of hydrated water can still depend on the packing density of the adhered particles; especially at high packing densities, where hydration shells can significantly overlap, deviations from linearity may occur. ${ }^{30}$

In Figure 5.3A, an example of four parallel QCM-D measurements is presented, where the DOPE-biotin fraction was varied between $0.1-5 \%$. The first step, corresponding to the adsorption of the vesicles and their subsequent rupture, indicates the formation of high quality SLBs (i.e. $\Delta f=-24 \pm 1 \mathrm{~Hz}$ and $\Delta D<0.5 \times 10^{-6}$ ) on the $\mathrm{SiO}_{2}$-coated sensors. ${ }^{27}$ An intriguing property of SLBs is the lateral mobility of individual lipid constituents. The lateral mobility of the lipid bilayer, as well as of SAv bound to the biotin groups in a subsequent step, was confirmed using a fluorescently labeled lipid and fluorescently labeled SAv, respectively. DOPC-based SLBs with 1 mol\% DOPE-biotin showed a lateral mobility of bound SAv similar to that of the native SLB, as was verified by fluorescence recovery after photobleaching (FRAP). 
(A)

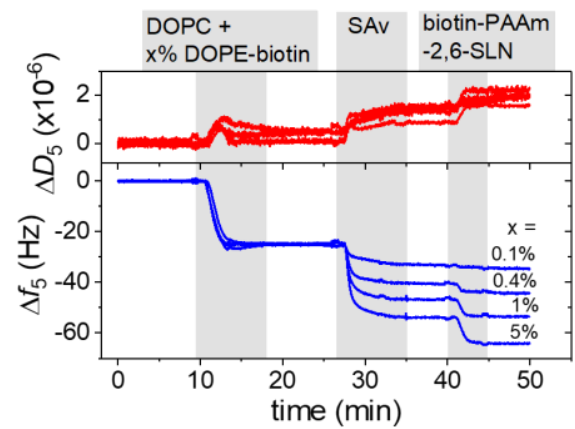

(B)

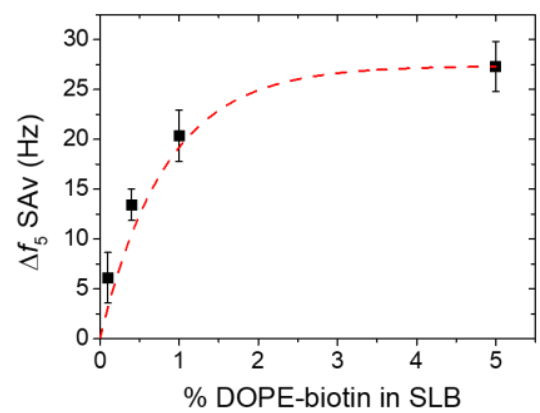

(C)

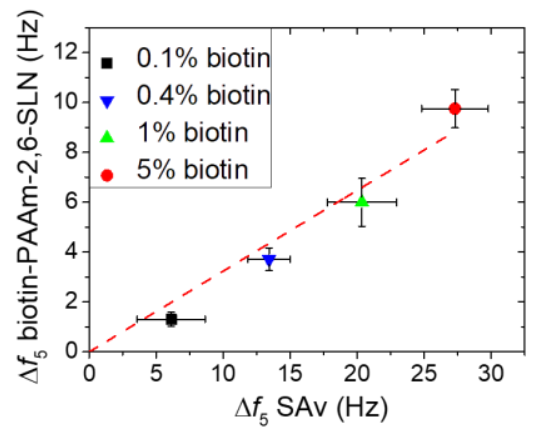

Figure 5.3. Control over the SLN density at the SLB platform. (A) Example of four parallel QCM-D measurements showing SLB formation using DOPC vesicles with a molfraction $x(0.1,0.4,1$ and $5 \%)$ of DOPE-biotin followed by binding of SAv $(0.5 \mu \mathrm{M})$ and subsequently of biotin-PAAm-2,6-SLN (4 $\mu \mathrm{g} / \mathrm{ml})$. Grey areas indicate the binding steps and white areas indicate buffer wash steps. All steps are under flow. (B) Correlation between QCM-D frequency shifts $\left(\Delta f_{5}, 5^{\text {th }}\right.$ overtone) of SAv binding as a function of the DOPE-biotin fraction. The red dashed line is a guide to the eye. (C) Correlation between QCM-D frequency shifts of the biotin-PAAm-2,6-SLN binding as a function of the frequency shift for SAv binding. The red dashed line is a linear fit to the data points.

Subsequently, all four substrates were washed with buffer and incubated with SAv. The frequency shift induced by adsorption of SAv as a function of the fraction of biotin in the SLB is reported in Figure 5.3B. The data shows a close-to-linear trend between the biotin density and the coverage of SAv up to $1 \%$ of DOPE-biotin, but the SAv coverage saturated at higher DOPE-biotin fractions. This observation suggests that above 1-2 mol\% of DOPEbiotin, the surface reaches physical saturation with SAv, which is in agreement with previously reported dense packing of SAv at SLBs that were functionalized with $5 \%$ or $10 \%$ of biotin. ${ }^{31,32}$ The frequency shift of the subsequent binding of biotin-PAAm-2,6-SLN onto the SAv-modified substrates was found to be linearly related to the coverage of SAv that was reached in the preceding step (Figure 5.3C). 
The results discussed above show that this platform is suited to tune the density of the sialic acid residues presented at the SLB platform. When we assume (i) that every SAv binds to two biotin moieties of DOPE-biotin present in the SLB, ${ }^{20}$ and (ii) that all biotin moieties of biotin-PAAm-SLN bind to and saturate the remaining available binding pockets of SAv, SLN densities values are estimated between 0.92 and $45.8 \mathrm{pmol} / \mathrm{cm}^{2}$ for 0.1 and $5 \%$ of biotin, respectively, here ignoring packing effects of SAv. Experimental average SLN densities ranged from 3.5 to $26 \mathrm{pmol} / \mathrm{cm}^{2}$, corresponding to 6.9 and $2.5 \mathrm{~nm}$ average spacing between SA residues, respectively. These values are based on an estimated $80 \%$ water content (based on experimental values ranging from $70-90 \%$ obtained for other large biomolecules ${ }^{21}$ and the assumption that the Sauerbrey model is valid (a reasonable assumption considering the small increase in dissipation for the polymer binding step). The observed differences between the calculated and the experimental values for the SLN densities has reasonable explanations at both the lower and higher biotin densities: At a low fraction of DOPE-biotin in the SLB, and a concomitantly low coverage of SAv, the polymeric sugar probably binds to the surface with only two (of approx. 5.5) biotin moieties per polymer chain, allowing the attachment of a higher relative amount of polymer on the surface. At the other limit, the calculated value does not take into account the SAv saturation on the surface that occurs at a biotin percentage above $2 \%$ (Figure 5.3B), and thus not every biotin from DOPE-biotin can bind to SAv because of steric hindrance and, therefore, this omission leads to an overestimation of the polymer density on the surface. Yet, both the experimental and model values are average densities, and do not take into account the probably inhomogeneous SLN distribution over the sensor surface which is related to the use of a polymer with a fixed degree of functionalization with biotin and SLN moieties. This issue is discussed in more detail below.

\subsubsection{Rosette binding on the SLB platform}

The specificity and selectivity of the interaction between the rHA rosettes and the SLNdisplaying platform were investigated by studying the adsorption of the different nanoparticles onto SLBs with varying types and densities of SLN receptors. After verifying the formation of biotin-functionalized SLBs, the subsequent binding of SAv and of a biotinylated PAAm polymer, two different concentrations ( 0.14 and $0.56 \mathrm{nM})$ of $\mathrm{Cal} / 07 \mathrm{rHA}$ rosettes were flown over SLBs modified with biotin-PAAm (without SLN) or biotin-PAAm2,6-SLN. Figure 5.4A shows the successful binding of rosettes to surfaces that were functionalized with 2,6-SLN, while no binding was observed in the absence of 2,6-SLN at the SLB. The higher dissipation signals relative to the obtained frequency shifts, in comparison with the results presented in Figure 5.3A, suggests that the rosettes interact with the SLB as intact particles. These results indicate that nonspecific interactions between the 
platform and the rosettes are negligible and that the binding of the rosettes to the SLNfunctionalized platform is caused by specific, i.e. SLN-HA, interactions.

(A)

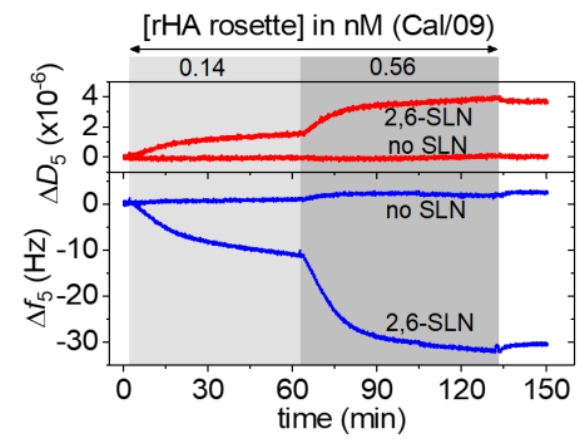

(B)

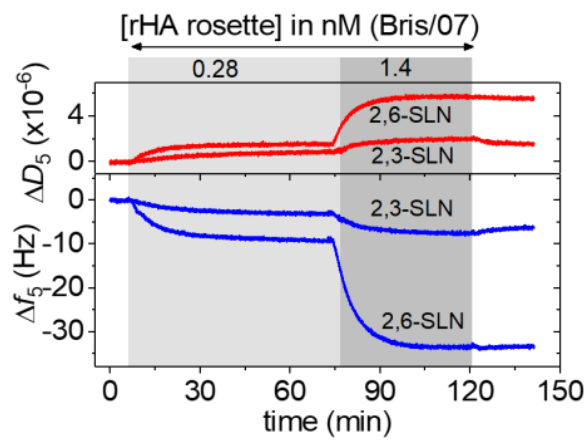

Figure 5.4. Selectivity of the binding of HA rosettes at the SLB platform. (A) QCM-D results of the binding of A/California/07/2009 (Cal/09) rHA rosettes to SLBs modified with biotin-PAAm-2,6-SLN or biotin-PAAm (without SLN). (B) QCM-D results of the binding of A/Brisbane/59/07 (Bris/07) rHA rosettes to SLBs modified with biotin-PAAm-2,6-SLN or biotin-PAAm-2,3-SLN. Steps shown here were performed after (not shown): formation of SLB presenting biotin groups, subsequent binding of SAv, and of biotin-PAAm with/without SLN groups. DOPE-biotin densities were (A) $1 \%$ and (B) $0.4 \%$. Grey areas indicate the binding steps and white areas indicate buffer wash steps. All steps were recorded under flow.

Various influenza viruses are known to bind selectively to specific glycan structures. Therefore, the selectivity of the binding of the Bris/07 rHA rosettes to both 2,6-SLN and 2,3SLN-functionalized SLBs was evaluated. A much higher (approx. 4-fold) QCM-D response was observed (see Figure 5.4B) for the 2,6-SLN-modified SLBs indicating a preference for binding of the Bris/07 rHA virus particles to the human 2,6-sialic acid residues. This difference was not due to a different density of SA residues bound to the sensor surface, since the coverages of biotin-PAAm-SLN at the biotin-SAv-modified SLB were comparable $\left(<10 \%\right.$ difference in $\left.\Delta f_{5}\right)$. The rHA rosette binding was evaluated at two concentrations, showing an increased amount of binding at the higher concentration but with similar selectivity. Even more selective binding was observed in the case of binding of $\mathrm{Cal} / 09$ and NC/99 rHA clusters to 2,6-SLN-modified SLBs: no significant binding was observed for either of these clusters on 2,3-SLN surfaces while significant binding was observed at 2,6SLN surfaces (see also data presented in Figure 5.6 below).

To determine the overall dissociation constant $\left(K_{d}\right)$ of the interaction of Cal/ $09 \mathrm{rHA}$ clusters with the 2,6-SLN-modified SLBs, solutions of Cal/09 rHA clusters at concentrations ranging from 0.14 to $4.2 \mathrm{nM}$ were titrated at the surface, and adsorptions were monitored with QCM- 
D. Biotin fractions in the SLB of 0.4 and $5 \mathrm{~mol} \%$ were used, and Figure $5.5 \mathrm{~A}$ reports the frequency shifts obtained in the titration performed with the SLB containing $0.4 \%$ of DOPEbiotin. Figure 5.5A shows clear binding steps at all concentrations, visible both in the frequency and dissipations signals, in agreement with the adsorption of soft particles. The adsorption steps reached a plateau in approx. $10 \mathrm{~min}$, while flow of the respective solutions was maintained for $40 \mathrm{~min}$, indicating that equilibrium was reached in each step. The reversibility of the particle binding is further indicated by the observed, though slow, desorption upon switching the flow to buffer after the last particle solution. The data confirms qualitatively that the rosettes allow the assessment of their binding affinity by employing regular titrations performed under thermodynamic equilibrium.

(A)

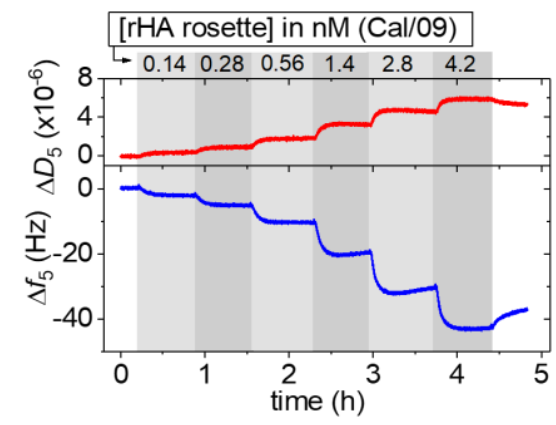

(B)

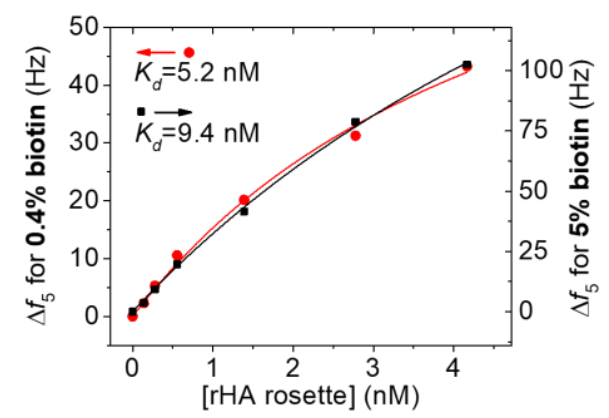

Figure 5.5. Affinity of $\mathrm{Cal} / 09 \mathrm{rHA}$ rosettes at the $2,6-\mathrm{SLN}$ surface and effect of sugar density. (A) QCM-D titration of the Cal/09 rosettes at a 2,6-SLN-presenting SLB with 0.4 mol\% of DOPE-biotin present in the SLB. Grey areas indicate the binding steps and white areas indicate buffer wash. All steps were performed under flow. Surface functionalization up to the rHA cluster binding was monitored as well but not shown here. (B) Binding curves from QCM-D titrations for Cal/09 rHA clusters at 2,6SLN surfaces starting from $0.4 \%$ (red circles, left y-axis) and 5\% (black squares, right y-axis) DOPEbiotin. Langmuir model fitting (solid lines) provided the binding constants shown.

Figure 5.5B shows the resulting binding data when plotting the plateau values of the frequency shift after each rosette binding step versus the concentration of the rosette. A $K_{d}$ of $5.2 \mathrm{nM}$ was found from fitting the $0.4 \mathrm{~mol} \%$ DOPE-biotin data with a standard 1:1 (Langmuir) model. When the same type of titration was performed on a 2,6-SLN-modified SLB with a higher fraction ( $5 \mathrm{~mol} \%$ ) of DOPE-biotin, which resulted in a three times higher surface coverage of 2,6-SLN (based on Figure 5.3C), a very similar $K_{d}$ of $9.4 \mathrm{nM}$ was found (Figure 5.5B). In correspondence with this relatively strong binding, limited, but notable, desorption was observed at the measurement time scale when washing the surface with buffer after the titration (Figure 5.5A). 
The Langmuir fits of the dissociation constants (Figure 5.5B) require co-fitting of the frequency shift plateau values that correspond to saturation of the surface with rHA nanoparticles. For the $0.4 \%$ and $5 \%$ platforms, these saturation frequencies, $\Delta f_{\max }$, were 95 and $335 \mathrm{~Hz}$, respectively. These values agree reasonably well with the relative differences in SLN receptor and SAv densities at these platforms as mentioned above. However, the plateau values estimated by these fits have a relatively large error, since the titration data do not level off sufficiently to estimate more accurate values of the saturation levels. Limited stock concentrations of the rosettes prohibited us, however, from extending the titrations to higher concentrations.

QCM measurements of the binding of biotinylated lipid bilayer vesicles of $100 \mathrm{~nm}$ in diameter at SAv-modified SLBs showed a maximal binding frequency of about $150 \mathrm{~Hz}$ at dense vesicle coverage (see Chapter 7). This suggests that the here used smaller rHA rosettes probably bind in a close to dense fashion at the $5 \%$ platform and that the plateau frequency will most likely not be much larger than now estimated. Consequently, the estimated $K_{\mathrm{d}}$ values will not be much higher than the fitted values given above. Overall, this analysis indicates that the dissociation constants are definitely in the low $\mathrm{nM}$ regime.

Noteworthy, the $K_{\mathrm{d}}$ values for the interaction of the $0.4 \%$ and $5 \%$ platforms with the Cal/09 rosette are very similar. This seemingly contradicts published work performed on whole viruses which have shown strong dependencies of the binding affinity on the (polyvalent) sugar density. ${ }^{8,13,29}$ At the same time, however, it must be noted that these data may not be directly comparable, as these are often performed at only one virus concentration. As a consequence, full titrations (i.e., with different concentrations of virus to obtain different surface coverages), like done here for the rosettes, are normally not performed with whole viruses. For example, concentrations of $100 \mathrm{pM}$ of whole influenza virus were used by Gamblin et al. ${ }^{13}$ to achieve either partial or full virus coverage of surfaces coated with the same biotin-PAAm-2,6-SLN polymer as used in this work, and were used for monitoring relative differences between viruses without determining the binding constants.

Similar titrations were performed for $\mathrm{rHA}$ rosettes derived from NC/99 (at $0.4 \mathrm{~mol} \%$ DOPEbiotin only) and Bris/07 (at $0.4 \mathrm{~mol} \%$ and $5 \mathrm{~mol} \%$ DOPE-biotin) (see Figures 5.6), and the resulting overall dissociation constants are summarized in Table 5.1. Comparing the results for the three rosettes, very similar dissociation constants were found for the 2,6-SLN presenting surfaces, all in the low nM concentrations. Both the $\mathrm{Cal} / 09$ and Bris/07 rosettes showed (slightly) higher dissociation constants, i.e. weaker binding, at the $5 \%$ platforms in comparison to the $0.4 \%$ platforms. The differences in binding affinity may be due to the error involved with estimating the saturation frequency values, as indicated above, and possibly to small deviations from the linear frequency dependence at the densely packed 5\% surface (see below), but it contrasts data on whole viruses that show generally stronger binding at higher 
receptor densities. Moreover, higher saturation values were obtained for Bris/07 clusters compared to the other clusters tested here. This may be due to a difference in size of the nanoparticles and, therefore, a different packing density on the surface, as well as a difference in the hydration of the rosettes. However, when the data were fitted by fixing the saturation values to $100 \mathrm{~Hz}$ and $300 \mathrm{~Hz}$ at $0.4 \mathrm{~mol} \%$ and $5 \mathrm{~mol} \%$ DOPE-biotin, respectively, the $K_{d}$ values obtained from the fitting did not decrease significantly: values of $1.9 \mathrm{nM}$ and $6.4 \mathrm{nM}$ were found for the lower and higher SLN densities, respectively, confirming the same low$\mathrm{nM} K_{d}$ range already observed for the $\mathrm{Cal} / 09$ rosettes described above.

Table 5.1. Dissociation constants for rHA rosettes of three different viruses at 2,6-SLN-presenting surfaces with $0.4 \mathrm{~mol} \%$ or $5 \mathrm{~mol} \%$ DOPE-biotin. In brackets are given the saturation frequency shifts calculated from the Langmuir fits for each titration.

\begin{tabular}{|l|l|l|l|}
\hline $\begin{array}{l}\text { DOPE-biotin } \\
(\mathbf{m o l} \%)\end{array}$ & $\begin{array}{l}K_{d} / \mathbf{n M}\left(\Delta f_{\text {max }} / \mathbf{H z}\right) \\
\text { Cal/09 }\end{array}$ & $\begin{array}{l}K_{d} / \mathbf{n M}\left(\Delta f_{\text {max }} / \mathbf{H z}\right) \\
\text { Bris/07 }\end{array}$ & $\begin{array}{l}K_{d} / \mathbf{n M}\left(\Delta f_{\text {max }} / \mathbf{H z}\right) \\
\text { NC/99 }\end{array}$ \\
\hline $\mathbf{0 . 4}$ & $5.2(95)$ & $3.2(130)$ & $3.4(71)$ \\
\hline $\mathbf{5}$ & $9.4(335)$ & $20(739)$ & - \\
\hline
\end{tabular}


(A)

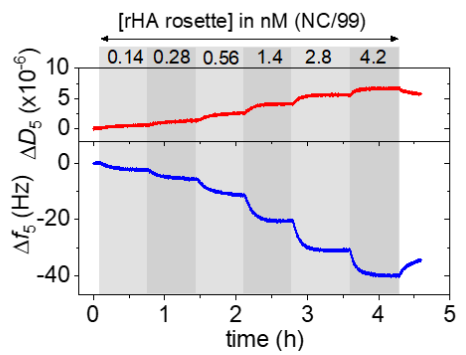

(C)

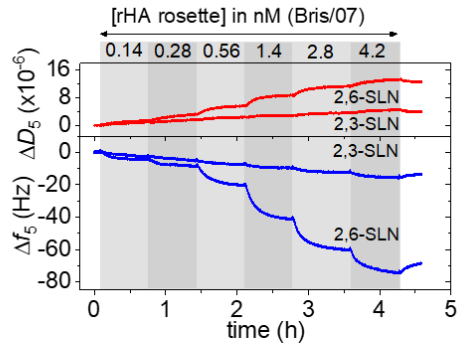

(E)

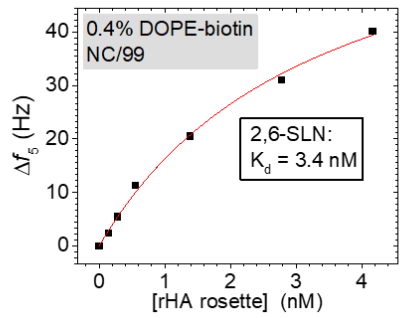

(G)

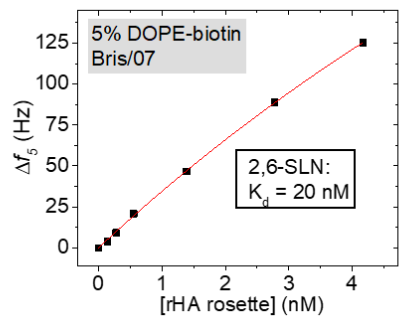

(B)

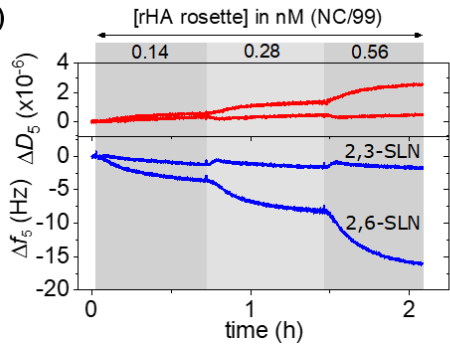

(D)

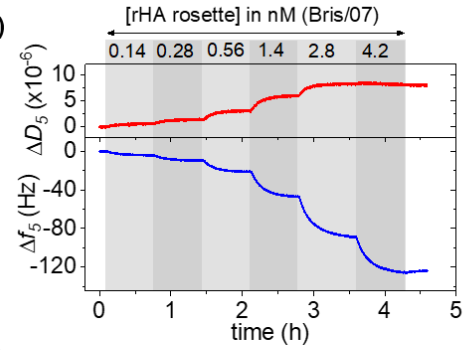

(F)

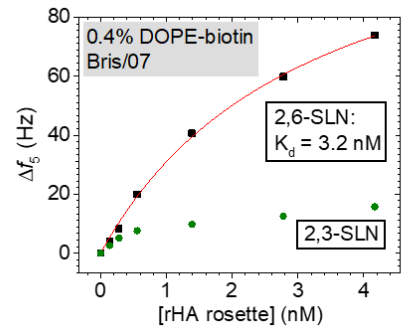

(H)

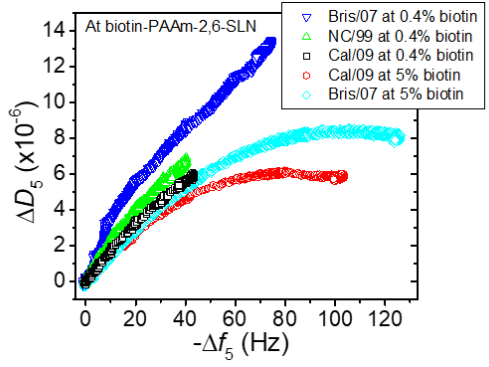

Figure 5.6 QCM-D binding profiles for titrations of rHA clusters onto SLB platforms and Langmuir binding model fitted to the binding data: (A) NC/99 rHA rosettes at a 2,6-SLN surface with $0.4 \mathrm{~mol} \%$ DOPE-biotin, (B) NC/99 HA rosettes at 2,3-SLN and 2,6-SLN surfaces with $0.4 \mathrm{~mol} \%$ DOPE-biotin, (C) Bris/07 rHA rosettes at 2,3-SLN and 2,6-SLN surfaces with 0.4 mol\% DOPE-biotin, and (D) Bris/07 HA cluster at a 2,6-SLN surface with $5 \mathrm{~mol} \%$ DOPE-biotin. Grey areas indicate the binding steps and white areas indicate washing with HEPES saline buffer at $\mathrm{pH}$ 7.4. All steps were performed under flow. (E) NC/99 at 0.4\% DOPE-biotin in SLB with 2,6 SLN (see A), (B) Bris/07 at 0.4\% DOPEbiotin in SLB with 2,6 SLN (see C) and (C) Bris/07 at 5\% DOPE-biotin in SLB with 2,6 SLN (see D). Dissociation constants $K_{\mathrm{d}}$ are given and plateau values were co-fitted with $K_{\mathrm{d}}$. Plateau values obtained from the fits are 71,130 and 739 , respectively for $\mathrm{A}, \mathrm{B}$ and $\mathrm{C}$. (H) $\Delta D_{5}$ as function of $-\Delta f_{5}$ for the rHA cluster titration step for the three tested clusters at surfaces with $0.4 \%$ or $5 \%$ DOPE-biotin, and with the 2,6-SLN receptor. 
As mentioned above, the relative contribution of hydrated water can depend on the packing density of the adhered entities, in this case the rHA rosettes. To evaluate whether possible hydration shell overlap influences the observed binding curves, we evaluated the dissipation signal as a function of the frequency shift for all titrations. Figure 5.6H shows that these $\Delta f / \Delta D$ plots were largely linear at $0.4 \mathrm{~mol} \%$ DOPE-biotin density, whereas at $5 \mathrm{~mol} \%$ DOPEbiotin density, the corresponding titrations showed nonlinear behavior with the $\Delta D$ leveling off at higher $\Delta f$ values, which may be related to increasingly overlapping hydrations shells of the rHA rosettes. This indicates that the relative frequency shifts and the saturation frequencies are more reliable for the $0.4 \%$ platforms, and therefore we interpret the binding data obtained at the $5 \%$ platforms to be essentially very similar in affinity as observed for the $0.4 \%$ ones.

When we assume a plateau value to hold for a particular rosette (for example, of $130 \mathrm{~Hz}$ for Bris $/ 07$ at the $0.4 \%$ platform), $K_{d}$ values for the $2,3-\mathrm{SLN}$ platforms can be determined as well, leading to a $K_{d}$ value of $26 \mathrm{nM}$ of the Bris $/ 07$ rosette on the $0.4 \%$ platform. The one order of magnitude weaker binding to the 2,3-platform compared to the 2,6, is a clear signature of the difference in binding selectivity of the HA of this rosette.

As observed (Figure 5.5, and Table 5.1, $\Delta f_{\max }$ values), the absolute amounts of binding are higher at the higher sugar densities. However, these results do not show the expected increased affinity for the higher sugar density. Instead, the affinities ( $K_{\mathrm{d}}$ values) appear unaffected by the SLN surface density suggesting that the sugar density sensed by the HA rosettes does not change with increasing densities of biotin-PAAm-SLN. Therefore, we here propose that this insensitivity of the rosette binding to the sugar density is caused by a fixed local SLN density, due to restriction of the interaction area of a rosette to a single polymeric biotin-PAAm-SLN at the SLB platform.

Figure 5.7A shows a schematic top view of the surface and how a rosette particle interacts with it. Looking at the composition and structure of the SLN-modified polymer, the biotinPAAm-SLN contains approx. 115 acrylamide monomer units with a stretched main chain of approx. $30 \mathrm{~nm}$, of which, on average, 22 monomer units contain an SLN moiety and 5.5 a biotin group. One polymer chain can therefore bind 2-3 SAv proteins simultaneously. Indeed, adsorbed biotin-PAAm-SLN has been shown to cover an area with a diameter of $15 \mathrm{~nm},{ }^{33}$ i.e., of $175 \mathrm{~nm}^{2}$, which can easily accommodate the area of the SAv molecules it binds to (approx. $25 \mathrm{~nm}^{2}$ per protein). From the SAv-bound biotin moieties located at the surface, small chain segments with a length of a few nm may stick out upward and sideward, exposing SLN units (and their linker chains) to provide additional flexibility. 
(A)

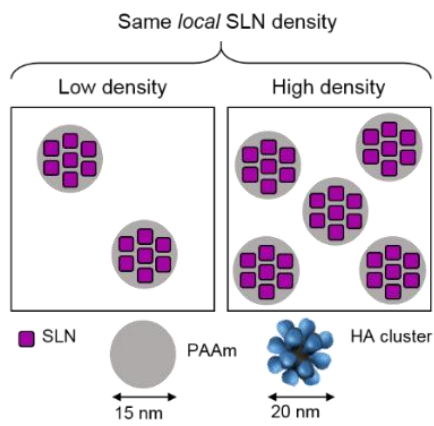

(B)

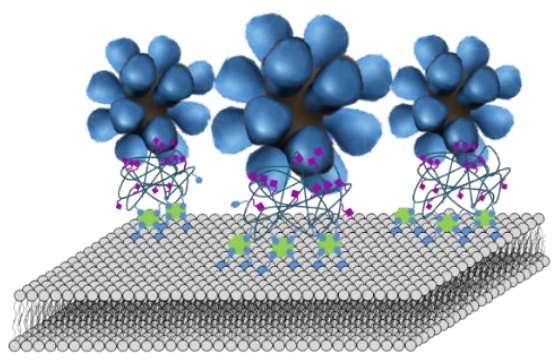

Figure 5.7. Interaction and contact area of an HA rosette binding to a single biotin-PAAm-SLN polymer at the SLB platform. (A) Schematic presentation of the constant local SLN density sensed by the HA rosettes for different biotin-PAAm-SLN coverages. (B) Representation of a single rosette interacting with three of its HA trimers with a single SLN-polymer at the SLB substrate.

The HA clusters have a diameter of $22 \mathrm{~nm}$, assuming a diameter of about twice the length of one HA trimer. ${ }^{22}$ With 10-12 HA trimers, we can view such a particle as an icosahedron with an HA trimer at (almost) each apex, with an angle of $63^{\circ}$ between neighboring trimers. This gives a contact area in which three trimers interact with the substrate, while the other trimers will be $>5 \mathrm{~nm}$ away from the surface. At the protruding tips of the trimers, tip-tip distances of $15 \mathrm{~nm}$ can be estimated in this geometry, which is not far off from the $11 \mathrm{~nm}$ trimer-trimer distance in whole viruses. ${ }^{34,35}$ The somewhat larger tip-tip distance in the rosettes is a direct result of the much higher curvature of the smaller rHA rosettes compared to the whole virus. Taken together, these considerations indicate an excellent match between the contact area of a rHA rosette and that of a single biotin-PAAm-SLN polymer molecule displayed at the sensor platform. This analysis supports the observed lack of density dependence in the binding behavior of the rHA rosettes, and it also explains the seemingly contradictory coverage-dependent virus binding observed in literature. Because the whole virus has a diameter of approximately $100 \mathrm{~nm}$, it has a much larger contact area and valency with the substrate than an rHA nanoparticle. As a consequence, the virus can interact with multiple biotin-PAAm-2,6-SLN polymer molecules simultaneously, whereas the rosettes only bind to a single polymer molecule at a time, making the interaction of the whole virus sensitive to the polymeric SLN density whereas that of the rosette is not. ${ }^{13}$

The relatively small and well-defined contact area between an rHA rosette and the substrate allows for a detailed description of the multivalent interaction and the overall affinity resulting from the interaction. From an estimated interaction area involving three HA trimers, a valency of 6-9 can be estimated, depending on whether all three sites of a trimer can interact or not. For a tripodal arrangement of trimers, maximally two sites of each bonding trimer can 
be in direct contact with the substrate at any time. Yet, the third site of these trimers is at a distance of approx. $2.5 \mathrm{~nm}$ from the surface. Seen the length and flexibility of the biotinPAAm-SLN polymer and the linker connecting the SLN moieties to the polyacrylamide backbone, we estimate that this distance can be bridged easily by the SLN-modified polymer segments protruding from the surface.

The overall binding affinity, $K_{\mathrm{ov}}$ (which is the inverse of $K_{\mathrm{d}}$ experimentally assessed above), of a multivalent ligand at a surface, following methodology developed earlier in our group, ${ }^{36}$ can be described as follows (Equation 1).

$$
\frac{1}{K_{d}}=K_{o v}=K_{i}\left(K_{i} E M\right)^{n-1}
$$

Here, $K_{\mathrm{i}}$ is the intrinsic affinity constant of a single interaction pair, here between an HA monomeric binding site and an SLN moiety, EM is the effective molarity, which is a measure for the probability of intramolecular bond formation applicable to additional interaction pairs formed upon formation of the first intermolecular interaction, and $n$ is the valency of the multivalent interaction. Here, we ignore statistical pre-factors and differences in probabilities of intramolecular bond formation resulting from the tripodal trimeric arrangement, which would formally need a nested multivalent approach. Yet, because of the flexibility of the biotin-PAAm-SLN polymer, and the similar distances between binding sites with an HA trimer $(5 \mathrm{~nm})$ and between sites from neighboring trimers $(7-8 \mathrm{~nm})$, we here assume one value for $E M$ to hold for all intramolecular binding steps of the rHA particle to the surface. Furthermore, Equation 1 only holds when the multivalent enhancement factor, $K_{\mathrm{i}} E M$, which is a measure of how much $K_{\mathrm{ov}}$ is enhanced when an additional binding site is added to the multivalent interaction, is substantially larger than $1 .{ }^{37}$

From the titrations with the rHA rosettes at the $0.4 \%$ platforms (see Table 5.1) and the nanomolar $K_{d}$ values found here, $K_{o v}$ values can be calculated to be approx. 2-3 $\times 10^{8} \mathrm{M}^{-1}$. Values for the monovalent interaction affinity $\left(K_{\mathrm{i}}\right)$ of SLN with HA have been reported in the literature for different influenza variants, and we here assume a value of $1000 \mathrm{M}^{-1}$ (a $K_{\mathrm{d}}$ of $1 \mathrm{mM}) .{ }^{13}$ When assuming all sites of three HA trimers to be involved $(n=9), K_{\mathrm{i}} E M$ can be calculated to be approx. 5, leading to an $E M$ value of approx. $5 \mathrm{mM}$. For two sites per HA trimer $(n=6), K_{\mathrm{i}} E M$ can be calculated to be around 12, leading to an $E M$ value of approx. 12 $\mathrm{mM}$. It should be noted that this analysis of the $K_{\mathrm{i}} E M$ and $E M$ values is rather insensitive to changes in $n$ and $K_{\text {ov }}$. This is a direct result of the exponential relationship shown in Equation 1. When rewritten as Equation 2, it becomes clear that $K_{\mathrm{i}} E M$ is only logarithmically dependent on the ratio $K_{\mathrm{ov}} / K_{\mathrm{i}}$ and inversely on the number of intramolecular bonds, $n-1$. 


$$
K_{i} E M=\log \left(\frac{K_{o v}}{K_{i}}\right) /(n-1)
$$

Therefore, limited accuracy in the determination of $K_{\mathrm{ov}}$ can be tolerated, as even variations of an order of magnitude have limited influence on $K_{\mathrm{i}} E M$. Likewise, the range of $n$ values assumed here has only limited effect on $K_{\mathrm{i}} E M$, as already shown above. Errors in $K_{\mathrm{i}}$ have a similarly low effect on $K_{\mathrm{i}} E M$, but have of course a direct influence on $E M$.

$E M$ values on the order of $10 \mathrm{mM}$ are not unreasonable for such surface densities, and slightly higher values (on the order of $100 \mathrm{mM}$ ) have been obtained for cyclodextrin host-guest surface assemblies that have a higher surface receptor density. ${ }^{38}$ Besides the difference in binding site density, the lower $E M$ value obtained for the rHA rosettes compared to other systems might be attributed to the rigidity of the rosettes interacting with the receptor surface. It should be noted that assuming a lower valency leads to a higher $E M$ value needed to explain the overall affinity, as explained above.

Apparently and noteworthy for this system, $K_{\mathrm{i}} E M$ is well above 1 confirming the validity of Equation 1, but is at the same time only moderately high, on the order of 10 . The moderate nature of the value of $K_{\mathrm{i}} E M$ indicates that an increase of the valency of the system has only a moderate effect on the overall affinity. In other words, the here observed difference of approx. 5 orders of magnitude in affinity between the monovalent $\left(K_{\mathrm{i}}\right)$ and multivalent interaction $\left(K_{\mathrm{ov}}\right)$, is reached with 6-9 molecular interaction pairs (of which 1 is regarded as intermolecular, and 5-8 as intramolecular), so less than 1 order of magnitude per added site. Such avidities are not uncommon for biological systems like influenza inhibitors, ${ }^{39}$ but are in contrast to much stronger multivalent effects observed for synthetic systems where $K_{\mathrm{i}} E M$ values of $>1000$ have been observed. ${ }^{38,40}$

What is the biological relevance of the multivalent enhancement factor $K_{\mathrm{i}} E M$ ? Apart from the molecular understanding of what a binding site contributes to the overall affinity increase in a multivalent system, it gives insight into the dynamics of a system. The ratio of lifetimes of the bound and unbound states of an interaction pair in an intramolecular system is given by $K_{\mathrm{i}} E M: 1$, and therefore the corresponding relative bound/unbound fractions by $K_{\mathrm{i}} E M /\left(K_{\mathrm{i}} E M+1\right)$ and $1 /\left(K_{\mathrm{i}} E M+1\right)$, respectively. For moderate values of $K_{\mathrm{i}} E M$, say ranging from 0.1-10, these bound and unbound lifetimes are of the same order of magnitude, indicating that each interaction pair is dynamically equilibrating between its bound and unbound states, the frequency of which is dictated by the intrinsic dissociation rate constant, $k_{\mathrm{d}, \mathrm{i}}$. For considerably stronger multivalent systems with $K_{\mathrm{i}} E M>>10$, for example $>1000$ as observed before for cyclodextrin surfaces, ${ }^{38,40}$ the bound lifetime is orders of magnitude higher than the unbound one, and consequently the bound/unbound dynamics is reduced. This kinetic trapping at high $K_{\mathrm{i}} E M$ has been observed in an earlier study, ${ }^{39}$ where only a 
divalent guest showed measurable surface diffusion along a cyclodextrin-coated surface, while mobility of a trivalent guest was not observed due to too strong binding.

The binding energy landscape of a multivalent particle at a surface is therefore described by both a thermodynamic parameter (the difference between the overall and monovalent affinities) as well as a kinetic parameter (the average fraction of bound sites). Figure 5.8 shows this energy landscape graphically, by plotting the bound fraction, $K_{\mathrm{i}} E M /\left(K_{\mathrm{i}} E M+1\right)$, and the avidity parameter, $\log K_{\mathrm{ov}}-\log K_{\mathrm{i}}$, as a function of the multivalency parameters, i.e., the valency, $n$, and the multivalent enhancement factor, $K_{\mathrm{i}} E M$. When $K_{\mathrm{i}} E M<0.1$, the system behaves basically as a monovalent system: $K_{\mathrm{ov}} \approx K_{\mathrm{i}}$ and the bound fraction of the interaction sites (and for each site individually) is below $10 \%$. At high $K_{\mathrm{i}} E M,>10, K_{\mathrm{ov}}$ scales as given by Equation 1, and thus $\log K_{\mathrm{ov}}$ is linearly dependent on $n$ and on $\log K_{\mathrm{i}} E M$. That means that systems with high valencies reach very high $K_{\mathrm{ov}}$ values. Taken together with a bound fraction that approaches 1 , indicating that all sites are practically all of the time in the bound state, such systems get kinetically trapped: neither spontaneous desorption, which would require dissociation of all binding sites, nor interfacial mobility, which is based on partial site dissociation, are possible under these circumstances. In between these extremes, we call these systems "weakly multivalent": for moderate values of $K_{\mathrm{i}} E M$, ranging from 0.1-10 (as indicated green in Figure 5.8), the system is multivalent and dynamic at the same time. Additional binding sites do contribute to the overall affinity, but with less than one order of magnitude, and the fractions of bound and unbound sites are comparable, as well as their lifetimes. Therefore, such systems can exhibit dynamic behavior, especially in processes like interfacial mobility in which only partial site dissociation is needed. We coin this part of the multivalent binding energy landscape to be called the "sweet spot". 


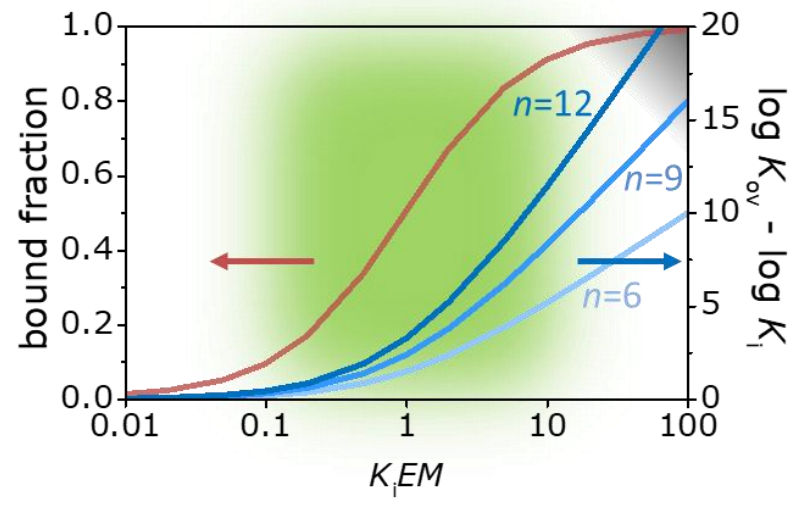

Figure 5.8. Energy landscape of multivalent interactions. Average bound fraction (left y axis), of all interaction pairs at any given time, given by $K_{\mathrm{i}} E M /\left(K_{\mathrm{i}} E M+1\right)$, and avidity parameter $\log K_{\mathrm{ov}}-\log K_{\mathrm{i}}$ (right y axis), here for three cases with $n=6,9$, and 12 , as a function of $K_{\mathrm{i}} E M$. The dark grey area (right upper corner) indicates the kinetic trap: slowing dynamics of the system when the number of potentially interacting sites, $n$, increases at high $K_{\mathrm{i}} E M$ : the bound fraction approaches 1 and $\log K_{\mathrm{ov}}$ scales with $\log$ $K_{\mathrm{i}} E M$ and with $n$. The green area indicates the "sweet spot": the multivalent enhancement factor is not too low $\left(K_{\mathrm{i}} E M<0.1\right.$, bound fraction $\left.<0.1\right)$, where an increased valency does not lead to enhanced multivalent binding, nor too high $\left(K_{\mathrm{i}} E M>10\right.$, bound fraction $\left.>0.9\right)$, where the system becomes kinetically trapped.

As a result of the above analysis, we believe that the biological origin of the here observed weakly multivalent behavior of HA rosettes is inherent to the function of the adhesion process of influenza in real life: a virus may bind to a cell surface or to the mucus layer, but the interaction remains dynamic until a site is found at the cell surface where endocytosis is induced. This notion also provides insight in why the intrinsic binding affinity of an HA site of influenza is always of the same order of magnitude: mutations that would take the viruscell surface interaction outside the sweet spot would either render the virus non-binding or running into a kinetic trap upon interaction, which are both detrimental for virus proliferation. How realistic is the rosette-SLB interaction for mimicking the interaction of whole viruses at cell surfaces and for understanding the interaction at a quantitative level? This question has aspects that affect the platform and those that deal with the rosette as a virus-like particle. While the cell surface with its glycocalyx is a tremendously complex system, ${ }^{41}$ we here look only to the density of the displayed glycans. On the cell level, the quantitative determination of the glycan density is a recent and important technical development, and densities of $10^{7}$ sialic acids per cell have been reported. ${ }^{42}$ However, knowledge on local areal density, type of glycan and determinations on relevant cell types will have to be performed to provide a 
more quantitative comparison. At a more technical level, the BLI method employs SAvcoated surfaces which have a similar density ${ }^{43}$ as the SLB platform developed here. Since the BLI method has been used on whole viruses, ${ }^{8,13}$ we are confident that our platform can exhibit the right glycan densities to study the binding of whole viruses with similar quantitative rigor as the rosettes described here.

When comparing smaller virus-like particles, such as the rHA clusters employed here, with whole viruses, some considerations need to be discussed. As stated above, a virus is considerably larger than a rosette, and some differences are expected for these systems for their binding behavior on platforms like the one reported here. First of all, as larger particles experience slower diffusion towards the surface and whole viruses are normally applied at lower particle concentrations, reaching thermodynamic equilibrium for whole viruses binding to the interaction platform might be slower, and therefore verification of equilibrium will be necessary when designing full titration experiments to acquire thermodynamic binding constants. Moreover, several examples have been reported in the literature where binding of whole viruses is observed on platforms using a fixed concentration of $100 \mathrm{pM}$. $^{8,13}$ Therefore, relevant values of $K_{\mathrm{ov}}$ of the interaction of these viruses are expected to be in the range of, approximately, $10^{10}-10^{13} \mathrm{M}^{-1}$, which are significantly higher than the ones measured for the rHA clusters reported here. Obviously, higher values of $K_{\mathrm{ov}}$ are expected, as the contact area of a whole virus with the platform (or host cell) surface is expected to be much larger than the one of a rosette, and consequently many more HA trimers are involved in the overall interaction. When we assume that, for example, only $5 \%$ of the outer surface area of a virus binds to the platform surface, and that the trimer-trimer distance in a virus is 11 $\mathrm{nm},{ }^{34,35}$ an average of approx. $12 \mathrm{HA}$ trimers, i.e. $36 \mathrm{HA}$-sugar molecular interaction pairs, is involved in the interaction with the platform surface, which will increase the avidity accordingly. When we assume at the same time that the HA densities at a whole virus and a rosette are similar - and we note that $E M$ in the $K_{\mathrm{i}} E M$ factor is primarily governed by this density -, the individual HA-sugar interaction pairs will remain dynamic, which will cause the overall binding behavior of the virus to be dynamic as well. Future work on studying the overall binding behavior of whole viruses and their dynamics will have to be performed to verify this behavior experimentally.

\subsection{Conclusions}

We have reported the development of a platform that mimics the multivalent interaction of influenza A viruses at host cell membranes. The use of biotinylated supported lipid bilayers (SLBs) provides control over the type and density of sialoglycan receptors on the surface. 
Selectivity for human sialic acid residues was established as expected for the here used recombinant hemagglutinin (rHA) rosettes. Low nanomolar affinities for the rHA rosettes binding to the SA-presenting surfaces were obtained from full titration curves. Due to the small size of the rosette and its limited number of HA trimers compared to the whole virus, the interaction area and the valency in binding to a surface can be estimated relatively well. This allowed us to assess the extent of multivalent binding, and quite low multivalent enhancement factors, $K_{\mathrm{i}} E M$, of about 5-10 were found, indicating that each additional binding site contributes with less than one order of magnitude to the overall binding affinity of the rHA particle. Because of the similar HA site density present at whole influenza A viruses, we assume that these have similarly low multivalent enhancement factors as the rosettes studied here.

By evaluating the relationship between the overall binding affinity $K_{\mathrm{ov}}$, the individual $K_{\mathrm{i}}$, the valency $n$, and the effective molarity $E M$, a binding energy landscape has been sketched in which a sweet spot is evident for weakly multivalent systems, that is, for systems in which the individual binding sites equilibrate between bound and unbound with similar frequencies, rendering the multivalent system dynamic in nature. Future work will be focused on scaling the interaction area and valency to the values found in whole viruses. In addition, the methodology and analysis developed here may be applied to screen for future antiviral drugs or antibodies, which have the potential to block influenza virus binding. ${ }^{39,44}$ Finally, the quantitative assessment of weak multivalency may also be applicable to study different virushost cell interactions, or other biological systems in which multivalent interactions drive cellular responses, such as the mono- or low-valency ligand interactions triggering the B-cell antigen receptor. ${ }^{45-47}$

\subsection{Acknowledgments}

Dr. Mark L. Verheijden is acknowledged for the help in the development of the SLB platform and for the FRAP measurements. Dr. Erhard van der Vries is acknowledged for the fruitful discussions and Prof. Pascal Jonkheijm for the help in the analysis of the QCM data. Dr. Kai Ludwig, Freie Universität Berlin, core facility "BioSupraMol" is acknowledged for the TEM measurements, and Manon Cox and Indresh Srivastava from Protein Sciences corporation for providing the rHA clusters. 


\subsection{Experimental section}

\subsubsection{Materials}

Chemicals were purchased from Sigma Aldrich and Acros Organics. Commercial lipids were obtained from Avanti Polar Lipids. Streptavidin labelled with Alexa Fluor ${ }^{\circledR} 488$ (SAv488) was obtained from ThermoFisher. HEPES buffer contained 0.01 M HEPES and 0.15 M sodium chloride was made using Milli-Q water (MQ, Millipore, $18.2 \mathrm{~m} \Omega$ ) and adjusted to $\mathrm{pH} 7.4$ at $25^{\circ} \mathrm{C}$ using sodium hydroxide. Biotin-PAA-SLN was obtained from Lectinity and used as received. rHA protein clusters were obtained from Protein Sciences Corporation. The concentration of the stock solutions of the protein clusters used in this work ranged from 100 $\mathrm{nM}$ to $246 \mathrm{nM}$.

\subsubsection{Methods}

\section{QCM-D measurements}

QCM-D measurements were performed using a Qsense Analyser (Biolin Scientific). Measurements were performed at $22{ }^{\circ} \mathrm{C}$ and operated with four parallel flow chambers, using two Ismatec peristaltic pumps with a flow rate of $100 \mu \mathrm{l} / \mathrm{min}$. Throughout this work, the fifth overtone was used for the normalized frequency $\left(\Delta f_{5}\right)$ and dissipation $\left(\Delta D_{5}\right)$. $\mathrm{SiO}_{2}$-coated sensors (QSX303, Biolin Scientific) were used. During every rHA protein cluster addition, solutions were recycled.

\section{Large unilamellar vesicles (LUV) and supported lipid bilayer (SLB) formation}

1,2-Dioleoyl-sn-glycero-3-phosphocholine (DOPC) and 1,2-dioleoyl-sn-glycero-3phosphoethanolamine-N-(cap biotinyl), sodium salt (biotin-PE) were stored in chloroform at $-20^{\circ} \mathrm{C}$. The head group modified lipid-dye conjugate, Texas Red-1,2-dihexadecanoyl-snglycero-3-phosphoethanolamine (TR, ThermoFisher scientific) was stored in methanol at $20{ }^{\circ} \mathrm{C}$. Dissolved lipids were mixed in desired molar ratios before use and dried under a flow of nitrogen in a glass vial in order to create a film of lipid material at the glass wall. This film was further dried under vacuum for at least $1 \mathrm{~h}$ and subsequently hydrated by vortexing with Milli-Q water to form multilamellar vesicles at $1 \mathrm{mg} / \mathrm{mL}$. The lipid suspension was extruded 11 times through a polycarbonate membrane (Whatman) with $100 \mathrm{~nm}$ pore size, resulting in large unilamellar vesicles (LUVs) that were stored in the fridge and used within two weeks. The LUVs' size was measured with DLS after preparation. 


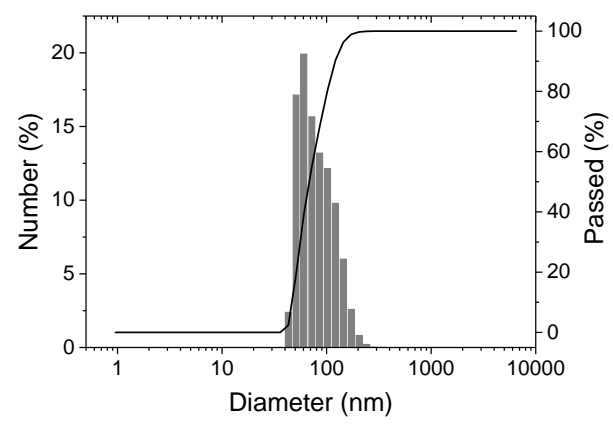

Figure 5.9. Dynamic light scattering (DLS) data of DOPC vesicles containing 5 mol\% DOPE-biotin, extruded $11 \mathrm{x}$ through a membrane with a $100 \mathrm{~nm}$ pore size.

For SLB fabrication, vesicles were diluted to a concentration of $0.1 \mathrm{mg} / \mathrm{ml}$ in HEPES directly before use. SLB formation was achieved by flowing this solution on a cleaned and activated surface. For flat QCM-D sensors or glass bottom well plates, cleaning was performed using a $2 \mathrm{wt} \%$ sodium dodecyl sulfate (SDS) solution and thorough rising with Milli-Q. Activation was performed with 30 min UV/ozone treatment (for QCM-D sensors) using a Bioforce chamber (Nanosciences) or overnight incubation in 2\% Hellmanex and again thorough Milli$\mathrm{Q}$ rinsing (for well plates). The quality of SLBs was monitored by fluorescence recovery after photobleaching (FRAP) or in situ by QCM-D (where high quality SLB defined as $\Delta f=-24 \pm$ $1 \mathrm{~Hz}$ and $\left.\Delta D<0.5^{*} 10^{-6}\right)$. After SLB formation, care was taken to keep the surface submerged in buffer and without bubbles.

\section{Fluorescence recovery after photobleaching (FRAP)}

A DOPC SLB was doped with $0.2 \mathrm{~mol} \%$ of TR and $1 \%$ of biotin-PE. Subsequently, the surface was incubated with $0.2 \mu \mathrm{M} \mathrm{SAv} 488$ for $1 \mathrm{~h}$, and washed carefully with buffer for at least 15 times. Using a confocal microscope, a spot of $10 \mu \mathrm{m}$ diameter was bleached and subsequently, the fluorescence intensity in this bleached region was monitored. The intensity was normalized and corrected for acquisition bleaching by using the fluorescence intensity in a location not too close to the bleached spot. The FRAP protocol consisted of 11 imaging loops ( $1 \mathrm{~s}$ interval) before bleaching, 10 loops bleaching with no delay in between loops and 300 loops of recovery ( $1 \mathrm{~s}$ interval). For confocal microscopy, a Nikon confocal (A1) microscope was used equipped with a $488 \mathrm{~nm}$ laser and a 525/50 nm emission filter and with 
a $561 \mathrm{~nm}$ laser with a 595/50 nm emission filter. In microscopy images displayed in this work, contrast and brightness were adapted for using ImageJ.

(A)
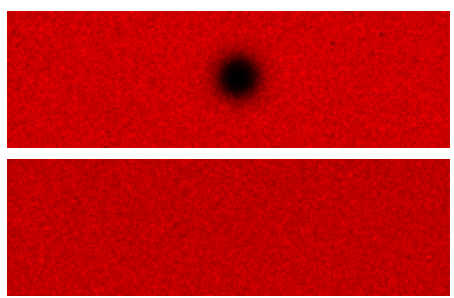

(B)

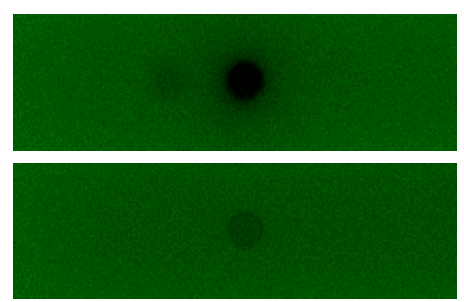

(C)

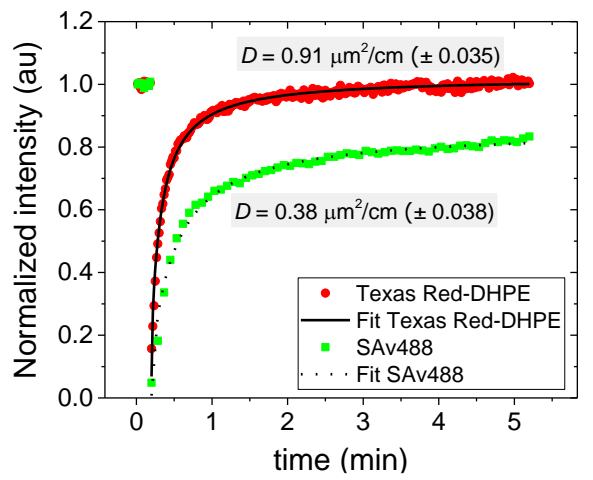

Figure 5.10. Fluorescence recovery after photobleaching (FRAP) by confocal microscopy of DOPC SLB with $0.2 \mathrm{~mol} \%$ TR-DHPE and $1 \mathrm{~mol} \%$ DOPE-biotin after $1 \mathrm{~h}$ incubation of $0.2 \mathrm{uM} \mathrm{SAv} 488$ and subsequent rinsing with HEPES buffer. A) red channel from TR-DHPE after photobleaching (top) and after 5 min recovery (bottom). B) green channel from SAv488 after photobleaching (top) and after 5 min recovery (bottom). C) Fluorescence intensity recovery profiles vs time of the Texas Red-DHPE and SAv488 after photobleaching.

\section{Transmission electron microscopy (TEM)}

The original solution of rHA was diluted 1:2 with PBS. Then $5 \mu 1$ of the suspension was pipetted onto a hydrophilized (by $60 \mathrm{~s}$ glow discharging at $8 \mathrm{~W}$ in a BALTEC MED 020 device (Leica Microsystems, Wetzlar, Germany)) Formvar ${ }^{\circledR}$-supported carbon-covered microscopical copper grid (400 mesh). After $30 \mathrm{~s}$, a piece of filter paper was used to remove excess fluid. Subsequently, $5 \mu$ of a contrast-enhancing heavy metal staining solution (1\% phosphotungstic acid, $\mathrm{pH}$ 7.4) was applied and blotted again after 45 s. After air-drying, a 
standard holder was used to transfer the sample into a Talos L120C microscope (Thermo Fisher Scientific Inc., Waltham, Massachusetts, USA) equipped with a $\mathrm{LaB}_{6}$-cathode operated at an acceleration voltage of $120 \mathrm{kV}$. Micrographs were recorded with a $4 \mathrm{k} \times 4 \mathrm{k}$ Ceta $^{\mathrm{TM}} 16 \mathrm{M}$ camera at a nominal magnification of 57,000x.

\section{Calculation of the quantification of receptors on a surface}

Considering that one DOPC lipid covers $0.725 \mathrm{~nm}^{2}$ and, therefore, the lipid density in SLB is 1.38 molecule per $\mathrm{nm}^{2}\left(=2.3 \times 10^{-10} \mathrm{~mol} / \mathrm{cm}^{2}=\mathrm{a}\right)$, we obtain as follows:

- fraction DOPE-biotin = $\mathrm{x}$;

$-\Theta(b t, S L B)=x \times a=x a ;$

$-\Theta(\mathrm{SAv})=1 / 2 \mathrm{xa}$

- $\Theta(\mathrm{bt}, \mathrm{PAA})=\mathrm{xa}$;

- $\Theta(\mathrm{SLN}, \mathrm{PAA})=4 \times \mathrm{xa}(=$ ratio $\mathrm{SLN} /$ biotin in PAA $)$.

Therefore at $\mathrm{x}=0.1 \%$ : $\Theta(\mathrm{SLN})=0.92 \mathrm{pmol} / \mathrm{cm}^{2}$, etc .

\subsection{References}

1. Molinari, N.-A. M.; Ortega-Sanchez, I. R.; Messonnier, M. L.; Thompson, W. W.; Wortley, P. M.; Weintraub, E.; Bridges, C. B. The Annual Impact of Seasonal Influenza in the US: Measuring Disease Burden and Costs. Vaccine 2007, 25, 5086-5096.

2. Iuliano, A. D.; Roguski, K. M.; Chang, H. H.; Muscatello, D. J.; Palekar, R.; Tempia, S.; Cohen, C.; Gran, J. M.; Schanzer, D.; Cowling, B. J.; Wu, P.; Kyncl, J.; Ang, L. W.; Park, M.; Redlberger-Fritz, M.; Yu, H.; Espenhain, L.; Krishnan, A.; Emukule, G.; van Asten, L. et al. Estimate of Global Seasonal Influenza-Associated Mortality: A Modelling Study. Lancet 2018, 391, 1285-1300.

3. Medina, R. A.; García-Sastre, A., Influenza A Viruses: New Research Developments. Nat. Rev. Microbiol. 2011, 9, 590-603.

4. Mammen, M.; Choi, S.-K.; Whitesides, G. M. Polyvalent Interactions in Biological Systems: Implications for Design and Use of Multivalent Ligands and Inhibitors. Angew. Chem. Int. Edit. 1998, 37, 2754-2794.

5. Wagner, R.; Wolff, T.; Herwig, A.; Pleschka, S.; Klenk, H.-D. Interdependence of Hemagglutinin Glycosylation and Neuraminidase as Regulators of Influenza Virus Growth: A Study by Reverse Genetics. J. Virol. 2000, 74, 6316-6323.

6. Connor, R. J.; Kawaoka, Y.; Webster, R. G.; Paulson, J. C. Receptor Specificity in Human, Avian, and Equine H2 and H3 Influenza Virus Isolates. Virology 1994, 205, 17-23.

7. Matrosovich, M.; Tuzikov, A.; Bovin, N.; Gambaryan, A.; Klimov, A.; Castrucci, M. R.; Donatelli, I.; Kawaoka, Y. Early Alterations of the Receptor-Binding Properties of H1, H2, and H3 Avian Influenza Virus Hemagglutinins after Their Introduction into Mammals. $J$. Virol. 2000, 74, 8502-8512. 
8. Vachieri, S. G.; Xiong, X.; Collins, P. J.; Walker, P. A.; Martin, S. R.; Haire, L. F.; Zhang, Y.; McCauley, J. W.; Gamblin, S. J.; Skehel, J. J. Receptor Binding by H10 Influenza Viruses. Nature 2014, 511, 475-477.

9. Herfst, S.; Imai, M.; Kawaoka, Y.; Fouchier, R. A. M. Avian Influenza Virus Transmission to Mammals. In Influenza Pathogenesis and Control - Volume I, Eds. Springer International Publishing, 2014, 137-155.

10. Garten, R. J.; Davis, C. T.; Russell, C. A.; Shu, B.; Lindstrom, S.; Balish, A.; Sessions, W. M.; Xu, X.; Skepner, E.; Deyde, V.; Okomo-Adhiambo, M.; Gubareva, L.; Barnes, J.; Smith, C. B.; Emery, S. L.; Hillman, M. J.; Rivailler, P.; Smagala, J.; de Graaf, M.; Burke, D. F. et al. Antigenic and Genetic Characteristics of Swine-Origin 2009 A(H1N1) Influenza Viruses Circulating in Humans. Science 2009, 325, 197-201.

11. Bai, H.; Wang, R.; Hargis, B.; Lu, H.; Li, Y. A SPR Aptasensor for Detection of Avian Influenza Virus H5N1. Sensors 2012, 12, 12506-12518.

12. Carvalho, S. B.; Moleirinho, M. G.; Wheatley, D.; Welsh, J.; Gantier, R.; Alves, P. M.; Peixoto, C.; Carrondo, M. J. T. Universal Label-Free In-Process Quantification of Influenza Virus-Like Particles. Biotechnol. J. 2017, 12, 1700031.

13. Xiong, X.; Coombs, P. J.; Martin, S. R.; Liu, J.; Xiao, H.; McCauley, J. W.; Locher, K.; Walker, P. A.; Collins, P. J.; Kawaoka, Y.; Skehel, J. J.; Gamblin, S. J. Receptor Binding by a Ferret-Transmissible H5 Avian Influenza Virus. Nature 2013, 497, 392-396.

14. Jung, H.; Robison, A. D.; Cremer, P. S. Multivalent Ligand-Receptor Binding on Supported Lipid Bilayers. J. Struct. Biol. 2009, 168, 90-94.

15. Gooding, J. J.; Parker, S. G.; Lu, Y.; Gaus, K. Molecularly Engineered Surfaces for Cell Biology: From Static to Dynamic Surfaces. Langmuir 2014, 30, 3290-3302.

16. Satav, T.; Huskens, J.; Jonkheijm, P. Effects of Variations in Ligand Density on Cell Signaling. Small 2015, 11, 5184-5199.

17. Koçer, G.; Jonkheijm, P. Guiding hMSC Adhesion and Differentiation on Supported Lipid Bilayers. Adv. Healthc. Mater. 2017, 6, 1600862.

18. Wasserberg, D.; Cabanas-Danés, J.; Prangsma, J.; O’Mahony, S.; Cazade, P.-A.; Tromp, E.; Blum, C.; Thompson, D.; Huskens, J.; Subramaniam, V.; Jonkheijm, P. Controlling Protein Surface Orientation by Strategic Placement of Oligo-Histidine Tags. ACS Nano 2017, 11, 9068-9083.

19. Houseman, B. T.; Mrksich, M. The Microenvironment of Immobilized Arg-Gly-Asp Peptides Is an Important Determinant of Cell Adhesion. Biomaterials 2001, 22, 943-955.

20. Dubacheva, G. V.; Araya-Callis, C.; Geert Volbeda, A.; Fairhead, M.; Codée, J.; Howarth, M.; Richter, R. P. Controlling Multivalent Binding through Surface Chemistry: Model Study on Streptavidin. J. Am. Chem. Soc. 2017, 139, 4157-4167.

21. van Weerd, J.; Karperien, M.; Jonkheijm, P. Supported Lipid Bilayers for the Generation of Dynamic Cell-Material Interfaces. Adv. Healthc. Mater. 2015, 4, 2743-2779.

22. Rhodes, D. G.; Holtz, K.; Robinson, P.; Wang, K.; McPherson, C. E.; Cox, M. M.; Srivastava, I. K. Improved Stability of Recombinant Hemagglutinin Using a Formulation Containing Sodium Thioglycolate. Vaccine 2015, 33, 6011-6016.

23. Böttcher, C.; Ludwig, K.; Herrmann, A.; van Heel, M.; Stark, H. Structure of Influenza Haemagglutinin at Neutral and at Fusogenic $\mathrm{pH}$ by Electron Cryo-Microscopy. FEBS Lett. 1999, 463, 255-259.

24. Ward, B. J.; Landry, N.; Trépanier, S.; Mercier, G.; Dargis, M.; Couture, M.; D’Aoust, M.A.; Vézina, L.-P. Human Antibody Response to N-Glycans Present on Plant-made Influenza Virus-Like Particle (VLP) Vaccines. Vaccine 2014, 32, 6098-6106. 
25. McBrayer, A.; Camp, J. V.; Tapp, R.; Yamshchikov, V.; Grimes, S.; Noah, D. L.; Jonsson, C. B.; Bruder, C. E. Course of Seasonal Influenza A/Brisbane/59/07 H1N1 Infection in the Ferret. Virol. J. 2010, 7, 149.

26. Daum, L. T.; Canas, L. C.; Smith, C. B.; Klimov, A.; Huff, W.; Barnes, W.; Lohman, K. L. Genetic and Antigenic Analysis of the first A/New Caledonia/20/99-like H1N1 Influenza Isolates Reported in the Americas. Emerg. Infect. Dis. 2002, 8, 408-412.

27. Lind, T. K.; Cárdenas, M. Understanding the Formation of Supported Lipid Bilayers via Vesicle Fusion-A Case that Exemplifies the Need for the Complementary Method Approach. Biointerphases 2016, 11, 020801.

28. Xiong, X.; Martin, S. R.; Haire, L. F.; Wharton, S. A.; Daniels, R. S.; Bennett, M. S.; McCauley, J. W.; Collins, P. J.; Walker, P. A.; Skehel, J. J.; Gamblin, S. J. Receptor Binding by an H7N9 Influenza Virus from Humans. Nature 2013, 499, 496-499.

29. Collins, P. J.; Vachieri, S. G.; Haire, L. F.; Ogrodowicz, R. W.; Martin, S. R.; Walker, P. A.; Xiong, X.; Gamblin, S. J.; Skehel, J. J., Recent Evolution of Equine Influenza and the Origin of Canine Influenza. Proc. Natl. Acad. Sci. U. S. A. 2014, 111, 11175-11180.

30. Reviakine, I.; Johannsmann, D.; Richter, R. P. Hearing What You Cannot See and Visualizing What You Hear: Interpreting Quartz Crystal Microbalance Data from Solvated Interfaces. Anal. Chem. 2011, 83, 8838-8848.

31. Reviakine, I.; Brisson, A. Streptavidin 2D Crystals on Supported Phospholipid Bilayers: Toward Constructing Anchored Phospholipid Bilayers. Langmuir 2001, 17, 8293-8299.

32. Larsson, C.; Rodahl, M.; Höök, F. Characterization of DNA Immobilization and Subsequent Hybridization on a 2D Arrangement of Streptavidin on a Biotin-modified Lipid Bilayer Supported on SiO2. Anal. Chem. 2003, 75, 5080-5087.

33. Bovin, N. V. Polyacrylamide-based Glycoconjugates as Tools in Glycobiology. Glycoconjugate J. 1998, 15, 431-446.

34. Wasilewski, S.; Calder, L. J.; Grant, T.; Rosenthal, P. B. Distribution of Surface Glycoproteins on Influenza A Virus Determined by Electron Cryotomography. Vaccine 2012, $30,7368-7373$.

35. Harris, A.; Cardone, G.; Winkler, D. C.; Heymann, J. B.; Brecher, M.; White, J. M.; Steven, A. C. Influenza Virus Pleiomorphy Characterized by Cryoelectron Tomography. Proc. Natl. Acad. Sci. U. S. A. 2006, 103, 19123-19127.

36. Huskens, J.; Mulder, A.; Auletta, T.; Nijhuis, C. A.; Ludden, M. J. W.; Reinhoudt, D. N. A Model for Describing the Thermodynamics of Multivalent Host-Guest Interactions at Interfaces. J. Am. Chem. Soc. 2004, 126, 6784-6797.

37. Hunter, C. A.; Anderson, H. L., What is Cooperativity? Angew. Chem. Int. Edit. 2009, 48, 7488-7499.

38. Mulder, A.; Huskens, J.; Reinhoudt, D. N. Multivalency in Supramolecular Chemistry and Nanofabrication. Org. Biomol. Chem. 2004, 2, 3409-3424.

39. Bhatia, S.; Lauster, D.; Bardua, M.; Ludwig, K.; Angioletti-Uberti, S.; Popp, N.; Hoffmann, U.; Paulus, F.; Budt, M.; Stadtmuller, M.; Wolff, T.; Hamann, A.; Bottcher, C.; Herrmann, A.; Haag, R. Linear Polysialoside Outperforms Dendritic Analogs for Inhibition of Influenza Virus Infection In Vitro and In Vivo. Biomaterials 2017, 138, 22-34.

40. Perl, A.; Gomez-Casado, A.; Thompson, D.; Dam, H. H.; Jonkheijm, P.; Reinhoudt, D. N.; Huskens, J. Gradient-Driven Motion of Multivalent Ligand Molecules along a Surface Functionalized with Multiple Receptors. Nat. Chem. 2011, 3, 317-322.

41. Ohtsubo, K.; Marth, J. D., Glycosylation in Cellular Mechanisms of Health and Disease. Cell 2006, $126,855-867$. 
42. Chen, Y.; Ding, L.; Liu, T.; Ju, H., Arrayed Profiling of Multiple Glycans on Whole Living Cell Surfaces. Anal. Chem. 2013, 85, 11153-11158.

43. Guo, H.; Rabouw, H.; Slomp, A.; Dai, M.; van der Vegt, F.; van Lent, J. W. M.; McBride, R.; Paulson, J. C.; de Groot, R. J.; van Kuppeveld, F. J. M.; de Vries, E.; de Haan, C. A. M., Kinetic Analysis of the Influenza A Virus HA/NA Balance Reveals Contribution of NA to Virus-Receptor Binding and NA-Dependent Rolling on Receptor-containing Surfaces. PLOS Pathog. 2018, 14, e1007233.

44. Bangaru, S.; Zhang, H.; Gilchuk, I. M.; Voss, T. G.; Irving, R. P.; Gilchuk, P.; Matta, P.; Zhu, X.; Lang, S.; Nieusma, T.; Richt, J. A.; Albrecht, R. A.; Vanderven, H. A.; Bombardi, R.; Kent, S. J.; Ward, A. B.; Wilson, I. A.; Crowe, J. E., A Multifunctional Human Monoclonal Neutralizing Antibody that Targets a Unique Conserved Epitope on Influenza HA. Nat. Commun. 2018, 9, 2669.

45. Kim, Y.-M.; Pan, J. Y.-J.; Korbel, G. A.; Peperzak, V.; Boes, M.; Ploegh, H. L. Monovalent Ligation of the B Cell Receptor Induces Receptor Activation but Fails to Promote Antigen Presentation. Proc. Natl. Acad. Sci. U. S. A. 2006, 103, 3327-3332.

46. Avalos, A. M.; Bilate, A. M.; Witte, M. D.; Tai, A. K.; He, J.; Frushicheva, M. P.; Thill, P. D.; Meyer-Wentrup, F.; Theile, C. S.; Chakraborty, A. K.; Zhuang, X.; Ploegh, H. L. Monovalent Engagement of the BCR Activates Ovalbumin-Specific Transnuclear B Cells. $J$. Exp. Med. 2014, 211, 365-379.

47. Villar, R. F.; Patel, J.; Weaver, G. C.; Kanekiyo, M.; Wheatley, A. K.; Yassine, H. M.; Costello, C. E.; Chandler, K. B.; McTamney, P. M.; Nabel, G. J.; McDermott, A. B.; Mascola, J. R.; Carr, S. A.; Lingwood, D., Reconstituted B Cell Receptor Signaling Reveals Carbohydrate-Dependent Mode of Activation. Sci. Rep. 2016, 6, 36298. 


\section{Chapter 6}

\section{Multivalent Interaction of the Influenza Virus at Sialoglycan-functionalized Supported Lipid Bilayers}

In this chapter, the study of the interaction of whole viruses on receptor-functionalized supported lipid bilayers (SLBS) is reported. In particular, the SLB platform described in the previous chapter has been adapted and investigated for the quantification of binding affinities of whole viruses with sialoglycan receptors at the interface. After the formation of biotinylated SLBS and the subsequent adsorption of streptavidin, the surfaces were functionalized with tunable densities of monovalent artificial sialoglycan cell surface receptors, and their interaction with three variants of the influenza virus was tested. The binding selectivity of both hemagglutinin (HA) and neuraminidase (NA) virus proteins for specific receptors was established. Full titrations with whole viruses were conducted, and the binding constants at varying receptor densities were determined, which resulted in affinities in the picomolar range. Measurements of plateau values for the adsorption of whole viruses on surfaces, obtained at different receptor densities, showed a superselective binding of the viruses. In this way, the quantification of a receptor threshold density needed for the binding of virus at the surface was determined. Quantitative analysis of the binding affinities allowed the estimation of the contact area of a virus with the receptor-functionalized platform, which resulted to be 1-5\% of the total virus area, corresponding to a total number of interaction pairs between 9 and 45. These results confirm that the binding of the virus to this cell surface mimic occurs in the weakly multivalent regime. Variation of the receptor length showed that strong affinity dependencies on the linker length can occur. 


\subsection{Introduction}

The influenza A virus (IAV) is a pathogen that infects millions of people every year causing an acute viral disease of the respiratory tract. ${ }^{1,2}$ Based on the antigenicity of their hemagglutinin (HA) and neuraminidase (NA) coat proteins, viruses are classified into $16 \mathrm{HA}$ subtypes (H1-H16) and 9 NA subtypes (N1-N9). ${ }^{3}$ Based on the specificity of HA and NA, viruses show different affinities for sialoglycan receptors present at the outer surface of cells of the respiratory tract. In particular, some virus variants present affinities for receptors found on avian cells, while others show a preference for binding to mammalian/human receptors. Interspecies transmission of IAVs circulating in birds has occasionally led in the past to severe influenza outbreaks in mammals, including humans. ${ }^{4}$ For example, the H1N1 'Spanish flu' pandemic of $1918 / 1919$, caused by the transmission of the avian influenza virus to humans, killed 50 million people worldwide. Similarly, the H2N2 ‘Asian' in 1957 and H3N2 'Hong Kong' 1968 influenza pandemics originated from reassortant viruses, i.e. hybrid viruses consisting of a mixture of human and avian influenza genes. ${ }^{5,6}$

For predicting infectivity and future pandemics, reliable methods to measure the affinity of several types of viruses and their mutated forms for specific receptors are essential for a better understanding of the binding and the relation to disease properties. In the development of platforms, control of various parameters, such as receptor surface density and the number (valency) of individual protein-carbohydrate binding pairs at the virus-cell interface, are essential for a better understanding of the factors that determine viral pathogenicity and transmissibility.

Biolayer interferometry (BLI) is a label-free technique commonly used in the study of the binding selectivity of viruses for specific receptors. The technique allows the variation of the sugar density expressed at the interface. ${ }^{7-9}$ Effects of virus mutations on the selectivity for specific receptors have been successfully reported. ${ }^{8,10}$ Despite the success of BLI, the technique presents some limitations. In particular, quantitative analyses are difficult to perform, despite the possibility of qualitatively assessing the receptor selectivity of viruses. Determination of binding affinities with full virus titrations are normally not performed as a constant concentration of a virus is typically used to determine full or partial coverage of receptor-functionalized surfaces. ${ }^{7}$ Moreover, due to the type of substrates generally employed in the preparation of BLI sensors, typical biological properties of cell surfaces, such as lipid mobility, are not reproduced and the arrangement of the receptors at the interface is scarcely known. Therefore, BLI provides limited information about multivalent binding parameters such as valency, affinity and effective molarity.

Supported lipid bilayer (SLB)-based platforms, such as the one reported in Chapter $5,{ }^{11}$ therefore, appear to be an exquisite alternative for BLI for the quantification of receptor-virus 
interactions. In Chapter 5, we have shown that a suitably modified SLB platform can be used to discriminate different HA nanoparticles. More importantly, full titrations provided direct access to the overall binding affinities, and other parameters such as valency and effective molarity were determined from a quantitative multivalent analysis of the HA nanoparticle titrations. This analysis resulted in the affirmation that HA nanoparticles bind in a weakly multivalent fashion at such surfaces.

In this contribution, we investigate the use of an SLB-based platform for the quantification of the interaction of whole influenza viruses with receptor-modified surfaces. SLBs were modified with controllable densities of biotinylated, monovalent sialoglycan receptors. After confirming the selectivity and specificity of the interaction of viruses with the interaction platform, modified with either human-like or avian-like receptors, the binding affinities were assessed employing full titrations. Plateau values for the adsorption of whole viruses on surfaces were obtained for varying receptor densities, allowing the measurement of the receptor threshold density required for the binding of the viruses. Lastly, the SLB-virus interaction was investigated for receptors with varying lengths. The tunable sugar density together with an accurate estimation of the number of HA trimers involved in the interaction enables the use of a multivalent binding model for a understanding of the interaction at a molecular level.

\subsection{Results and discussion}

\subsubsection{Receptor density control at sialoglycan-modified SLBs}

In order to study the interaction of influenza A viruses at the interface of receptor-modified surfaces, we employed and adapted the SLB-based platform previously described in Chapter 5. Briefly, after activating a silicon dioxide surface with UV/ozone, a DOPC-based SLB containing a controllable molar fraction of a biotinylated lipid (DOPE-biotin) was formed at the substrate. In a subsequent step, streptavidin (SAv) was bound to the biotin-modified SLB, followed by the addition of a biotinylated sialyl-N-acetyllactosamine (SLN)-based receptor (Figure 6.1). As previously shown, the control of the molar fraction of DOPE-biotin in the lipid mixture during the formation of the SLB, ensures the control over the SAv density, which is related to the density of receptors at the surface. In this chapter, a monovalent biotinylated receptor was used for the modification of the platform, compared to the polyvalent one described in the previous chapter. The monovalent receptor provides a better control of the receptor density on the surface and avoids differences between local and global densities which were experienced using the multivalent receptors. ${ }^{11}$ 


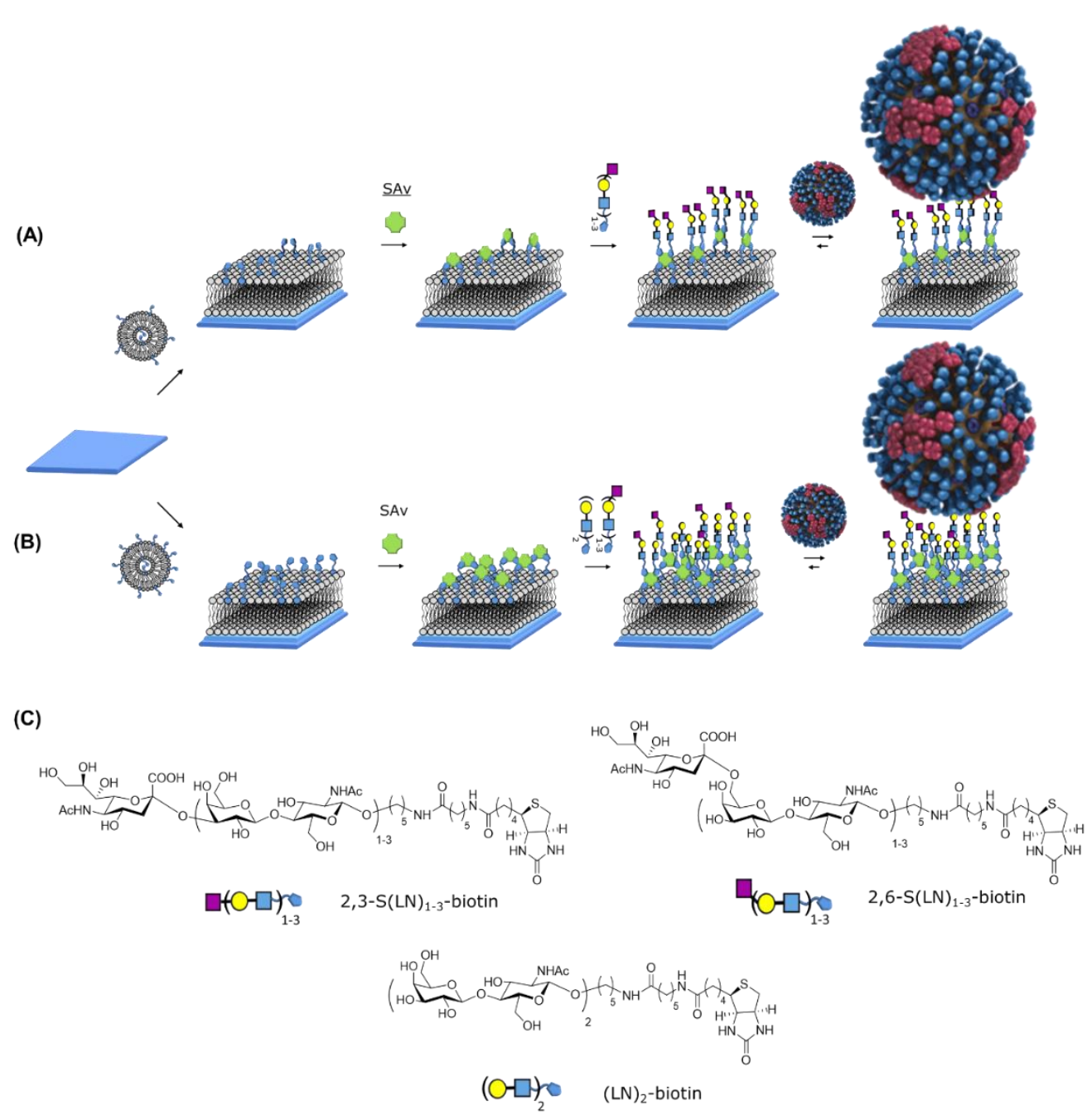

Figure 6.1. Schematic representation of the functionalization of the SLB-based platform with monovalent biotinylated SLNs and its interaction with full viruses, in which the SLN density can be varied in two different ways: in (A) the SLN density is tuned by varying the molar fraction of DOPEbiotin in SUVs used for forming the SLB; in (B) the SLN density is controlled by fully covering SLBs with SAv (i.e. using a 2\% molar fraction of DOPE-biotin in SUVs) and mixing the SLN receptor in varying ratios with a dummy receptor $\left((\mathrm{LN})_{2}\right.$-biotin). (C) Chemical structures of the biotinylated sialoglycan receptors employed.

The SAv-SLB platform allows two methods of controlling the SLN density. The first method, also used in Chapter 5, provides control over the SLN density by variation of the DOPEbiotin fraction in the SLB (Figure 6.1A). Specifically, as the SAv uses two of the four 
available binding pockets to bind to two biotins in the SLB and the remaining two are used for the binding with biotinylated molecules, ${ }^{12}$ the SLN ligand density is directly correlated to the DOPE-biotin fraction in the SLB. As a second method, to avoid possible experimental deviations in the SAv density, we employed platforms densely packed with SAv, and supplied the SLN receptor in a mixture with a biotinylated dummy sugar (here typically biotin-(LN) $)_{2}$ ) (see Figure 6.1B). Control over de molar ratio of the two sugars provides the desired SLN density control in this case.

SLNs containing three repeat units of $\mathrm{N}$-acetyllactosamine $\left(\mathrm{S}(\mathrm{LN})_{3}\right)$ were used here as virusbinding receptors primarily. The additional saccharides, which function as a flexible linker, ensure a larger length of the receptors facilitating the binding with viruses. Both 2,3 and 2,6$\mathrm{S}(\mathrm{LN})_{3}$ were used in this work for the modification of surfaces. In the last section, however, also the length was varied to shorter sequences with only 1 or $2 \mathrm{LN}$ repeats to study the effect of the linker length on virus binding.

\subsubsection{Virus binding at sialoglycan-modified SLBs}

The formation of the platform as well as the subsequent binding of viruses was studied with quartz crystal microbalance with dissipation monitoring (QCM-D). Figure 6.2A shows the in-situ formation of the platform monitored in real-time by following the frequency change of every adsorption step. As more thoroughly described in Chapter 5, SLBs were formed by rupture of small unilamellar vesicles (SUVs) with a diameter of $100 \mathrm{~nm}$ on activated silicon dioxide surfaces. $\Delta f_{5}$ values of approximately $24 \mathrm{~Hz}$ and $\Delta D_{5}<$ of 0.5 obtained upon vesicle addition, confirmed the formation of good quality SLBs. The first two steps in Figure 6.2A show the formation of a stable SLB containing $1 \%$ of DOPE-biotin in the lipid mixture and the subsequent formation of a SAv layer. Subsequently, a smaller, though clear, frequency shift, together with an evident dissipation change, was observed upon addition of either biotinylated 2,3 or $2,6-\mathrm{S}(\mathrm{LN})_{3}$, with no relevant differences between the two different receptors. The stable frequency signals obtained upon rinsing with buffer demonstrate the stability of the formed sialoglycan-functionalized platform. 
(A)

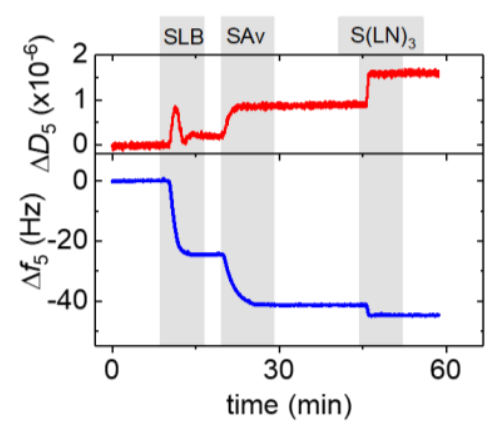

(B)
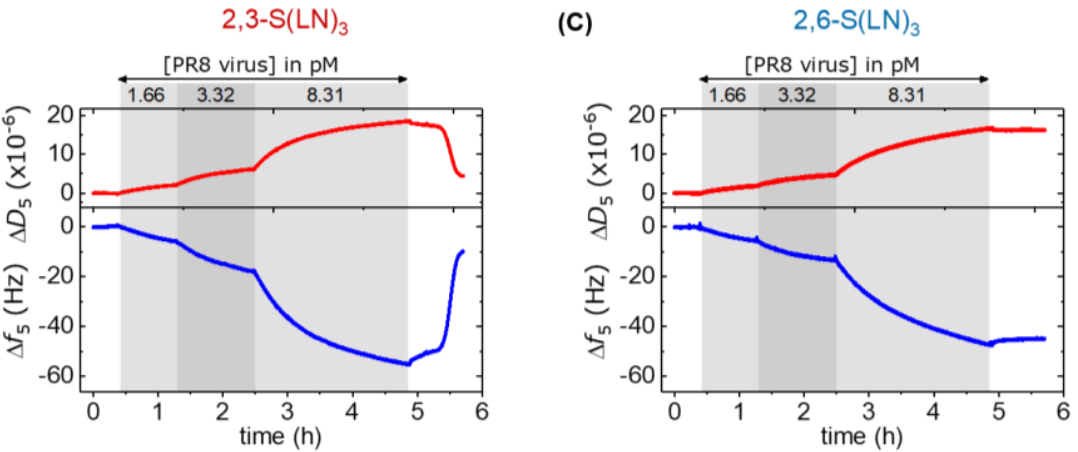

Figure 6.2. QCM-D graphs representing: (A) Formation of the sialoglycan-presenting SLB platform. SLBs containing $1 \mathrm{~mol} \%$ of DOPE-biotin were formed on $\mathrm{SiO}_{2}$ sensors. Subsequently, SAv and either biotinylated 2,3 or $2,6-\mathrm{S}(\mathrm{LN})_{3}(100 \%)$ were added. Adsorption of PR8 virus on (B) $2,3-\mathrm{S}(\mathrm{LN})_{3}$ or $(\mathrm{C})$ $2,6-\mathrm{S}(\mathrm{LN})_{3}$-modified SLBs. Blue lines represent the frequency shift $\left(\Delta f_{5}\right)$ and the red lines the dissipation change $\left(\Delta D_{5}\right)$. Gray areas represent additions (in $\mathrm{B} / \mathrm{C}$ : of virus in the presence of zanamivir) while white areas represent buffer washing steps (in the absence of zanamivir).

After the successful formation of the interaction platform, the binding with viruses was tested. In preliminary studies, UV-inactivated A/Puerto Rico/8/34/Mount Sinai H1N1 (PR8) viruses (see Experimental Section) were used to study the interaction. Hereto, after the addition of SLN receptors on the surface, full viruses were added to study their interaction with the receptor-modified platforms. In order to prevent the sialic acid-cleaving activity of the NA protein, which would remove the sialic acid residues from the surface, virus adsorption steps were carried out in PBS buffer containing $100 \mu \mathrm{M}$ of zanamivir, a wellknown NA inhibitor. Increasing concentrations (1.66, 3.32 and $8.30 \mathrm{pM})$ of PR8 in PBS buffer were added onto surfaces functionalized with 2,3 or $2,6^{\prime}-\mathrm{S}(\mathrm{LN})_{3}$, and the responses were monitored with QCM. Figure 6.2B/C shows the frequency shifts observed in response to the addition of PR8 to the two surfaces. Notably, comparable frequency shifts, 
accompanied by large dissipation signal changes, were observed for both surfaces, with amplitudes proportional to the concentration of PR8 in solution. The observed responses of PR8 indicate a binding affinity of the virus HAs for both the 2,3 and 2,6 receptors, in agreement with the literature. ${ }^{13}$ At the same time, the absence of any frequency shift (data not shown) obtained upon virus addition to surfaces functionalized either with only SAv or with $(\mathrm{LN})_{2}$-biotin, proved the specificity of the virus-receptor interactions.

These preliminary results confirmed that the developed platform is suitable for the study of whole viruses at the interface. In order to establish whether the selectivity of a particular virus for a specific receptor can be detected, two different recombinant, $\mathrm{UV}$-inactivated viruses were tested on the platform. In particular, the H1N1 A/Common teal/NL/10/00 (CT/NL/00) and H2N9 A/Mallard/Sweden/36/03 (M/Sw/03) avian viruses, both expected to present a higher affinity for the $2,3-\mathrm{S}(\mathrm{LN})_{3}$ receptor, were tested on the platform. Figure $6.3 \mathrm{~A} / \mathrm{B}$ shows the QCM response of the surfaces after addition of solutions with 8.3 and $16.6 \mathrm{pM}$ virus. The larger frequency responses observed for surfaces modified with 2,3-S(LN) $)_{3}$ compared to 2,6$\mathrm{S}(\mathrm{LN})_{3}$ for both the recombinant viruses confirmed the expected preference of these virus variants for avian receptors. In particular, the $\mathrm{CT} / \mathrm{NL} / 00$ virus showed a 2-fold stronger binding on the 2,3-platform, while the $\mathrm{M} / \mathrm{Sw} / 03$ virus showed even a 5-fold enhancement. These results confirm the possibility of using the SLB platform for testing virus selectivity. 


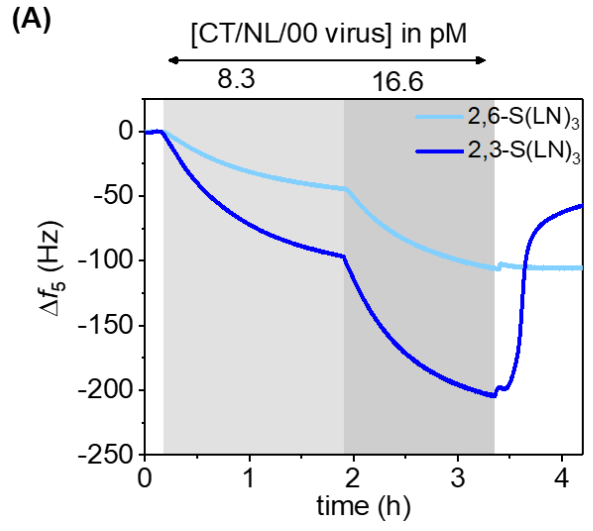

(C)

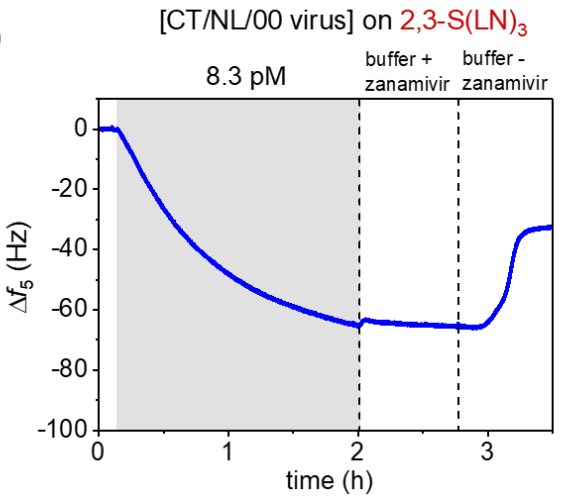

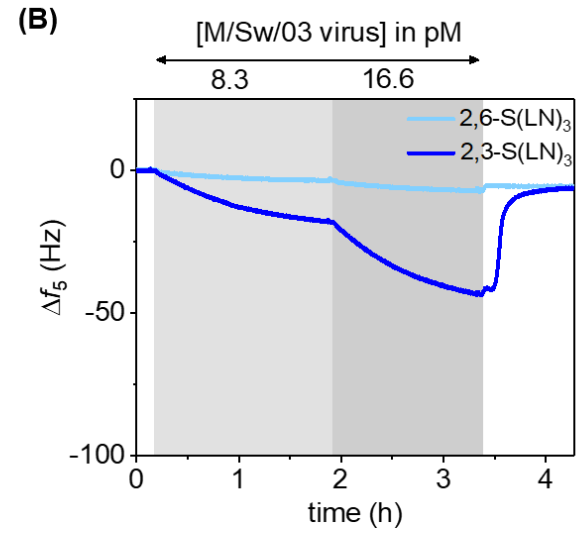

(D)

[CT/NL/00 virus] on 2,6-S(LN) 3

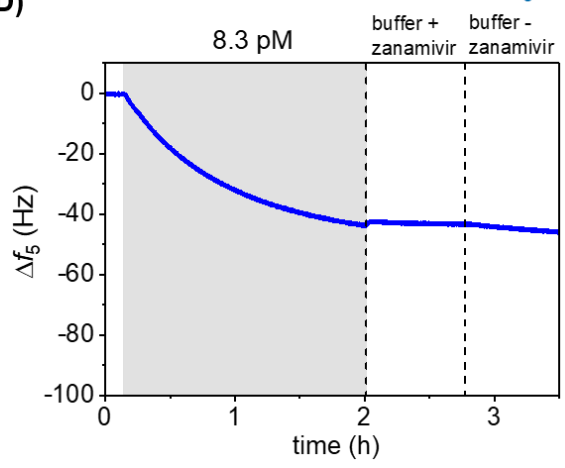

Figure 6.3. QCM-D measurements for probing the selectivity of virus binding to receptor-modified surfaces. Binding of (A) CT/NL/00 and (B) M/Sw/03 viruses (in presence of zanamivir) on 2,3 and 2,6$\mathrm{S}(\mathrm{LN})_{3}$-modified SLBs (employing $2 \%$ DOPE-biotin and $\left.100 \% \mathrm{~S}(\mathrm{LN})_{3}\right)$. Binding of the CT/NL/00 virus on platforms with $(\mathrm{C}) 2,3-\mathrm{S}(\mathrm{LN})_{3}$ and $(\mathrm{D}) 2,6-\mathrm{S}(\mathrm{LN})_{3}$ followed by rinsing with $\mathrm{PBS}$ with and without $100 \mu \mathrm{M}$ of zanamivir. Gray areas represent virus binding (in the presence of zanamivir) whereas white areas represent buffer rinsing steps (without zanamivir unless specified differently).

Interestingly, for all three viruses tested, no virus desorption was observed (Figure 6.2B/C, Figure $6.3 \mathrm{~A} / \mathrm{B}$ ) for the $2,6-\mathrm{S}(\mathrm{LN})_{3}$-functionalized surfaces upon rinsing with buffer without zanamivir subsequent to the binding of the virus. In contrast, a fast and almost complete desorption was observed for the 2,3-S(LN) 3 platform. When zanamivir was present in the rinsing buffer, the viruses were maintained on the surface until the zanamivir was removed (Figure 6.3C/D). These observations are attributed to differences in binding affinity and reactivity of NA for the two receptors. ${ }^{14}$ The rinsing of the surfaces in the absence of zanamivir apparently reinstates the enzymatic activity of NA. When comparing the release rates for the three viruses, some interesting aspects can be noted. PR8 and M/Sw/03 desorb practically completely, whereas $30-50 \%$ of CT/NL/00 remains after a steep desorption step. 
Also interesting to note is that a higher coverage of CT/NL/00 provides a shorter lag time before desorption sets in and leads to more complete desorption in the end. These effects may be in agreement with a model in which the viruses move along the surface but stay attached to the surface as long as SLN moieties are present, and only desorb when the SLN density falls below a critical density. However, a more detailed investigation of these aspects falls outside the scope of this study. These data confirm that the SLB platform used in this study is suitable not only for the investigation of HA binding for several virus variants, but also to study the role and the activity of NA.

\subsubsection{Quantification of the virus-receptor affinity at the SLB platform}

After confirming that selectivity and specificity of the interaction between receptorfunctionalized SLBs and viruses can be detected, the binding affinity of the interaction was determined. For this purpose, $2,3-\mathrm{S}(\mathrm{LN})_{3}$-modified SLBs were used to quantify the binding of the PR8 virus, as no significant difference was observed between the two receptors at the specific SLN densities used in the preliminary experiments. The correlation between the QCM response and the concentration of PR8, observed in the previous selectivity studies, suggests that the assessment of the binding affinity can be achieved by performing full titrations with the whole viruses.

First, a titration of PR8 was performed on an SLB functionalized with a high coverage of 2,3$\mathrm{S}(\mathrm{LN})_{3}$ receptors. Based on the observations made in Chapter 5, biotin molar fractions in the SLB above $2 \%$ lead to a densely packed SAv layer on top of the SLB. Therefore, an SLB containing $2 \%$ of DOPE-biotin was chosen for this experiment, resulting in a $2,3-\mathrm{S}(\mathrm{LN})_{3}$ density of approximately $2.9 \mathrm{pmol} / \mathrm{cm}^{2}$. Figure $6.4 \mathrm{~A}$ shows the titration performed with PR8 concentrations ranging between 8.31 and $166 \mathrm{pM}$, for which each solution was flushed for $40 \mathrm{~min}$. For each virus addition, approximately $90 \%$ of the total frequency shift was obtained within the first $30 \mathrm{~min}$, whereas in the remaining $10 \mathrm{~min}$ a significantly smaller change was observed. This suggests that the chosen time was sufficient for the viruses to approach thermodynamic equilibrium at these concentrations. Therefore, we assume that the $K_{\mathrm{d}}$ value of the interaction can be assessed with full titrations. Interesting to note also is that at the highest concentration (166 pM) hardly any more virus bound to the surface, indicating that the surface became fully covered. 
(A)

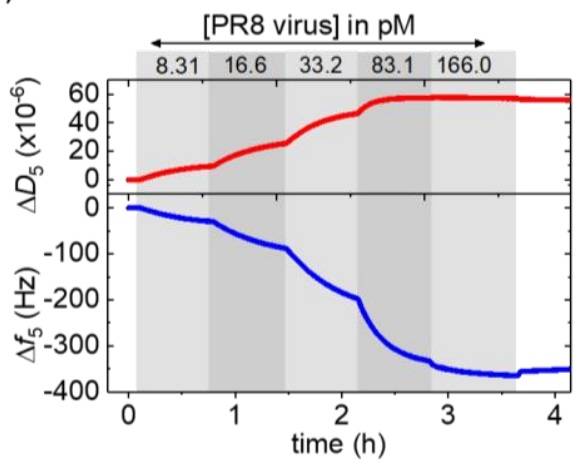

(C)

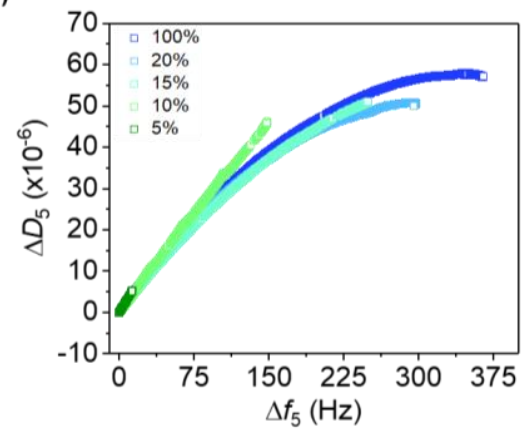

(B)

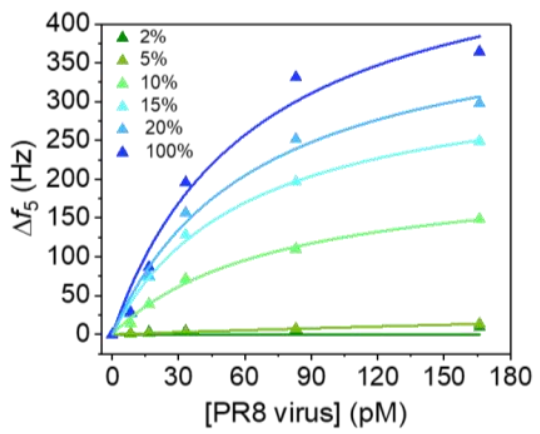

(D)

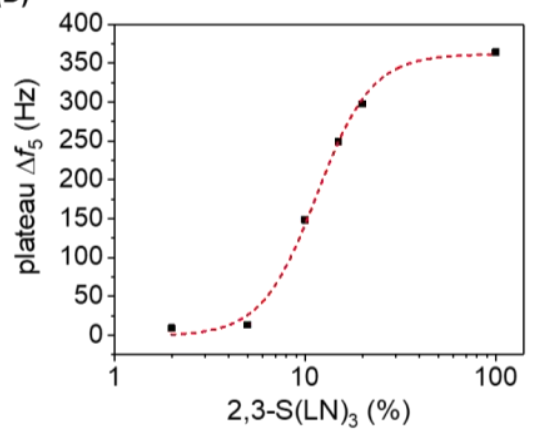

Figure 6.4. (A) QCM-D measurement of a titration of PR8 onto a 2,3-S(LN)3-modified SLB containing $2 \%$ molar fraction of DOPE-biotin. The SLB was subsequently functionalized with SAv and with $1 \mu \mathrm{M}$ of biotinylated 2,3-S(LN) 3 (no dummy sugar used). Surface functionalization up to the virus binding was monitored as well but not shown here. Gray areas indicate the virus adsorption steps (in the presence of zanamivir) and the white areas indicate the buffer steps (without zanamivir). (B) Frequency shifts (data points) and Langmuir fits (lines) obtained from titrations of PR8 virus binding to surfaces containing varying densities of $2,3-\mathrm{S}(\mathrm{LN})_{3}$. Percentages refer to the $2,3-\mathrm{S}(\mathrm{LN})_{3}$ molar fraction used in the receptor mixture with $(\mathrm{LN})_{2}$-biotin for the functionalization of the $\mathrm{SAv}$-coated surfaces (see Figure 6.1B). (C) Plots of $\Delta D_{5} / \Delta f_{5}$ derived from titrations of $\mathrm{PR} 8$ for varying relative 2,3-S(LN) 3 densities on the surface. (D) Plot of plateau frequency shift values measured from the titrations shown in (B) versus the relative density of the $2,3-\mathrm{S}(\mathrm{LN})_{3}$ receptor on the surface. The dashed line is a guide to the eye.

Figure 6.4B (100\% dataset) shows the binding curve obtained from the PR 8 titration (Figure $6.4 \mathrm{~A}$ ) by plotting the values of the frequency shifts after $40 \mathrm{~min}$ adsorption time, measured for every virus addition as a function of the virus concentration. A Langmuir fit of the obtained binding curve allowed the quantification of the dissociation constant of the virus with the platform, which resulted to be $65 \mathrm{pM}$. When using a Langmuir model for the fitting of the binding curve, the plateau value of the frequency shift, indicating the saturation of the surface with viruses, is co-fitted in the numerical analysis. The saturation value obtained from 
the Langmuir fit in Figure 6.4B (100\% dataset) resulted to be $533 \mathrm{~Hz}$. The frequency responses measured in the titration at high virus concentrations, i.e., at 83 and $166 \mathrm{pM}$, suggest that the actual saturation of the surface with viruses may be reached at a lower frequency. Specifically, the decreasing dissipation changes correlated with the frequency shifts obtained at higher virus concentrations suggests that, at such concentrations, the stiffness of the adsorbed layer is changing, indicating that the viruses start touching and that a densely packed virus layer is already being approached (Figure 6.4A and Figure 6.4C, $100 \%$ dataset). This may in part explain the relatively poor fit quality obtained in the Langmuir fit for this dataset, possibly caused by an underestimation of the frequency shifts obtained at higher virus densities. Therefore, it may be reasonable to assume that an actual plateau value can be estimated as $360 \mathrm{~Hz}$. When fixing the saturation value at $360 \mathrm{~Hz}$, only a 2-fold lower $K_{d}$ was found, corresponding to $29 \mathrm{pM}$. This observation confirms that the binding constant is anyway in the picomolar range, in agreement with previous reports of viruses binding on different glycan array platforms, ${ }^{15,16}$ and that the inaccuracy of the plateau value has only a limited effect on the fitted $K_{d}$ value.

The platform developed here presents the possibility of finely tuning the receptor surface density at the interface. This allows investigation of the effect of the ligand density on the binding affinity. For this purpose, in order to tune the 2,3-S(LN) $)_{3}$ density at the SLB interface a $2 \%$ molar fraction of DOPE-biotin in the SLB was used to obtain surfaces fully covered with SAv. Thereafter, the biotinylated $\mathrm{S}(\mathrm{LN})_{3}$ was mixed with the dummy $(\mathrm{LN})_{2}$-biotin in different ratios, thus providing control over the density of SLN at the surface (Figure 6.1B). In this way, the molar ratio of 2,3-S(LN $)_{3}$ in the glycan mixtures was varied between $2 \%$ and $100 \%$. By assuming a 1:1 ratio between DOPE-biotin in the SLB and biotinylated receptor anchored to the SAv, and noting that saturation of surfaces with SAv occurs for molar fractions of biotinylated lipids above $1 \%$ (see Chapter 5), these percentages lead to densities ranging between 0.09 and $2.9 \mathrm{pmol} / \mathrm{cm}^{2}$.

Figure $6.4 \mathrm{~B}$ shows the binding curves obtained from the titrations and the corresponding Langmuir fits at varying receptor densities. Interestingly, the measurements showed that the binding of the virus was strongly influenced by the density of receptors on the surface, and lower 2,3-S(LN $)_{3}$ densities led to a lower surface coverage with viruses, resulting in reduced plateau frequency shift values. Surprisingly, however, the fitted $K_{\mathrm{d}}$ values hardly varied, and values between 62 and 67 pM were obtained. In contrast, one might have expected that lower receptor densities would cause smaller binding affinities, but this is clearly not the case. Moreover, the Langmuir fits followed the datapoints better at lower receptor densities (Figure 6.4B), indicating that dense virus packing played less of a role. The plots of the dissipation signal as a function of the frequency change (Figure 6.4C) confirmed that the dissipation signal is virus coverage-dependent, and thus that the frequency values at higher virus 
coverages are less reliable. Overall, comparison of the datasets obtained at different receptor densities (Figure 6.4B) indicates that the virus binds at all platforms with similar affinities, but lower maximal coverages are achieved at lower densities. This may tentatively be explained by receptor clustering occurring at these platforms, whereby diffusion of lipidanchored and receptor-exposing SAv molecules along the interface permits receptors to group together in the contact area with a bound virus, at the same time leaving other areas deprived of sufficient receptors to bind more virus particles. Further investigation of this phenomenon falls, however, outside the scope of this study, although a study on receptor recruitment in a model system is presented in Chapter 7.

By plotting the plateau values, obtained for each titration as presented in Figure 6.4B, as a function of the molar fraction of $2,3-\mathrm{S}(\mathrm{LN})_{3}$ in solution, it was possible to estimate the threshold value of the $2,3-\mathrm{S}(\mathrm{LN})_{3}$ density necessary for the binding of the PR 8 virus. Figure 6.4D shows the sigmoidal curve obtained from the plot, which indicates a strongly non-linear behavior of the plateau value as function of the receptor density. In this way, a threshold of $12 \%$ of $2,3-\mathrm{S}(\mathrm{LN})_{3}$ was obtained, corresponding to a density of $0.33 \mathrm{pmol} / \mathrm{cm}^{2}$.

The sigmoidal nature of the curve (Figure 6.4D) is indicative of superselective binding of viruses on the surface, which is a direct consequence of the multivalent binding of the virus. ${ }^{17}$ When receptors are too far apart, the virus can bind only monovalently to the surface and the weak monovalent interaction does not provide a stable adsorption of viruses on the surface. As soon as the ligand density is high enough to ensure multivalent binding, in addition to the mobility of the receptor on the surface, a drastic increase of the binding is observed. Around the threshold value, a more than linear increase of the virus coverage is observed, and the receptor densities are apparently high enough to provide a stable multivalent binding. Therefore, at high receptor densities (above the threshold value), the differences in binding affinity of viruses for specific receptors may become less evident, if not completely absent. Contrarily, clear differences could be observed at receptor densities close to threshold densities. Hence, the determination of exact threshold density values for the binding of viruses is crucial in the determination of binding selectivity. This might also explain the similar binding affinities of PR8 for both 2,3 and 2,6-SLN observed above.

How many interactions are involved at the interface upon the binding of a virus? In order to address this question, few considerations need to be taken into account. First of all, viruses have a diameter of approx. $100 \mathrm{~nm}$ and present approximately $300 \mathrm{HA}$ trimers on their membrane. ${ }^{18}$ This leads to a quite high HA binding site density $\left(1.5 \mathrm{pmol} / \mathrm{cm}^{2}\right)$. At the same time it is known that a virus has a quite rigid structure and therefore a limited deformation of the virus membrane is expected to occur upon binding to the surface. If we assume that only $1 \%$ of the virus surface interacts with a cell membrane, only 3 HA trimers interact with the surface, corresponding to a maximum of 9 protein-receptor interaction pairs. When instead a 
contact area of 5\% is assumed, $15 \mathrm{HA}$ trimers are estimated to be involved in the interaction, i.e., maximally 45 interacting pairs.

As previously used for HA rosettes (see Chapter 5), ${ }^{19}$ the overall multivalent binding affinity $\left(K_{o v}\right)$ can be described as follows:

$$
\frac{1}{K_{d}}=K_{o v}=K_{i}\left(K_{i} E M\right)^{n-1}
$$

With $K_{\mathrm{i}}$ representing the monovalent interaction, EM the effective molarity and $n$ the number of interactions involved at the interface, respectively. From all titrations performed with PR8, binding affinities of approx. $65 \mathrm{pM}$ were obtained, resulting in a $K_{\mathrm{ov}}$ value of approximately $1.5 \times 10^{10} \mathrm{M}^{-1}$. For $K_{\mathrm{i}}$, a value of approx. $1000 \mathrm{M}^{-1}\left(K_{\mathrm{d}}=1 \mathrm{mM}\right)$ can be assumed, based on previous reports. ${ }^{20}$ When using $3(n=9)$ or $15(n=45)$ HA trimers binding to the receptors, a multivalent enhancement factor $\left(K_{\mathrm{i}} E M\right)$ is calculated to be 7.9 or 1.5 , resulting in $E M$ values of $7.9 \mathrm{mM}$ and $1.5 \mathrm{mM}$, respectively. Most noteworthy, these values confirm that also whole viruses bind in the weakly multivalent regime as was already established for HA particles (Chapter 5).

When taking the values for the HA rosettes $\left(K_{o v}=5 \mathrm{nM}, K_{\mathrm{i}} E M=4.6\right.$, while assuming $n=9$ and $K_{\mathrm{i}}=1000 \mathrm{M}^{-1}$ ) in comparison, it is plausible that the whole viruses have a larger contact area than the HA particles, as observed by their larger size (100 vs $25 \mathrm{~nm})$ and a 2 orders of magnitude larger overall affinity. With a $K_{\mathrm{i}} E M$ of 4.6 , the 2 orders of magnitude larger affinity is achieved with 3 additional interaction pairs, which would indicate that a full virus can reach the here observed affinities with a number of interactions of about 12 , corresponding to 4 trimers or $1.3 \%$ of the total virus area. Taking into account the observed receptor threshold density of $0.33 \mathrm{pmol} / \mathrm{cm}^{2}$, which is about a factor $4-5$ lower than the HA site density at the virus surface, the contact area of a virus with the surface may provide access to maximally about $50 \mathrm{HA}$ sites, corresponding to $5.5 \%$ of the surface area. This analysis confirms that the estimation of the contact area of $1-5 \%$ of the virus surface area is in line with the observed affinities.

The difference between the necessary minimal receptor density (i.e., the threshold density) and the HA site density of the virus is striking. It may indeed indicate that not all HA sites need to be involved in binding simultaneously to achieve sufficient binding strength. However, as mentioned above, recruitment may occur as well, and local receptor densities may be higher than estimated from the averages. At the one extreme, when the viruses are densely packed, each virus occupies a surface footprint of approx. $2.6 \times 10^{4} \mathrm{~nm}^{2}$. At $100 \%$ relative sugar density, corresponding to $2.9 \mathrm{pmol} / \mathrm{cm}^{2}$, which is actually 2 -fold higher than the estimated HA density at the virus surface, this indicates that our platform is able to saturate all HA sites and even provide local oversaturation so that statistical affinity 
enhancement by redundancy is possible. At this limit, we presume all SAv sites are bound to a biotin group of an SLN receptor, so two SLNs per SAv.

At decreasing SLN fractions in the mixture with the dummy biotin-(LN)2, however, the probability of obtaining two SLNs per SAv becomes less and less likely, and the distribution will shift to a mixture of SAv molecules with 0 and 1 SLN per SAv. Therefore, at decreasing receptor densities, the maximal SLN density that can potentially be achieved by recruitment will lower, to half of the original value, i.e., $1.4 \mathrm{pmol} / \mathrm{cm}^{2}$, which is now comparable to the HA site density at the virus. When now viewing the lower receptor density limit where dense virus packing occurs, which is at a relative SLN density of approx. 30\%, corresponding to an average of $0.86 \mathrm{pmol} / \mathrm{cm}^{2}$, there are approx. $130 \mathrm{SLN}$ moieties available per virus particle in the footprint area, which is much more than needed to saturate the 9-45 HA sites. At the same time, $9 \%$ of the SAv is bound with 2 SLNs, $42 \%$ with 1 SLN, and $49 \%$ with none. With this distribution, recruitment may still provide all SLN-SAv dimers in the contact area and thus the same local SLN density as at $100 \%$ relative coverage.

At the threshold density of $12 \%$, corresponding to $0.33 \mathrm{pmol} / \mathrm{cm}^{2}$, only $1.4 \%$ of the SAv molecules has 2 SLNs, while $21 \%$ has 1 SLN and $78 \%$ has none. At the same time, the area over which recruitment can occur is twice larger (as the coverage of virus is only half at the threshold density), indicating that about 50 SLNs are available per virus particle. In this situation, binding has to occur mostly through monovalent SLN-SAv moieties, and recruitment seems necessary to explain the observed coverage. At an average SLN density of $5 \%$, corresponding to $0.14 \mathrm{pmol} / \mathrm{cm}^{2}$, no virus adsorption is observed anymore. This may indicate that the entropic penalty for recruitment becomes too high at this low density.

\subsubsection{Influence of the receptor length on the interaction affinity}

A real biological environment presents a tremendously high complexity compared to the simplified SLB system described here. Therefore, many more factors besides the receptor density can influence a biological multivalent interaction, such as the one of a virus with a cell membrane. For this purpose, systems which provide better mimics for the complexity of real biological systems, notably of the glycocalyx, need to be developed.

A first step in increasing the platform complexity can be found in the modification of surfaces with receptors presenting different lengths. For this reason, we employed the SLB platform to investigate the role of the receptor length in the binding with viruses. Following the procedure reported above, SLBs containing 2\% of DOPE-biotin were functionalized with either 2,3 or 2,6-SLNs containing one, two or three LN units (see Figure 6.1B/C). Subsequently, titrations were performed on the functionalized surfaces, and binding curves 
were obtained for each receptor. Figure 6.5 shows the binding curves and corresponding Langmuir fits obtained for these titrations.

(A)

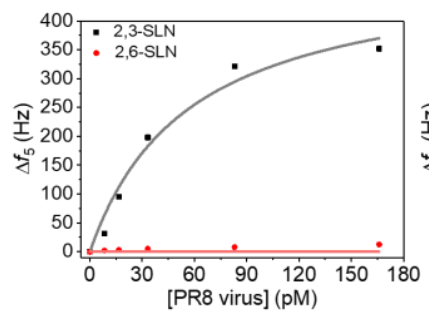

(B)

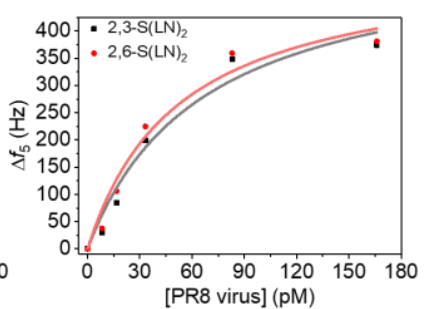

(C)

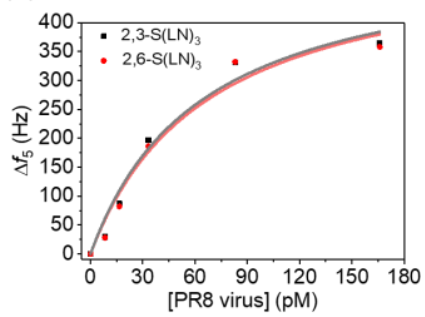

Figure 6.5. Binding curves obtained for full QCM-D titrations of PR8 viruses on SLBs containing $2 \%$ of DOPE-biotin and functionalized with (A) 2,3 or 2,6-SLN, (B) 2,3 or 2,6-S(LN)2, and (C) 2,3 or 2,6$\mathrm{S}(\mathrm{LN})_{3}$.

Interestingly, for the 2,6-S(LN) functionalized surfaces, viruses showed no binding with receptors presenting the mono-SLN. The introduction of a second LN unit, however, contributed to a much pronounced binding and no differences were observed between $\mathrm{S}(\mathrm{LN})_{2}$ and $\mathrm{S}(\mathrm{LN})_{3}$. In contrast, in the case of 2,3-SLN-modified SLBs no significant differences were observed for the three different receptor lengths.

The data obtained from the measurements showed a clear effect of receptor length on the binding of viruses, suggesting that the virus-receptor interactions do not only depend exclusively on the affinity between the binding pocket and the receptor, but also on other, e.g. steric, factors. In particular the drastic difference in binding shown for the 2,6-S(LN)n receptors, indicates a critical length parameter to be involved in efficient binding. Considering the high receptor density chosen for these measurements, the observed absence of binding for 2,6-SLN cannot be attributed to a too low density. However, an increase in linker length does not only provide better accessibility but also increased rotational degrees of freedom which may lead to enhanced entropic losses upon binding. Future studies, with different glycans and variation of density, possibly accommodated with molecular modeling, will have to shed more light on the various contributions of these effects on the binding behavior.

\subsection{Conclusions}

Summarizing, we have reported here a study of the interaction of influenza A viruses with an SLB-based platform which allows control over the sialoglycan receptor density. Receptor binding selectivities of three different viruses were established with QCM-D, and release profiles in the absence of NA inhibitor showed differences in NA activity. Binding affinities 
for whole PR8 viruses to 2,3-S(LN) $)_{3}$-presenting surfaces were assessed with full titrations, which provided $K_{\mathrm{d}}$ values in the picomolar range. Measurement of the binding affinities at varying receptor densities showed a superselective binding of the viruses, and a receptor threshold density of $0.33 \mathrm{pmol} / \mathrm{cm}^{2}$ was determined. A contact area between an adsorbed virus and the receptor-functionalized platform was estimated to be between 1 and $5 \%$ of the total virus surface, resulting in 9-45 HA-receptor interacting pairs involved in the multivalent interaction. Values for the multivalent enhancement factor, $K \mathrm{i} E M$, were found to range between 1.5 and 7.9. Similarly to what we have reported in the study of the binding of rHA clusters (Chapter 5), the binding of whole viruses is weakly multivalent, where each additional binding contributes moderately to the overall affinities, thus providing dynamicity to the whole interaction.

We have demonstrated that this platform is suitable for the investigation of binding affinities. In the future, it can be used as a tool to investigate, for example, the hazard of new arising virus mutants. At the same time, we believe that this platform and the methods used in this work are suitable for the investigation of a large range of biological multivalent interactions.

\subsection{Acknowledgements}

Dr. Erhard van der Vries and Malte Tieke (University of Utrecht) are acknowledged for providing the viruses and for fruitful discussions. Prof. dr. Geert-Jan Boons and Zeshi Li (University of Utrecht) are thanked for providing the biotinylated receptors. Dr. Maria Candelaria Bertolino is acknowledged for the help with the QCM measurements.

\subsection{Experimental section}

\subsubsection{Materials}

Chemicals were purchased from Sigma-Aldrich, while commercial lipids were obtained from Avanti Polar Lipids. Streptavidin was purchased from ThermoFisher and dissolved in $10 \mathrm{mM}$ PBS buffer ( $1 \mathrm{mg} / \mathrm{mL}$, in 2,7 mM potassium chloride and $137 \mathrm{mM}$ sodium chloride, $\mathrm{pH}$ 7.4) at $25{ }^{\circ} \mathrm{C}$ using Milli-Q water (MQ, Millipore, $18.2 \mathrm{~m} \Omega$ ). Biotinylated glycans were prepared based on already reported procedures. ${ }^{22-23}$ 


\subsubsection{Methods}

\section{Virus stock preparation}

Influenza A/Puerto Rico/8/34 virus (Mt. Sinai strain) stocks were prepared by propagating the virus in 10-days-old embryonated chicken eggs at $33^{\circ} \mathrm{C}$ (GD Animal health, Deventer, the Netherlands). Allantoic fluids were harvested after 48-72 $\mathrm{h}$ and cleared from debris by centrifugation at $3000 \mathrm{rpm}$ for $10 \mathrm{~min}$ at $4^{\circ} \mathrm{C}$. Subsequently, the viruses were pelleted by centrifugation at $7000 \mathrm{rpm}$ for $18 \mathrm{~h}$ at $4^{\circ} \mathrm{C}$ and resuspended in PBS (pH 7.4) (Lonza). Viruses were then purified further by loading of the virus sample on a discontinuous sucrose gradient $(10-50 \% \mathrm{w} / \mathrm{v})$ and centrifugation for $45 \mathrm{~min}$ at 25,000 rpm using a SW41 swing-out rotor. The virus-containing sucrose layer was finally harvested and dialyzed (Slide-A-Lyzer, Thermo Scientific) for $48 \mathrm{~h}$ at $4^{\circ} \mathrm{C}$ to remove the remaining sucrose. Finally, the virus particle count was determined using a NS300 nano-particle tracking analyzer (Malvern, Nanosight), and diluted to a final stock concentration of $1 \times 10^{11}$ particles $/ \mathrm{ml}, \mathrm{UV}$-inactivated $\left(50 \mathrm{~mJ} / \mathrm{cm}^{2}\right.$, at a wavelength of $365 \mathrm{~nm}$ ) and aliquots were frozen at $-80^{\circ} \mathrm{C}$. Inactivation was confirmed by growing of these viruses on Madin-Darby canine kidney (MDCK) cells. A hemagglutininin (HA) assay was performed as described elsewhere ${ }^{21}$ to obtain a titer of 2048 . The same procedure was followed to obtain stocks of recombinant influenza A/H1N1 virus $\mathrm{A} /$ Common teal/NL/10/00 and A/H2N9 A/Mallard/Sweden/36/03, both at a final concentration of $1 \times 10^{10}$ particles $/ \mathrm{ml}$ and an HA titer of 256 .

\section{Small unilamellar vesicle (SUV) preparation}

Supported lipid bilayer (SLB) formation and streptavidin deposition were carried out as follows. 1,2-Dioleoyl-sn-glycero-3-phosphocholine (DOPC) and 1,2-dioleoyl-sn-glycero-3phosphoethanolamine-N-(cap-biotinyl), were stored in chloroform at $-20^{\circ} \mathrm{C}$. Dissolved lipid solutions were mixed in desired molar ratios before use and dried under a flow of nitrogen in a glass vial in order to create a film of lipid material at the glass wall. This film was further dried under vacuum for at least $1 \mathrm{~h}$ and subsequently hydrated with Milli-Q water to form multilamellar vesicles at $1 \mathrm{mg} / \mathrm{mL}$. The lipid suspension was extruded 11 times through a polycarbonate membrane (Whatman) with a $100-\mathrm{nm}$ pore size, resulting in small unilamellar vesicles (SUVs) that were stored in the refrigerator and used within 2 weeks. For SLB fabrication, vesicles were diluted to a concentration of $0.1 \mathrm{mg} / \mathrm{mL}$ in PBS directly before use. SLB formation was achieved by flowing this solution over a cleaned and activated $\mathrm{SiO}_{2}$ surface. The quality of the SLBs was monitored in situ by QCM-D, where a high quality SLB was characterized by $\Delta f=-24 \pm 1 \mathrm{~Hz}$ and $\Delta D<0.5 \times 10^{-6}$. 


\section{QCM-D measurements}

QCM-D measurements were performed using a QSense analyzer (Biolin Scientific). $\mathrm{SiO}_{2}$ coated sensors (QSX303, Biolin Scientific) were used. The sensors were cleaned using a 2 $\mathrm{wt} \%$ sodium dodecyl sulfate (SDS) solution and thoroughly rinsed with Milli-Q. Activation was performed with $20 \mathrm{~min}$ UV/ozone treatment, and the baseline was made flushing PBS buffer. Measurements were performed at $22{ }^{\circ} \mathrm{C}$ and operated with four parallel flow chambers, using two Ismatec peristaltic pumps with a fixed flow rate of $30 \mu \mathrm{L} / \mathrm{min}$. Throughout this work, the fifth overtone $\left(\Delta f_{5}\right)$ was used for the normalized frequency and dissipation $\left(\Delta D_{5}\right)$.

\subsection{References}

1. Medina, R. A.; García-Sastre, A., Influenza A viruses: new research developments. Nat. Rev. Microbiol. 2011, 9, 590-603.

2. Landolt, G. A.; Olsen, C. W., Up to new tricks - A review of cross-species transmission of influenza A viruses. Anim. Health Res. Rev. 2007, 8, 1-21.

3. Neumann, G.; Noda, T.; Kawaoka, Y., Emergence and pandemic potential of swine-origin H1N1 influenza virus. Nature 2009, 459, 931-939.

4. Matrosovich, M.; Tuzikov, A.; Bovin, N.; Gambaryan, A.; Klimov, A.; Castrucci, M. R.; Donatelli, I.; Kawaoka, Y., Early Alterations of the Receptor-Binding Properties of H1, H2, and H3 Avian Influenza Virus Hemagglutinins after Their Introduction into Mammals. J.Virol. 2000, 74, 8502-8512.

5. Taubenberger, J. K.; Kash, J. C., Influenza Virus Evolution, Host Adaptation, and Pandemic Formation. Cell Host Microbe 2010, 7, 440-451.

6. Chen, L.-M.; Davis, C. T.; Zhou, H.; Cox, N. J.; Donis, R. O., Genetic Compatibility and Virulence of Reassortants Derived from Contemporary Avian H5N1 and Human H3N2 Influenza A Viruses. PLOS Pathog. 2008, 4, e1000072.

7. Xiong, X.; Martin, S. R.; Haire, L. F.; Wharton, S. A.; Daniels, R. S.; Bennett, M. S.; McCauley, J. W.; Collins, P. J.; Walker, P. A.; Skehel, J. J.; Gamblin, S. J., Receptor binding by an H7N9 influenza virus from humans. Nature 2013, 499, 496-499.

8. Vachieri, S. G.; Xiong, X.; Collins, P. J.; Walker, P. A.; Martin, S. R.; Haire, L. F.; Zhang, Y.; McCauley, J. W.; Gamblin, S. J.; Skehel, J. J., Receptor binding by H10 influenza viruses. Nature 2014, 511, 475-477.

9. Zhang, H.; de Vries, Robert P.; Tzarum, N.; Zhu, X.; Yu, W.; McBride, R.; Paulson, James C.; Wilson, Ian A., A Human-Infecting H10N8 Influenza Virus Retains a Strong Preference for Avian-type Receptors. Cell Host Microbe 2015, 17, 377-384.

10. Collins, P. J.; Vachieri, S. G.; Haire, L. F.; Ogrodowicz, R. W.; Martin, S. R.; Walker, P. A.; Xiong, X.; Gamblin, S. J.; Skehel, J. J., Recent evolution of equine influenza and the origin of canine influenza. P. Natl. Acad. Sci. U.S.A. 2014, 111, 11175-11180.

11. Di Iorio, D.; Verheijden, M. L.; van der Vries, E.; Jonkheijm, P.; Huskens, J., Weak Multivalent Binding of Influenza Hemagglutinin Nanoparticles at a SialoglycanFunctionalized Supported Lipid Bilayer. ACS Nano 2019, 13, 3413-3423. 
12. Dubacheva, G. V.; Araya-Callis, C.; Geert Volbeda, A.; Fairhead, M.; Codée, J.; Howarth, M.; Richter, R. P., Controlling Multivalent Binding through Surface Chemistry: Model Study on Streptavidin. J. Am. Chem. Soc. 2017, 139, 4157-4167.

13. Meng, B.; Marriott, A. C.; Dimmock, N. J., The receptor preference of influenza viruses. Influenza Other Resp. 2010, 4, 147-153.

14. Kobasa, D.; Kodihalli, S.; Luo, M.; Castrucci, M. R.; Donatelli, I.; Suzuki, Y.; Suzuki, T.; Kawaoka, Y., Amino Acid Residues Contributing to the Substrate Specificity of the Influenza A Virus Neuraminidase. J. Virol. 1999, 73, 6743-6751.

15. Srinivasan, K.; Raman, R.; Jayaraman, A.; Viswanathan, K.; Sasisekharan, R., Quantitative Description of Glycan-Receptor Binding of Influenza A Virus H7 Hemagglutinin. PLOS ONE 2013, 8, e49597.

16. Viswanathan, K.; Koh, X.; Chandrasekaran, A.; Pappas, C.; Raman, R.; Srinivasan, A.; Shriver, Z.; Tumpey, T. M.; Sasisekharan, R., Determinants of Glycan Receptor Specificity of H2N2 Influenza A Virus Hemagglutinin. PLOS ONE 2010, 5, e13768.

17. Martinez-Veracoechea, F. J.; Frenkel, D., Designing super selectivity in multivalent nanoparticle binding. P. Natl. Acad. Sci. U.S.A. 2011, 108, 10963-10968.

18. Harris, A.; Cardone, G.; Winkler, D. C.; Heymann, J. B.; Brecher, M.; White, J. M.; Steven, A. C., Influenza virus pleiomorphy characterized by cryoelectron tomography. P. Natl. Acad. Sci. U.S.A. 2006, 103, 19123-19127.

19. Huskens, J.; Mulder, A.; Auletta, T.; Nijhuis, C. A.; Ludden, M. J. W.; Reinhoudt, D. N., A Model for Describing the Thermodynamics of Multivalent Host-Guest Interactions at Interfaces. J. Am. Chem. Soc. 2004, 126, 6784-6797.

20. Xiong, X.; Coombs, P. J.; Martin, S. R.; Liu, J.; Xiao, H.; McCauley, J. W.; Locher, K.; Walker, P. A.; Collins, P. J.; Kawaoka, Y.; Skehel, J. J.; Gamblin, S. J., Receptor binding by a ferret-transmissible H5 avian influenza virus. Nature 2013, 497, 392-396.

21. Rimmelzwaan, G. F.; Baars, M.; Claas, E. C. J.; Osterhaus, A. D. M. E., Comparison of RNA hybridization, hemagglutination assay, titration of infectious virus and immunofluorescence as methods for monitoring influenza virus replication in vitro. J. Virol. Methods 1998, 74, 57 66.

22. Li, T.; Liu, L.; Wei, N.; Yang, J.-Y.; Chapla, D. G.; Moremen, K. W.; Boons, G.-J., An automated platform for the enzyme-mediated assembly of complex oligosaccharides. Nat. Chem. 2019, 11, 229-236.

23. Lau, K.; Thon, V.; Yu, H.; Ding, L.; Chen, Y.; Muthana, M. M.; Wong, D.; Huang, R.; Chen, $\mathrm{X}$., Highly efficient chemoenzymatic synthesis of $\beta 1-4$-linked galactosides with promiscuous bacterial $\beta 1$-4-galactosyltransferases. Chem. Commun. 2010, 46, 6066-6068. 


\section{Chapter 7}

\section{Recruitment of Receptors at Supported Lipid Bilayers Promoted by the Multivalent Binding of Ligand-Modified Unilamellar Vesicles}

The development of model systems that mimic biological interactions and allow the control of both receptor and ligand densities, is essential for a better understanding of biomolecular processes, such as the clustering of receptors at interfaces, at a molecular level. Here we report a synthetic system based on supported lipid bilayers (SLBS) for the investigation of the clustering of receptors. Biotinylated SLBS, used as cell membrane mimics, were functionalized with streptavidin (SAv), used here as receptor. Subsequently, biotinylated small (SUVS) and giant (GUVS) unilamellar vesicles were bound to the SAv-functionalized SLBS by multivalent interactions and found to induce the recruitment of both SAv on the SLB surface and the biotin moieties in the vesicles. The recruitment of receptors was investigated with quartz crystal microbalance with dissipation monitoring (QCM-D), which allowed the identification of the biotin and SAv densities necessary to obtain receptor recruitment. The optical visualization of the clustering at the interface of individual GUVS with the SLB platform was achieved with fluorescence microscopy, showing recruitment of SAv at the contact area as well as the deformation of the vesicles upon binding. Two different vesicle binding regimes were observed for lower and higher biotin densities in the vesicles. $A$ quantitative analysis of the molecular parameters implied in the interaction, such as the number of receptors recruited at the interacting area, shows a correlation between the receptor density at the interface and the contact area. 


\subsection{Introduction}

The clustering of receptors in cell membranes plays an important role in a large number of biological processes. In living cells, phenomena such as signal transduction, which are fundamental for immunological responses and neurotransmission, are often associated with the formation of domains and the clustering of receptors at a cell surface. ${ }^{1-3}$ Multivalent ligand-receptor interactions at the interface, in combination with the fluidity of the cell membrane, promote the rearrangement and co-localization of receptors on a surface, and thereby govern these biological responses. ${ }^{4}$

The molecular processes of binding, diffusion and clustering occur at characteristic length and time scales, and these can be distinctly different from those associated with the biological processes that they induce. To deconvolute the various contributions to the biological processes, the molecular and biophysical aspects of receptor clustering need to be investigated. Molecular aspects, such as the number of receptors involved in the interactions, the local receptor density and the lateral diffusion on the cell membrane, are critical factors playing a role in these phenomena. ${ }^{5}$ To provide quantitative insight into these molecular parameters, it is necessary to build synthetic models that can mimic the biological interaction at the interface and in which parameters such as receptor density and surface fluidity can be controlled and quantified.

Supported lipid bilayers (SLBs) have been reported extensively to be good cell-membrane mimics, and they are already employed heavily for their excellent antifouling properties. ${ }^{6-7}$ Among their manifold advantages, SLBs present a two-dimensional fluidity, a very important feature that allows the mimicking of mobility and rearrangement processes occurring at a cell membrane. ${ }^{8}$ The fluidity of an SLB can be tuned by changing the chemical composition of the lipids. ${ }^{9}$ Moreover, the possibility of modifying the composition of the SLB by incorporating a controllable fraction of a functionalized lipid, which, for example, allows the attachment of receptors, provides an exquisite method to control the surface density. ${ }^{10}$

Here we report a well-defined SLB model system that allows the study and the microscopic visualization of the phenomenon of receptor clustering at a cell membrane, by mimicking a biological interaction occurring at the interface. Our goal is to investigate whether the interaction of multivalent ligand carriers, such as vesicles with ligand binding sites anchored to fluidic membranes, can cause ligand clustering at the surface they bind to, and how this phenomenon is correlated to the densities of receptor and ligand sites expressed at the interface. Accordingly, SLBs and vesicles were chosen as mimics for the fluidic membrane and for the interacting multivalent biological system, respectively, owing to the possibility of accurately controlling both ligand and receptor densities at the interface in these systems. 
The strong, non-covalent biotin-streptavidin interaction was taken as a model for a typical biological interaction. Biotinylated SLBs were used as bio-mimetic platforms, which were functionalized with streptavidin (SAv), used here as receptor. Biotinylated small (SUVs; approx. $100 \mathrm{~nm}$ ) and giant (GUVs; approx. 15-20 $\mu \mathrm{m}$ ) unilamellar vesicles were employed as multivalent carriers to induce recruitment of SAv on the SLB surface. Specifically, SUVs were used in ensemble surface binding studies using quartz crystal microbalance with dissipation monitoring (QCM-D). Because of their size, GUVs were used for direct optical visualization of individual recruitment events by fluorescence microscopy. By controlling the densities of both biotin and SAv at the interface, we quantitatively analyzed the clustering of the receptor sites at the interface and investigated the role of both ligand and receptor density on a fluid surface. An analysis of the size of the contact area between vesicle and SLB is also provided in order to evaluate the number of interacting sites involved during the receptor clustering.

\subsection{Results}

\subsubsection{Ensemble binding of $100-n m$ unilamellar vesicles to supported lipid bilayers}

In order to investigate the recruitment of receptors at an SLB interface induced by a multivalent interaction, we first employed biotinylated small unilamellar vesicles (SUVs) with a diameter of $100 \mathrm{~nm}$, able to bind multivalently to a SAv-functionalized SLB. Here, the strong non-covalent interaction between biotin and $\operatorname{SAv}\left(K_{\mathrm{d}}=10^{-14} \mathrm{M}\right)^{11}$ was chosen as a model for a general ligand-receptor interaction occurring in a real biological system. The high affinity of this interaction is expected to provide the maximal possible recruitment.

Figure 7.1 reports a schematic representation of the formation of the platform used in this work and the interaction with SUVs. In a first step, a biotinylated SLB is formed on an activated $\mathrm{SiO}_{2}$ substrate. For the formation of the SLB, unilamellar vesicles consisting of 1,2dioleoyl-sn-glycero-3-phosphocholine (DOPC) mixed with varying molar ratios of a 1,2dioleoyl-sn-glycero-3-phosphoethanolamine-N-(biotinyl) (DOPE-biotin) were formed by extrusion through a polycarbonate filter with a diameter of $100 \mathrm{~nm}$, and the vesicle size was confirmed by dynamic light scattering measurements. These vesicles are known to rupture on activated $\mathrm{SiO}_{2}$ surfaces forming stable and mobile bilayers. ${ }^{12}$ The presence of biotin in the SLB allows the binding of SAv in a following step. In particular, by mixing DOPC with DOPE-biotin in different molar ratios, it is possible to precisely tune the (average) density of 
biotin moieties displayed at the interface. Thereby, the average density of SAv absorbed on the surface during the second step, is determined during the vesicle preparation step.

(A)

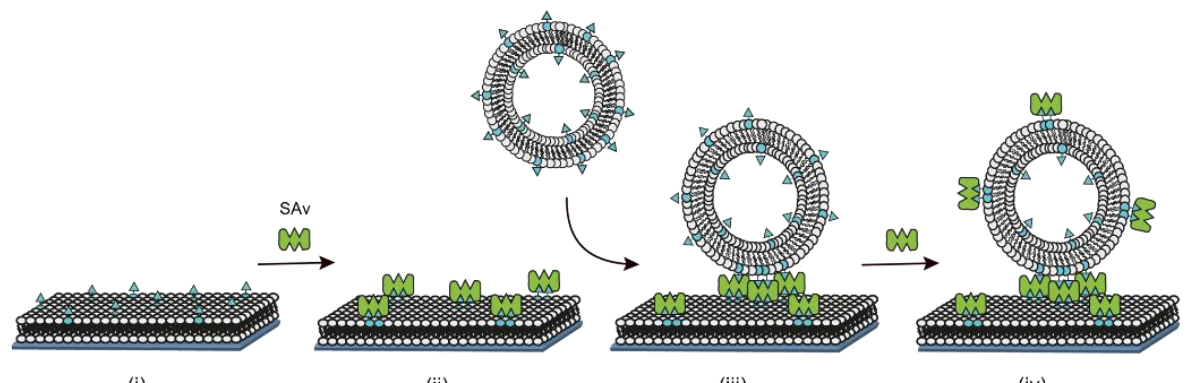

(i)

(B)

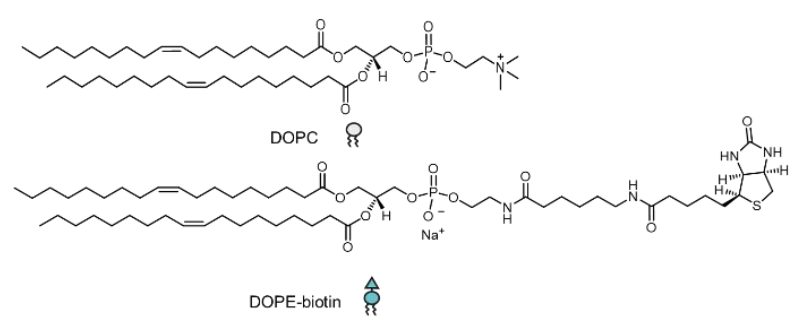

(C)

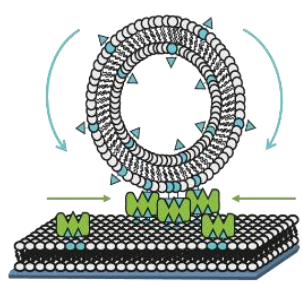

Figure 7.1: (A) Schematic representation of the study of SAv clustering at biotin-containing SLBs induced by the multivalent interaction with biotinylated vesicles (SUVs or GUVs). (i) DOPE-biotindoped SLBs are formed on activated $\mathrm{SiO}_{2}$ surfaces, (ii) $\mathrm{SAv}$ is subsequently bound onto the SLB, (iii) biotinylated vesicles are interacting to the SAv-modified surface, and lastly (iv) free SAv is again added to the substrate to evaluate the fraction of free biotin groups in the SUVs after adsorption. (B) Chemical structures of the components used in the system. (C) Schematic representation of the clustering of the biotin groups on the adsorbing vesicles (blue) concomitant to the recruitment of SAv at the SLB interface (green).

In this work, three different biotin densities were chosen for the formation of SLB platforms, for which $0.1 \mathrm{~mol} \%, 0.4 \mathrm{~mol} \%$ and $2 \mathrm{~mol} \%$ of DOPE-biotin were used in the lipid mixture. As we reported previously, ${ }^{10}$ an increasing molar fraction of DOPE-biotin in the SLB up to approximately $1 \%$ leads to a linear response of adsorbed SAv. Higher concentrations, however, cause a physical saturation of the surface with SAv. Taken these observations into account and assuming that a single SAv binds to two biotinylated lipids on the surface, ${ }^{13}$ the biotin molar ratios chosen for the formation of SLB lead to (average) SAv densities of 0.11, 0.46 , and $1.57 \mathrm{pmol} / \mathrm{cm}^{2}$. Two remaining SAv binding pockets are therefore assumed to be available at SLB-bound SAv for further interactions with biotin ligands presented at the adsorbing vesicles.

In order to probe the lateral mobility of the SLB itself and of SAv bound onto the SLB, both the lateral diffusion of a dye-modified lipid added to the lipid membranes containing varying 
biotin molar fractions and that of adsorbed SAv were assessed through quantitative fluorescence recovery after photo bleaching (FRAP). Figure 7.2 shows the FRAP plots of Texas-Red fluorescence emitted from the dye-modified lipid in the SLB before modification with SAv, and those of of Alexa Fluor 488-labeled SAv, for different biotin densities in the SLB. The FRAP curves were fitted to a diffusion model modified by the Bessel function, ${ }^{14}$ from which the diffusion coefficients of the lipids for each SLB composition were obtained (see Table 7.1). For all biotin densities used in this work, the SLB showed mobility, even when modified with a densely packed SAv layer (2\% DOPE-biotin).

(A)

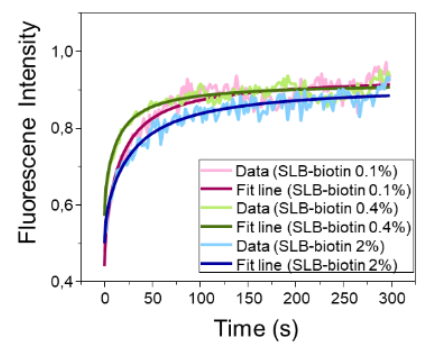

(B)

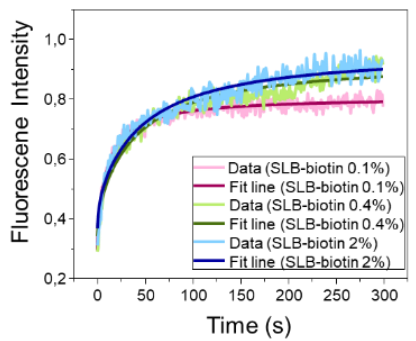

(C)

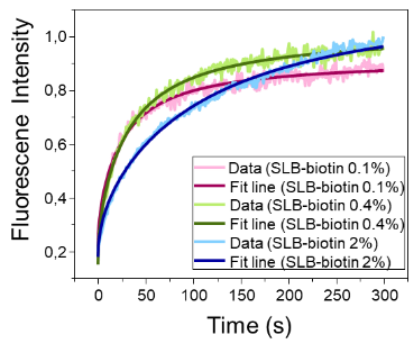

Figure 7.2. Confocal FRAP curves on SLBs with $0.1,0.4$ and 2 mol\% biotin. FRAP of the Texas Redlabeled SLB (A) before and (B) after the anchoring of Alexa Fluor 488-labeled SAv. (C) FRAP of the Alexa Fluor 488-labeled SAv anchored on the SLB. The fitting curves were obtained from the modified Bessel function and the fitted diffusion constants are listed in Table 7.1.

Table 7.1. Diffusion coefficients determined with the FrapAnalyser from Luxembourg University. Processed with double normalization and a modified Bessel fitting.

\begin{tabular}{|c|c|c|c|}
\hline $\begin{array}{l}\text { DOPE-biotin in } \\
\text { SLB }(\mathrm{mol} \%)\end{array}$ & $\begin{array}{l}\text { Diffusion constant } \\
\text { of SLB before } \mathrm{SAv} \\
\left(\mu \mathrm{m}^{2} / \mathrm{s}\right)\end{array}$ & $\begin{array}{c}\text { Diffusion constant } \\
\text { of SLB after SAv } \\
\left(\mu \mathrm{m}^{2} / \mathrm{s}\right)\end{array}$ & $\begin{array}{c}\text { Diffusion constant } \\
\text { of } \mathrm{SAv} \\
\left(\mu^{2} / \mathrm{s}\right)\end{array}$ \\
\hline 0.1 & $1.7 \pm 0.3$ & $2.5 \pm 0.2$ & $1.2 \pm 0.1$ \\
\hline 0.4 & $1.2 \pm 0.4$ & $0.76 \pm 0.10$ & $0.97 \pm 0.06$ \\
\hline 2 & $1.1 \pm 0.2$ & $0.68 \pm 0.09$ & $0.31 \pm 0.02$ \\
\hline
\end{tabular}

After the formation of a SAv layer on the surface, biotinylated SUVs composed of DOPC mixed with DOPE-biotin were added on the surface. SUVs are ideal multivalent carriers, the size of which can be finely controlled in the extrusion step. This size control is important in our studies, because it allows proper quantification of the number of interactions and the interaction area at the interface. The SUVs were prepared in the same way as the vesicles 
employed in the formation of the SLBs, but were re-dissolved in buffer before extrusion. As for the SLBs, varying the molar ratios of DOPE-biotin and DOPC in the lipid mixture allows control over the biotin density in the SUVs. In this work, SUVs were made containing DOPEbiotin concentrations in the range of $0.025 \%$ to $5 \%$.

Quartz crystal microbalance with dissipation monitoring (QCM-D) was used to monitor both the in-situ formation of the interaction platform, consisting of the biotinylated SLB and the SAv layer attached onto it, and the subsequent interaction of SUVs with this platform in real time. Figure 7.3A shows a typical QCM-D measurement in which every adsorption step described above is observed by monitoring the frequency shift ( $\Delta f_{5}$, blue line). Initially, after obtaining a stable baseline, an $\operatorname{SLB}\left(\Delta f_{5}=24 \pm 1 \mathrm{~Hz}\right.$ and $\left.\Delta D_{5}<0.5 \times 10^{-6}\right)$ was formed on a $\mathrm{SiO}_{2}$-covered QCM sensor. Subsequently, the surface was rinsed with buffer and a solution of SAv $(1 \mu \mathrm{M})$ was added onto the SLB. Adsorption of SAv onto the SLB was confirmed by a clear frequency shift, and surfaces were rinsed again with buffer in order to remove the non-bound SAv from the surface. As described before, ${ }^{10}$ the frequency shift of the SAv adsorption step depended on the fraction of DOPE-biotin used in the vesicles to make the SLBs. Consequently, the binding of SAv is specific, and occurs through biotin-SAv interaction pair formation. In the following SUV addition step, a frequency shift confirms the interaction of the vesicles at the SAv-covered platform. The addition of SAv or biotinylated SUVs on an SLB containing no DOPE-biotin did not show any frequency shift (data not shown), thus confirming the specificity of the interactions observed. Additionally, the large change of frequency in the presence of SAv, accompanied by a large dissipation change, suggests that the vesicles remain intact upon binding, maintaining their vesicular structure while interacting with the platform. ${ }^{15}$ The frequency shift obtained upon vesicle adsorption appeared to be strongly correlated to the density of both SAv at the interface and the biotin content in the vesicles. As a last step, SAv was again added onto the surface in order to detect any free biotin moieties in the SUVs remaining after the interaction with the SAv-coated SLB surface, thereby obtaining information about possible recruitment occurring in the adsorbed SUVs. 


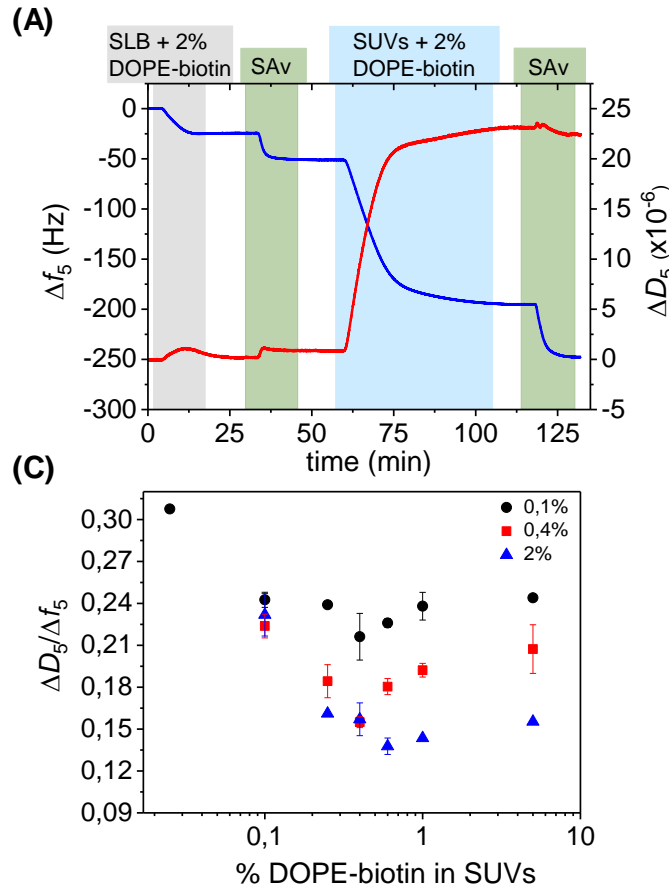

(B)

(D)
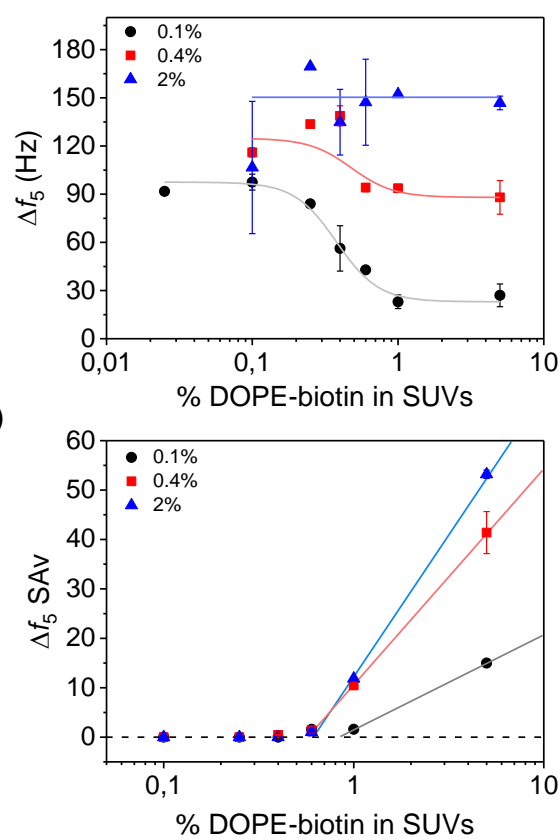

Figure 7.3. (A) QCM-D measurement showing stepwise: the formation of an SLB doped with $2 \mathrm{~mol} \%$ of DOPE-biotin, adsorption of SAv, the interaction with SUVs containing $2 \mathrm{~mol} \%$ of DOPE-biotin, and another adsorption step of SAv. The $5^{\text {th }}$ overtone was used throughout the experiments. The frequency $\operatorname{shift}\left(\Delta f_{5}\right.$, left axis) is shown in blue, and the change in dissipation $\left(\Delta D_{5}\right.$, right axis) in red. The different shadings correspond to the different additions according to Figure 7.1. (B) Limiting frequency shifts obtained for the SUV adsorption steps as a function of the DOPE-biotin fraction in the SUVs, in their interaction with SLBs containing different $(0.1,0.4$ or $2 \%)$ biotin-DOPE fractions and saturated with SAv. Black, red and blue lines are guides to the eye. (C) Plot of $\Delta D / \Delta f$ values versus the molar fraction of DOPE-biotin in SUVs measured on SLBs with biotin fractions of $0.1 \%$ (black), $0.4 \%$ (red), and $2 \%$ (blue). (D) Frequency shifts of adsorption steps of SAv (final adsorption step shown in Figures 7.1 and 7.3A) on SUVs bound to SAv-modified SLBs containing different percentages of biotin.

In order to investigate the effect of the biotin density present in the SUVs on the interaction with the SAv-modified SLB surface, the adsorption steps of SUVs containing different percentages of biotin, ranging from $0.025 \%$ to $5 \%$, were measured on SLBs bearing different SAv densities. In the first series of measurements, SLBs containing 0.1\% DOPE-biotin were chosen in order to provide a low-density SAv layer on the surface with a relatively large (average) spacing between each protein. After forming the interaction platform, as described above, SUVs bearing different fractions of DOPE-biotin were added to the surface. Figure 7.3B shows the values of frequency shifts obtained for the binding of the SUVs, measured after signal saturation was achieved followed by rinsing of the surface with buffer. 
Interestingly, in the case of an SLB functionalized with $0.1 \%$ of biotinylated lipids, the vesicle adsorption onto the surfaces appeared to be correlated to the biotin content used in the lipid mixture of the adsorbed SUVs, where both frequency and dissipation signals stabilized at specific values depending on the biotin concentrations of the vesicles. In particular, a low content of biotin in the SUVs, i.e., $0.025 \%$ and $0.1 \%$, led to larger vesicle adsorption steps, while higher biotin contents caused smaller frequency changes. A minimum adsorption, which gave a frequency shift of only $25 \%$ of those obtained at low biotin fractions, was obtained for both the $1 \%$ and $5 \%$ molar fractions, and a clear transition between high and low vesicle binding was observed at approximately $0.4 \mathrm{~mol} \%$ of biotin. The differences in vesicle adsorption are exclusively attributed to the differences in DOPE-biotin content in the SUVs as no other factors are expected to play a role. Differences in size between SUVs with different biotin fractions measured with DLS were within $10 \%$ (see Experimental Section, Table 7.2). Moreover, no correlation was observed between vesicle size and the biotin content, therefore the small differences can be attributed exclusively to variations in preparation. Other factors, such as different molecular weights due to the presence of different DOPE-biotin molar ratios, were found negligible considering the low fractions used.

Interestingly, when the same set of experiments was repeated on SLBs containing higher biotin densities, i.e. $0.4 \%$ and $2.0 \%$ biotin, different trends were observed in comparison to the $0.1 \%$ biotin SLB. In the case of an SLB with $0.4 \%$ biotin, a correlation between biotin content and vesicle adsorption, similar to the one found for the $0.1 \%$ platform, was observed. However, the values of the frequency shifts in this series of experiments were consistently higher than the ones measured for the $0.1 \%$ biotin SLB, but the difference was most pronounced at the high biotin fractions. This observation suggests that, at a higher SAv density on the surface, a higher amount of vesicles was adsorbed onto the surface. When the $2 \%$ biotin SLB was used, the biotin content in the SUVs appeared to have no influence at all on the adsorption of vesicles, and high frequency shifts were obtained for all of the SUV biotin densities used here. Most likely, the frequency shift (of approx. $150 \mathrm{~Hz}$ ) obtained in this case corresponds to a dense packing of vesicles.

In order to estimate whether or not differences in biotin density in the SUVs and SLBs affect the way in which the vesicles are adsorbed on the surface, e.g., by affecting the contact area and/or the viscoelastic properties of the vesicle-SLB layer, the ratio between $\Delta D_{5}$ and $\Delta f_{5}$ was determined for each SUV step (Figure 7.3C). The $\Delta D_{5} / \Delta f_{5}$ ratios were measured for each set of experiments using $0.1 \%, 0.4 \%$ and $2.0 \%$ of biotin molar fraction in the SLB. Interestingly, differences were observed between these series of measurements, obtained for different SAv densities on the SLB. Specifically, a lower $\Delta D_{5} / \Delta f_{5}$ ratio was observed for vesicles adsorbed on SLBs containing a higher SAv density, particularly evident again at 
high biotin\% in the SUVs. Therefore a high SAv density on the surface appeared to lead to an increased stiffness of the surface upon binding of vesicles with clear differences between SUVs containing high biotin contents. At very low percentages of biotin in the SUVs, instead, similar $\Delta D_{5} / \Delta f_{5}$ ratios were observed, despite the differences in SAv density on the surface. Interestingly, all series showed a dip in the $\Delta D_{5} / \Delta f_{5}$ ratio at $0.4-0.6 \%$ biotin fraction in the SUVs, coinciding with the biotin percentage in Figure 7.3B at which the binding curves go from a relatively sparsely packed vesicle layer (at high biotin\%) to a dense vesicle packing (at low biotin\%).

After the adsorption of SUVs on the surface, as shown in Figure 7.3A, a solution of SAv was added again. In this way, we aimed to determine the availability of biotin on the SUV surfaces after binding to the interacting platform and thus to investigate the recruitment of biotin moieties displayed at the SUVs. The SAv addition was performed for every combination of biotin densities in SUVs and SLBs. Figure 7.3D reports the frequency changes observed upon SAv addition onto the SUVs pre-adsorbed on the SLB surface with $0.1 \%, 0.4 \%$ and $2 \%$ biotin. Notably, for SUVs containing DOPE-biotin fractions below $0.6 \%$, no SAv binding was observed for any of the SAv densities at the SLB. This observation implies that complete recruitment of all biotin moieties in the vesicles had occurred. Higher biotin contents in the SUVs led to an increased adsorption of SAv onto the vesicles, with an onset at approx. 0.6$0.9 \%$ of biotin in the SLB. Here, the total amount of bound SAv resulted to be strongly dependent on both the density of SUVs adhered to the surface as well as the biotin fraction in the SUVs. Notably, the onset of SAv binding to the vesicles coincides with the biotin density at which the transition occurs in the vesicle binding density (Figure 7.3B) and in the $\Delta D_{5} / \Delta f_{5}$ ratio (Figure $7.3 \mathrm{C}$ ).

\subsubsection{Single-vesicle binding of giant unilamellar vesicles to supported lipid bilayers}

In order to visualize the clustering of receptors at the SLB interface with imaging techniques such as fluorescence microscopy, giant unilamellar vesicles (GUVs) were used as a model for immobilization onto the SLB. Although the biotin density of SUVs can be precisely controlled, their nanoscale size prevents the direct visualization of receptor clustering and contact area, hence necessitating the use of larger vesicles (here, GUVs). Both the GUVs and the SLBs were made from lipid mixtures of DOPC, DOPE-biotin, and Texas Redfunctionalized 1,2-dihexadecanoyl-sn-glycero-3-phosphoethanolamine (Texas Red-DHPE). After the deposition of the biotinylated SLB, Alexa Fluor 488-labeled SAv was anchored onto the membrane surface to allow direct visualization of recruited SAv molecules in the 
contact area between the GUV and the SLB, which occurs upon adhesion of biotinylated GUVs by the formation of biotin-SAv affinity pairs.

Fluorescence microscopy images of typical individual, bound vesicles, obtained at different focal planes and at different biotin fractions $(0.1,0.4$, and $2 \%)$ in the SLB, are shown in Figure 7.4. The red color of the Texas Red label implemented in the GUVs appears to be evenly spread in the GUV membrane, and allows visualization of the size and shape of the vesicles. Cross section views of the center section of the GUVs are shown in the $1^{\text {st }}$ column, and the bottom section that is in contact with the SLB surface is shown in the $2^{\text {nd }}$ column. The data shows that GUVs with diameters of 15 to $20 \mu \mathrm{m}$ stayed intact upon adhesion to the SLB. By gradually lowering the focal plane closer to the binding interface at the SLB, the contact area between the adhered GUVs and the SLB became apparent. Most notably, this area overlapped with the area of green fluorescence emitted by the Alexa Fluor 488-labeled SAv ( $3^{\text {rd }}$ column in Figure 7.4). Whereas the green SAv fluorescence was homogeneously distributed over the surface before vesicle adhesion (not shown), binding of the vesicles caused the concentration of the SAv molecules at the vesicle-SLB contact area to facilitate the immobilization of the vesicles. Some bright green specks of higher fluorescence intensity were observed on the SLBs with 0.4 and 2 mol\% biotin receptors, which is likely due to the localized aggregation of SAv molecules and/or the rupture of some vesicles on the SLBs at higher biotin concentrations. Qualitatively, the co-localized fluorescence of the vesicles and SAv in the contact area supports recruitment of SAv into the contact area upon adsorption of the vesicles. 


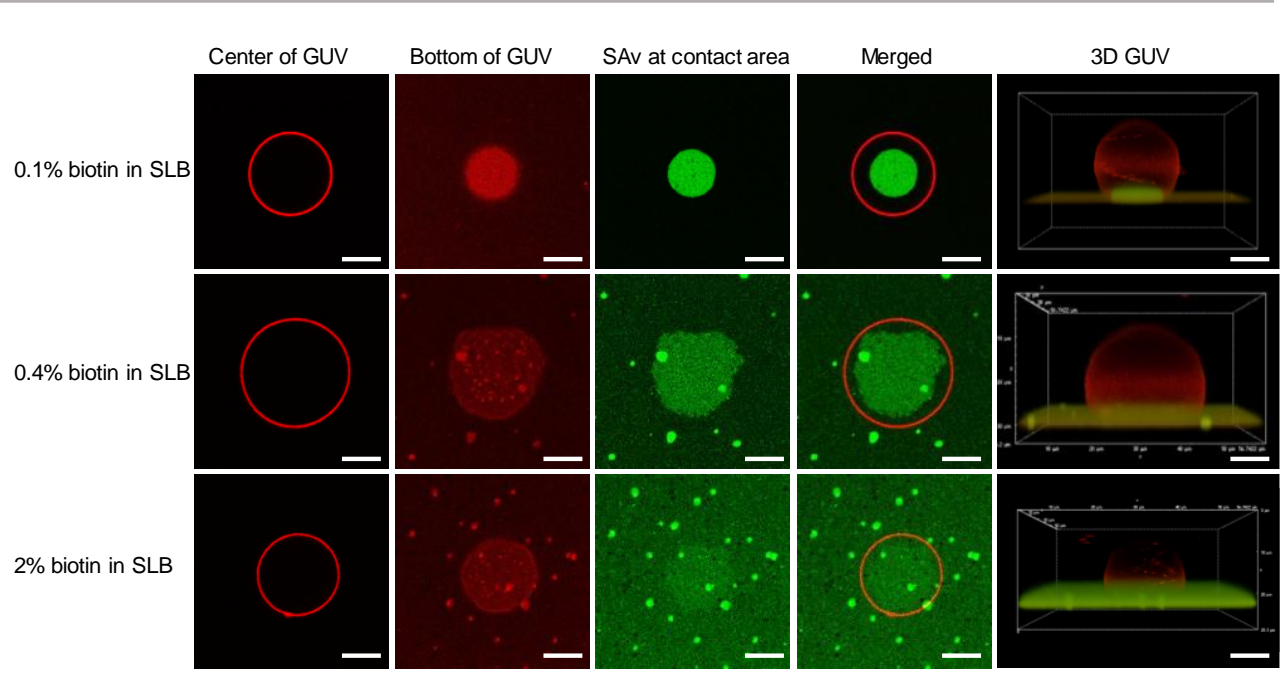

Figure 7.4. Fluorescence microscopy images of immobilized GUVs (with $0.1 \mathrm{~mol} \%$ biotin-DOPE) on biotin/SAv-modified SLBs containing biotin receptors of different densities (0.1, 0.4 and $2 \mathrm{~mol} \%$, shown in top, center, and bottom rows, respectively) obtained at different focal planes. $1^{\text {st }}$ column: the widest/center section of the GUV; $2^{\text {nd }}$ column: the bottom of GUV obtained from the contact area between the GUV and the SLB; $3^{\text {rd }}$ column: clustering of SAv molecules at the contact area; $4^{\text {th }}$ column: merged images of the $1^{\text {st }}$ and $3^{\text {rd }}$ columns; $5^{\text {th }}$ column: 3D reconstructions of immobilized GUVs. The confocal z-stacks were obtained by scanning the GUV from bottom to top with distance steps of 0.3 $\mu \mathrm{m}$. Scale bars indicate $5 \mu \mathrm{m}$.

To study the effect of the receptor density on the clustering process, we first fixed the biotin density in the GUVs $(0.1 \mathrm{~mol} \%)$ but varied the biotin concentration in the SLB $(0.1,0.4$ and $2 \mathrm{~mol} \%$ ), similarly to what was done in the QCM-D experiments described above. At this low mol\% of biotin in the GUVs, as described above for the SUVs with $0.1 \mathrm{~mol} \%$ biotin, all or most biotin moieties of the GUVs are expected to be used in binding to the SLB. As shown in Figure 7.4, for the SLB with $0.1 \mathrm{~mol} \%$ biotin, the binding area, visualized both in red and green $\left(2^{\text {nd }}\right.$ and $3^{\text {rd }}$ columns $)$, was much smaller $\left(4^{\text {th }}\right.$ column $)$ than the cross section area (i.e., the center, $1^{\text {st }}$ column) of the GUV. The green fluorescence was bright and with high contrast (Figure 7.4), indicating an efficient, high density clustering, with no or only few SAv molecules remaining unbound outside the contact area of the vesicle. 
(A)

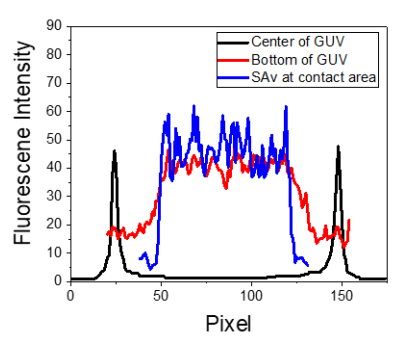

(B)

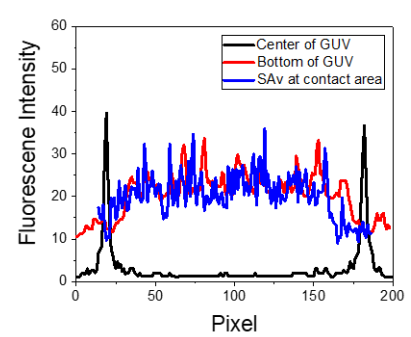

(C)

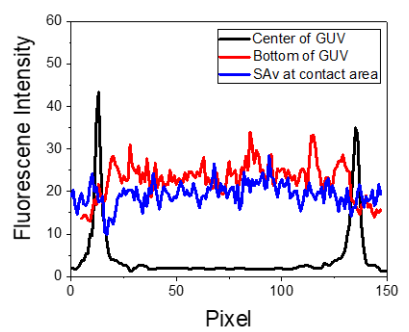

Figure 7.5. The fluorescence profiles of immobilized GUVs on the SLB. (A) $0.1 \mathrm{~mol} \%$ biotin-GUV on $0.1 \mathrm{~mol} \%$ biotin-SLB, (B) $0.1 \mathrm{~mol} \%$ biotin-GUV on $0.4 \mathrm{~mol} \%$ biotin-SLB, (C) $0.1 \mathrm{~mol} \%$ biotin-GUV on $2 \mathrm{~mol} \%$ biotin-SLB.

When the biotin concentration in the SLB was increased to $0.4 \mathrm{~mol} \%$, the contact area, relative to the center ( $4^{\text {th }}$ column in Figure 7.4 ), became larger than for the SLB with $0.1 \mathrm{~mol} \%$ biotin. At the same time, a weak but clearly visible green fluorescence remained outside of the binding site, yielding a lower contrast (Figure 7.5). Both trends continued for the SLB with $2 \mathrm{~mol} \%$ biotin (Figure 7.5C), which can be attributed to the increased biotin density at the SLB interface that led to a higher density of fluorescent SAv. Most likely, as described for the SUVs with $0.1 \mathrm{~mol} \%$ biotin discussed above, all or most biotin moieties of the GUVs are being used in binding to the SLB.

During the receptor clustering process, deformable GUVs may undergo morphological changes upon binding to the surface of the SLB. In order to visualize the deformation of GUVs, confocal microscopy was used to provide 3D structures of the GUVs. As the $5^{\text {th }}$ column in Figure 7.4 shows, a GUV bound to the surface of the SLB with $0.1 \mathrm{~mol} \%$ biotin exhibited a clear deformation leading to a flat contact area between the GUV and the SLB. As the biotin density in the SLB was increased to 0.4 and $2 \mathrm{~mol} \%$, a larger deformation of the GUVs became apparent from the sideview of their 3D structures.

To quantitatively analyze the deformation of GUVs after receptor clustering, changes of the area ratio of a GUV, which was defined as the ratio between the contact area ( $3^{\text {rd }}$ column in Figure 7.4) and the projected (widest/center) area of a GUV ( $1^{\text {st }}$ column in Figure 7.4), were plotted as a function of the vesicle size (Figure 7.6A). The morphological changes depended on the fraction of biotin receptors at the SLB interface, as shown in Figure 7.6C. In the case of $0.1 \mathrm{~mol} \%$ biotin, the area ratio almost stayed constant at around 0.25 independent of the vesicle size, however, this value reached approx. 0.8 when the biotin density in the SLB was raised to 0.4 or $2 \mathrm{~mol} \%$, indicating that a larger deformation of vesicles was induced by higher receptor densities. It is likely that the increased biotin density at the SLB facilitated more biotin receptors in the GUV to move into the contact area and interact with SAv, thus 
providing more biotin-SAv interaction pairs that induce larger morphological changes with concomitantly larger contact areas.

(A)

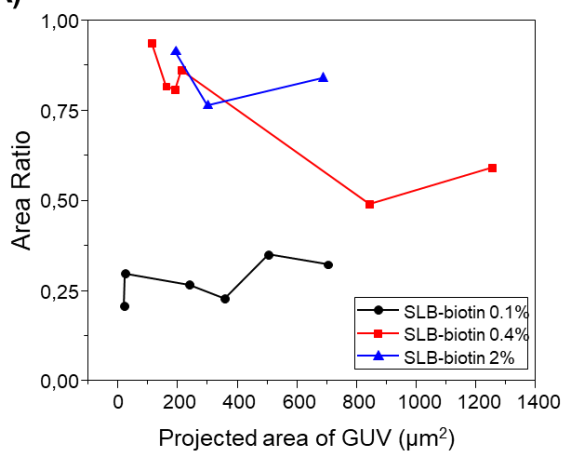

(C)

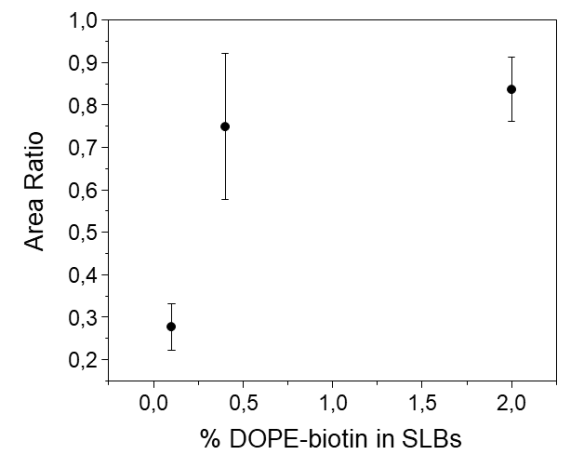

(B)

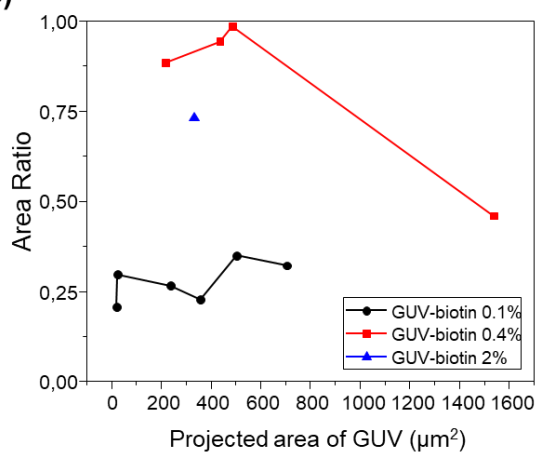

(D)

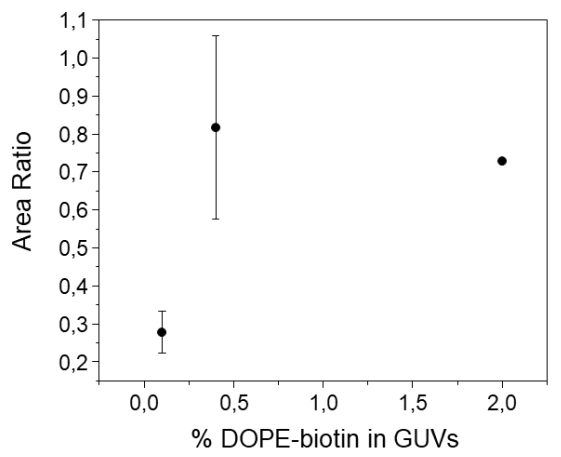

Figure 7.6. Changes of area ratios as a function of the GUVs projected area (i.e. the cross-section area). (A) GUVs with $0.1 \mathrm{~mol} \%$ biotin immobilized on the SLB of different biotin densities $(0.1,0.4$ and 2 mol\%). (B) GUVs with different biotin densities (0.1, 0.4 and 2 mol\%) immobilized on the SLB with $0.1 \mathrm{~mol} \%$ biotin. (C) Area ratios of the contact area (3rd column in Figure 7.4) and the cross-section area (1st column in Figure 7.4) of GUVs (with $0.1 \mathrm{~mol} \%$ biotin) immobilized on SLBs with different biotin densities $(0.1,0.4$ and $2 \mathrm{~mol} \%)$. (D) Area ratios of GUVs containing different biotin densities $(0.1,0.4$ and 2 mol\%) immobilized on SLBs with 0.1 mol\% biotin. Here only one datapoint is shown for $2 \mathrm{~mol} \%$ DOPE-biotin in the GUVs due to a lower stability in this case.

Furthermore, the receptor clustering was studied by changing the biotin density in the GUVs (0.1, 0.4 and $2 \mathrm{~mol} \%)$ adsorbing onto SLBs with a fixed biotin concentration $(0.1 \mathrm{~mol} \%)$. As Figure 7.7A shows, the green fluorescence of the contact areas for GUVs with 0.4 and 2 mol\% biotin was all bright and with high contrast, comparable to the GUVs with $0.1 \mathrm{~mol} \%$ biotin ( $1^{\text {st }}$ row in Figure 7.4), indicating an efficient clustering of SAv molecules on the SLB at a low receptor density $(0.1 \mathrm{~mol} \%$ biotin) regardless of the biotin density in the vesicles. 
Although the fluorescence intensities of SAv at the contact area for GUVs with different biotin densities were not that different (Figure 7.7B and 7.7C), the area ratios in these three cases were distinct from each other. By extracting the area ratios of vesicles of different sizes (Figure 7.6B), the morphological changes for GUVs of different biotin densities are shown in Figure 7.6D. Similar to the trend in Figure 7.6C, the area ratios of vesicles increased also when the biotin densities in the GUVs were increased to 0.4 and $2 \mathrm{~mol} \%$. This suggests that, in the case of $0.1 \mathrm{~mol} \%$ biotin in the GUVs, all biotin moieties from the GUVs can be arranged into biotin-SAv interaction pairs within a relatively small area. When the biotin density in the GUVs is increased to 0.4 and $2 \mathrm{~mol} \%$, more biotin-SAv interaction pairs are formed, which induces larger morphological changes.

(A)

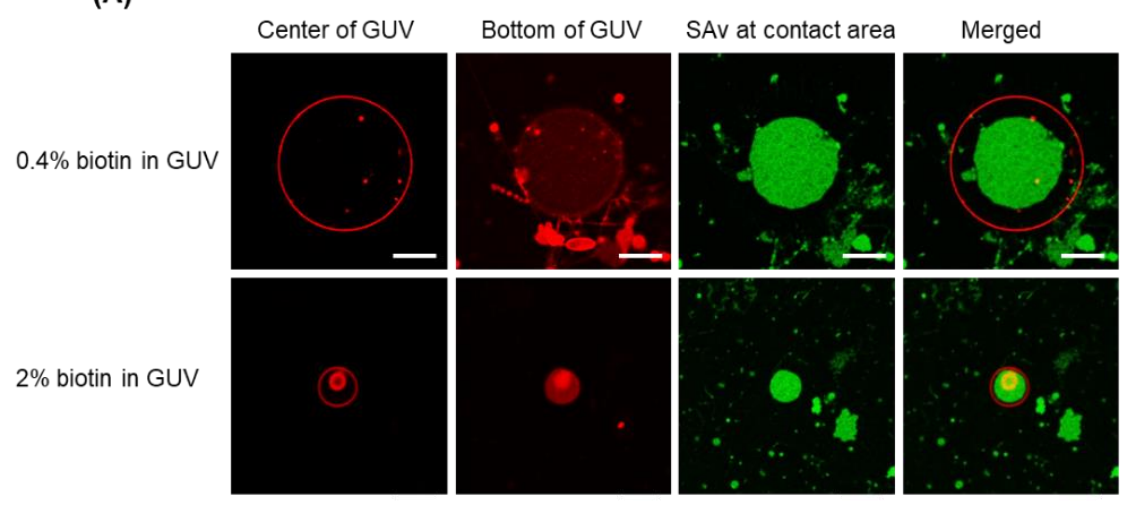

(B)

(C)
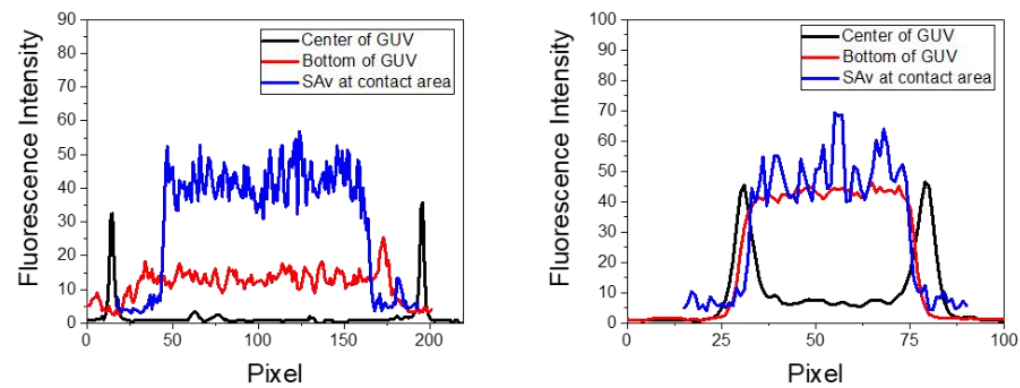

Figure 7.7. (A) Fluorescence microscopy images of the immobilized GUVs with biotin ligands of different densities $(0.4$ and $2 \mathrm{~mol} \%)$ on SLBs with $0.1 \%$ biotin. 1 st column: the widest/center section of the GUV; 2nd column: the bottom of GUVs obtained from the contact area between the GUV and the SLB; 3rd column: clustering of SAv molecules at the contact area; 4th column: merged images of the $1 \mathrm{st}$ and $3 \mathrm{rd}$ columns. Scale bars indicate $5 \mu \mathrm{m}$. The fluorescence profiles of GUVs containing (B) $0.4 \mathrm{~mol} \%$ and (C) $2 \mathrm{~mol} \%$ biotin on the SLB doped with $0.1 \%$ biotin. 
In the case of GUVs with $2 \mathrm{~mol} \%$ biotin, the stability was not as high as in the other cases, and most vesicles ruptured (Figure 7.8). It is likely that the high biotin\% in the GUVs drives the system towards an increased contact area between the GUV and the SLB that promotes vesicle rupture. This is also an indirect confirmation that, at $0.1 \%$ biotin in the GUVs, all biotins are being used in the binding to the SLB, whereby an increase of the biotin\% in the SLB cannot lead to further increase of the contact area.

(A)

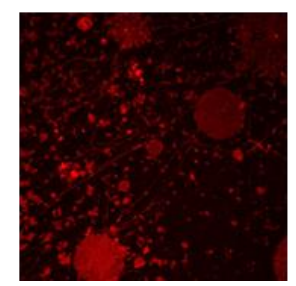

(B)

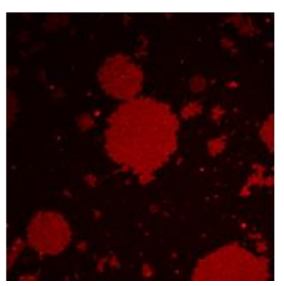

(C)

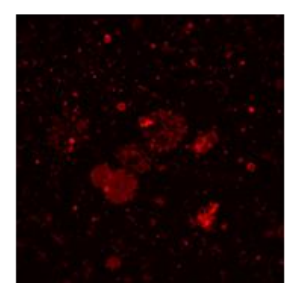

(D)

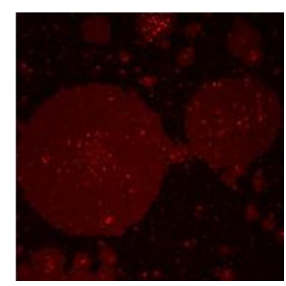

Figure 7.8. Ruptured GUVs on the SLB. (A) $0.4 \mathrm{~mol} \%$ biotin-GUV on $0.4 \mathrm{~mol} \%$ biotin-SLB, (B) 0.4 mol\% biotin-GUV on 2 mol\% biotin-SLB, (C) 2 mol\% biotin-GUV on 0.4 mol\% biotin-SLB, (D) 2 mol\% biotin-GUV on $2 \mathrm{~mol} \%$ biotin-SLB.

\subsection{Discussion}

All the distinctive trends in the vesicles binding to the SLB observed above show that the biotin densities both in the vesicles and in the SLB play an important role in the recruitment of biotin/SAv interaction pairs into the contact area. Here we attempt to analyze what effects play at the molecular level during the binding of the vesicles to the SLB and how this affects the recruitment and the deformation of the vesicles at the interface. When viewing the biotin\% in the SLBs and the vesicles as ranging from low to high, various regimes can be distinguished. The different regimes in these vesicles binding processes are depicted in Figure 7.9. 


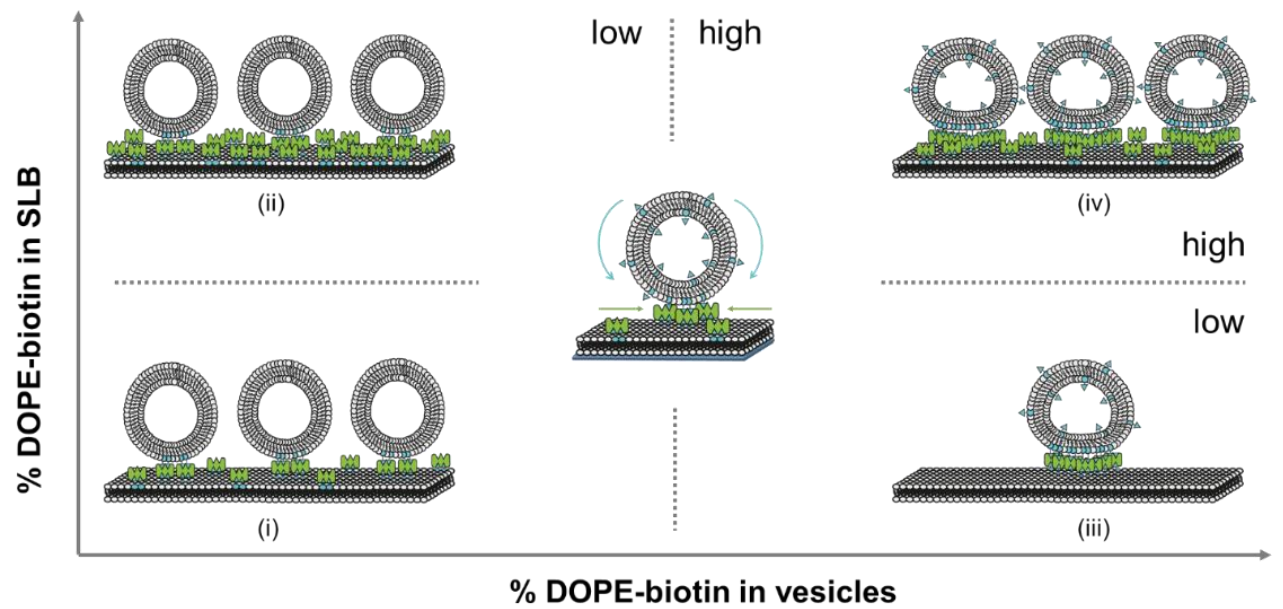

Figure 7.9. Schematic representation of the adsorption of vesicles for varying DOPE-biotin molar ratios both in the vesicles (from left to right) and in the SLB (from bottom to top), indicating situations where the biotin\% in the vesicles is limiting (top left) or in the SLBs (bottom right), and where vesicle deformation is high (right) and vesicle density is high (top).

First we consider the effect of a low biotin density in the vesicles $(0.025$ to $0.1 \mathrm{~mol} \%)$ on their binding at SLB surfaces functionalized with a low density of SAv. As shown in Figure 7.3B, low biotin densities in the SUVs cause a high coverage of vesicles on surfaces functionalized with low SAv densities ( 0.1 and $0.4 \mathrm{~mol} \%$ biotin), leading to large frequency shifts (case (i) in Figure 7.9). Similarly, when surfaces are functionalized with a higher density of SAv on the SLB, a similar coverage of vesicles is observed (Figure 7.3B and case (ii) in Figure 7.9), implying that the density of adsorbed vesicles is not influenced by the SAv density at the SLBs. This suggests that the adsorption of vesicles is determined by the amount of biotin in the vesicles. In particular, all the biotin moieties on the vesicle are employed in the binding with SAv on the SLB surface, as demonstrated by the absence of SAv adsorption on bound vesicles for such biotin density (Figure 7.3D). Apparently, the low biotin density in the vesicles in cases (i) and (ii) promotes the formation of only a limited number of biotinSAv interaction pairs, resulting in recruitment of SAv molecules from a limited area surrounding the vesicle, thus promoting a relatively high coverage of the SLB surface with vesicles. This was confirmed with the $\Delta D_{5} / \Delta f_{5}$ ratio calculated for low biotin content in SUVs. In fact, a similar ratio was obtained for all three SAv densities (Figure 7.3B), suggesting that no difference in the density of the vesicles on the surface is observed. The measured stiffness can therefore be attributed to a densely packed vesicle layer formed on 
the SLB. Moreover, the absence of SAv adsorption after vesicle deposition (Figure 7.3D), demonstrates that the biotin moieties displayed on the SUVs are all bound to SAv at the surface. Therefore, in this regime, recruitment occurs exclusively for the biotins present in the SUVs.

Subsequently, we consider the effect of a high biotin density in the vesicles, i.e. in the range of 1 to $5 \mathrm{~mol} \%$, on their binding at the SLB interface functionalized with a low density of SAv (case (iii) in Figure 7.9). As shown in Figure 7.3B, high biotin densities in the vesicles cause a lower coverage of the vesicles on the surface functionalized with low SAv densities ( 0.1 and $0.4 \mathrm{~mol} \%$ biotin), leading to small frequency shifts. This phenomenon can be attributed to the enhanced recruitment of SAv on the surface promoted by the binding of the vesicles. Due to the mobility of the SLB, SAv can diffuse at the interface and as a consequence, it is likely that as soon as a single SAv-biotin interaction occurs, more proteins bind at the SLB interface that is in contact with the bottom of vesicles. The anchoring of a large number of SAv with vesicles thus causes a depletion of free SAv on the SLB interface. The recruitment of SAv was confirmed by the observation of the contact area in GUVs adsorbed to SLBs and of depletion of SAv outside the contact area which provided a high contrast (Figure 7.4). Overall, compared to case (i), the higher biotin\% in the vesicles in case (iii) promotes stronger recruitment and the formation of a larger number of interaction pairs involving a larger number of SAv molecules, leading to a concomitantly larger contact area. The higher coverage of vesicles with a high biotin $\%$ observed at larger biotin densities on the SLB (2 mol\%), demonstrated that the depletion of SAv on the surface is prevented in this case. In other words, when the surface can supply more SAv, it is possible to accommodate a larger density of vesicles (case (iv) in Figure 7.9). When surfaces are densely covered with SAv, the depletion is fully suppressed and the binding of vesicles is purely determined by the packing density of SUVs on the surface. The adsorption of SUVs on SLBs containing increasing SAv densities, leads to an increase in stiffness of the surface, as also demonstrated by the different $\Delta D_{5} / \Delta f_{5}$ ratios obtained for SLBs containing $0.1,0.4$ and $2 \%$ of biotinylated lipids (Figure 7.3C). However, the similar vesicle coverage obtained with $1 \%$ to $5 \%$ of biotin in the vesicles, suggests that no further depletion of SAv on the SLB occurs, meaning that the maximal density of SAv at the interface with a vesicle is reached with $1 \%$ of biotin density in the SUVs. Beyond this value, the contact area of the SUVs does not further increase. As a consequence, a higher content of biotin in the SUVs implies a higher amount of free biotin in the SUVs remaining after adsorption. Conclusively, in both cases (iii) and (iv), the biotin density at the vesicle is higher than that is used for bond formation at the contact area, leaving free unused biotin moieties available upon adsorption, as witnessed by the SAv attachment to these moieties (Figure 7.3D). 
The cut-off values obtained from Figure 7.3D allow a quantitative estimation of the contact area of a vesicle with the surface. Assuming an average diameter of an SUV of approx. 100 $\mathrm{nm}$ and the footprint of a single lipid molecule of $0.725 \mathrm{~nm}^{16}$ (leading to approx. 43000 lipids in the outer leaflet at an area of $31000 \mathrm{~nm}^{2}$ ), we estimate that approximately 260 biotins can be involved in the interaction at the interface at the observed cut-off of $0.6 \mathrm{~mol} \%$ biotin in the SUVs. As a consequence, a maximum of approx. $130 \mathrm{SAv}$ can be recruited in the contact area. By setting a single SAv area to $25 \mathrm{~nm}^{2}$, the area occupied by densely packed SAv is approximately $3250 \mathrm{~nm}^{2}$, corresponding to $10 \%$ of the SUV surface area. At the same time, this cut-off represents roughly the boundary at which the biotin moieties in SLB and vesicle are balanced: at lower biotin\% in the SUVs, the biotin density in the SUV is limiting, and recruitment occurs primarily within the SUV, consuming all of its biotin moieties in its interaction with the SLB. Above the $0.6 \%$ boundary, the biotin (and SAv) density in the SLB is limiting, and recruitment occurs primarily within the SLB, thus recruiting SAv molecules from larger areas, leading to concomitantly lower vesicle coverages.

Also the SLB areas from which recruitment occurs can be estimated. A maximal dense packing of equally sized spheres on a surface is $90.6 \%$, while the random parking limit is approx. 55\% of the underlying surface area. The QCM data for the additional SAv bound to SUVs on an SLB (Figure 7.3D) can provide additional information. Of all values shown in this graph, the one with the highest value, corresponding to $5 \%$ biotin-modified SUVs at a $2 \%$ biotin SLB, is the most reliable, as it was measured at a dense SUV layer (150 Hz for the vesicle adsorption step) and the 5\% vesicles have the highest fraction of unused biotins. The observed frequency in this case $(53 \mathrm{~Hz})$ is approx. twice that of a densely packed SAv layer on a $2 \%$ biotin SLB $(27 \mathrm{~Hz})$. When we assume that the QCM sensitivity for the SAv adsorption is the same on an SLB vs a vesicle-coated SLB, the SAv density can be calculated as $0.08 \mathrm{SAv}$ per $\mathrm{nm}^{2}$ of SLB area. This SAv density can be reached when the vesicle packing density is approx. $66 \%$ which is well within the range of the parking limit and the densest possible packing. At vesicle frequency changes below $150 \mathrm{~Hz}$, the vesicle density is correspondingly lower, and the SLB area per vesicle increases. As shown in Figure 7.3B, this effect is most pronounced for high biotin\% in the SUVs and low biotin\% in the SLB. But also at low biotin\% in the SUVs (left side of Figure 7.3B), the small differences in frequency change may indicate that the coverage at lower biotin $\%$ is not completely dense (approx. $60 \%$ of the densest packing at $0.1 \%$ biotin in the SLB).

For comparison with the SUV data, the recruited numbers of SAv inside the contact area of bound GUVs were analyzed as well. It is, however, important to note that the GUV assembly is generally done for a relatively short time at much lower vesicle concentrations than in the case of the SUVs. Therefore, high vesicle densities are never observed, and in principle every vesicle can recruit SAv molecules from a sufficiently large SLB area. Because of their size, 
the contact area of a bound GUV can actually be measured (Figure 7.4). The projected area ratios shown in Figure 7.6 can be recalculated in a straightforward manner to the contact area per vesicle area. The high area ratios of approx. 0.8 correspond to a relative contact area of $21 \%$ of the vesicle surface area (see Experimental Section, Table 7.3). This is somewhat higher than the $10 \%$ estimated from the SUV data described above. Only when the biotin\% in both the SLB and the GUV is $0.1 \%$, the area ratio is lower (approx. 0.3 ), which corresponds to a contact area of $7 \%$. When we take the number of biotin moieties in the $0.1 \%$ GUVs into account, we note that the measured contact areas are quite a lot (a factor 4-15) larger than needed for a dense SAv packing that would saturate all these biotin groups. Most likely, the energy penalty required to deform the GUVs is a lot lower than the SUVs, thus allowing a larger contact area and a relatively low-density SAv packing within it. The lower contact areas observed at the $0.1 \%$ biotin in both GUV and SLB is attributed to insufficient recruitment time, see below.

To estimate the timescale at which recruitment and depletion may occur, we can consider the diffusion time. In a homogeneous and two-dimensional system, the diffusion coefficient $D$ can be defined through the relation: ${ }^{17}$

$$
t \approx x^{2} / 4 D
$$

Here $x$ indicates the displacement of molecules (here biotin-lipid-anchored SAv) in a clustering process and $t$ the time. For SUVs of $100 \mathrm{~nm}$ with $0.1 \mathrm{~mol} \%$ biotin, and assuming that all biotins of the SUV are involved in binding, all SAv of a $200 \mathrm{~nm}$ diameter area of an SLB with $0.1 \mathrm{~mol} \%$ biotin are expected to be recruited. When the SUV has a $5 \mathrm{~mol} \%$ biotin density, the recruited area increases to a diameter of $1.4 \mu \mathrm{m}$. Assuming a diffusion constant on the order of $1 \mu \mathrm{m}^{2} / \mathrm{s}$ (Table 7.1), these areas correspond to recruitment times of $0.01-0.5$ $\mathrm{s}$, which is way faster than the QCM times used here. For GUVs, however, the larger vesicle size leads to larger recruitment areas and therefore longer recruitment times, which can for a $10 \mu \mathrm{m}$ vesicle range from 100-5000 s for recruitment within the SLB and on the order of 100 s for recruitment within the GUV itself. Typically, we took the images of the GUVs approx. a few min after adsorption, which is OK to achieve practically complete recruitment for the SLBs with 0.4 and $2 \%$ of biotin. The longest time is expected for the $0.1 \%$ of biotin in both GUV and SLB, and therefore the observed smaller contact areas, combined with the complete absence of SAv surrounding the bound vesicles in this case, may be a sign of incomplete recruitment within the contact area to achieve saturation of all biotins of the GUV within the given time. 


\subsection{Conclusions}

In this work, the clustering of SAv molecules on biotin-modified SLBs induced by the strong multivalent binding with biotinylated SUVs and GUVs was quantitatively analyzed. Different regimes were found for the binding of SUVs in which the modulation of clustering is attributed to the densities of biotin moieties both in the vesicles and the SLBs. The dependence of the contact area between the vesicles and the SLB was measured with a GUV model system to understand how the receptor density affected the formation of receptor clustering. The deformation of individual GUVs was quantitatively analyzed to show the induced morphological changes during the binding process. Both SUVs and GUVs show that the clustering response upon vesicle binding is dependent on the receptor density in the membrane, which therefore leads to different working mechanism for the binding process. Here, the weak affinity are of great relevance for the understanding of biological systems, in which the speed of recruitment is also a critical issue for quantitative analysis and can be explored further in our next work. These results may offer a useful tool for assisting the analysis of biological examples of ligand/receptor clustering, for example of virus binding on cell membranes.

\subsection{Acknowledgements}

Joris Meulman is acknowledged for the help with the QCM measurements and Yao Lu for the FRAP and confocal microscopy measurements.

\subsection{Experimental section}

\subsubsection{Materials}

Chemicals were purchased from Sigma Aldrich. 1,2-Dioleoyl-sn-glycero-3-phosphocholine (DOPC), 1,2-dioleoyl-sn-glycero-3-phosphoethanolamine-N-(cap biotinyl), sodium salt (DOPE-biotin) were purchased from Avanti Polar Lipids, while Texas Red-1,2dihexadecanoyl-sn-glycero-3-phosphoethanolamine (TR-DHPE) was obtained from Thermo Fisher Scientific. Streptavidin and streptavidin-Alexa-Fluor ${ }^{\circledR}$ were obtained from Thermo Fischer Scientific. SAv was dissolved in 0.1 M PBS (0.01 M sodium dihydrogen phosphate and $0.15 \mathrm{M}$ sodium chloride, $\mathrm{pH} 7.4$ ) at a concentration of $20 \mu \mathrm{g} \mathrm{mL}^{-1}$. 


\subsubsection{Methods}

\section{Substrate cleaning and preparation}

QCM-D sensors were immersed in a $2 \mathrm{wt} \%$ sodium dodecyl sulfate (SDS) solution for 30 min , thoroughly rised with Milli-Q and dried under nitrogen stream. Activation was performed with $20 \mathrm{~min}$ UV/ozone treatment using a Bioforce chamber (Nanosciences).

\section{Preparation of small unilamellar vesicles (SUVs) and giant unilamellar vesicles (GUVs)}

Lipids were first dissolved in chloroform and mixed in desired molar ratio in a glass vial. Afterwards, the solvent was evaporated with a nitrogen stream and the obtained lipidic film was dried for at least 1 hour in a dessicator connected to a vacuum vacuum pump. The dried film was then resuspended in MilliQ water or PBS buffer with a concentration of $1 \mathrm{mg} / \mathrm{mL}$. The lipid suspensions were extruded 11 times through a polycarbonate membrane (Whatman) with $100 \mathrm{~nm}$ pore size, and the obtained SUVs were stored in the fridge and used within maximum two weeks. The size of the vesicles was measured by dynamic light scattering (DLS) before use.

For the preparation of GUVs, drops of the solution containing the lipid mixture were put on 2 titanium oxide-coated glass slides and the solvent was evaporated with a flow of nitrogen gas to create uniform lipid films. The lipid-coated slides were dried in a vacuum desiccator for $1 \mathrm{~h}$. The dried lipid-coated slides and a clean PDMS spacer are put together to form a capacitor cell. The conductive sides of both slides were faced inward and were fixed with a clamp to form a chamber. The chamber was filled with $200 \mathrm{mM}$ sucrose buffer solution and sealed with plastic paraffin film. Electro-formation was then carried out using a function generator. A $10 \mathrm{~Hz}$ sinusoidal potential with a $1 \mathrm{~V}$ peak-to- peak amplitude was applied across the chamber for $2 \mathrm{~h}$, after which the frequency was reduced to $2 \mathrm{~Hz}$ for $1 \mathrm{~h}$. The GUVs were extracted from the chamber using a pipette, stored in an Eppendorf vial $(2 \mathrm{ml})$ in the dark and used the same day. The direct usage of the GUVs is necessary because of the relatively high instability of larger vesicles. 
Table 7.2. Size of SUVs containing varying molar fraction of DOPE-biotin determined by DLS.

\begin{tabular}{|c|c|}
\hline $\begin{array}{c}\text { DOPE-biotin in DOPC } \\
\text { vesicles }(\boldsymbol{\%})\end{array}$ & Vesicles size (nm) \\
\hline $\mathbf{0 . 0 2 5}$ & $90 \pm 30$ \\
\hline $\mathbf{0 . 1}$ & $86 \pm 29$ \\
\hline $\mathbf{0 . 2 5}$ & $92 \pm 30$ \\
\hline $\mathbf{0 . 4}$ & $83 \pm 27$ \\
\hline $\mathbf{0 . 6}$ & $92 \pm 28$ \\
\hline $\mathbf{1 . 0}$ & $93 \pm 30$ \\
\hline $\mathbf{5}$ & $79 \pm 26$ \\
\hline
\end{tabular}

\section{Preparation of the supported lipid bilayers (SLBs) in QCM measurements}

For the fabrication of SLB, vesicles were diluted to a concentration of $0.1 \mathrm{mg} / \mathrm{ml}$ in PBS buffer directly before use. SLBs were obtained by flowing this solution on a cleaned and activated surface, after obtaining a stable baseline. The quality of the SLBs was monitored by fluorescence recovery after photobleaching (FRAP) or in situ by QCM-D (where high quality SLBs are defined by $\Delta \mathrm{f}=-24 \pm 1 \mathrm{~Hz}$ and $\Delta \mathrm{D}<0.5 \times 10-6)$.

\section{Preparation of the supported lipid bilayers (SLBs) in FRAP and confocal microscopy measurements}

For the FRAP and GUV assembly experiments, lipid mixtures of DOPC, Texas Red-DHPE and Biotinyl-cap-PE (molar ratio 99.85:0.05:0.1) were used to form the supported lipid bilayers (SLBs) using the vesicle fusion method. SLBs were deposited in the wells of a 96well plate with a glass bottom. Before the formation of the SLB, $400 \mu \mathrm{L}$ sodium hydroxide ( $\mathrm{NaOH}, 2 \mathrm{M}$ ) solution was added to the glass substrate for $1 \mathrm{~h}$ to form a hydrophilic surface. Afterwards, the wells were rinsed with Milli-Q water three times and incubated with $200 \mu \mathrm{L}$ SUV solution for $30 \mathrm{~min}$ at room temperature. A detect-free SLB was then formed by the rupture of SUVs onto the hydrophilic glass substrate. Excess lipids were removed from the well by rinsing with MilliQ water three times. After SLB formation, care was taken to keep the surface submerged in buffer and without bubbles. 


\section{Immobilization of giant unilamellar vesicles}

Before the adhesion of GUVs, the SLB-coated substrate was incubated with Alexa Fluor 488SAv $(200 \mu \mathrm{L}, 20 \mu \mathrm{g} \mathrm{mL}-1)$ for $20 \mathrm{~min}$ and then rinsed consecutively with PBS and sucrose buffer, each for three times. After that, $50 \mu \mathrm{L}$ GUV solutions were added to the well and incubated for another $30 \mathrm{~min}$. Then, the well was gently rinsed with sucrose buffer three times to remove excess GUVs.

\section{QCM-D measurements}

QCM-D measurements were performed with a Qsense Analyser from Biolin Scientific and $\mathrm{SiO}_{2}$-coated sensors (QSX303, Biolin Scientific) were used throughout this work. Measurements were done at $22{ }^{\circ} \mathrm{C}$ and operated with four parallel flow chambers, using two Ismatec peristaltic pumps with a flow rate of $20 \mu \mathrm{l} / \mathrm{min}$. For every measurement, the fifth overtone was used for the normalized frequency $\left(\Delta f_{5}\right)$ and dissipation $\left(\Delta D_{5}\right)$.

\section{FRAP measurements}

By a confocal microscope, a circular spot of $10 \mu \mathrm{m}$ in diameter was bleached, then the fluorescence intensity in the bleached regions was monitored. For the SLB immobilized at the bottom of the 96-well plate, the FRAP protocol consisted of 11 imaging loops $(1 \mathrm{~s}$ interval) before bleaching, 10 loops bleaching with no delay in between loops, and 300 loops of recovery ( $1 \mathrm{~s}$ interval). Then the FRAP curves were fitted in a diffusion model for circular spot by the modified Bessel functions. ${ }^{14}$

\section{Confocal microscopy}

Confocal laser scanning microscopy (CLSM, Nikon A1) was used to observe immobilized GUVs and the SLB. The Texas Red-labeled GUVs were examined by CLSM with an excitation wavelength $\left(\lambda_{\mathrm{ex}}\right)$ of $595 \mathrm{~nm}$, while the Alexa Fluor $488 \mathrm{SAv}$ was measured with $\lambda_{\text {ex }}$ of $495 \mathrm{~nm}$.

\section{Calculation of the quantification of streptavidin (SAv) on a surface}

Assuming that one DOPC lipid covers $0.725 \mathrm{~nm}^{2}$, i.e. a lipid density in the SLB corresponding to 1.38 molecules per $\mathrm{nm}^{2}\left(=2.3 \times 10-10 \mathrm{~mol} / \mathrm{cm}^{2}=\mathrm{a}\right)$, and that a SAv binds to two biotin in SLB, we obtain as follows:

- fraction DOPE-biotin $=\mathrm{x}$;

- density of DOPE-biotin $=\mathrm{x} \times \mathrm{a}=\mathrm{xa}$;

- density of SAv = $1 / 2 x a$; 
Therefore at $\mathrm{x}=0.1 \%$ : Density of SAv $=0.11 \mathrm{pmol} / \mathrm{cm}^{2}$, etc.

Calculations of SAv numbers in Table 3 by using the parameters labeled in Figure 7.10

- the surface area of the capped GUV: $A$ cap $=\pi * D *(h+d / 2)$

- the contact area of a GUV: c.a. $=\pi *(d / 2)^{2}$

- the surface area of an intact GUV: $A$ ves $=A$ cap + c.a.

- the equivalent diameter of the capped GUV: $D^{\prime}=\operatorname{sqrt}(A$ ves $/ \pi)$

- the area ratio of the contact area to the project area of a GUV: area ratio $=d^{2} / D^{2}$

- the number of lipids in a GUV: \# lip ves $=\left(A\right.$ ves $\left.* 10^{6}\right) / 25$

- the number of biotinyl lipids in a GUV (with 0.1 mol\% biotin): \# biotin ves = \# lip ves * $0.1 \%$

- the area of the recruited SAv: c.a. recr SAv $=1 / 2$ \# biotin ves $* 25 * 10^{-6}$

- the ratio of the contact area to the area of the recruited SAv: c.a. ratio $=$ c.a./ c.a. recr SAv 


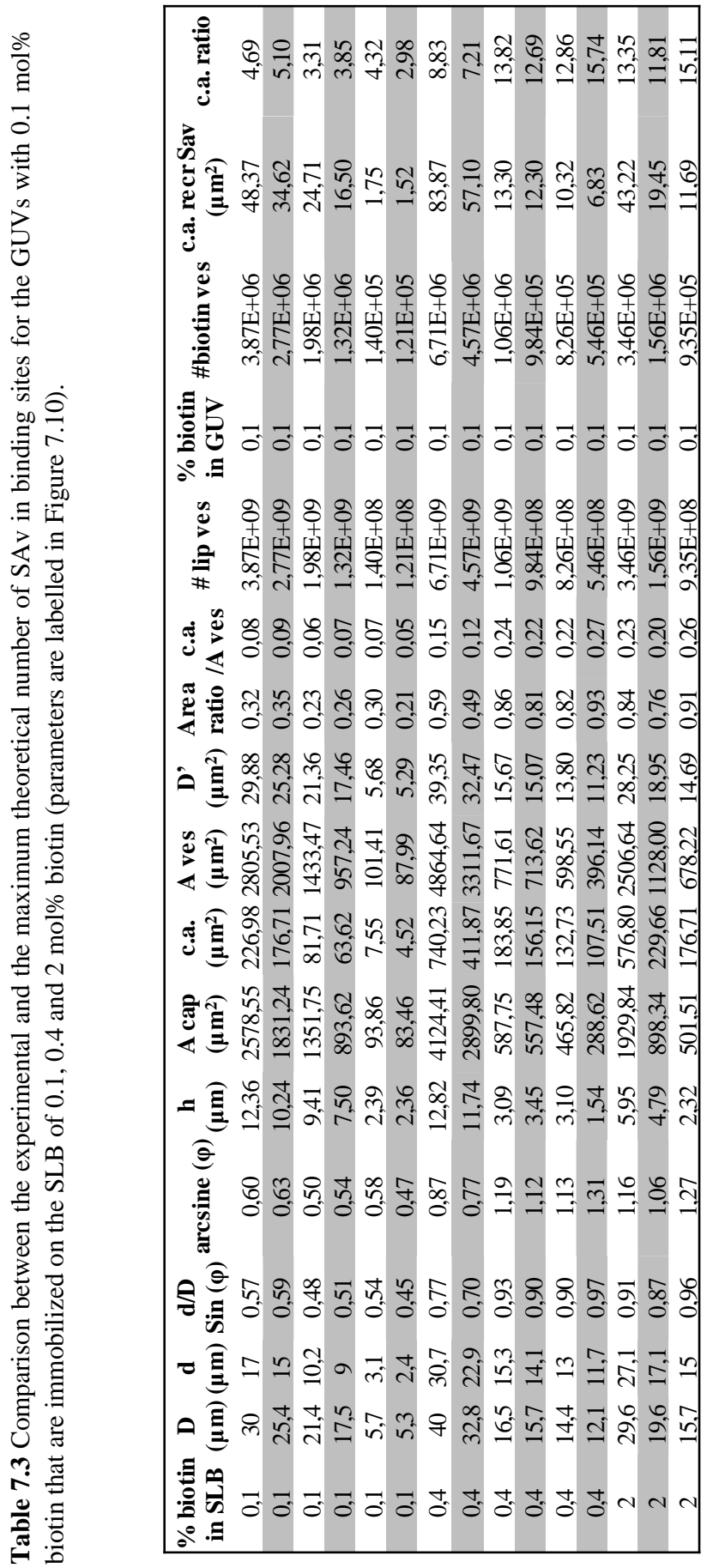




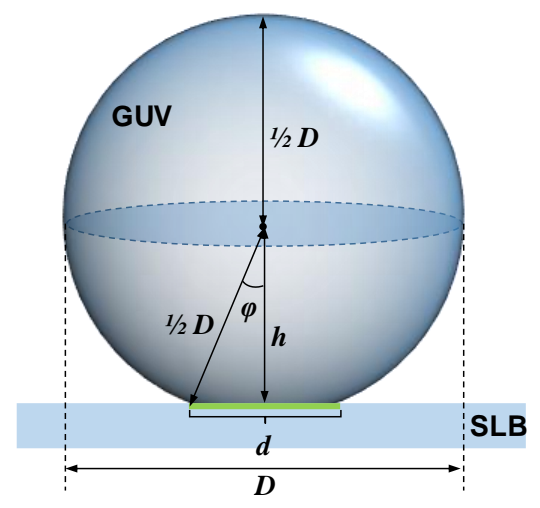

Figure 7.10. Calculation model of the capped-sphere for immobilized GUV on the SLB.

\subsection{References}

1. Tolar, P.; Hanna, J.; Krueger, P. D.; Pierce, S. K., The Constant Region of the Membrane Immunoglobulin Mediates B Cell-Receptor Clustering and Signaling in Response to Membrane Antigens. Immunity 2009, 30, 44-55.

2. Grochmal, A.; Ferrero, E.; Milanesi, L.; Tomas, S., Modulation of In-Membrane Receptor Clustering upon Binding of Multivalent Ligands. J. Am. Chem. Soc. 2013, 135, 10172-10177.

3. Renner, M.; Specht, C. G.; Triller, A., Molecular dynamics of postsynaptic receptors and scaffold proteins. Curr. Opin. Neurobiol. 2008, 18, 532-540.

4. Cochran, J. R.; Aivazian, D.; Cameron, T. O.; Stern, L. J., Receptor clustering and transmembrane signaling in T cells. Trends Biochem. Sci. 2001, 26, 304-310.

5. Dubacheva, G. V.; Curk, T.; Frenkel, D.; Richter, R. P., Multivalent Recognition at Fluid Surfaces: The Interplay of Receptor Clustering and Superselectivity. J. Am. Chem. Soc. 2019, 141, 2577-2588.

6. van Weerd, J.; Karperien, M.; Jonkheijm, P., Supported Lipid Bilayers for the Generation of Dynamic Cell-Material Interfaces. Adv. Healthc. Mater. 2015, 4, 2743-2779.

7. Glasmästar, K.; Larsson, C.; Höök, F.; Kasemo, B., Protein Adsorption on Supported Phospholipid Bilayers. J. Colloid Interf. Sci. 2002, 246, 40-47.

8. Jung, H.; Robison, A. D.; Cremer, P. S., Multivalent ligand-receptor binding on supported lipid bilayers. J. Struct. Biol. 2009, 168, 90-94.

9. Seu, K. J.; Cambrea, L. R.; Everly, R. M.; Hovis, J. S., Influence of Lipid Chemistry on Membrane Fluidity: Tail and Headgroup Interactions. Biophys. J. 2006, 91, 3727-3735.

10. Di Iorio, D.; Verheijden, M. L.; van der Vries, E.; Jonkheijm, P.; Huskens, J., Weak Multivalent Binding of Influenza Hemagglutinin Nanoparticles at a SialoglycanFunctionalized Supported Lipid Bilayer. ACS Nano 2019, 13, 3413-3423.

11. Green, N. M., Avidin. In Advances in Protein Chemistry, Anfinsen, C. B.; Edsall, J. T.; Richards, F. M., Eds. Academic Press: 1975; Vol. 29, pp 85-133.

12. Schönherr, H.; Johnson, J. M.; Lenz, P.; Frank, C. W.; Boxer, S. G., Vesicle Adsorption and Lipid Bilayer Formation on Glass Studied by Atomic Force Microscopy. Langmuir 2004, 20 , 11600-11606. 
13. Dubacheva, G. V.; Araya-Callis, C.; Geert Volbeda, A.; Fairhead, M.; Codée, J.; Howarth, M.; Richter, R. P., Controlling Multivalent Binding through Surface Chemistry: Model Study on Streptavidin. J. Am. Chem. Soc. 2017, 139, 4157-4167.

14. Soumpasis, D. M., Theoretical analysis of fluorescence photobleaching recovery experiments. Biophys. J. 1983, 41, 95-97.

15. Reviakine, I.; Rossetti, F. F.; Morozov, A. N.; Textor, M., Investigating the properties of supported vesicular layers on titanium dioxide by quartz crystal microbalance with dissipation measurements. J. Chem. Phys. 2005, 122, 204711.

16. Nagle, J. F.; Tristram-Nagle, S., Structure of lipid bilayers. BBA-Rev Biomembranes 2000, 1469, 159-195.

17. Atkins, P. W., Physical Chemistry. 5th Edition ed.; 1994. 


\section{Summary}

Influenza represents a serious global health issue that causes millions of infections every year. Quantification of the multivalent interaction of the influenza virus binding at a host cell surface can lead to a better understanding of its multivalent binding energy landscape and provide ways to tackle biological questions regarding influenza virulence and zoonoses. For this reason, the development of platforms and devices that allow the quantification of these interactions is required. Specifically, when designing such platforms, various prerequisites, such as good antifouling properties, control over the surface ligand density and capability of mimicking cell membranes, need to be met.

The research discussed in this thesis is aimed at developing surface chemistry methods that allow the selective modification of surfaces with biomolecules for the study of multivalent biological interactions, such as that of the influenza virus with cell surface receptors. Two different approaches were examined in this dissertation. In the first part of the thesis (Chapters 3 and 4), the use of functionalized poly-L-lysine (PLL) for the formation of polyelectrolyte monolayers has been discussed. With this method, the selective functionalization of several types of surfaces was achieved, and its efficacy in detecting DNA has been explored. The second part (Chapters 5-7) has focused on the formation of cell membrane mimics, based on supported lipid bilayers (SLBs), for the quantification of flu virus interactions.

Chapter 2 offered a literature review of the reported surface functionalization methods that allow control of the ligand density displayed at the interface. Particular attention is given to methods used in the investigation of multivalent biological interactions, mainly those involving protein-carbohydrate interactions. Self-assembled monolayers (SAMs), SLBs and different types of polymers have been employed in the modification of the surfaces discussed in the examples provided in this chapter.

Chapter 3 has discussed the combination of the use of PLL polymers and catalyst-free click chemistry reactions for the selective and fast modification of surfaces with biomolecules. Specifically, gold and silicon dioxide surfaces have been functionalized with PLLs bearing either tetrazine or dibenzocyclooctyne (DBCO) groups for the subsequent conjugation of either trans-cyclooctene or azide-modified DNA. The capability of recognizing complementary DNA sequences from aqueous solution and the control over the DNA probe density displayed on the surface were explored successfully.

Chapter 4 has reported the use of modified PLLs for the modification of polymeric surfaces such as cyclic olefin polymer (COP) and Ormostamp. Micropatterning techniques were 
employed for a selective and efficient functionalization of the substrates. Fluorescence microscopy was used for the optical inspection of the surface functionalization. The antifouling properties, as well as the stability of the surface modification over time were tested, confirming a stable functionalization of substrates with PLL. Finally, the selective recognition of complementary DNA was tested, showing the prospect of using PLL for the development of customized responsive (bio)interfaces in biomedical devices.

Chapter 5 shows the development of a supported lipid bilayer (SLB) platform for the quantification of the binding of the influenza virus at artificial cell receptors. By employing a tunable fraction of a functional ligand in the SLB, control over the receptor density was achieved. At the same time, the use of recombinant hemagglutinin (rHA) nanoparticles provided an accurate determination of the number of interaction pairs involved in the multivalent interactions. Quantification of binding affinities and selectivity of rHA nanoparticles for specific receptors were assessed. A multivalency model was employed for the analysis of the data, showing a weakly multivalent binding of rHA for the receptorfunctionalized surfaces.

The methodology developed in Chapter 5 was adapted in Chapter $\mathbf{6}$ for the quantification of the binding of full viruses with receptor-modified SLB surfaces. Binding affinities in the picomolar range and selectivities for human and avian receptors were assessed. Additionally, the dependence of the binding affinity on varying receptor densities was investigated. By plotting the virus binding saturation values versus different receptor coverages, a superselective binding behavior was observed. A multivalency model, in combination with observations made in Chapter 5, allowed the depiction of a virus binding energy landscape, confirming that the flu virus binds in a weakly multivalent manner.

In Chapter 7, the phenomenon of receptor clustering at the interface was investigated by making use of the intrinsic lipid mobility of SLBs. The streptavidin (SAv)-biotin interaction was used as model for the general ligand-receptor interactions. Specifically, the recruitment of SAv receptors, induced by binding of multivalent biotinylated small and giant unilamellar vesicles, was observed. Different vesicle binding regimes were observed at varying ligand/receptor densities. Both the interaction area and the number of molecules involved in the overall interaction were assessed in a quantitative fashion.

In summary, different surface modification techniques have been developed in this thesis for the study of biological interactions. Results obtained with PLL polymers showed the power of functionalizing a wide range of substrates for the controlled modification of surfaces with biomolecules while retaining their biological activity. At the same time, the SLB platform developed here provided access to the quantification of multivalent binding of the flu virus at artificial cell surface mimics with a precise control of the surface ligand/receptor density. 
We expect that the surface functionalization methods developed here can be used for the further development of biosensors, allowing quantification of multivalent interactions and the discrimination of different types of flu virus strains. These techniques can be employed for the investigation of a wider range of biological, monovalent and multivalent interactions at interfaces, thus providing insight into complex biomolecular mechanisms. 


\section{Samenvatting}

Influenza is een wereldwijd gezondheidsprobleem dat elk jaar miljoenen infecties veroorzaakt. Het kwantificeren van de multivalente interactie van het influenzavirus bij het binden aan het oppervlak van een gastheercel kan leiden tot het beter begrijpen van de eigenschappen van het energielandschap dat bij deze binding hoort. Met deze informatie kunnen verschillende biologische kwesties worden aangepakt aangaande de activiteit van influenza en het optreden van zoönose. Hiervoor moeten platforms en devices ontwikkeld worden die deze interacties kunnen bepalen. Bij het ontwerpen van een dergelijk platform zijn er verschillende vereisten waaraan voldaan moet worden, zoals goede antifoulingeigenschappen, controle over de liganddichtheid op het oppervlak en het vermogen om celmembranen na te bootsen.

Het onderzoek beschreven in dit proefschrift is gericht op het ontwikkelen van oppervlaktechemische methodes die de selectieve modificatie van oppervlakken met biomoleculen mogelijk maakt voor het bestuderen van multivalente biologische interacties. Hieronder valt bijvoorbeeld het binden van het influenzavirus met receptoren van een celmembraan. Twee verschillende benaderingen zijn onderzocht in dit proefschrift. In het eerste gedeelte (hoofdstukken 3 en 4) is het gebruik van gefunctionaliseerd poly-L-lysine (PLL) voor de vorming van polyelektrolyt-monolagen besproken. Met deze methode is de selectieve functionalisatie van verschillende types oppervlakken bereikt en tevens is de werkzaamheid in het detecteren van DNA onderzocht. Het tweede gedeelte (hoofdstukken 5-7) is gericht op het nabootsen van celmembranen gebaseerd op oppervlakte-geïmmobiliseerde lipide-bilagen voor het kwantificeren van interacties van het griepvirus.

Samengevat zijn in dit proefschrift verschillende oppervlaktemodificatietechnieken ontwikkeld voor het bestuderen van biologische interacties. Resultaten verkregen met PLLpolymeren bewijzen de kracht van het functionaliseren van een grote verscheidenheid aan substraten voor het gecontroleerd modificeren van oppervlakken met biomoleculen met behoud van hun biologische activiteit. Tegelijkertijd geeft het lipide-bilaag-platform dat hier beschreven is toegang tot het kwantificeren van de multivalente binding van het griepvirus aan kunstmatige celmembranen met nauwkeurige controle over de ligand/receptor-dichtheid aan het oppervlak.

Wij verwachten dat de oppervlaktefunctionaliseringmethodes die hier ontwikkeld zijn gebruikt kunnen worden voor de verdere ontwikkeling van biosensoren die de bepaling van multivalente interacties en het onderscheiden van verschillende types influenzastammen mogelijk maken. Deze technieken kunnen gebruikt worden voor het onderzoeken van een 
breder scala aan biologische, monovalente en multivalente interacties aan grensvlakken en zodoende meer inzicht bieden in complexe biomoleculaire mechanismes.

Meer informatie is verstrekt in de Engelstalige samenvatting van dit proefschrift. 


\section{Acknowledgments}

Several people have helped in different ways for the completion of my doctoral thesis and I would like to take the opportunity to thank you all.

I would like to start by thanking my supervisor, Jurriaan, for giving me the opportunity to achieve my $\mathrm{PhD}$ in your group. I am very thankful for your guidance during these four years, your continuous support and for keeping me always motivated. I will carefully guard all your valuable lessons, which made me become a better scientist and grow personally. I could not wish a better supervisor for my $\mathrm{PhD}$.

I would like to express my gratitude to the committee members: Prof. Geert-Jan Boons, Prof. Jeroen Cornelissen, Prof. Rainer Haag, Prof. Pascal Jonkheijm and Dr. Erhard van der Vries. I am very thankful for the time that you spent for reviewing my $\mathrm{PhD}$ thesis and being part of my graduation committee. Erhard, I would like to thank you for the nice and fruitful collaborations. I have really enjoyed all our meetings and I am thankful for the insightful discussions that we had about the, now friendly, influenza virus. Pascal and Jeroen, thank you for the fruitful, occasional, scientific discussions that we had in past years. I wish to thank the academic staff of the MnF/BNT cluster Nathalie, Wim, Tibor and Jos. Even though our research fields are sometimes distant, I found your questions and input during the colloquia very useful.

I would like to express my gratitude also to the MnF/BNT staff: Marcel, Richard, Regine and Bianca, thank you for your help in the lab; I could always count on you whenever I needed something. Nicole and Izabel, thank you for answering all of my 'small questions' whenever I came to your office.

I am very grateful to my paranymphs, Federico (Nino) and Jacopo, for their big help and support during the last four years. Nino, I am very glad that we met again here in Enschede and that I could go through this whole experience with you. Thank you for welcoming me here together with Beatrice more than four years ago, for helping me with my first steps in The Netherlands and for handling all my grumbling during these years. I am very grateful for all your support, not only as a colleague but also as a friend. I wish you a very bright future with your family.

Jacopo, we shared so many experiences together and there are so many things I would like to thank you for. Thanks for all the discussions, laughter, arguments and funny adventures that we had together. All these moments made me, in one way or another, grow up. I will always remember all the trips that we had together and all the airplanes in which, to comfort 
me, you fell asleep. I am pretty sure we will keep in touch, but for the moment, I wish you all the best for your academic future!

A big thank goes also to Luca, my unofficial paranymph, for your help in the last bits of my $\mathrm{PhD}$. I am very thankful for all the times that you listened to my problems and gave me strength. Thanks for your very contagious, positive energy and your friendship. I wish you luck for the completion of your doctorate.

Thanks also to my office mates Jenny and Gulistan for their help and support during the completion of my thesis. Jenny, I will always remember your energizing attitude towards life and I am pretty sure I will never forget all the times we laughed together. Thank you for your constant support and I wish you a lot of luck for your next steps.

I wish to thank all my colleagues and collaborators that became true friends during this adventure. Almudena, thank you for help and for your warm hugs which made my days better. I will always remember our talks and nice experiences together. Pramod, thank you for your constant positive mood which helped me go through my PhD. Maike, I enjoyed very much our conversations drinking a glass of good red wine. Thank you for all the nice moments together and for introducing me to the, now familiar, German culture. Candelaria, my friend, there are no words to describe how thankful I am to you for bringing your Argentinian sparkle in my $\mathrm{PhD}$ life. Thank you for encouraging me and supporting me in difficult moments, always giving a helping hand while holding a mate in the other one. Raquel (Mimi), Roberto (Bobo), Manu and Mark you were the first people I had the chance to meet in Enschede and I will always bring with me the nice moments that we had together. Mimi, our friendship started the first day that we met here in Enschede and I am very happy it is still very solid. Thank you for being always very supporting and comforting in all these years. I wish you all the best to you and Thomas and a lot of happiness for your kids. Bobo, I cannot forget all the times we laughed together, which sometimes started with only a quick look. Thanks for all those funny moments. Manu, thanks for your support and for our conversations, always useful and comforting. Mark, I enjoyed our very effective collaboration, especially all the talks we had.

I would like to thank Nico, Sara, Malte and Yao for the nice collaborations that we had and for the nice atmosphere during our work meetings. Good luck guys with the continuation of your work.

Moreover, during these years I was lucky to supervise four students: Erik, Sander, Christian and Joris. Thank you for contributing to this thesis, not only with experiments. It was fun working with you.

A very big thank goes to all the MnF and BNT (ex)colleagues. I am thankful to all of you for creating such a nice atmosphere in the group which I will miss very much. I will always bring 
with me all the good moments that I have shared with you. Gigi, thank you for helping me with the Samenvatting during your holidays.

A special thank goes also to my friends outside the group: Anna, Elio, Francesco, Lucia, Marco, Alice and Zuzanna. A wholehearted thank to all of you for sharing such good moments and adventures here in Enschede. Your presence contributed to create a memorable atmosphere and made me feel at home. Anna, needless to say, that all our adventures and trips took a special place in my heart. Thank you for always supporting me and being always present when I needed it. Francesco and Elio, I am pretty sure we will manage somehow to continue with our PES tournaments in the future.

Simon, there are no words to describe how important you have been during this journey. Thank you for all the support and for never leaving me alone, especially in the stressful moments. I feel so lucky to have you next to me in this adventure and in the coming ones. Last but not least, I would like to say a big thank to my family, for the immeasurable and constant support. Thank you for your love and always being by my side, even from such a distance. I will always bring this with me. Grazie! 


\begin{abstract}
About the author
Daniele Di Iorio was born in Formia, Italy on the $10^{\text {th }}$ of July 1990 . He studied Chemistry at "Sapienza" University of Rome where he gained his Bachelor's degree in January 2013, presenting a thesis entitled "Study of interaction between streptavidin and magnetite nanoparticles functionalized with biotin" under the supervision of Prof. Mario Barteri. In January 2015 he earned his Master's degree (summa cum laude), at the same University, with a thesis entitled "Specific interaction between superparamagnetic nanoparticles activated by lectin II and Gram positive bacteria (Staphylococcus aureus)" working again under the supervision of Prof. Mario Barteri.

Since June 2015 he has worked as a PhD student in the Molecular Nanofabrication group under the supervision of Prof. Dr. Ir. Jurriaan Huskens. The aim of his project is to study multivalency at interfaces in biological systems by exploiting the functionalization of surfaces.
\end{abstract}


